\title{
The art of feeling connected
}

Citation for published version (APA):

Luyten, T. (2019). The art of feeling connected: Interactive art as emotion-oriented care technology in nursing homes. [Doctoral Thesis, Maastricht University]. Ridderprint.

https://doi.org/10.26481/dis.20191010tl

Document status and date:

Published: 01/01/2019

DOI:

10.26481/dis.20191010tl

Document Version:

Publisher's PDF, also known as Version of record

\section{Please check the document version of this publication:}

- A submitted manuscript is the version of the article upon submission and before peer-review. There can be important differences between the submitted version and the official published version of record.

People interested in the research are advised to contact the author for the final version of the publication, or visit the DOI to the publisher's website.

- The final author version and the galley proof are versions of the publication after peer review.

- The final published version features the final layout of the paper including the volume, issue and page numbers.

Link to publication

\footnotetext{
General rights rights.

- You may freely distribute the URL identifying the publication in the public portal. please follow below link for the End User Agreement:

www.umlib.nl/taverne-license

Take down policy

If you believe that this document breaches copyright please contact us at:

repository@maastrichtuniversity.nl

providing details and we will investigate your claim.
}

Copyright and moral rights for the publications made accessible in the public portal are retained by the authors and/or other copyright owners and it is a condition of accessing publications that users recognise and abide by the legal requirements associated with these

- Users may download and print one copy of any publication from the public portal for the purpose of private study or research.

- You may not further distribute the material or use it for any profit-making activity or commercial gain

If the publication is distributed under the terms of Article $25 \mathrm{fa}$ of the Dutch Copyright Act, indicated by the "Taverne" license above, 

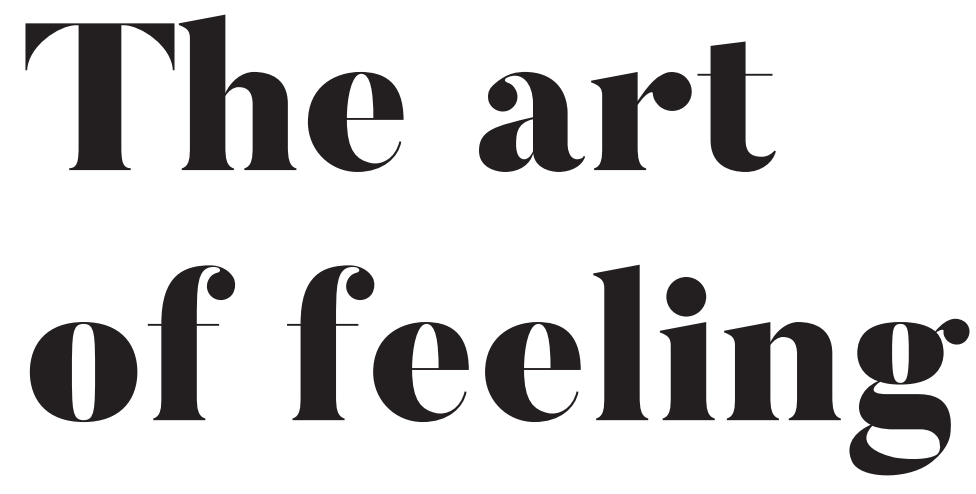

connected

Interactive art as emotion-oriented care technology in nursing homes 
Cover and layout: Tom Luyten

Print: Ridderprint BV - www.ridderprint.nl

ISBN 978-94-6375-580-1

Copyright (C) Tom Luyten, Maastricht 2019

No parts of this thesis may be reproduced, stored in a retrieval system, or transmitted, in any forms or by any means, electronically, mechanically, by photocopying, recording or otherwise, without the prior written permission of the author. 

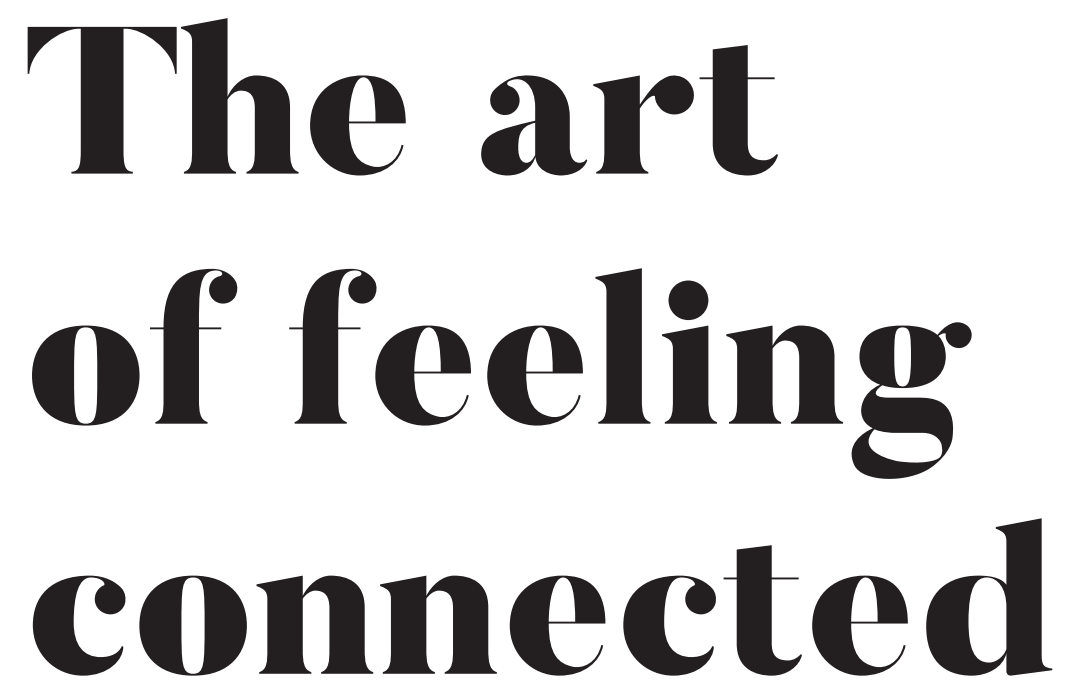

\section{Interactive art as emotion-oriented care technology in nursing homes}

\section{PROEFSCHRIFT}

ter verkrijging van de graad van doctor

aan de Universiteit Maastricht,

op gezag van Rector Magnificus, Prof. dr. Rianne M. Letschert, volgens het besluit van het college van Decanen,

in het openbaar te verdedigen op

donderdag 10 oktober 2019 om 10:00u

door

Tom Luyten 


\section{Promotores}

Prof. dr. L.P. de Witte

Prof. dr. S. van Hooren, Open Universiteit

\section{Co-promotor}

Dr. S.M. Braun, Zuyd Hogeschool Heerlen

\section{Leden beoordelingscommissie}

Prof. dr. F.R.J. Verhey (Voorzitter)

Prof. dr. P.F. Peters

Prof. dr. J.M.G.A. Schols

Dr. K. Slegers, Universiteit van Tilburg

Prof. dr. E.J.M. Wouters, Universiteit van Tilburg 


\section{CONTENTS}

\section{Phase $1 \quad$ Understanding the problem}

Chapter 1 Introduction

Chapter 2 Participant Responses to Physical, Open-ended 11 Interactive Digital Artworks: A Systematic Review International Journal of Arts and Technology, 10(2), 94-134

\section{Phase 2 Concepting and prototyping}

Chapter 3 The process of co-creating the interface for

VENSTER, an interactive artwork for nursing home residents with dementia Disability and Rehabilitation: Assistive Technology, 13(8), 809-818

\section{Phase 3}

\section{Pilot studies}

Chapter 4 How nursing home residents with dementia respond to the interactive art installation 'VENSTER'; A pilot study Disability and Rehabilitation Assistive Technology 13(1):1-8

Chapter 5 How groups of nursing home residents respond to 'the CRDL'; A pilot study Journal of Enabling Technologies, 12(4), 145-154

Chapter 6 How nursing home residents respond to the interactive art installation 'Morgendauw'; A pilot study Design for Health (submitted)

\section{Phase $4 \quad$ Synthesis}

Chapter $7 \quad$ General discussion

References

Summary

Samenvatting

Valorization

Dankwoord

About the author 


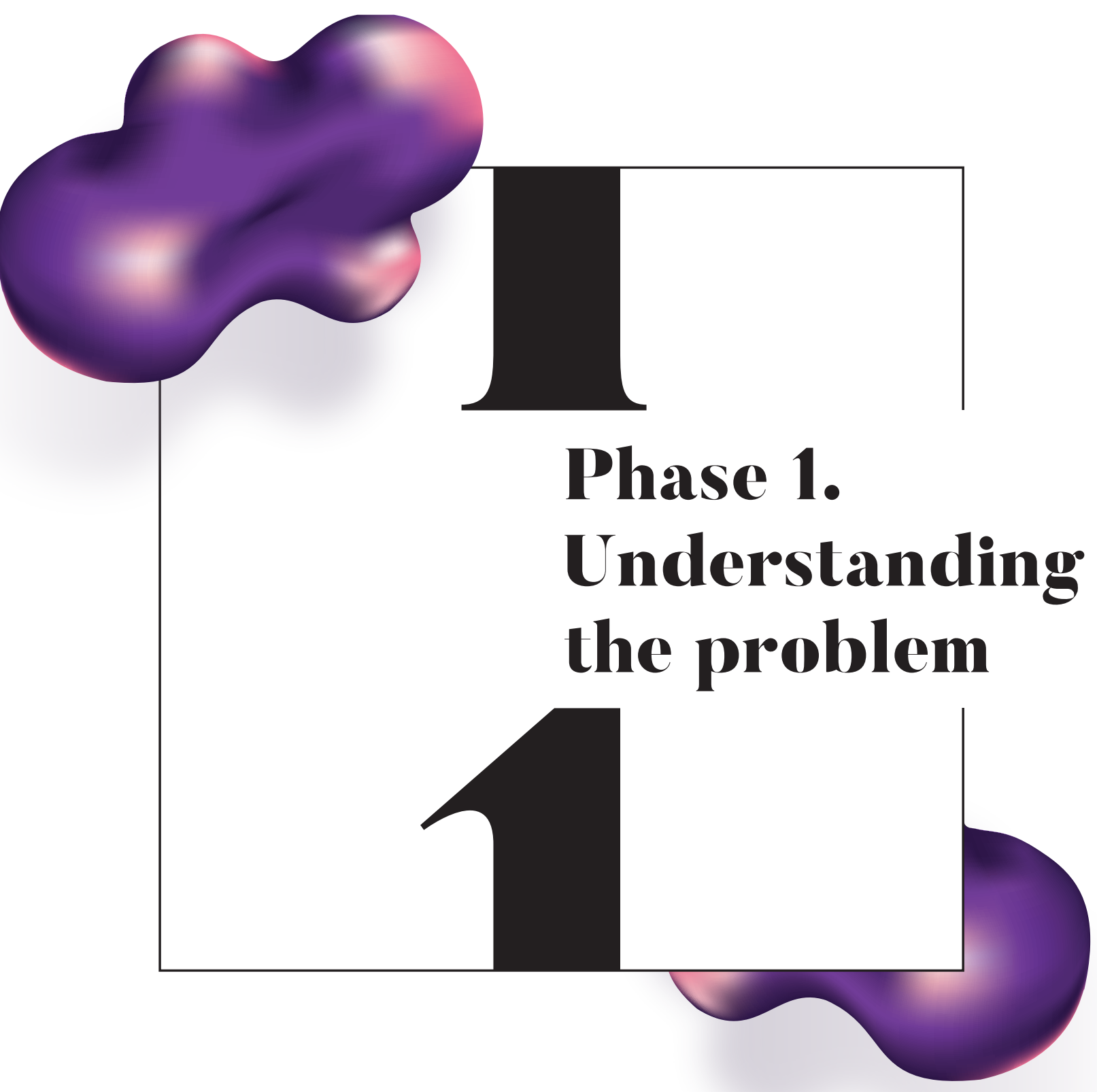




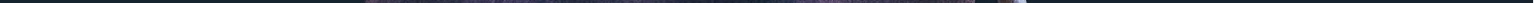


Chapter 1.

Introduction 


\section{Chapter 1}

In the Netherlands, when you are no longer able to live by yourself due to psychogeriatric problems, chronic physical conditions caused by old age or a combination of both, you are likely to move to a nursing home. In 2016, 117.000 people were living in Dutch nursing homes. Almost all inhabitants were over 80 years old, most of them female. Ninety-eight percent lived with physical limitations due to old age, chronic diseases such as Parkinson's Disease and Chronic Obstructive Pulmonary Disease (COPD) or due to the consequences of a stroke (CerebroVascular Accident). Cognitive complaints or problems ranging from forgetfulness to diagnosed dementia were seen in $73 \%$ of the nursing home inhabitants (Planbureau, 2017).

Because elderly care differs across countries and regions, it's not possible to compare nursing homes or their residents globally. The numbers on dementia, however, provide an idea of the global scale of the size of the problem of growing old. It is one of the major challenges we are facing with an ageing population.

In 2016, 47 million people lived with dementia worldwide and projections show numbers up to 131 million by 2050 . The global cost of dementia is estimated at a trillion dollars (Prince, Comas-Herrera, Knapp, Guerchet, \& Karagiannidou,

Although challenges remain, elderly care in the Netherlands is very good when compared to the rest of the world 2016). In 2017, 270.000 Dutch people were living with diagnosed dementia, of which 70.000 resided in a nursing home (Alzheimer-Nederland, 2017).

Dutch nursing homes have evolved. They used to resemble army barracks and focused merely on providing care. For over 10 years now, emotion-oriented care is the guiding philosophy in most nursing homes in the Netherlands and although challenges remain, elderly care in the Netherlands is very good when compared to the rest of the world (J. Schols \& Swelsen, 2019; J. M. Schols, 2008). Emotion-oriented care puts the experiences and emotions of the people living in the nursing home first. This philosophy shifts the role of care providers from task-oriented to relation-oriented (van Stenis, Van Wingerden, \& Kolkhuis Tanke, 2017). Everything provided within the nursing home is tailored to the residents' individual needs and possibilities (Finnema et al., 2005). This new way of providing care results in personalised activities and therapy and is reflected in the advancement of non-pharmacological therapy (Douglas, James, \& Ballard, 2004).

The physical nursing home environment is part of this emotion-oriented care philosophy. Modern institutions are, for example, equipped with smart systems to prevent wandering (Vuong, Chan, \& Lau, 2015) or reminiscence corners are created to recall past events and make it feel more like home (Huang et al., 2015). Although emotion-oriented care is the leading philosophy in nursing homes in the Netherlands and the overall quality is great when compared to other countries (J. Schols \& Swelsen, 2019), most residential care facilities in the Netherlands do not yet reflect contemporary dementia care visions (Van Steenwinkel, 


\section{Introduction}

Verstraeten, \& Heylighen, 2016). If Dutch nursing homes have to meet current and future standards, there's an additional financial gap estimated between 1,3 and 3,1 billion Euro that needs to be bridged (Nederlandse-Zorgautoriteit, 2017). Budget cuts impact the quality of care; $96 \%$ of personnel worries about the current developments in the care sector; $67 \%$ report they don't have enough time to spend with their clients (Boer \& Vreede, 2016). This reality presents a challenge: in order to keep providing a worthy and full life to elderly who live in nursing homes, innovations are needed that do not put extra pressure on the scarce budget and already burdened staff. Despite the efforts to make nursing homes look and feel more interesting or like home, most of them remain hospital like, standardized and uninviting. It's not ugly, not beautiful, but functional and institutionalized. Some of the activities and rooms that are used for therapy, for instance, are derived from mental health care but remain aesthetically unchanged and therefore may look childish and unappealing to adults that have lived a full life. An example are multi-sensory rooms. While there is evidence that multi-sensory therapy is beneficial (on the short-term) for elderly with dementia (Abraha et al., 2017), the rooms' aesthetics remain unchanged. This is remarkable, as research shows beauty (in general) makes us happy (Rautio, Filatova, Lehtiniemi, \& Miettunen, 2018). Art in hospitals, for instance, can make people feel safe, connected to the outside world and even speed up a rehabilitation process (Lawson \& Phiri, 2013; Nielsen, Fich, Roessler, \& Mullins, 2017).

In spite of all the benefits of emotion-oriented care, there's still inactivity and boredom during time in between activities (den Ouden et al., 2015). Residents say that they are generally happy with the physical environment of the nursing home and their rooms, but also report that they miss the things they really enjoy and relate to. There is a lack of cultural activities and they ask for better accommodations for their visitors (van Campen \& Verbeek-Oudijk, 2017). In other words, nursing homes lack the needed conditions

\section{Nursing homes lack the needed conditions for personal experience to take place} for personal experience to take place. Specifically experiences that are accessible all times and can be enjoyed by residents on their own or together with somebody else, without the help of a professional caregiver.

Especially the latter is a missed opportunity: the absence of cultural activities that are adapted in such a way that they can be carried out by the nursing home residents because 'Individual control of decision making and other activities', otherwise known as autonomy, is one of the six dimensions of well-being (Ryff \& Keyes, 1995) and directly linked to happiness (Ryff, 1989). In the recent manifest written by people who live with dementia they explicitly ask to provide them with as much autonomy as possible. They want help when needed, but also the opportunity to decide to do things on their own, or together with someone else (Alzheimer-Nederland, 2018). Lack of autonomy is characteristic of nursing home residents: people who live with dementia can have impaired thinking, loss of memory, problem-solving skills, and difficulties with communication 


\section{Chapter 1}

(Coleman \& Asiri, 2017), while physical limitations and assistive devices such as a stroller or wheelchair limit mobility. This makes them a challenging group to engage in any activity (Anderiesen, Scherder, Goossens, \& Sonneveld, 2014; Kolanowski, Resnick, Beck, \& Grady, 2013). How do we entice them to engage with a personal (cultural) experience, such as art, without the need for professional care/guidance?

Experience is an abstract concept. A working definition is needed. In his book Art as Experience, John Dewey states: "[...][Meaningful] experiences are those of which we say in recalling them, 'that was an experience'. It may have been something of tremendous importance [...] or it may have been something that in comparison was slight. [...] An experience has a unity, [...] constituted by a single quality that pervades the entire experience in spite of the variation of its constituent parts." He says for meaningful experiences there "is no need for a code or convention of interpretation; the meaning is as inherent [...] as is that of a flower garden" (Dewey, 1934, p.37-38). Ernest and Edmonds elaborate that "experience can take many forms, from pleasure to fear, from captivation to creation, of danger, of difficulty, of joy" (Edmonds, 2011, p.29). When the experience is triggered by the aesthetics of something, it is referred to as an aesthetic experience (Cupchik \& Winston, 1996).

An experience is thus a strictly personal event. It can be long, short, continuous or comprised of individual parts, pleasurable or scary, as long as it's perceived as meaningful, feels as a whole and the rest of the world disappears from your attention. There's no need for explicit explanation, you inherently know when you've had an experience.

\section{Art as an experience}

What better catalyst for a meaningful, subjective experience than art? Enjoying art in one of its many forms can be a strong, personal event. We all have a specific piece of music, a painting or an architectural building that connects to our inner most self. (Aesthetic) Experiences are an important part of being human and they remain intact even when the brain starts to deteriorate. Graphic designer Stefan Sagmeister paraphrases research by Daniel J. Graham, Simone Stockinger and Helmut Leder when he says "When we lose our mind, we can still recognize beauty" (Sagmeister, 2016). Graham et al found out that aesthetic judgment of artistic images represents an 'island of stability' for people with Alzheimer's Disease, while their condition causes profound cognitive disruption in most other respects (Graham, Stockinger, \& Leder, 2013, p.1). All the

What better catalyst for a meaningful, subjective experience than art? more reason to incorporate beauty in the lives of people with dementia. Pim Steerneman, chairman of an elderly care organization in the Netherlands goes a step further when he states that "Art and culture play a large role in people's lives [...] this shouldn't stop when you come to live in a care home" (Steerneman, 2012, p.3). 


\section{Introduction}

Unfortunately, art has an image problem. Somehow society thinks that art should be 'understood correctly' to be appreciated, that the viewer is supposed to figure out the intended meaning of the artwork (often well hidden by the artist). Somehow, society (or art education at schools) got stuck in some kind of 'symbolism'. This image is often associated with 'classical' or conceptual forms of art that seem to imply knowledge of the culture, history and politics of the artwork and of the art world in general. Without this knowledge the viewer is unable to decipher 'the generic and specific code of the work'. This results in displeasure and makes the viewer feel 'unworthy' or 'incompetent' (Bourdieu, Darbel, \& Schnapper, 1997). It's not hard to imagine that this deciphering exercise is impossible for people who live with dementia to do on their own. Recent programs ran by MOMA New York, Stedelijk Museum Amsterdam and the Van Abbe Museum in Eindhoven do show that it's still possible for people who live with dementia to enjoy art in a museum context, by organizing interactive, unforgettable tours where conversations take place about a selection of the collection (Heesbeen, Dröes, Hendriks, Koelewijn, \& Meiland, 2017; Rosenberg, 2009). One of the success factors seems to be interaction.

\section{Interactive art}

An increasingly popular form of art that relies entirely on interaction is called interactive art. Instead of gazing upon the works created by mysterious artists and interpreting them from a distance, interactive art bridges the gap between the artwork and its audience by involving the observer directly as an active participant. Instead

Interactive art bridges the gap between the artwork and its audience by involving the observer directly as an active participant of looking at or talking about the artwork, you become part of it.

To define interactive art, it is first necessary to describe what non-interactive art is as its counterpart. If we think about most non-interactive art, its physical appearance is entirely created by the artist. A painting as an object for example is finished at the moment the artist decides to lay down the final stroke of paint. The observer can look at the artwork and interpret it from a distance. The art experience itself arrises in the mental interaction between the static physical object of the piece of art, and the viewer. In contrast, an interactive artwork thrives on being touched and experimented with; the participant can actively try out and engage. It stimulates a physical interaction on top of the mental interaction with the piece of art. Interactive art "[...] has transformed longstanding notions of what it is to be a creator and a consumer" (Edmonds \& Candy, 2011, p.2). ".... It is the recipient's activity that gives form and presence to the interactive artwork, the recipient's activity is also the primary source of his aesthetic experience." (Kwastek, 2013), pag xvii). Because the physically passive viewer becomes an active participant and plays an important role in the final outcome of the work, every experience is personal, and differs from others. This lowers the threshold to participate in the artworks and could make them more accessible for nursing home residents. Examples of interactive art are 'Water 


\section{Chapter 1}

Light Graffiti' by Antonin Fourneau (Fourneau, 2013), 'Audience' by Random International (Random-International, 2008) or 'Scattered Light' by Jim Campbell (Campbell, 2010).

However, using the word 'art' for interactive installations or objects in elderly care is somewhat problematic, for they need to be usable by nursing home residents. Generally speaking, contemporary artists do not predefine the 'right way' for their audience to use and/or understand their art. Although possible experiences and use-cases of an artwork are considered by artists, they leave the figuring out and experiencing entirely up to the active participant. The interactive artwork only exists in the interaction, thus outside of the control of the artist, entirely in the experience of the participant. The boundaries between

The focus on aesthetics, experience and enjoyment, rather than usefulness or a goal sets this dissertation and the artworks studied within it apart the art and design worlds, if they exist at all, become blurred when we talk about interactive art. The experience provided by an interactive artwork can be categorized as 'art': it is not instrumental, but multi-interpretable and personal. In order to enable this experience through an interface, it also relies on usability and comprehension, which are associated with the world of design: instrumental and actively used (in daily life). The works presented here are "operative, but not functional" (Bianchini \& Verhagen, 2016, p.10)

Nevertheless, framing the artworks (and therefore the research in this $\mathrm{PhD}$ project) as 'art' has been a conscious decision in this $\mathrm{PhD}$-project. The focus lays on providing a meaningful, personal experience to nursing home residents during the inactive time in between activities and therapy. There is no instrumental goal. The need for requirements to be met in order to provide such an experience (e.g. develop and test an interface) does not change this main focus. By framing something as art, a mental context is created where things are approached and perceived differently from everyday objects. People tend to shift their expectations to aesthetics, experience and enjoyment, rather than usefulness or a goal. This sets this dissertation and the artworks studied within it apart from most, if not all, current technology that is available in the nursing home today.

\section{Interactive art in elderly care: Autonomous, open-ended}

\section{experiences}

Contrary to interactive art, most leisure technology in the nursing home is therapy, goal or activity-oriented and game-like. Although these games and activities are beneficial and fun for residents, they need intensive guidance from professionals and are planned as an activity on a certain moment of the day. Therefore, interactive artworks that end up in the nursing home should not be goal-oriented or game-like, but open-ended experiences that have no linearity (no beginning or ending). A successful open-ended experience in relation to interactive art is defined by Morrison as "one that promotes or requires exploratory 


\section{Introduction}

behaviour from the participants in order that they activate the work. [It] encourages the individual to initiate and perform their own creative acts (not [...] as an audience under a prescribed artist or set rules) [...]" (Morrison, Viller, \& Mitchell, 2011, p.7). This means people can start, stop, enter or exit at any time without breaking the experience or feeling that a goal wasn't achieved, and do this on their own, or with their visitors.

Some interactive art installations have found their way into care facilities: during the 70's Myron Krueger saw potential in his '(Nervous) Systems' for use in schools and in physical and cognitive rehabilitation. Both he and David Rokeby have reported on the experiences of disabled recipients with their work (Kwastek, 2013). More recent examples include the interactive installation 'Lunar' by studio Roosegaarde in a psychiatric ward for children (Roosegaarde, 2011) or the 'eye writer project' (FAT, 2003) that enabled bed ridden people to create graffiti with their eyes. Unfortunately, no interactive artworks could be identified in a nursing home facility.

\section{Goal of this thesis}

The main aim of this thesis is to explore the potential of interactive art as experienceoriented care technology in elderly care, specifically in the nursing home environment. Three sub-questions were formulated to achieve this aim:

1. How do you develop an interactive artwork for the nursing home environment?

2. (How) Do nursing home residents respond to interactive artworks?

3. Do the responses of nursing home residents differ, linked to the characteristics of an interactive artwork?

\section{Structure of the thesis}

This PhD-thesis is comprised of four phases (Figure 1, p.7). After 'understanding the problem' (Phase 1), two interactive artworks are 'conceptualized and prototyped' by the author (Phase 2), in co-creation with all stakeholders. A third existing artwork is selected and all three are evaluated in pilot studies (Phase 3). Results are synthesized and discussed and future directions formulated in the final phase (Phase 4).

\section{Phase 1: Understanding the problem}

\section{Chapter 1: Introduction}

The first chapter describes the broad problem space of budget cuts, general inactivity, lack of access to personalised activities and budget cuts in Dutch nursing homes which lead to a call for innovation, potentially in the form of interactive art. 


\section{Chapter 1}

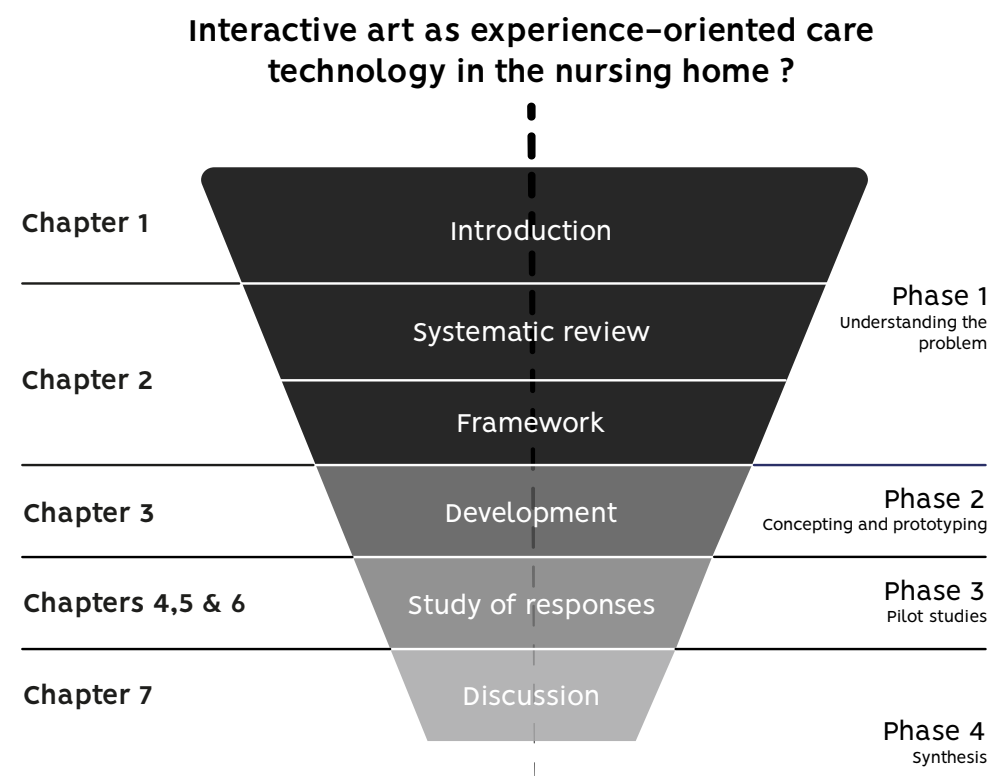

Where to go from here?

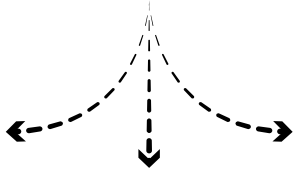

Figure 1: Overview of structure of the thesis

Chapter 2: Participant Responses to Physical, Open-ended Interactive Digital Artworks: A Systematic Review

This systematic review describes responses of people who visit museums and media festival to physical, open-ended interactive digital artworks found in literature. It informs the design process of the interactive artworks created and studied for the nursing home residents in this dissertation.

\section{Phase 2: Concepting and prototyping}

Chapter 3: The process of co-creating the interface for VENSTER, an interactive artwork for nursing home residents with dementia

The main aim of this article was to describe in detail the challenging design process of an interactive artwork for nursing home residents, in co-creation with all stakeholders and to share the used methods and lessons learned. This process is illustrated by the design of the interface of the interactive art installation 'VENSTER' as a case. 


\section{Introduction}

\section{Phase 3: Pilot studies}

Three artworks with different characteristics, ranging from a small table-top object with recognisable sounds to an abstract, room-filling installation, are subject to a pilot study in order to see whether nursing home residents respond to these interactive artworks and whether there are differences in their responses, linked to these characteristics.

Chapter 4: How nursing home residents with dementia respond to the interactive art installation 'VENSTER'; $A$ pilot study

The goal of this study is (1) to determine whether and how nursing home residents with dementia respond to the interactive art installation in general and (2) to identify whether responses change when the content type and therefore the nature of the interaction with the artwork changes.

Chapter 5: How groups of nursing home residents respond to 'The CRDL'; A pilot study

The purpose of this paper is to describe whether and how groups of nursing home residents respond to the interactive device "the CRDL".

Chapter 6: How nursing home residents respond to the interactive art installation 'Morgendauw'; A pilot study

The aim of the study was to investigate how nursing home residents respond to the abstract interactive art installation Morgendauw.

\section{Phase 4: Synthesis}

\section{Chapter 7: General discussion}

In chapter 7 the main findings of this thesis are discussed and the main questions answered. Subsequently, the implications for (creative) practice and research are reported. The discussion ends with an outline of future directions for the potential role of interactive art in health care; Where do we go from here? 

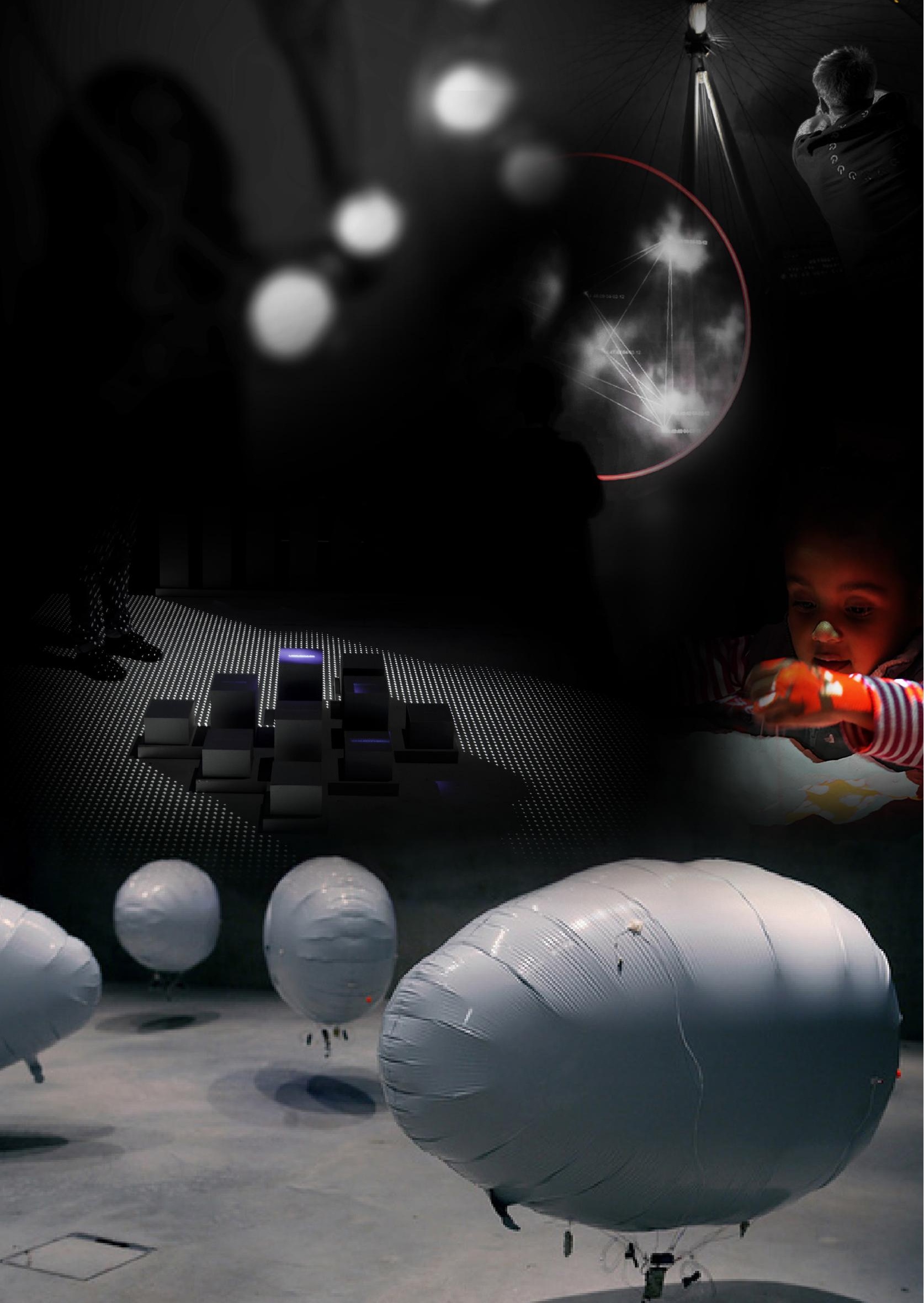
Chapter 2.

\section{Participant responses to physical, open-ended interactive digital artworks:}

A systematic review

Tom Luyten

Susy Braun

Susan van Hooren

Luc De Witte

International Journal of Arts and Technology, 10(2), 94-134 DOI: 10.1504/IJART.2017.084942 


\title{
Chapter 2
}

\begin{abstract}
The main aim of this systematic review was to describe responses of participants to physical, open-ended interactive digital artworks. Although human-to-artwork and human-to-human responses were found in the 22 identified artworks, more human-to-artwork responses were reported. Both types of responses were further categorised into physical, verbal, and cognitive/emotional responses.

The artworks varied from small table-top installations to large, dark open spaces, and had a range of interactive components and features from a heart rate interface to complete body movements. Results imply there is no straightforward relationship between the features of the artwork and the kind of response. However, two factors seemed to influence the participants' responses: the content (concrete or abstract) of the artwork, and the presence of others. Creating interactive artworks that challenge new audiences and/or evoke specific responses requires more knowledge about the dynamics of the interaction between people and interactive artworks.
\end{abstract}




\section{Systematic review}

\section{Introduction}

Enjoying art is a uniquely human capacity. A piece of art has the power to evoke thoughts and emotions (Robinson, 2007). Listening to your favourite song can make your day, while a modern art sculpture can provoke thoughts on ethics or the lightness of being. In noninteractive art, the artist is the creator. He/she shapes his/her ideas until he/she is satisfied, and then shares them with the world. The spectator, in turn, looks at the work and interprets it. If the piece is modified by this user interaction, it becomes interactive art (Nardelli, 2012).

With the advent of interactive artworks, the division between artist and audience has started to fade. In the words of Edmonds and Candy (2011): "In the past, we might have said that 'making' art is the prerogative of the artist whilst viewing it [is] that of the audience. In many ways, the phenomenon of 'interactive art' has transformed longstanding notions of what it is to be a creator and a consumer".

Interactive works of art thrive on being touched and experimented with; the passive viewer becomes an active participant and plays an important role in the final outcome of the work. In interactive art, the participant can touch, try out, and engage, which lowers the threshold to participating in the artworks and makes them more accessible. The participant becomes part of the artwork, and the meaning is formed during and through the interaction with the object ['embodied interaction' (Dourish, 2004)].

Interactive art comes in many shapes and forms. Figure 2 shows nine artworks in a matrix that ranges from virtual and scripted works like the art video game 'swords and sworcery' (Capybara Games and Superbrothers, 2011) [Figure 2(g)] to completely open-ended and physical works like the grid of plastic bags that reacts to movement in 'one hundred and eight' (Völker, 2010) [Figure 2(c)].

Although all examples of interactive artwork cited above are driven by electronics or computer technology, this is not a requirement. For instance, 'drawing machine \#1' by Griffiths (2009) (Figure 3) is a stationary bicycle that draws varying patterns using felt-tip markers and purely mechanical transfers.

Because of their fun nature and the attractiveness of participating in/interacting with them, interactive (art) installations are not only used to create aesthetic experiences in museums but are also now appearing in various other places to evoke specific responses between the participant and the artwork (human-to-artwork interaction) or responses between participants (human-to-human interactions).

As Her and Hamlyn (2010) noted: "Some of [these works] have even been placed as permanent installations with specific artistic intentions that relate to various public contexts". Examples of intentional interactive installations are 'branch out' (Burke et al., 2012) [Figure 4(a)], which triggers dialogue between strangers, 'BrightHearts' (SensoriumHealth, 2014) [Figure 4(b)] which relieves pain and enhances relaxation, and 'Moodwall' (Klink and Urban 


\section{Chapter 2}

Alliance, 2009) [Figure 4(c)] which tries to change one's perception of a neighbourhood.

Despite the creation of an increasing number of interactive installations, research on user experiences with them is scarce. In 2012, Schraffenberger and van der Heide (2012) published a literature review presenting the known interaction models for audience-artwork interaction. They identified frameworks that discuss artwork characteristics, user interactions with them, or both. Similarly, Jacucci et al. (2009) listed frameworks for studying aesthetic

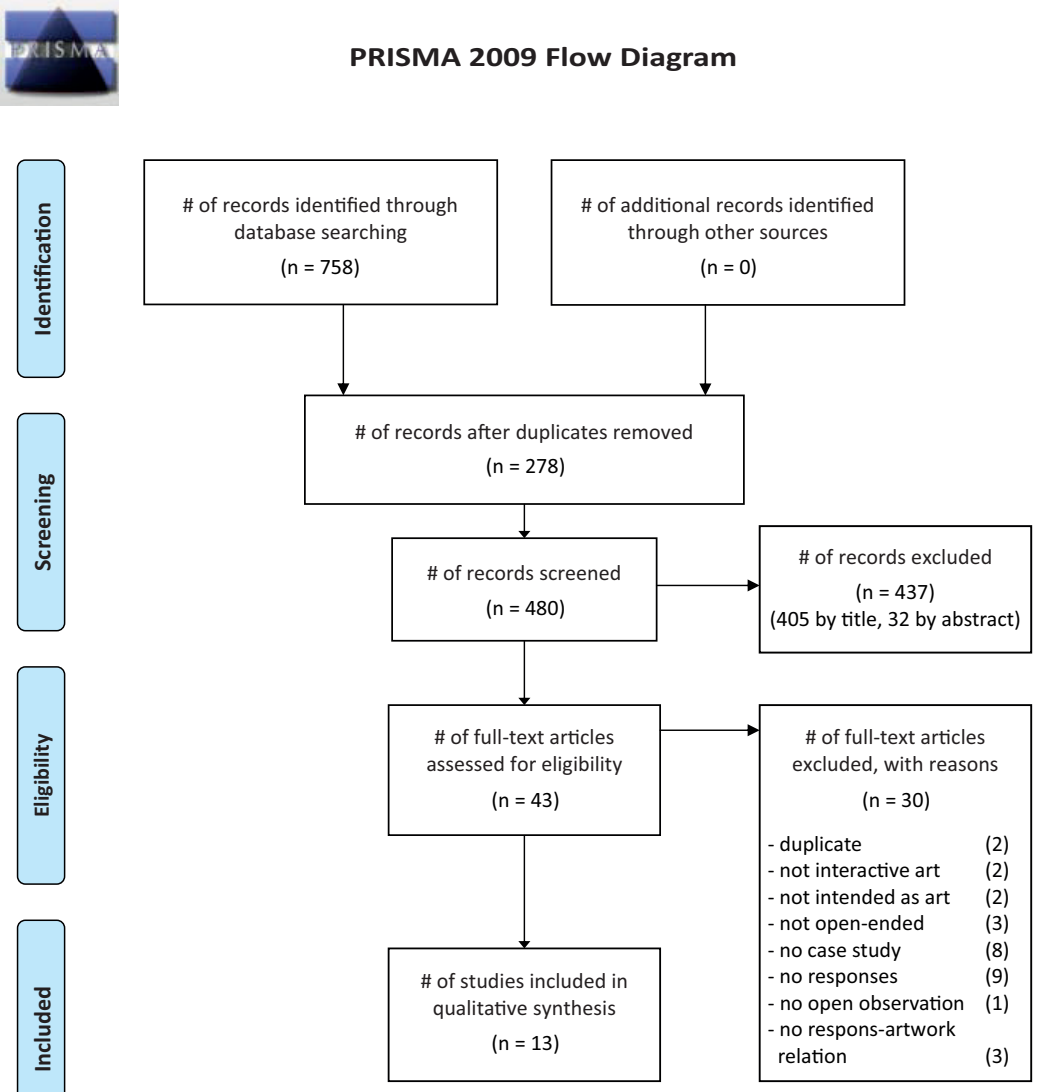

From. Moher D, Liberati A, Tetzlaff J, Altman DG, The PRISMA Group (2009). Preferred Reporting /tems for Systematic Reviews and MetaAnalyses: The PRISMA Statement. PLoS Med 6(6): e1000097. doi:10.1371/journal.pmed1000097

For more information, visit www.prisma-statement.org.

Figure 1: PRISMA 2009 flow diagram 


\section{Systematic review}

experiences with interactive art. However, none of these studies or the frameworks identified in them report actual participant responses.

The present review focuses on physical, open-ended interactive digital artworks, because of their potential as intentional works of art. The term 'physical' here excludes works that exist only in virtual space, such as video games, website art, or mobile phone applications. The term 'open-ended' implies that the artwork has no scripted narrative, and that participants are able to enter or leave the interaction at any moment. The interaction, that is, has no defined beginning or end. The term 'interactive' excludes works where the output is not influenced by the actions of the participant. Finally, 'digital' is defined here as involving reliance on electronics and/or computation, meaning that it excludes works that are purely mechanical. Examples of physical open-ended interactive digital artworks include 'Lunar' by Roosegaarde (2011) [Figure 5(a)], 'Starfield' by Lab212 (2012) [Figure 5(b)], 'Water Light Graffiti' by Fourneau (2013) [Figure 5(c)], and 'Weather Worlds' by Design I/O (I/O, 2013) [Figure 5(d)].

\section{Objective}

The objective of this paper is to present an overview of participant responses, both humanto-artwork and human-to-human, in relation to physical, open-ended interactive digital artworks.

\section{Methods}

\section{Search strategy}

A computer-supported search was conducted by the first author (TL) in the following databases:

\footnotetext{
Taylor and Francis Online (http://www.tandfonline.com)

- Taylor and Francis Online (http://www.
- ACM Digital Library (http://dl.acm.org)

- IEEE Xplore (http://www.ieee.org)

- $\quad$ Springer Link (http://link.springer.com)

- Google Scholar (http://scholar.google.com).
}

In view of the large number of terms used to identify these interactive artworks by their authors, a search strategy was defined that combined multiple terms (Figure 6). Not all databases used for this search could handle the initial query, so an alternative search was performed with a shorter query. 


\section{Chapter 2}

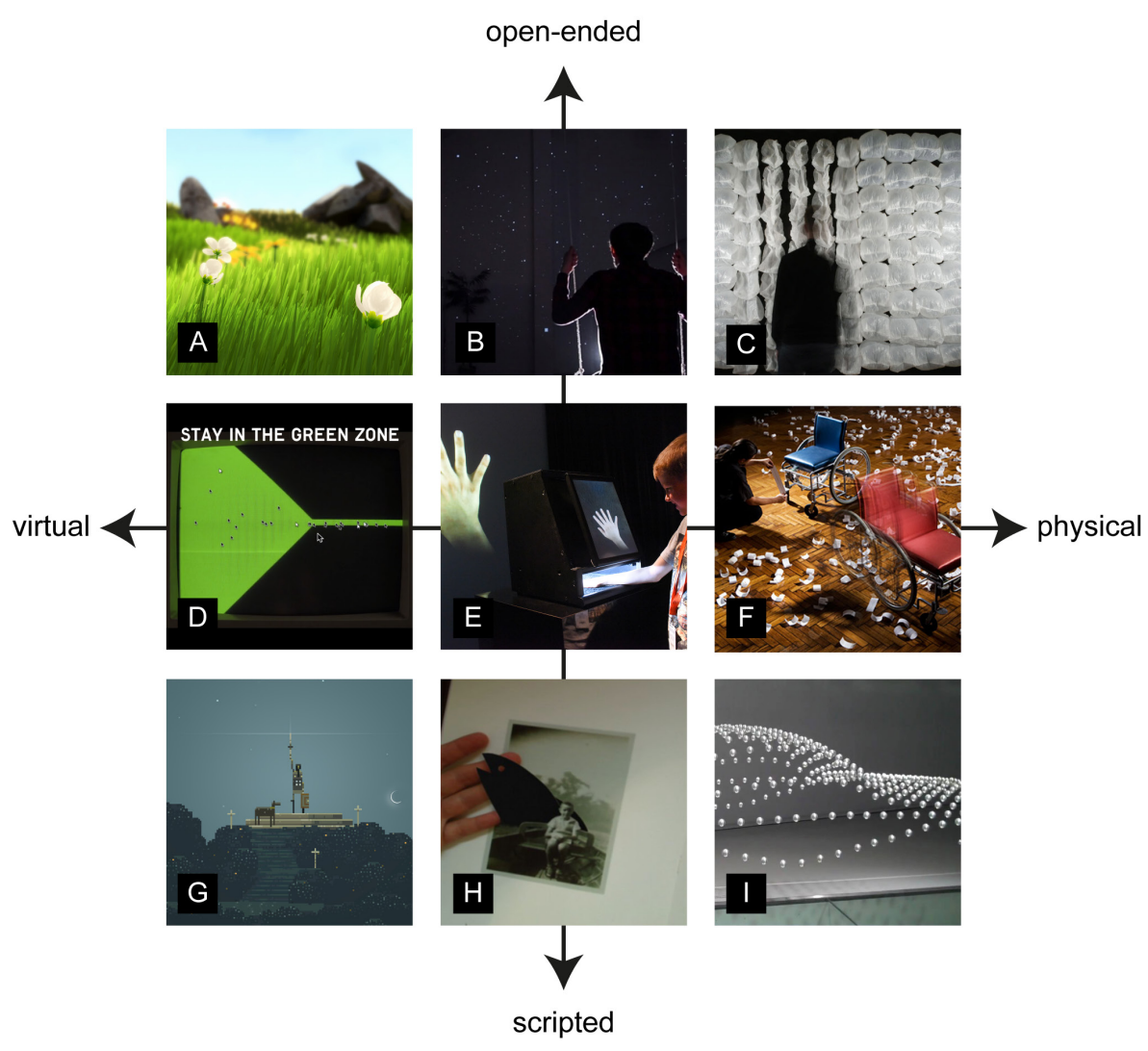

Figure 2: Nine interactive artworks in a two-axis matrix

Notes: Open-ended to scripted and virtual to physical;

(a) flower - Thatgamecompany and SuperVillain Studios,

(b) starfield - Lab212 (c) one hundred and eight - Nils Völker,

(d) do not touch - Moniker, (e) augmented hand series - Golan Levin, Chris Sugrue and Kyle McDonald, (f) fish and bird - Mari Velonaki, (g) sword \& sworcery - Capybara Games and Superbrothers,

(h) Le monde des montagnes - Camille Scherrer,

(i) kinetic sculpture BMW - ART+COM studios. 


\section{Systematic review}

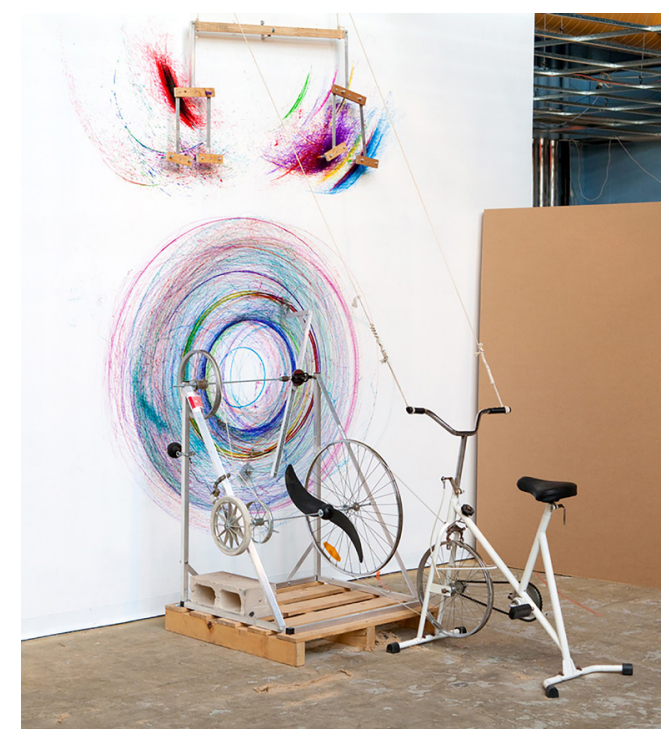

Figure 3: Drawing machine \#1 by Joseph L. Griffiths

Note: A purely mechanical interactive artwork.

Source: Griffiths (2009)
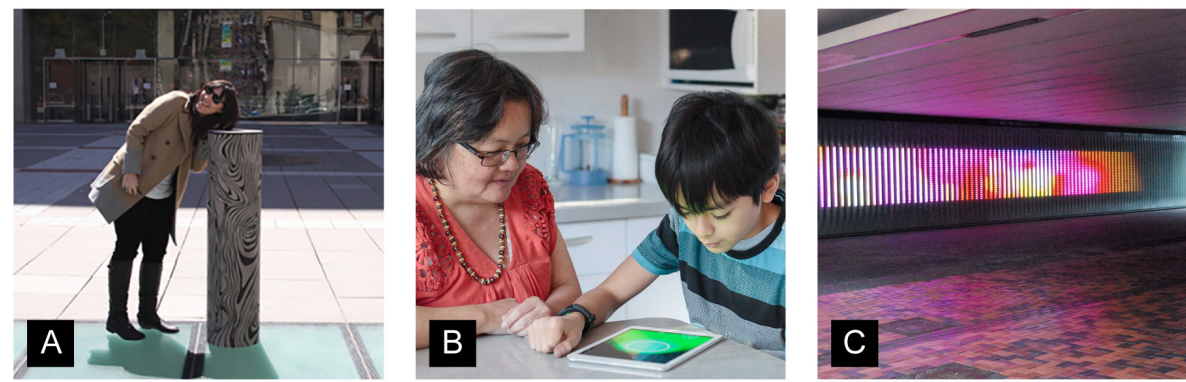

Figure 4: Three intentional interactive installations: (a) branch out,

(b) BrightHearts, (c) moodwall 


\section{Chapter 2}
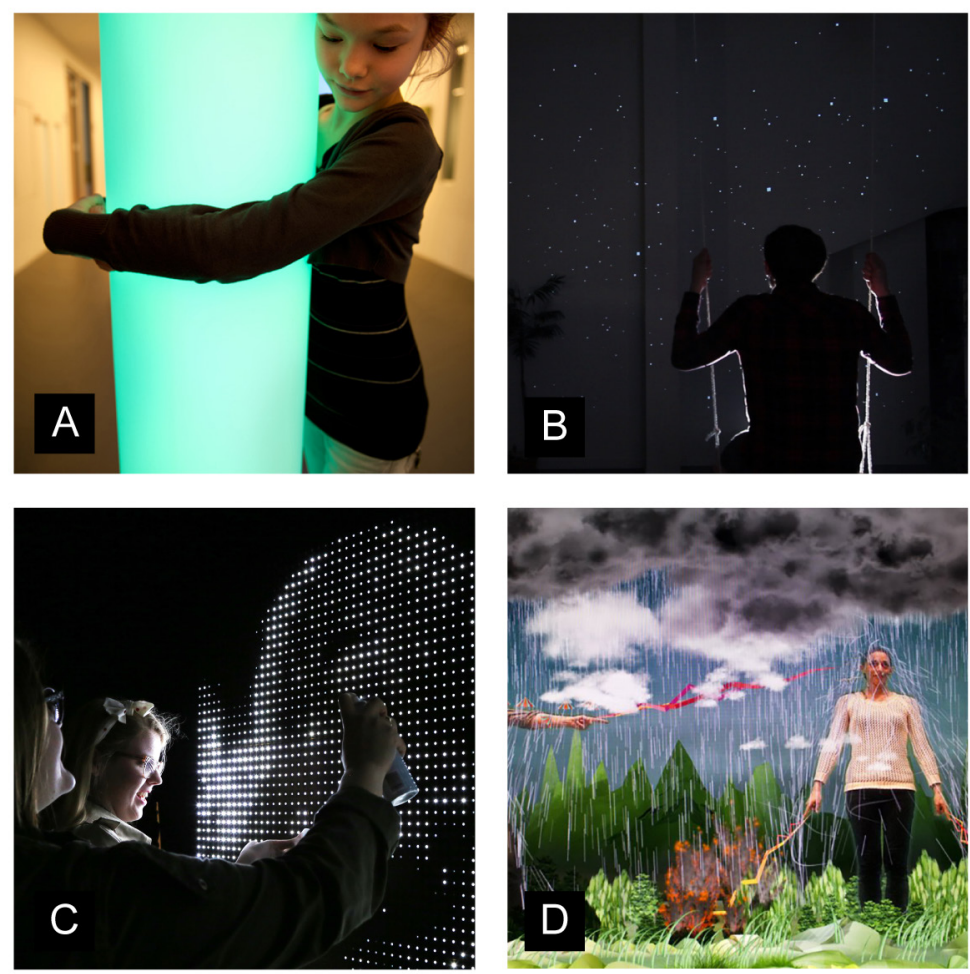

Figure 5: Four physical open-ended interactive digital artworks: (a) lunar, (b) Starfield, (c) Water Light Graffiti, (d) Weather Worlds

\section{Study selection}

All eligible journal articles, conference proceedings, book sections, and doctoral theses published in English between January 2008 and April 2014 and providing a qualitative or quantitative description of participant responses regarding physical open-ended interactive digital artworks were eligible for inclusion in this review. The studies to be included were selected independently by three of the researchers (TL, TD, SB). An overview of the selection process can be found in Figure 1. Selection took place based firstly on title, secondly on abstract, and thirdly on full text. Each researcher assigned to each study a score ranging from 0 to 2 : a score of 0 recommended that the article be excluded, a score of 1 meant doubt, and a score of 2 meant it should be included. The scores of the three researchers were added up, and articles with a total score of 3 and higher were included. 


\section{Systematic review}

\section{Data extraction}

Data regarding the number of times and the period during which a work is/was exhibited, the physical appearance of the artwork, interaction options (input and output), the number of participants (number of people observing), and the recorded user responses were extracted. The quality of the studies was not assessed. The extracted user response data was split into human-to-artwork responses and human-to-human responses, and divided further into verbal, physical, and cognitive/emotional responses. Verbal responses were defined as comprehensible audible feedback and physical responses as any observable bodily movement. Feelings and experiences observed in or reported by participants in response to or as a result of questions were categorised as cognitive/emotional responses.

\section{A. Query design:}

\begin{tabular}{|c|c|c|}
\hline Interactive & \multirow{6}{*}{ AND } & Art \\
\hline \multirow[t]{5}{*}{ Open-ended } & & Artwork* \\
\hline & & Environment* \\
\hline & & Installation* \\
\hline & & $\begin{array}{l}\text { Art } \\
\text { installation* }\end{array}$ \\
\hline & & $\begin{array}{l}\text { Art } \\
\text { environment* }\end{array}$ \\
\hline
\end{tabular}

\begin{tabular}{|c|c|c|}
\hline Audience & \multirow{6}{*}{ AND } & Interaction \\
\hline Participant ${ }^{*}$ & & Reaction \\
\hline Participator* & & Experience \\
\hline User* & & Participation \\
\hline Human-computer & & Behaviour \\
\hline Human-robot & & Play \\
\hline \multicolumn{3}{|l|}{ OR } \\
\hline \multicolumn{3}{|l|}{$\mathrm{HCl}$} \\
\hline UX & & \\
\hline
\end{tabular}

B. Query 1:

((interactive OR "open end") AND (art OR artwork* OR installation* OR "art installation*" OR "art environment" OR environment*))

AND

("audience" OR "participant*" OR "particpator*" OR "user" OR "human-computer" OR "human robot" AND (interaction OR reaction OR experience OR participation OR behaviour OR play) OR $\mathrm{HCl}$ OR UX)

\section{Query 2:}

(behaviour OR behavior OR interaction OR play OR results) AND ("interactive artwork" OR "interactive installation") 


\section{Chapter 2}

An overview of the interactive artworks, with a description of their appearance and workings (interaction possibilities), can be found in table 3. The extracted participant responses are listed in tables 4 and 5 . If user responses to an artwork were evaluated over multiple sessions, the results were combined in this review for ease of reference.

\section{Results}

\section{Selection process}

An overview of the selection process is shown in Figure 1. The search strategy resulted in 758 potentially relevant articles, 278 of which were duplicates due to the use of two queries. The title screening involved 480 titles which were screened and scored by three reviewers (TL, SB, TD), resulting in 405 being excluded. The other 75 titles each had a total score of 3 or more, meaning they proceeded to abstract screening. In the abstract screening stage, 43 of the articles attained a total score of 3 or more and were therefore forwarded to full-text review. During this final selection round, consensus (i.e., a total score of 6 , or 2 from each researcher) was needed for the articles to be included in data extraction. Ultimately, 13 articles were included (Bialoskorski et al., 2010; Costello et al., 2005; Deray and Simoff, 2012; Gurion and Jacoby, 2013; Her and Hamlyn, 2010; Hespanhol and Tomitsch, 2014; Hohl, 2009; Jacucci et al., 2009; Morgan and Gunes, 2013; Morrison et al., 2011b, 2008, 2011a; Muller, 2008).

\section{Data extraction}

13 articles were included in the analysis (Table 1), discussing 22 artworks (Table 1; Figure 7).

\section{Study population}

Most of the artworks studied $(n=16)$ were viewed by a population of between 2 and 60 people, ranging in age from under 16 to over 60 years, with an almost equal proportion of men and women. Four of the artworks had an unknown population of viewers.

\section{Exhibition time}

For almost half of the artworks in the studies $(n=8)$ there was no data available about exhibition frequency and/or duration; three were shown only once. The exhibition times of the remaining artworks $(n=6)$ ranged from twice (two days) to one month.

\section{Measurement instruments}

All artworks were evaluated using mixed methods (2-5 per artwork). The most commonly used methods were (video) observation $(n=12)$, interviews $(n=12)$ and video-cued recall $(n=6)$. 


\section{Systematic review}

Table 1: Overview of articles extracted and artworks studied in them

Study

\begin{tabular}{ll} 
First author & Title \\
\hline Gurion, T. & $\begin{array}{l}\text { Audio-only augmented reality for } \\
\text { social interaction }\end{array}$ \\
Jacucci, G. & $\begin{array}{l}\text { Bodily explorations in space: social } \\
\text { experience of a multimodal art } \\
\text { installation }\end{array}$
\end{tabular}

Morrison, A. Building sensitising terms to understand free-play in open-ended interactive art environments artworks studied Audio-only augmented reality system for social interaction [Figure 7(a)] Galassie [Figure 7(b)] Ombra di Stelle [Figure 7(c)]

ALAV [Figure 7(d)]

Drafting poems [Figure 7(e)]

Books of sand [Figure 7(f)]

Hohl, M. Designing the art experience: using Radiomap [Figure 7(g)] grounded theory to develop a model of participants' perception of an immersive telematic artwork

Morrison, A. Evoking gestures in interactive art

Bialoskorski, Experiencing affective interactive L. art

Deray, K. Framing interaction through engagement in interactive open ended environments

Her, J. Meaningful engagement: computer- based interactive media art in public space

Costello, B. Understanding the experience of interactive art: iamascope in beta_space

Space of two categories [Figure 7(h)]

Mood swings [Figure 7(i)]

High arctic [Figure 7(j)]

Event horizon [Fig. 7(k)]

Untitled [Figure $7(\mathrm{I})$ ]

Elysian Fields [Figure 7(n)]

Sprung! [Figure 7(0)]

Just a bit of spin (prototype) [Figure $7(p)]$

Just a bit of spin (redesign) [Figure 7(p)]

Hespanhol, Understanding the effects of

$\mathrm{H}$. contextual constraints on

Metastasis [Figure 7(q)] performative behaviour in interactive media installations

Morgan, E. Human non-verbal behaviour understanding in the wild for new media art

Muller, E. The experience of art: a curatorial study

Cardiomorphologies (prototype)

[Figure 7(s)]

Contagion (prototype) [Figure 7(t)]

Contagion (finished) [Figure $7(\mathrm{t})]$ 


\section{Chapter 2}

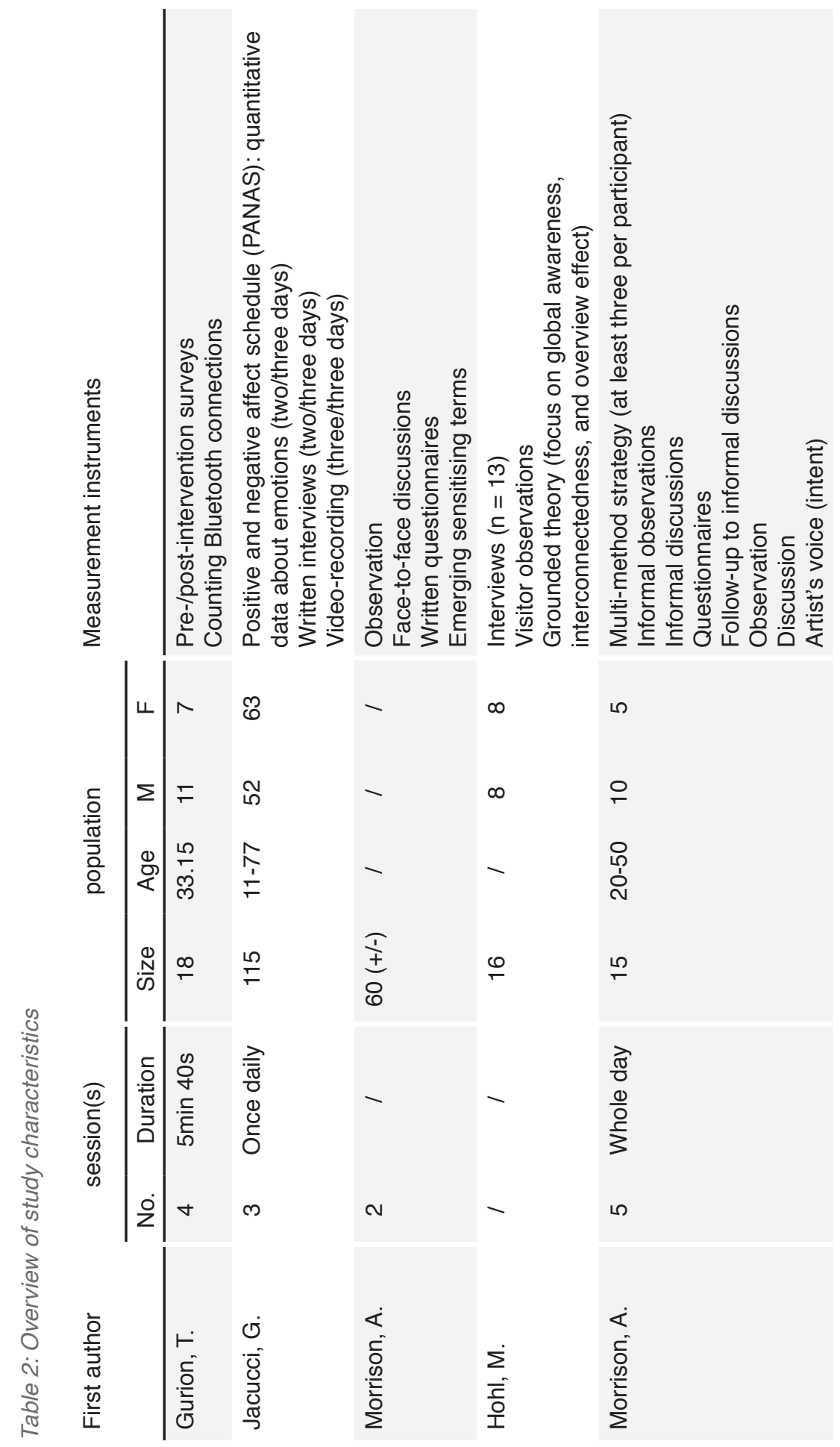


Systematic review

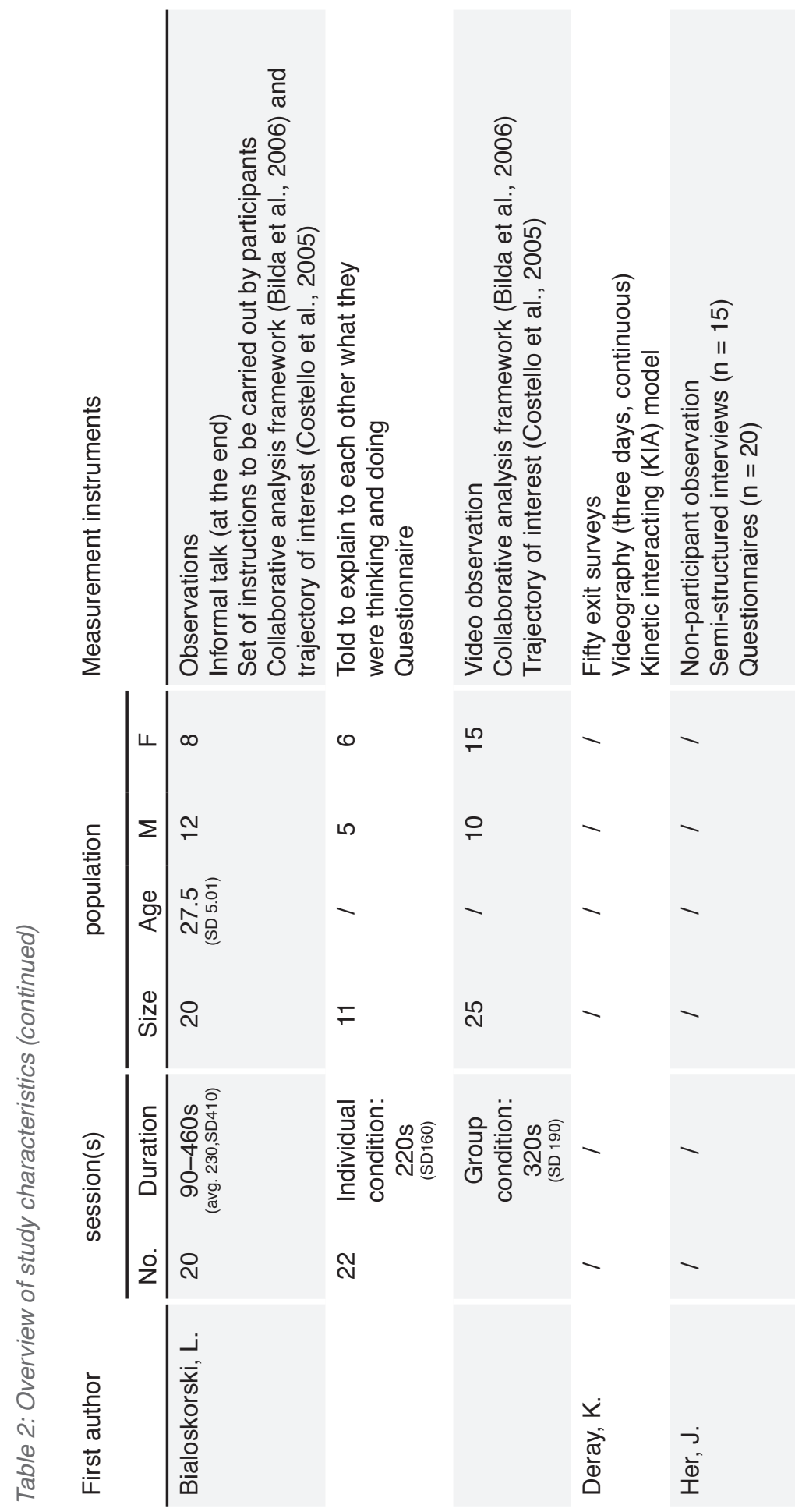




\section{Chapter 2}
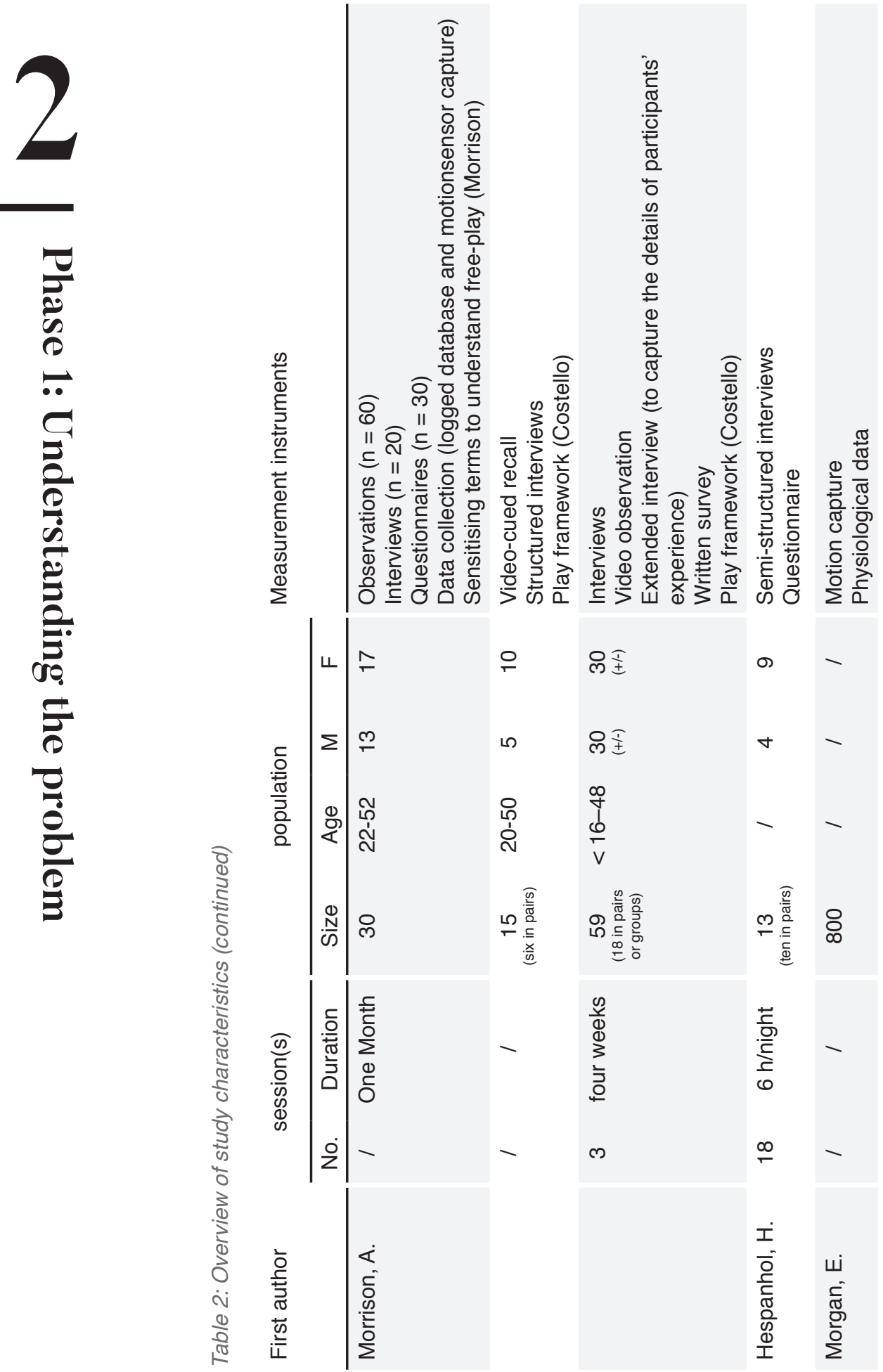

24 The art of feeling connected 
Systematic review

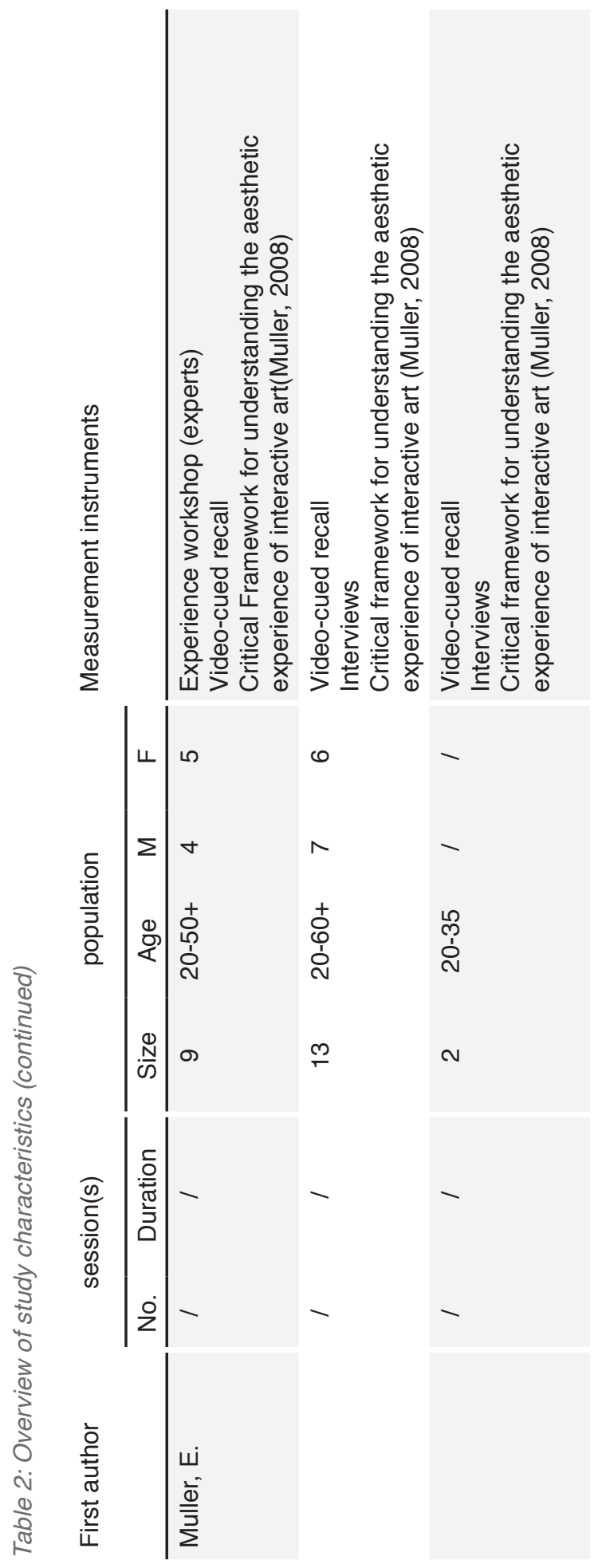

The art of feeling connected $\quad 25$ 


\section{Chapter 2}
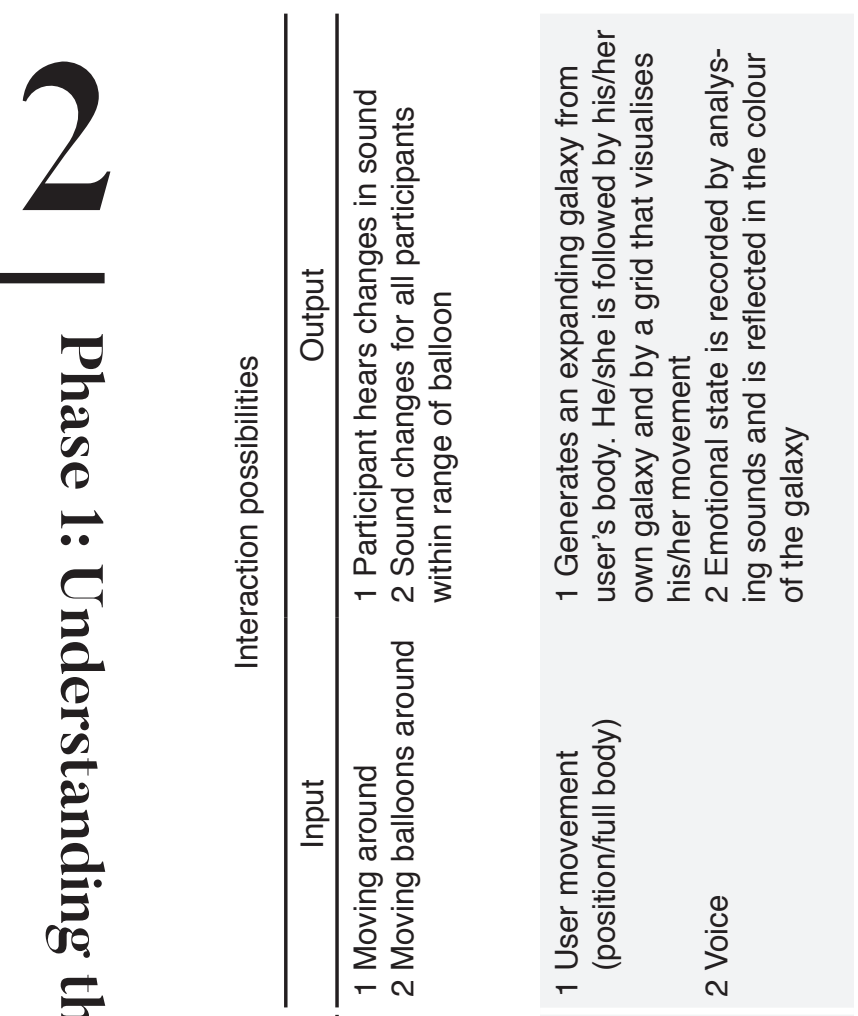

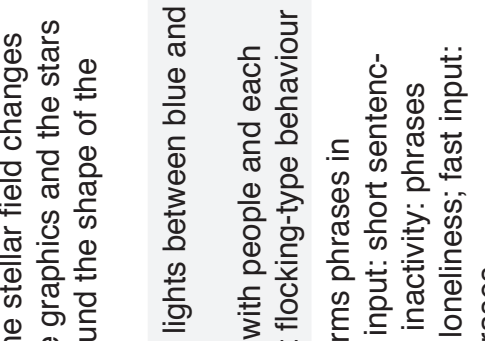
๑ 0

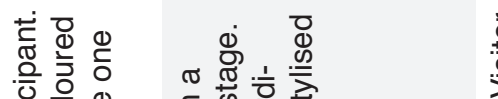

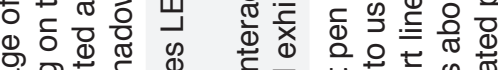

ब

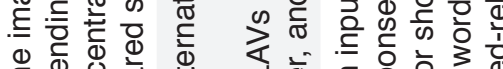

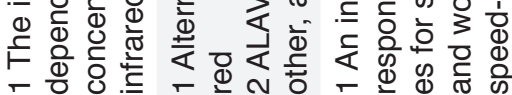

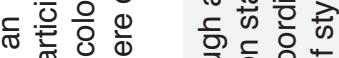

วิ응 \& $\frac{5}{3}$

옹 ㅇํㅇ

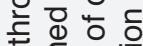

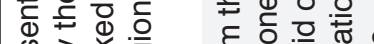

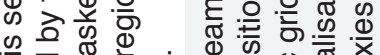

을

के

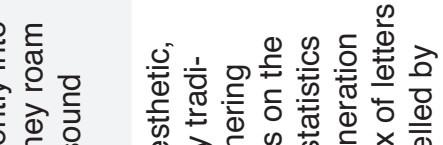

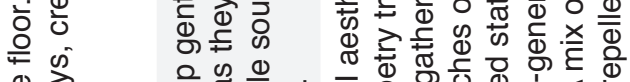

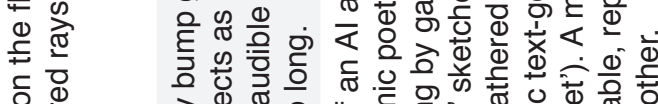

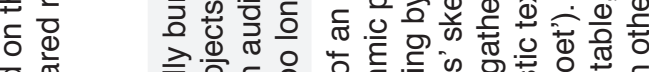

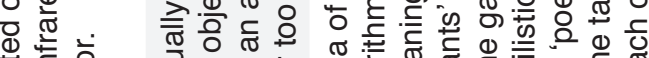

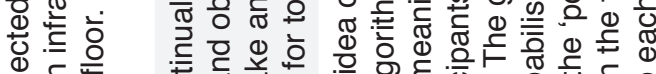

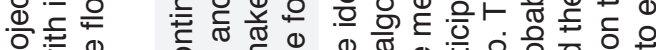
인

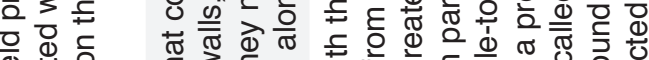
응 d 竞

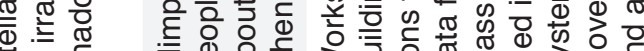

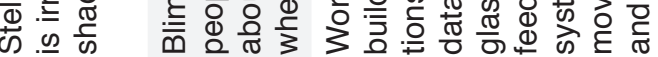

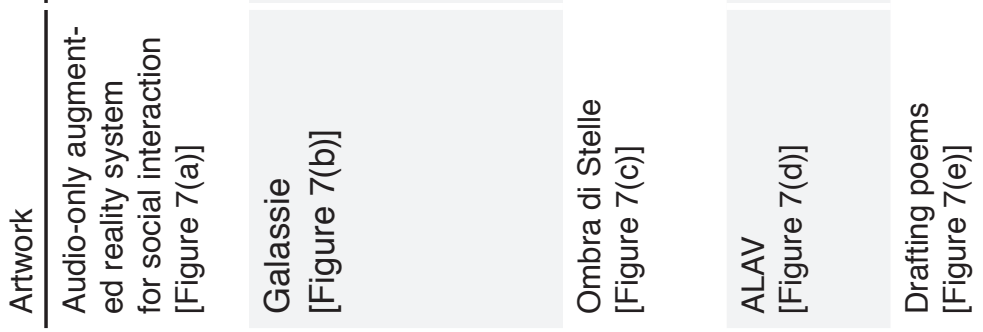




\section{Systematic review}

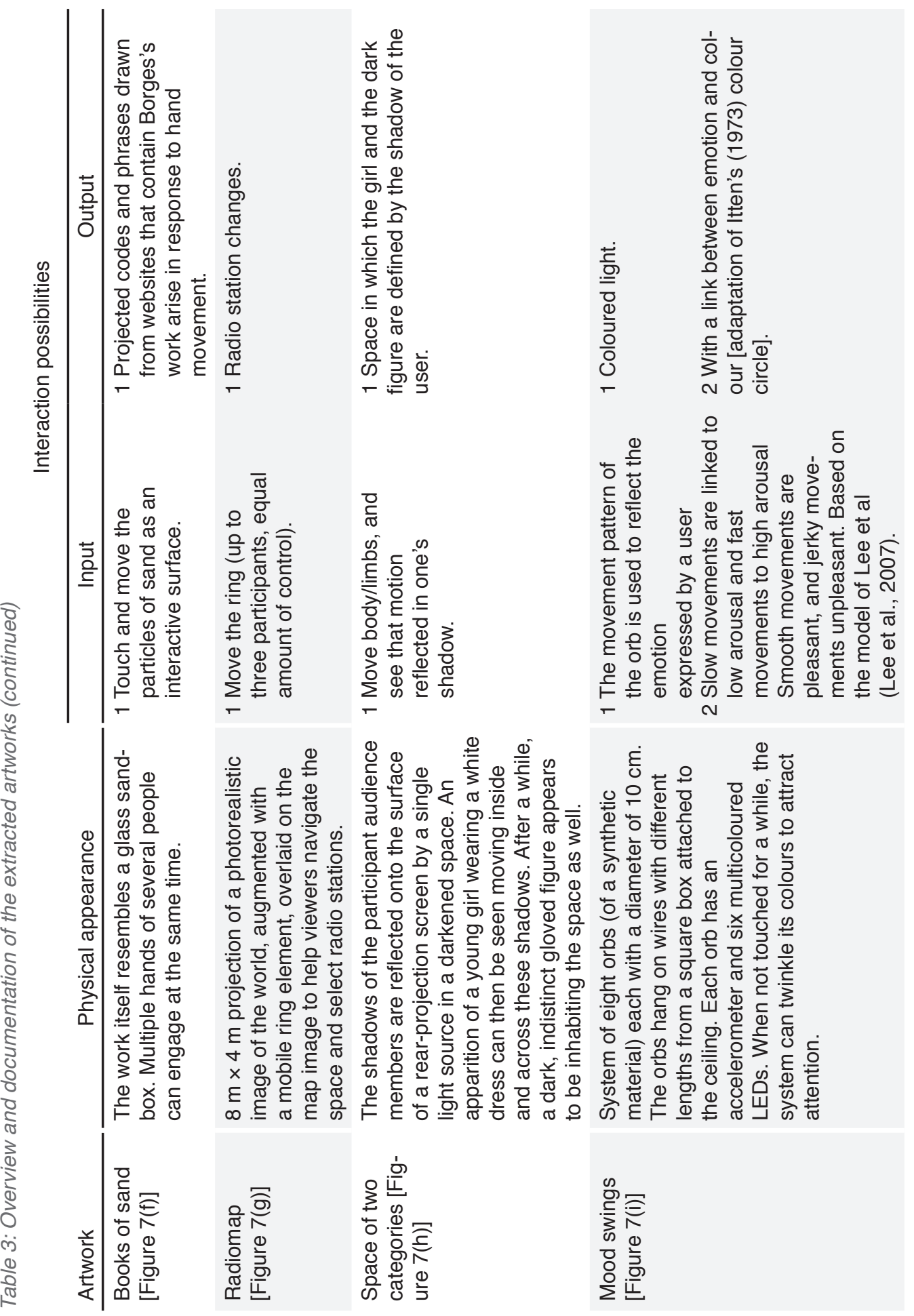




\section{Chapter 2}
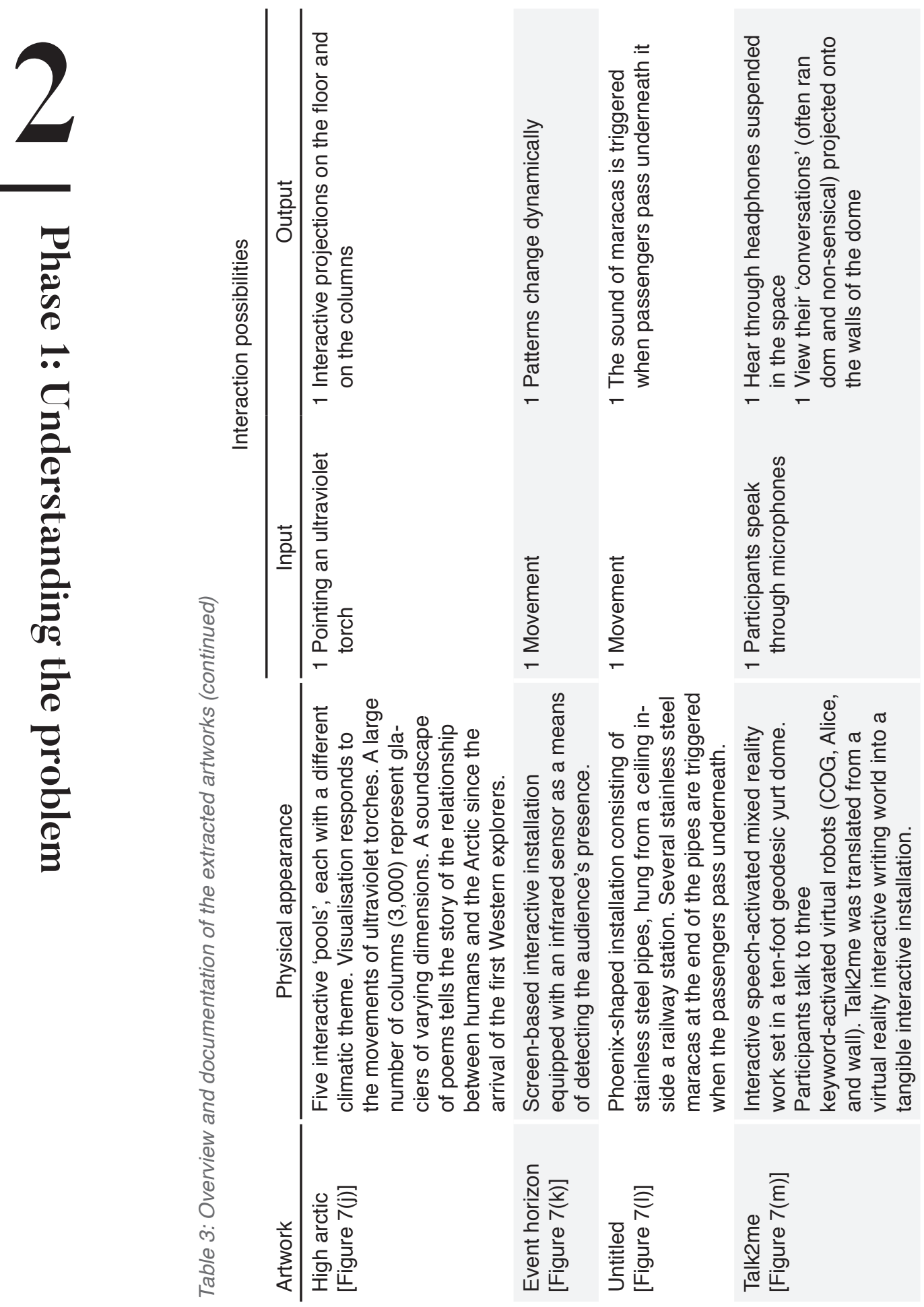


\section{Systematic review}

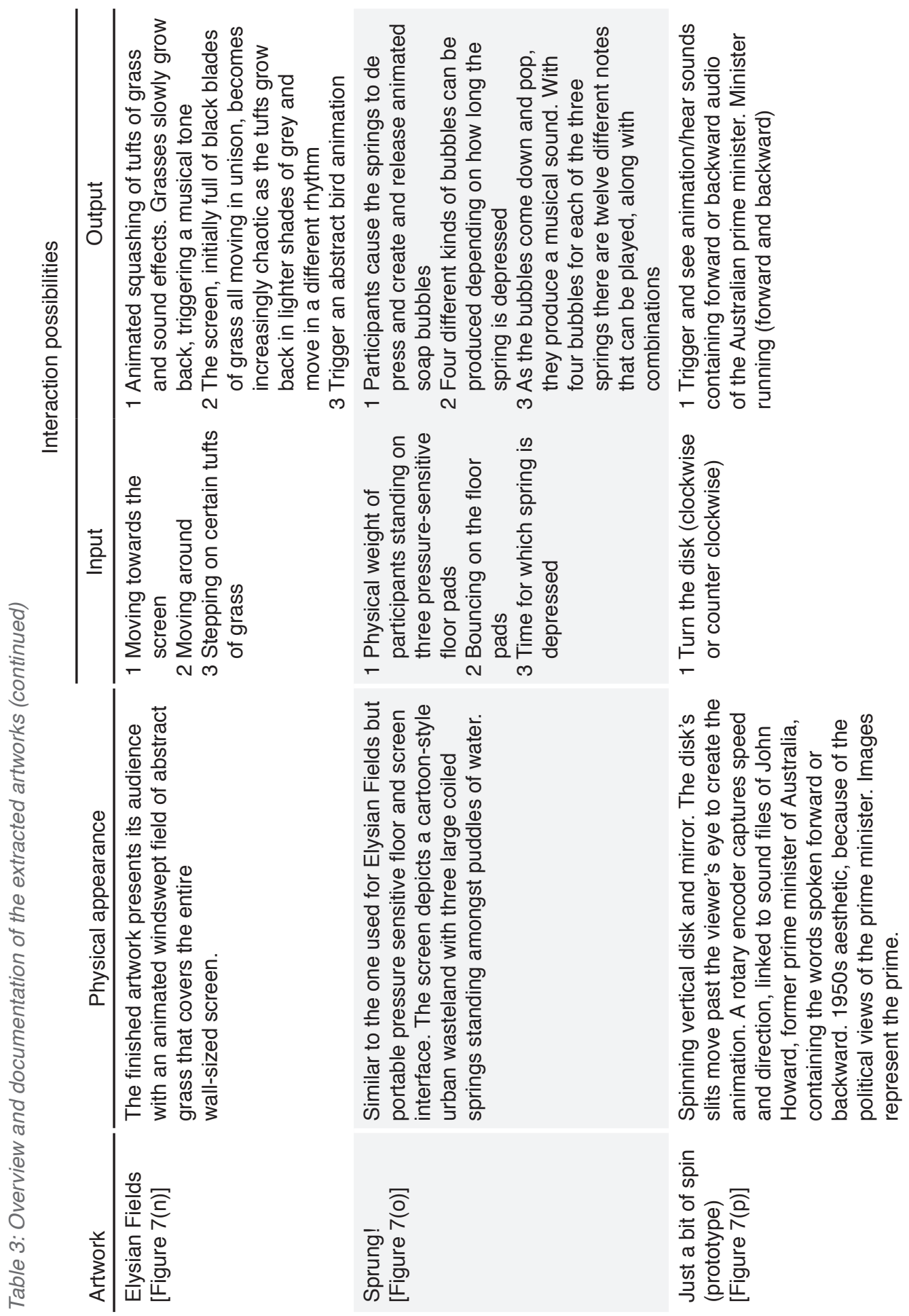




\section{Chapter 2}
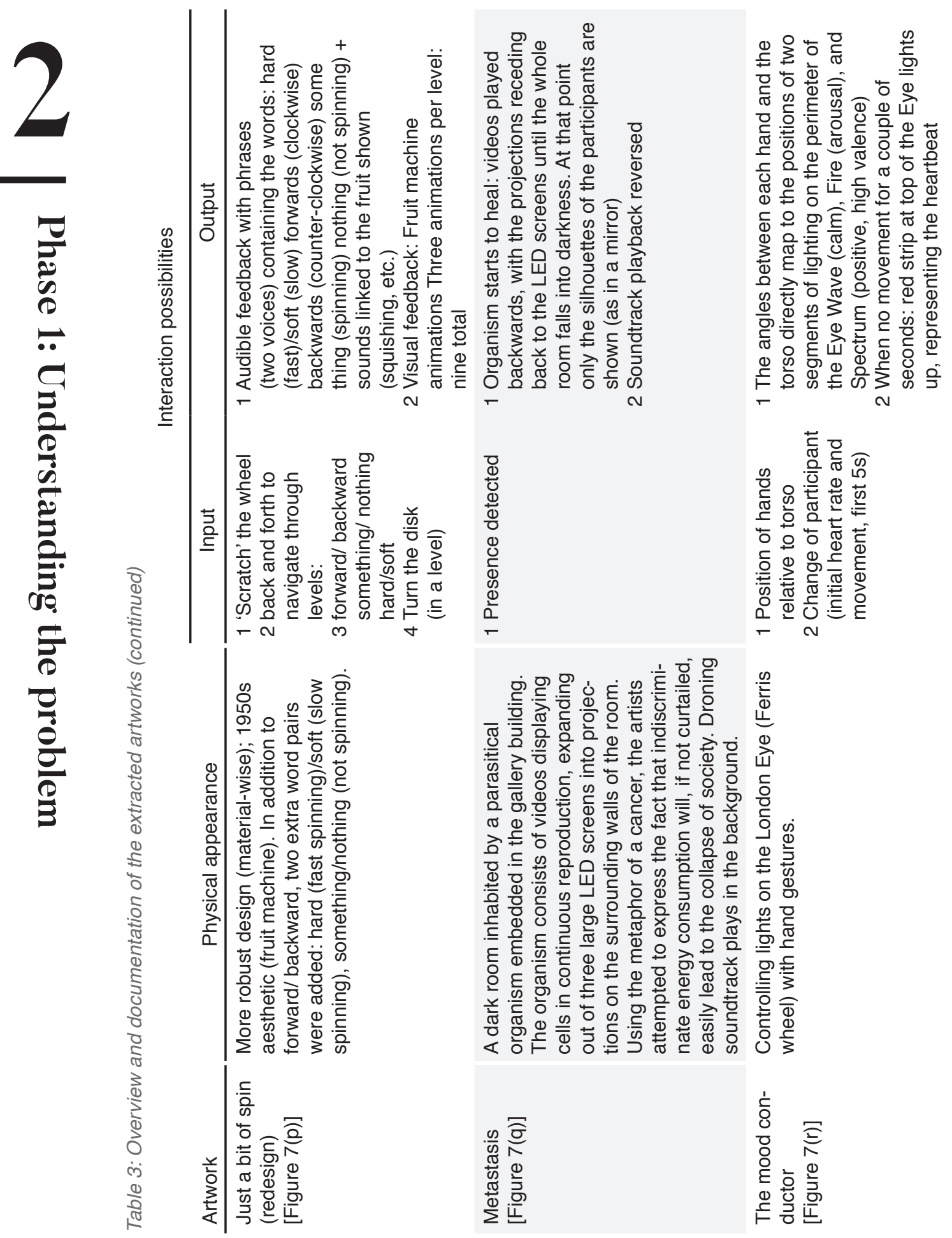


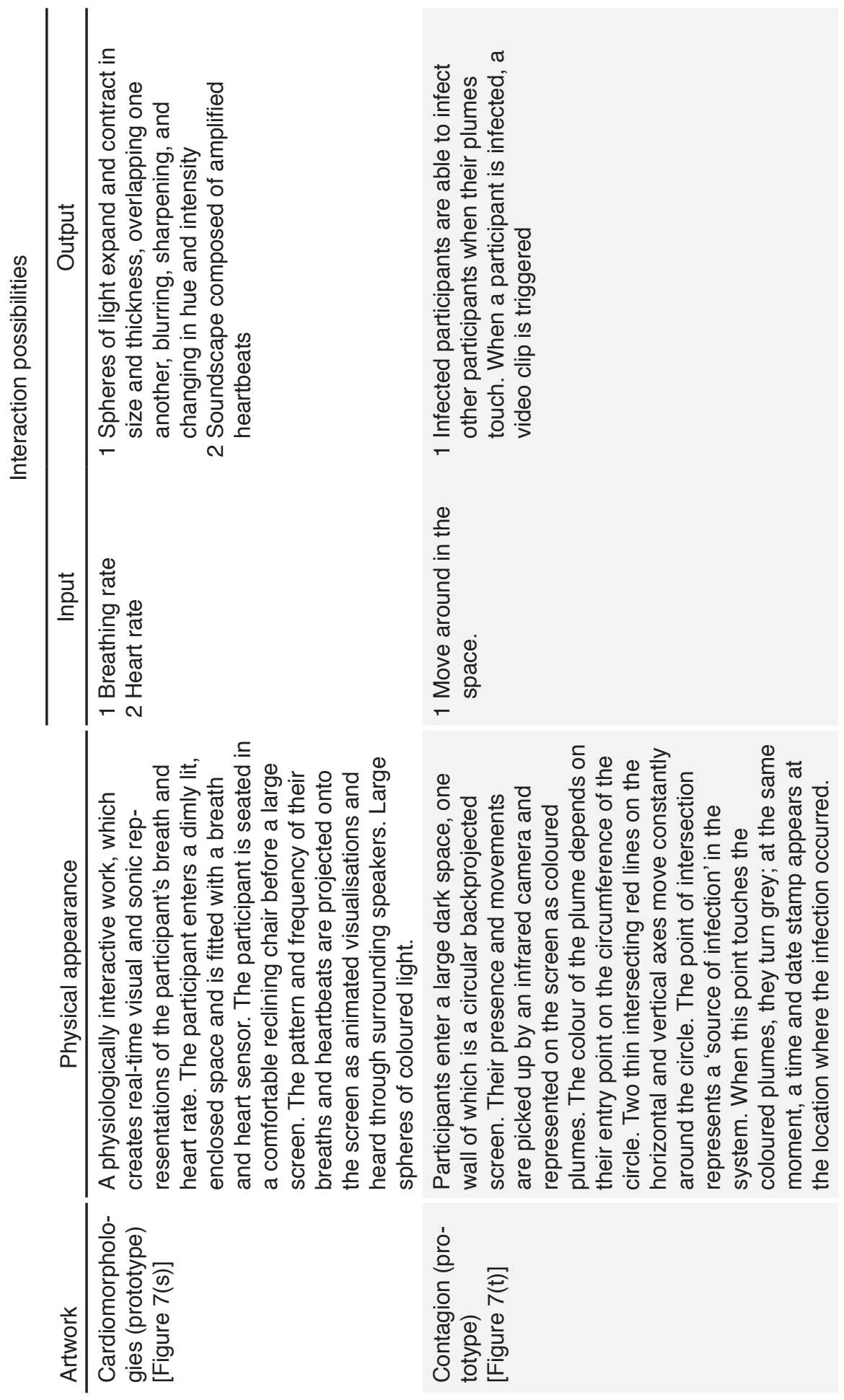




\section{Chapter 2}
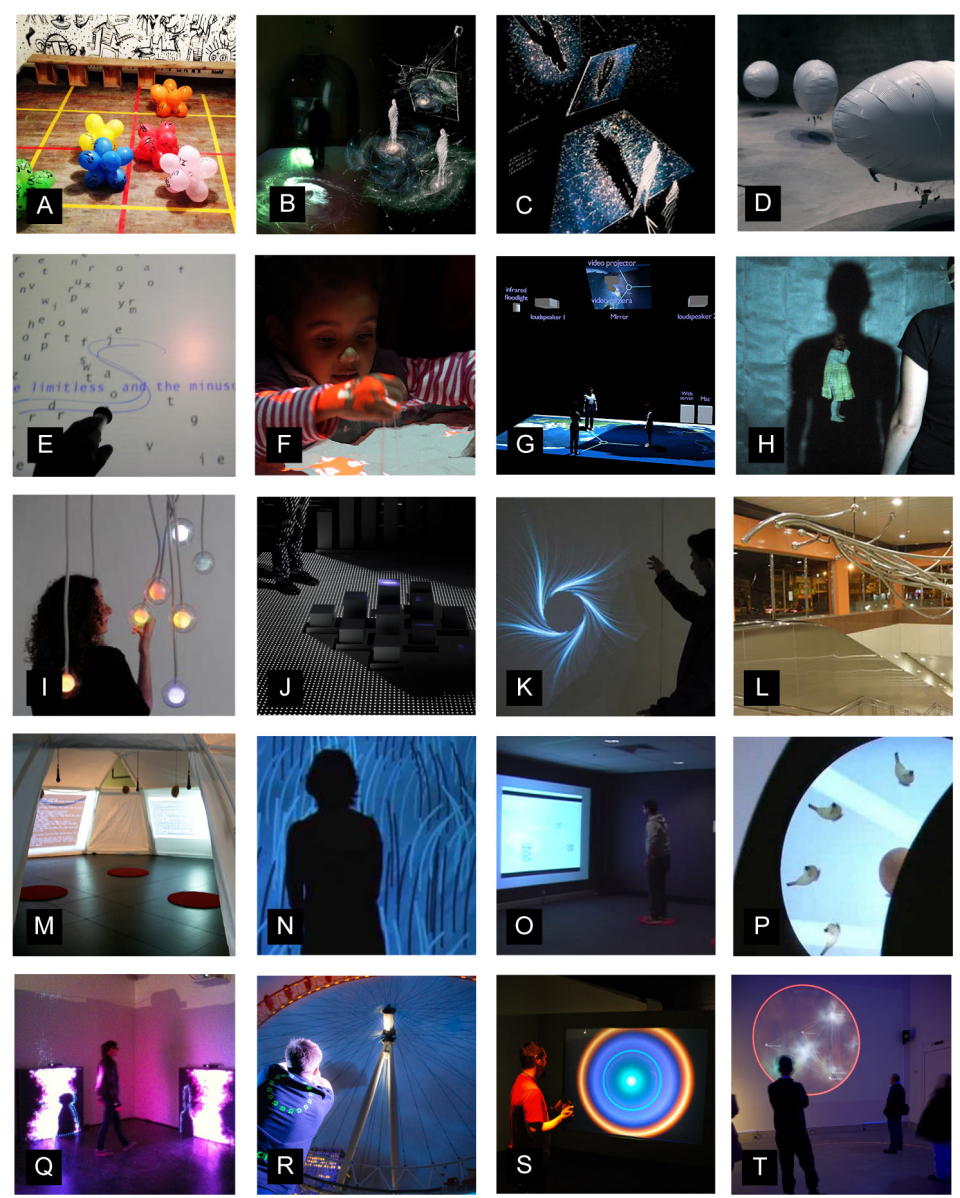

Figure 7: Visuals of extracted artworks,

(a) audio-only augmented reality system for social interaction - Gurion and Jacoby

(b) galassie - Studio Azzurro (c) Ombra di Stelle - Studio Azzurro (d) autonomous light air vessels - Nikhil Mitter and Jed Berk e) drafting poems: inverted potentialities Eitan Mendowitz (f) books of sand - Mariano Sardon (g) radiomap - Michael Hohl and Stephan Huber (h) space of two categories - Hanna Haaslahti (i) mood swings - Leticia Bialoskorski (j) high arctic - UVA (k) event horizon - author unknown (I) untitled - author unknown (m) Talk2me - Ann Morrison (N) Elysian Fields - Brigid Costello, Ian Gwilt and Dave Burraston (o) sprung! - Brigid Costello and Allistair Macinnes (p) just a bit of spin - Brigid Costello (q) metastasis - Luke Hespanhol (r) the mood conductor - Cinimod

Studio (s) cardiomorphologies - George Khut (t) contagion - Gina Czarnecki 


\section{Systematic review}

\section{User responses}

\section{Human-artwork}

All the included articles involved human-to-artwork responses (Table 4), which can be divided into verbal, physical, and cognitive/emotional responses. Further information on each of the types of human-to-artwork responses is given below.

\section{Verbal responses}

None of the artworks that were described in the articles used voice as an interface. There were four artworks for which verbal human-to-artwork responses were mentioned, as participants asked questions and provided comments on their (technical) workings (drafting poems and mood swings) or described out loud what they saw (ALAVs and contagion). It appears therefore that the verbal interactions mentioned were limited to figuring out how the artwork functions.

\section{Physical responses}

Fourteen artworks triggered physical responses. One of the recurring patterns is the correlation between the physical response of the participants and the affordance (Norman, 2002) of the artwork.

That is, in artworks in which physical objects were the main focus, participants' physical responses were based on the affordance of the object: batting or patting a flying blimp (ALAVs); swinging, squeezing, touching, tickling, stroking, hitting, or braiding orbs hanging from a wire (mood swings); or making waving, circular, pointing, and oscillating movements with a torch (high arctic).

In screen-centred installations, a distinction can be made between screens depicting concrete imagery and screens that show abstract content. When concrete, recognisable content was shown, participants responded according to the affordance of the depicted subject, as with the real objects mentioned above: stomped their feet as if actually crushing the projected grass (Elysian Fields); leaped, jumped, and tried to depress three projected springs at once, while feeling childlike and free to move in the game-like setting of sprung! or waved with varying speeds and high synchronicity in semi-circular movements at the interactive lights on the London Eye (mood conductor).

In contrast, when the screen showed abstract content, participants mostly used whole-body movements to find out what the responses of the artwork would be. In event horizon, people waved their hands and shook their feet, moved back and forth and even danced. Moving around and stepping in and out were recorded in contagion and spaces of two categories, where people also tried out different paces and movements. In cardiomorphologies, which differed from the other works in its specific heartbeat and breathe rate interface, participants 


\section{Chapter 2}

also tried to find out what the depicted abstract content meant by physically trying out divers options.

In large, dark open spaces people tend to 'experience the space' as a void. Comments like 'this is not a room' were made in radiomap. Likewise, in Talk2me, participants sat down and engaged, committing to the space. Gestures were deictic, a feature that can be linked to finding out the workings of the piece, just as with the screen-based installations with abstract content.

In smaller, table-top installations, motions tended to be more sensual, as seen in drafting poems and books of sand. In drafting poems, the movements on the table-top projection were larger than life, exaggerated, while in the real, augmented sand of books of sand they were more considered and slower in pace.

\section{Cognitive/emotional responses}

Just as with the physical responses, the most commonly noted cognitive response in artworks depicting abstract content was trying to figure out how the interactive artwork functions. This is described as 'understanding the functioning of the artwork' (galassie, Ombra di Stelle and event horizon), testing/mimicking results (drafting poems), exploring the interface as primary experience (radiomap) and searching for the limits of the installation by trying out different outcomes or searching for camera/screen boundaries and placement (cardiomorphologies and contagion). Participants' frustration derived mainly from the failure to understand how their actions impacted on the work beyond their immediate perception (metastasis).

In order to explore the meaning of an interactive artwork or to be immersed in it, it appears that the interface must be fully explored and understood. This was seen in space of two categories where it was noted that those who did not react as strongly to the reflective aspects of the artwork provided technical solutions more readily than those who did, implying that they did not figure out the interface. Morrison elaborates: 'The interaction starts at the moment of understanding'; and participants themselves confirmed this in cardiomorphologies: 'The interaction starts at the moment of understanding, prior [to which] everything is just mucking around'. Reaching the phase where the meaning is explored proved difficult: only $9 \%$ of individuals and $17 \%$ of groups reached it in mood swings. Therefore, Hohl argues when evaluating radiomap: 'A novel and unfamiliar method of navigation may not be recommended for computer mediated experience intended to facilitate reflective and introspective insights'. The interface is therefore the most important piece of an interactive artwork, because if it is lacking, the meaning is not even explored. Hespanhol and Tomitsch phrased this as follows: 'Immediate feedback that is directly mapped to the participant's actions is more important for engagement than a clear narrative'.

Feeling a personal connection and recognition with an aspect of an interactive artwork, 


\section{Systematic review}

like the sound of snow, can result in a more enthusiastic and immersive experience (e.g., Elysian Fields and just a bit of spin).

Closely linked to the feeling of perceiving large, dark open spaces as a void, participants mentioned underestimating the time spent in them (radiomap and space of two categories).

If participants feel shy, self-conscious, incompetent, or insecure, they may decide not to engage (just a bit of spin prototype, metastasis) or might take the role of passive observers, watching the activity and/or listening in on discussions (Talk2me, just a bit of spin redesign)

\section{Human-human}

All but four of the studies considered here include human-human response data (Table 5), although the available information is in general less extensive than that for humanartwork responses. Again, verbal, physical, and cognitive/emotional responses can be distinguished. Further information on each of the types of human-artwork responses is given below.

\section{Verbal responses}

In the recorded interhuman verbal responses, (brief) discussions about the work occurred spontaneously (ALAVs) and participants gave and received instructions about the way the artwork worked (ALAVs, drafting poems, Untitled, contagion (prototype), space of two categories). Participants verbally coached the person who was interacting with the artwork (drafting poems) or started to (verbally) work together (books of sand). People also verbally negotiated turns, for example 'are you done?' (books of sand, just a bit of spin).

\section{Physical responses}

If human-to-human physical responses were noted regarding an artwork, most of them involved participants interacting together with the artwork or with each other through the artwork. In three works with abstract content, it was observed that participants learned how to interact with the artwork by observing and imitating others or by trying it out together (galassie, Ombra di Stelle, and contagion).

Participation in a public environment was generally a democratic process. Participants were polite and shared freely in Talk2me. They coordinated their behaviour with that of their peers [called 'cooperative play' by Morrison; ALAV, drafting poems, books of sand, Talk2me (Morrison et al., 2011a)]. In the sandbox of books of sand, the researchers observed "[c]onsideration of and moving around the hands of others occurring naturally". Overall, participants naturally took turns testing and playing with the artwork: they handed over the pen (drafting poems), the activity spot (Talk2me), the wheel (just a bit of spin), or their turn (galassie, Ombra di Stelle) to the next user. 


\section{Chapter 2}

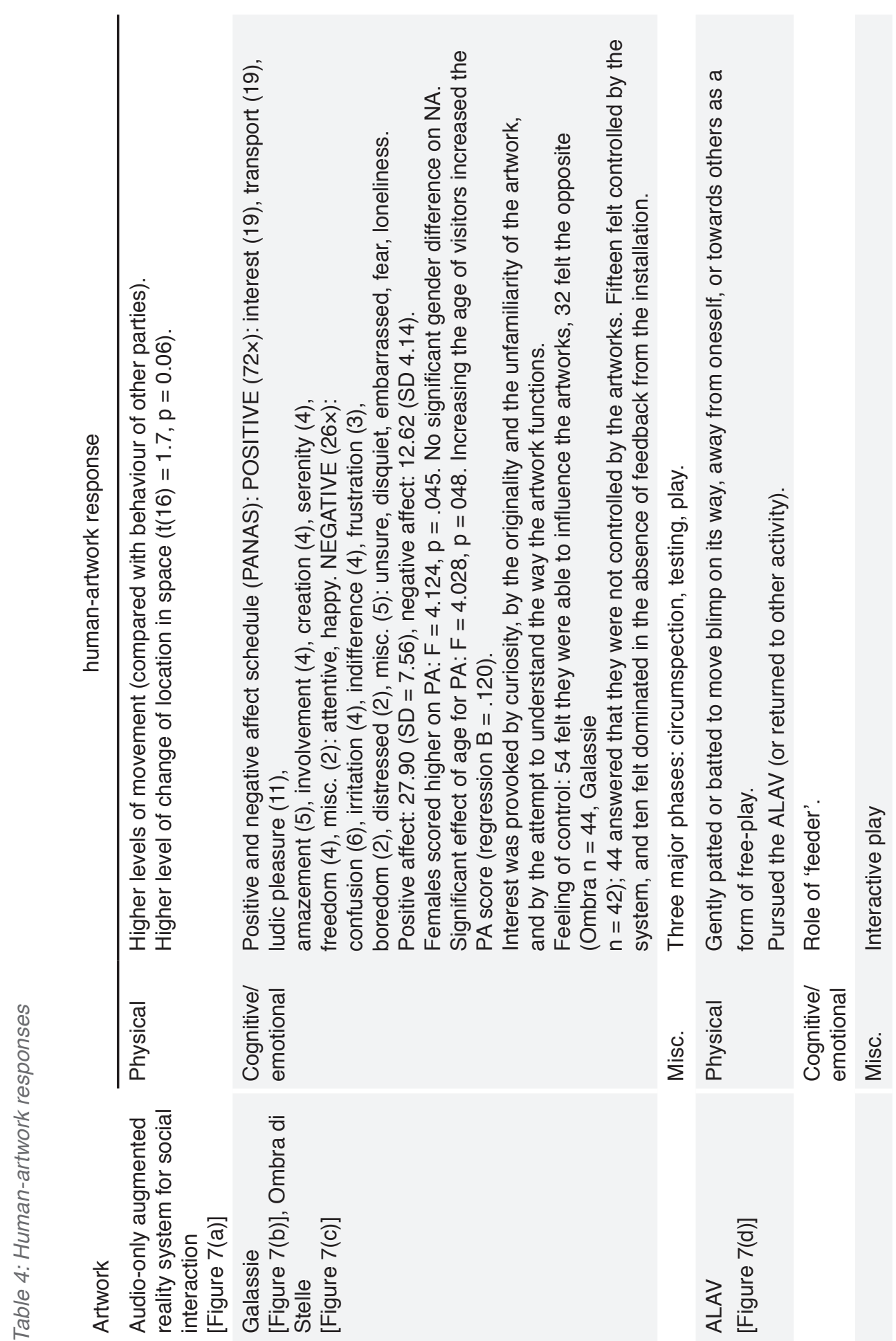


Systematic review

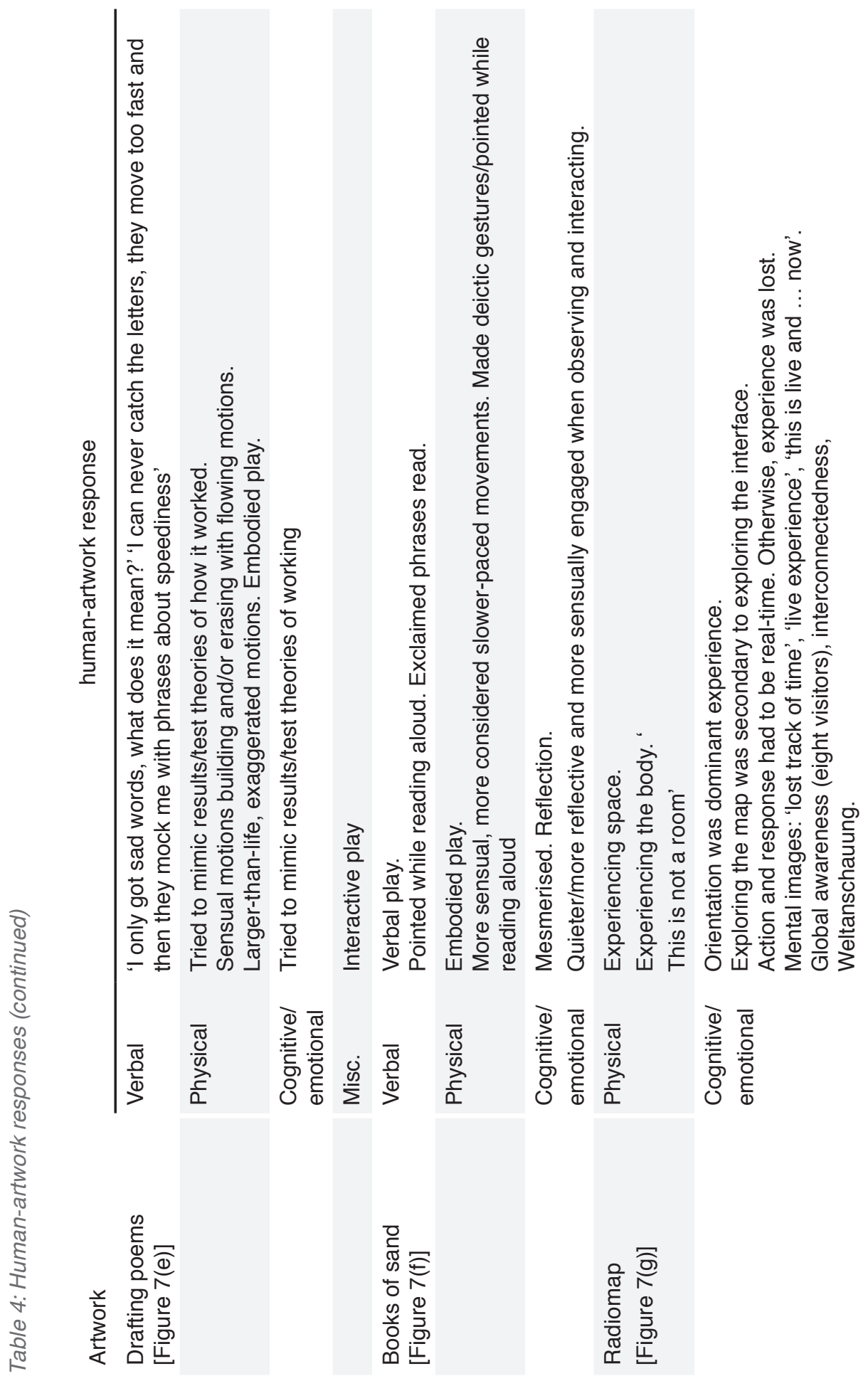




\section{Chapter 2}

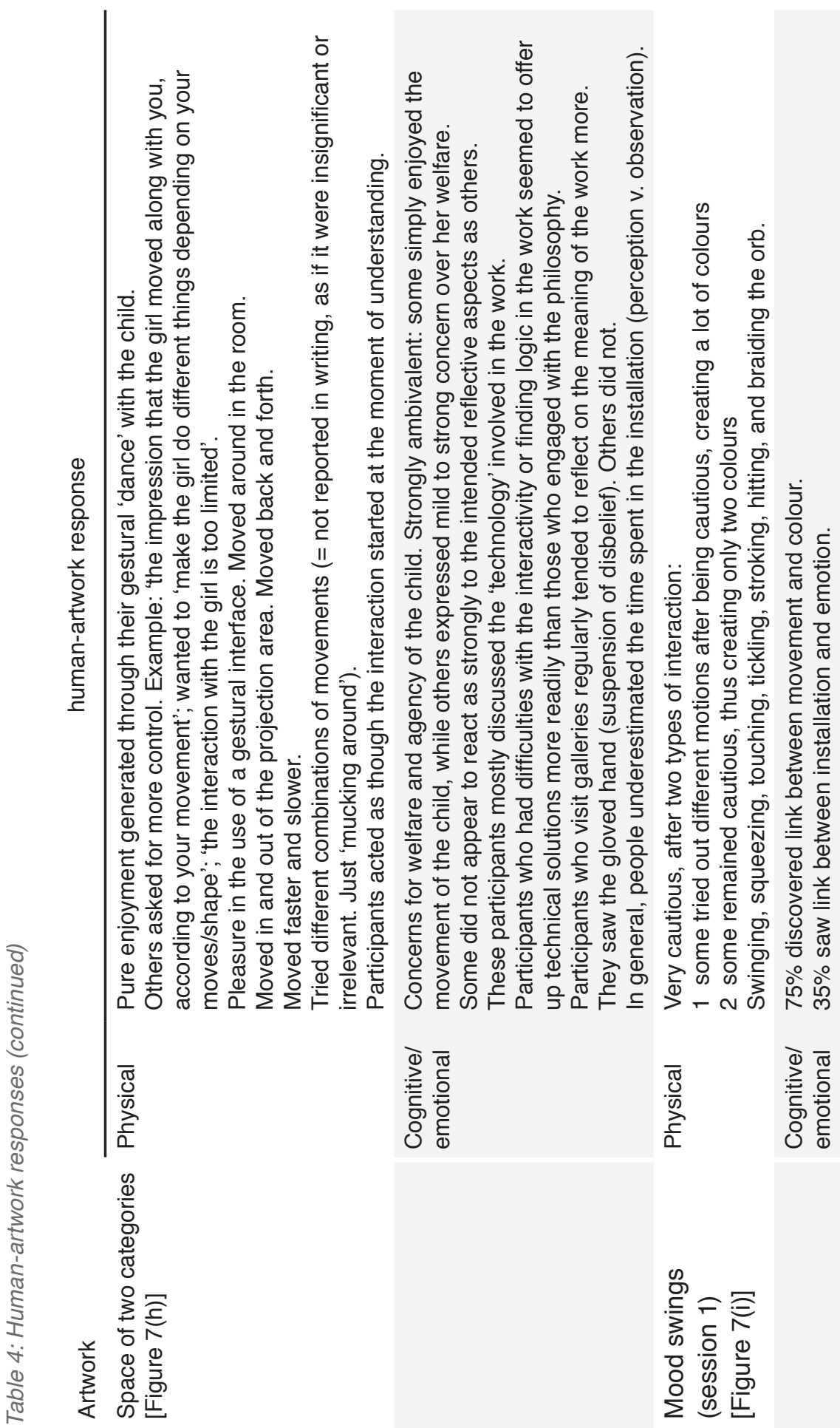




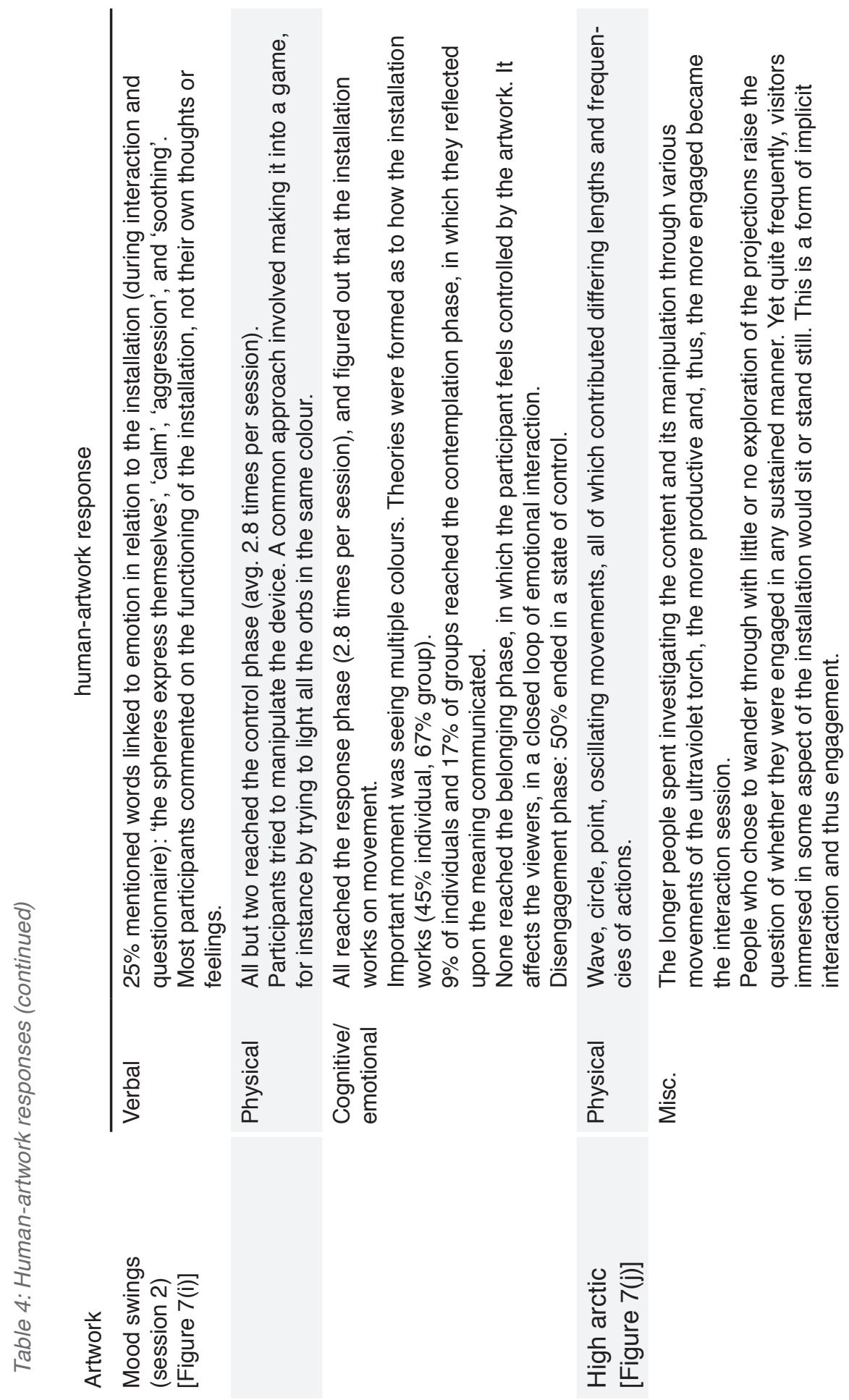




\section{Chapter 2}

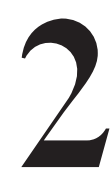

$\mid \frac{1}{4}$

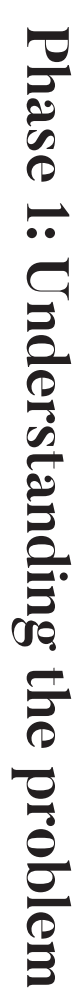

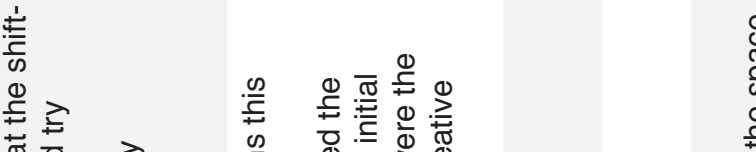

సٓ ত

宁 ฮ

竞高

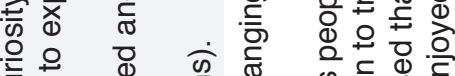

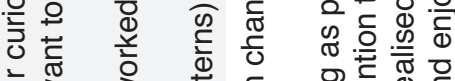

d

임

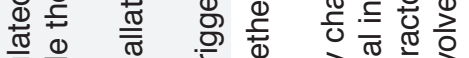

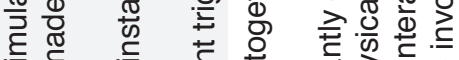

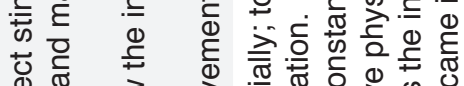

先 등 으

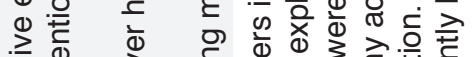

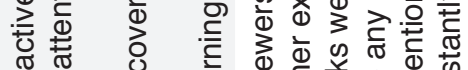

๘

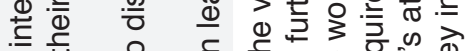

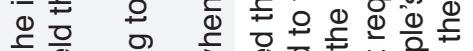

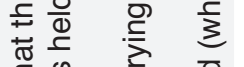

d 둔

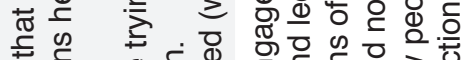

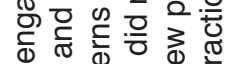

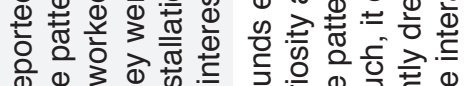

응 응

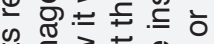

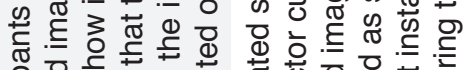

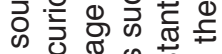

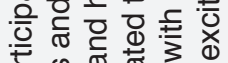

뜬 흔

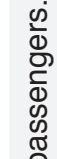

造

त

ญ

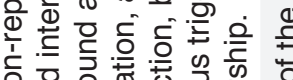

¿

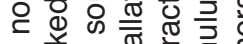

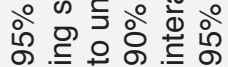

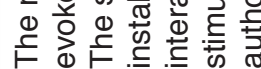

ลิ

몰

高

잉

$\stackrel{Ð 0}{\mp}$

을 을

ฮั สิ

3

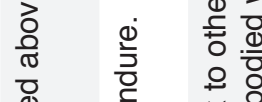

ర్

ठ ह

ช

엉

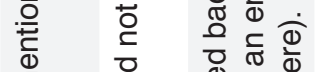

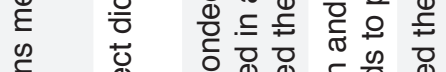

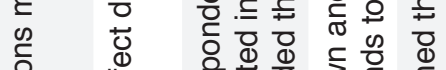

क्ष क्ष

$\stackrel{2}{ \pm}$

응

음

Ð

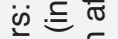

을 힝 음

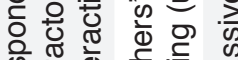

告

के एँ ए

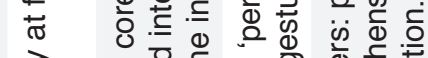

₹ 0 क

응 들

त్ ర్ 3

is ट ब

ॠ

$\stackrel{ \pm}{=} \frac{\pi}{0}$

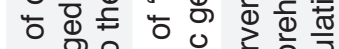

용요

웜

을 응

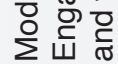

ํํㅇํำ

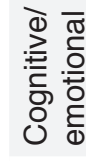

$\stackrel{\mathscr{0}}{\stackrel{\mathscr{N}}{2}}$

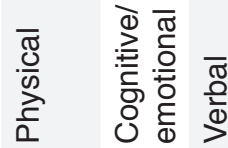

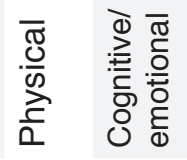



$\frac{\overline{0}}{\frac{0}{\infty}}$

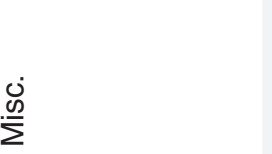

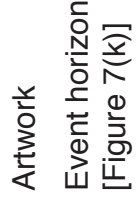

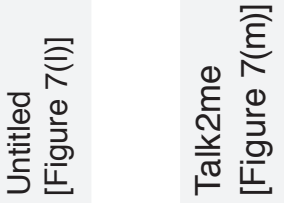




\section{Systematic review}

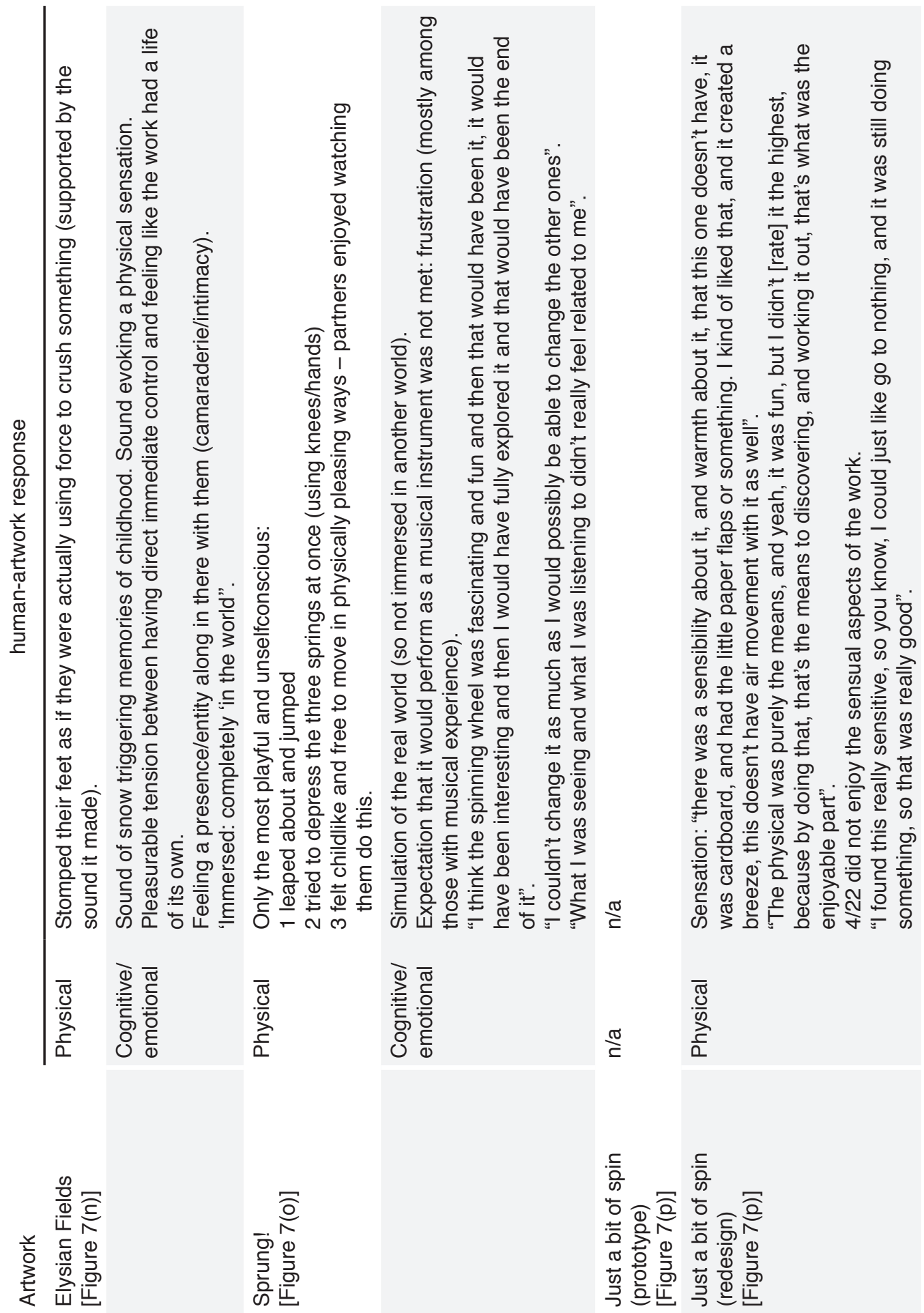




\section{Chapter 2}

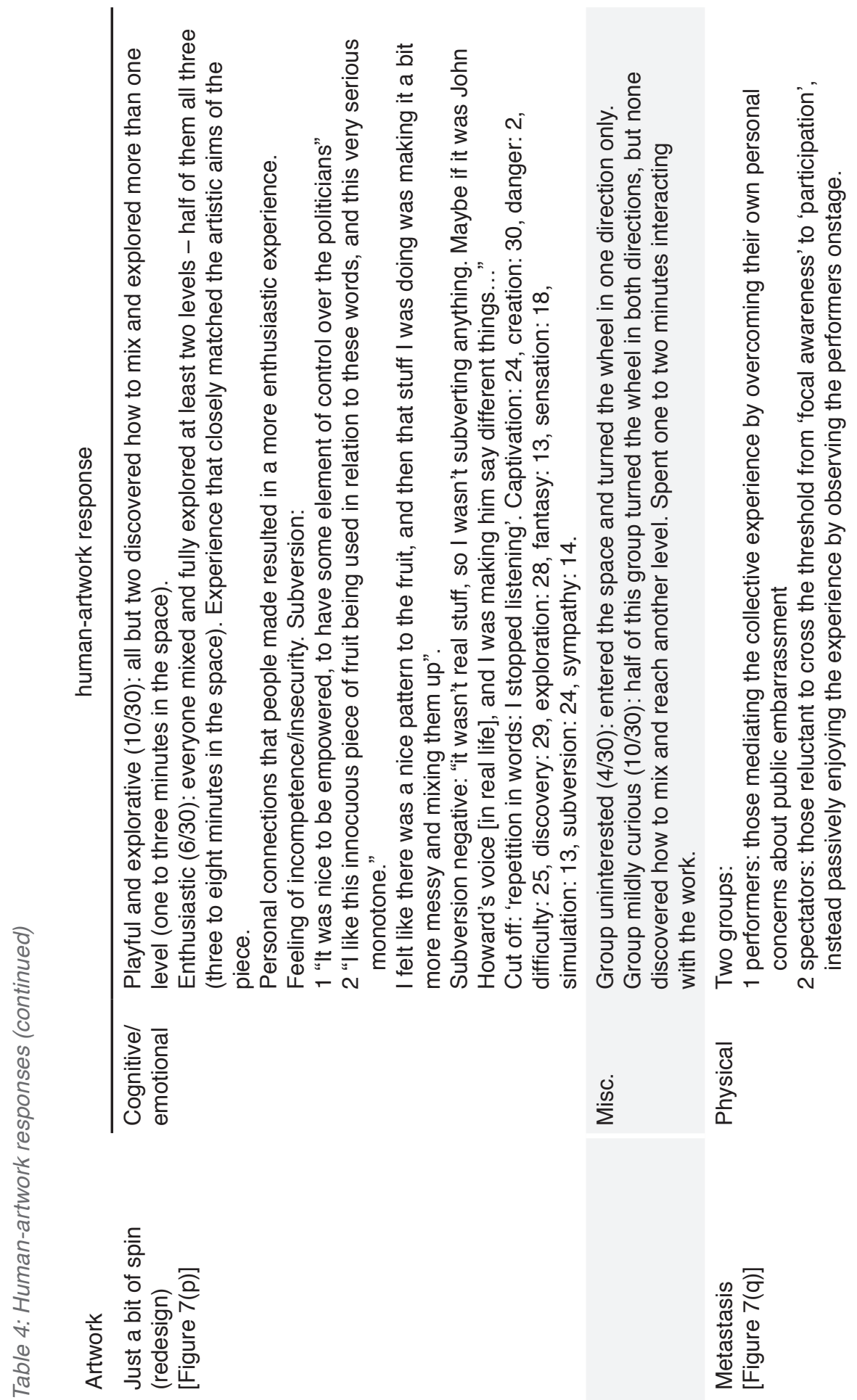


Systematic review

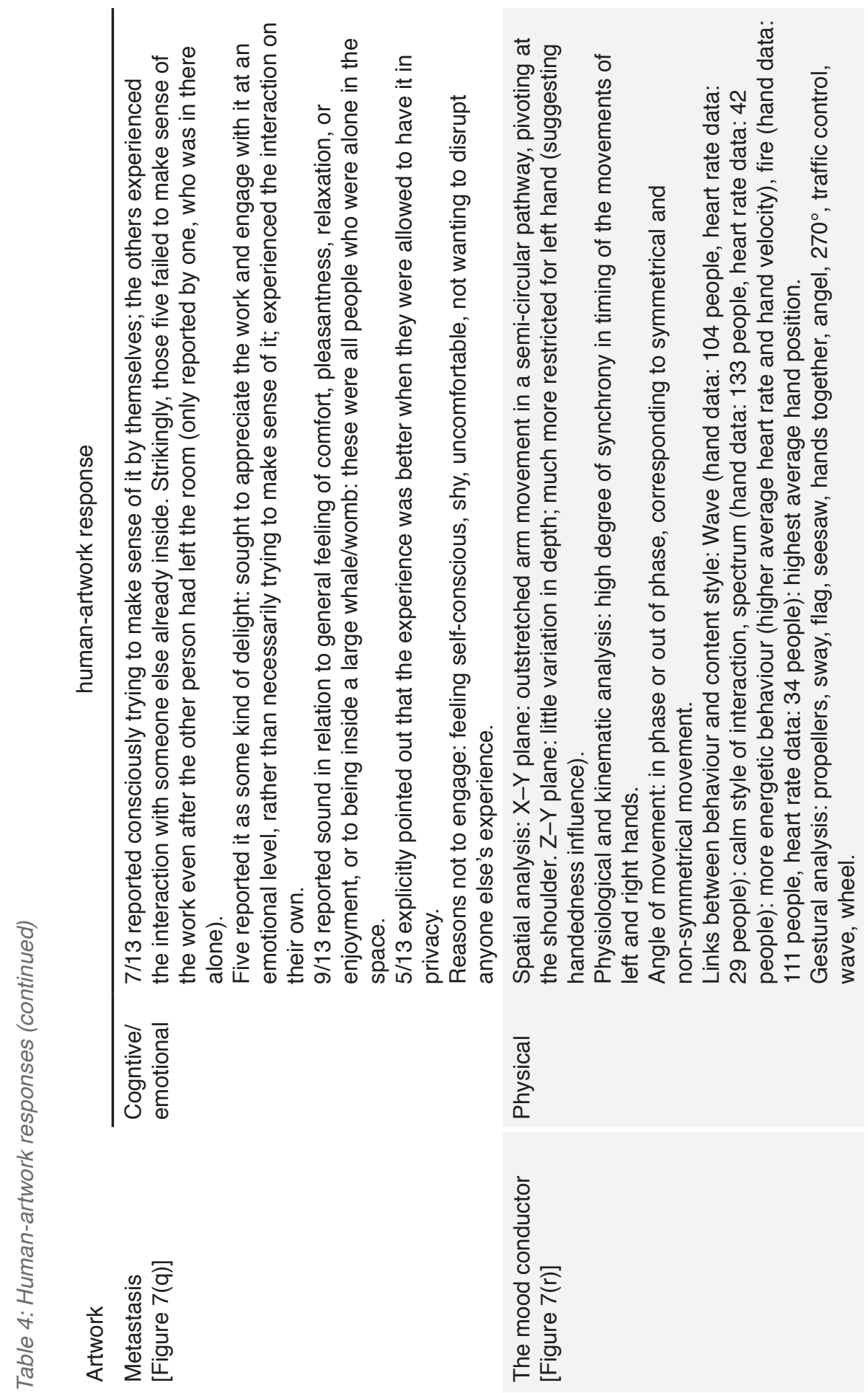




\section{Chapter 2}
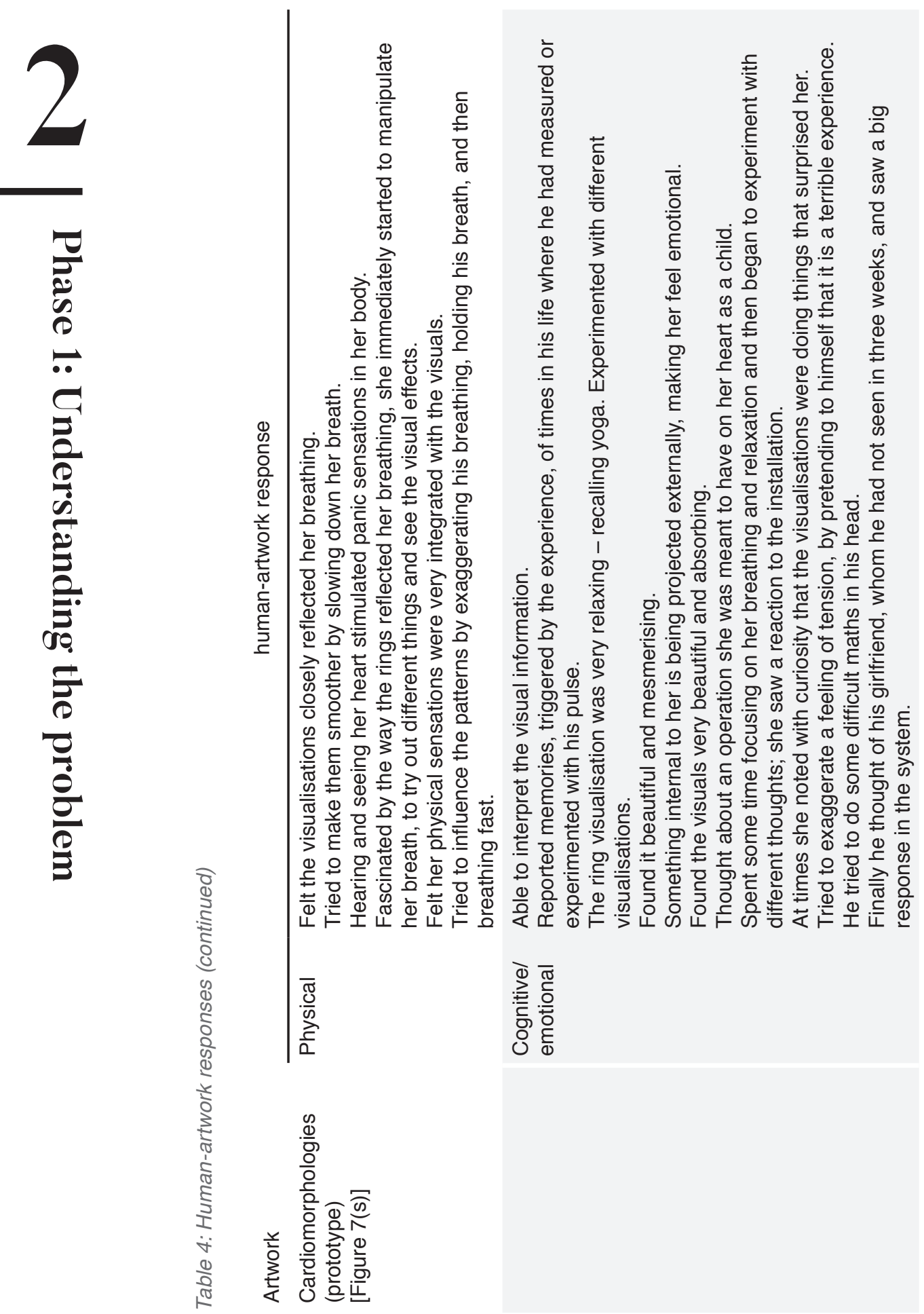
Systematic review

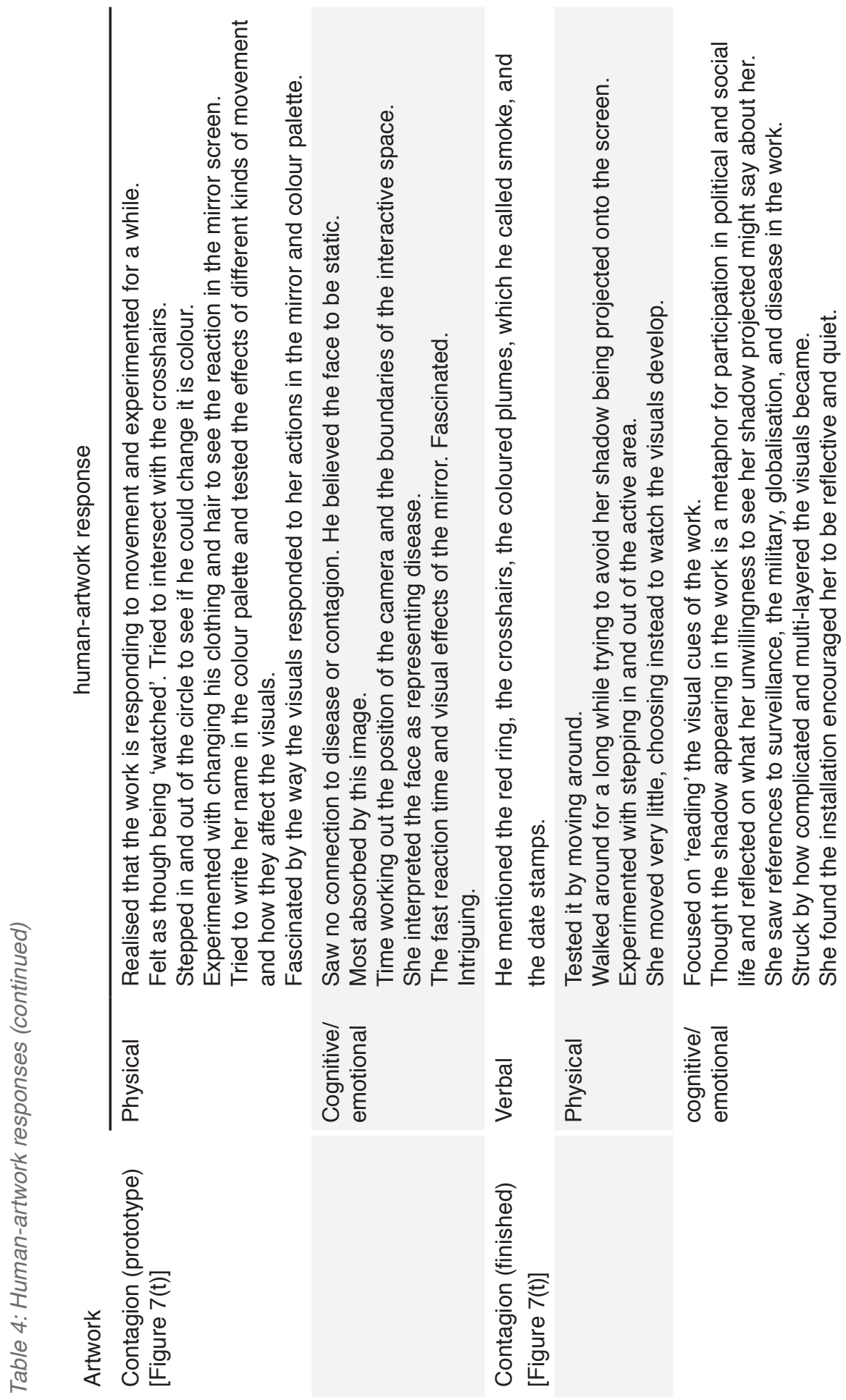




\section{Chapter 2}

\section{Cognitive/emotional responses}

In metastasis, participants noted a shift in their focus from their inner emotions to the other person's actions, negotiating the space, and managing joint actions. In galassie and Ombra di Stelle, participants were evenly divided between perceiving others' influence as positive or negative. In mood swings, however, participants in the group condition saw significantly more colours (mean 5.4) than participants in the individual condition (mean 3.8). Similarly, in high arctic, people who interacted with others learned from one another, and their collaboration led to extended time spent interacting with the artwork.

It is important to note that in high arctic all viewers appeared to be friends or relatives, a relation also found in metastasis: "previous acquaintance between the participants seems to be highly relevant for effective personal interaction when a casual encounter [was] forged within an immersive space. Almost all people who knew each other prior to the session (3 out of 4) felt inclined to interact when meeting within the space. Conversely, the majority of those who did not previously know each other (also 3 out of 4) decided not to engage in social interaction in this particular scenario. Previously established social ties seem to have been reinforced by the immersive situation" (Hespanhol and Tomitsch, 2014).

When people did not know each other, the affordance of the installation determines how they interact. In the playful ALAV installation, a sense of camaraderie developed as people batted the ALAVs towards each other and those who 'fed' the ALAVs bonded as well this in contrast with the informal shifting community of groups of people that lingered around the projections of poetry in the sand of the table-top sandbox in books of sand.

\section{Discussion}

The main aim of this article was to undertake a systematic review of studies describing responses of participants to physical, open-ended interactive digital artworks. Both human-to-artwork and human-to-human responses were seen regarding the 22 artworks that were reviewed, but the former were more frequently reported than the latter. Both types of responses were further categorised into physical, verbal, and cognitive/emotional responses.

The artworks varied from small table-top installations to large, dark open spaces, and had a range of interactive components and features, from a heart rate interface to complete body movements.

Based on the results of this review, there does not seem to be a straightforward relationship between the type of artwork (i.e., its features) and the kind of response (e.g., human-toartwork or human-to-human, or the subtype of response, such as physical response). However, two factors were identified that seemed to influence the participants' responses: the content (real or abstract) of the artwork, and the presence of others. 


\section{Systematic review}

The first thing participants did when they encountered an interactive installation for the first time was to figure out how the interface worked. Participants responded according to the affordance of the real or depicted object, and when they could relate to the things they saw/experienced, they connected more easily with the installation. When abstract content was shown, most participants first tried to figure out how the artwork functioned by trying out different options, alone or together. Thus, when creating an interactive artwork that wants to convey a message or aims to be an immersive experience, it would appear to be important to have an interface with a learning curve that is not too steep. When participants become frustrated figuring out the way the interface works, or when it becomes the most important part of the experience, a deeper level of understanding is never reached.

It should be pointed out that this is a fairly new phenomenon, and many of the participants whose data is presented here did not have prior experience with interactive art. Maybe understanding the interfaces of interactive artworks is an acquired skill? In space of two categories, it seems that being a frequent gallery visitor can also help one to more quickly 'read' the intentions of an artwork and to reflect on its meaning. As no returning visitors were identified in the present data, questions remain regarding how participants react when they encounter the same installation for a second, third, or fiftieth time. Will 'exploring the interface' be skipped in these cases, or is it a vital part of the experience that will persist if allowed, and should the interface evolve to remain interesting?

The effect of the presence of other people while interacting with an artwork is not necessarily clear or consistent, but it does seem that other visitors can influence one's experience. For instance, when people know each other, previously established social ties can be reinforced. Moreover, while the presence of strangers seems to be no problem in play-like environments, in more immersive works others are 'ignored' in a very natural way, but it can also be perceived as "another layer of complexity that distracts attention and prevents immersion into the actual environment" (Hohl, 2009, p.11), or by shifting their own focus from their inner emotions to the other person's actions. The 'social tolerance' of a given work might be proportionally linked to the distribution of focal points in the work. Interacting with an artwork in front of others may create a threshold to participation, leading instead to passive observation.

\section{Methodological considerations}

In order to be included in this review, articles needed to evaluate user responses to a physical, open-ended digital artwork. Because of the small number of articles discussing user responses to these types of artwork, no additional quality criteria were set.

We identified 13 studies that described responses of participants to 22 physical, open-ended interactive digital artworks. This is a very small number compared to the huge number of multimedia festivals, exhibitions, and commercial interactive installations that are built and exhibited every year. 


\section{Chapter 2}

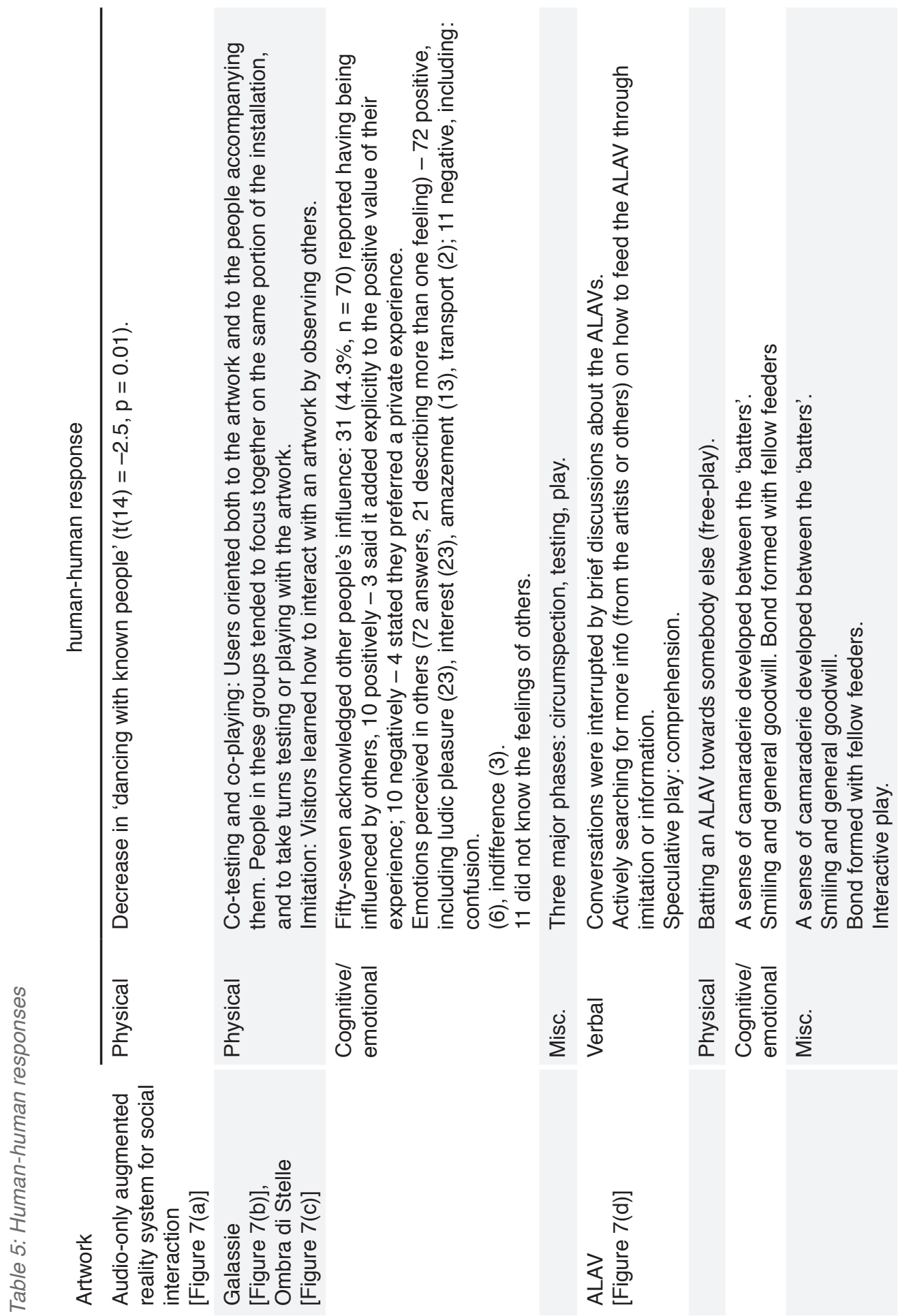


Systematic review

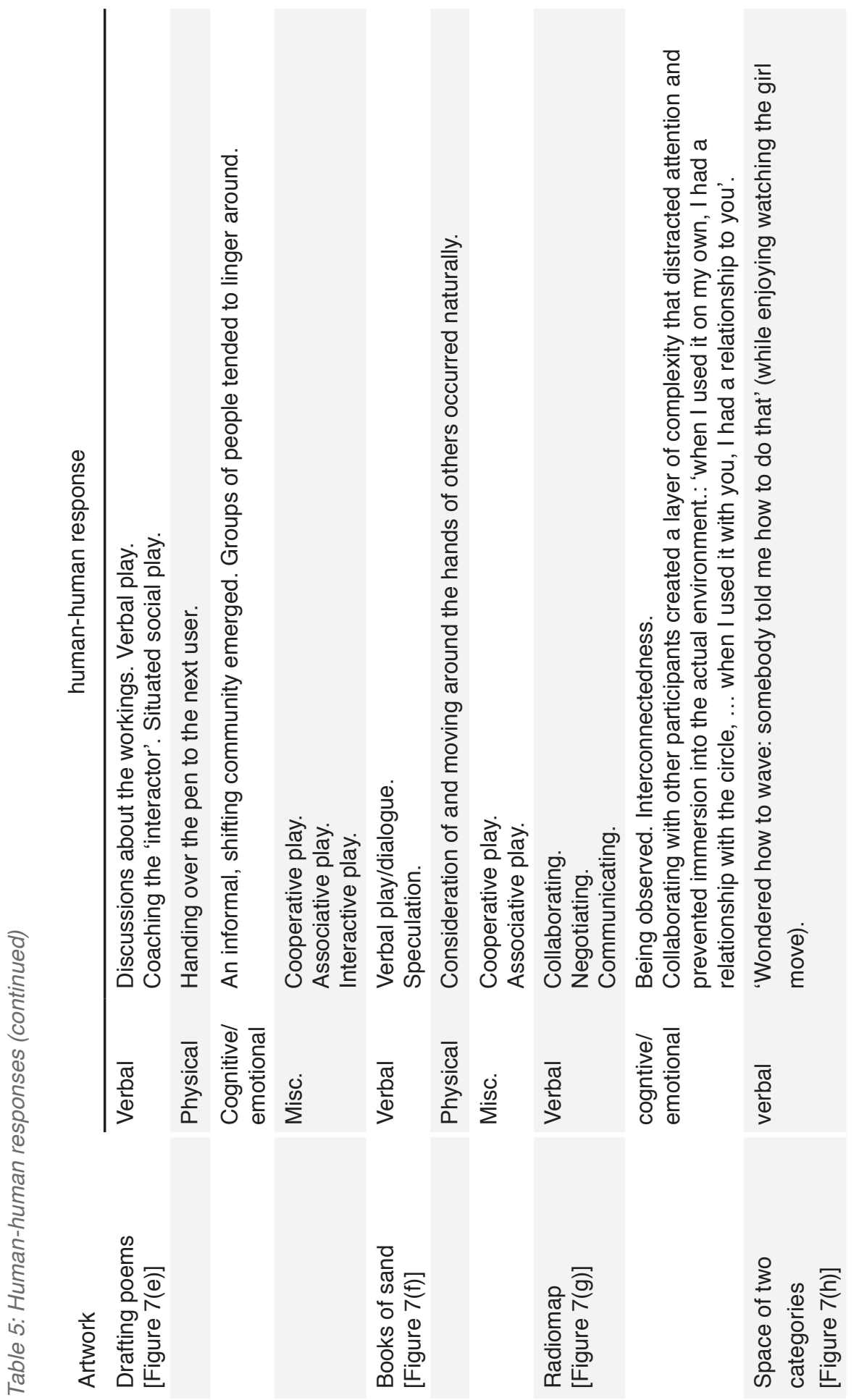




\section{Chapter 2}

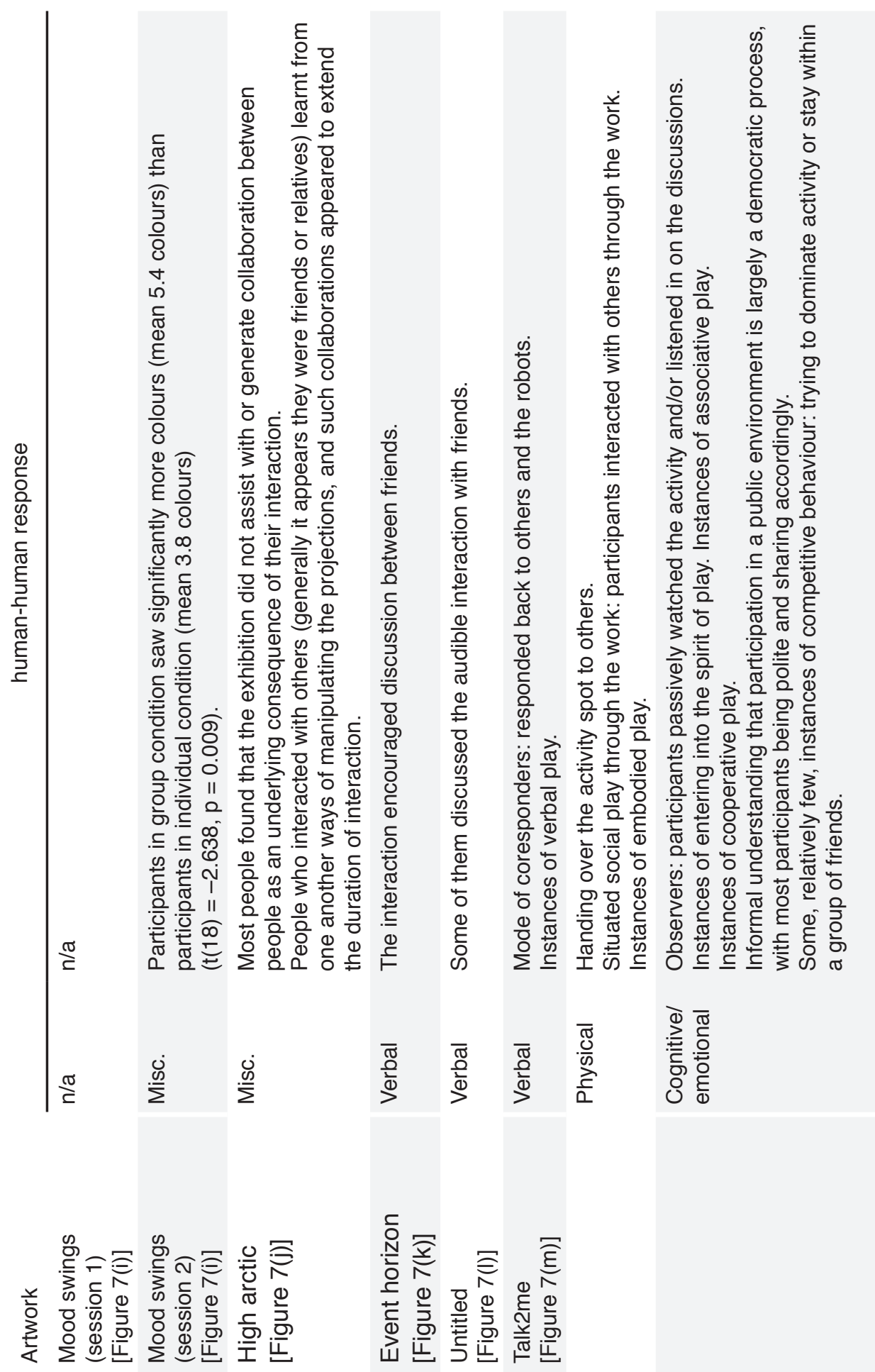

50 The art of feeling connected 
Systematic review

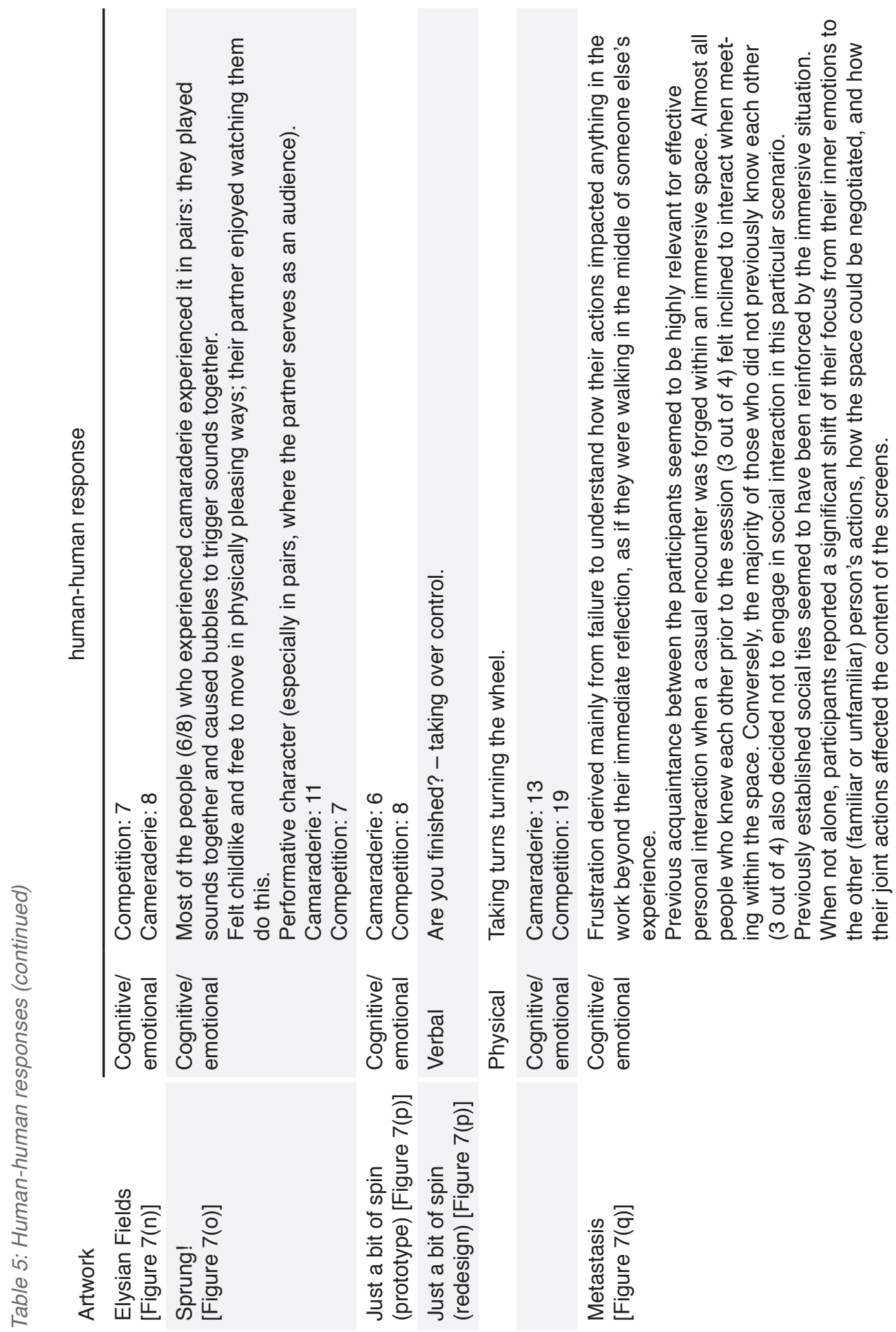




\section{Chapter 2}

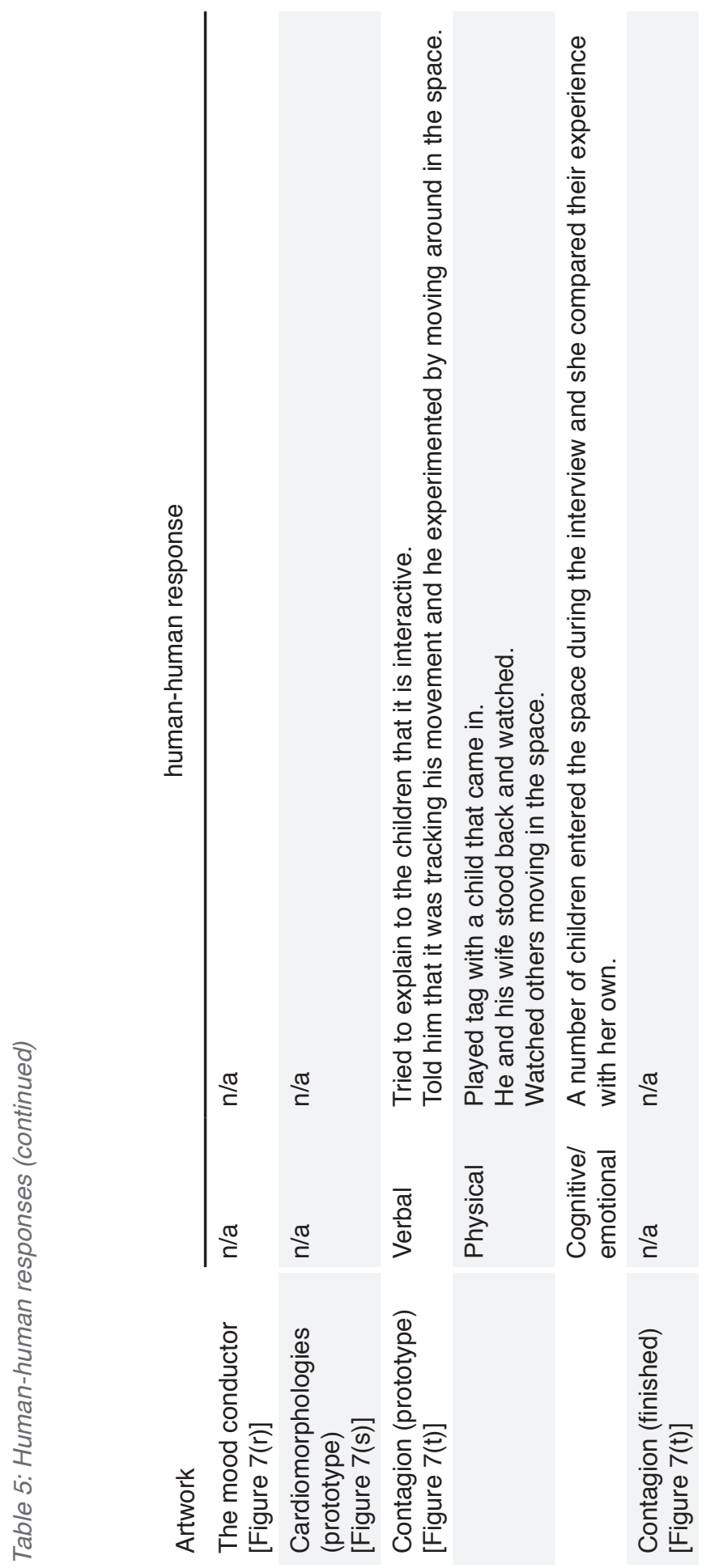




\section{Systematic review}

Because there is no standard database for studies into interactive art (on the model of e.g., PubMed for medical research), we selected five relevant databases based on the number of search results for the term 'interactive art'. A number of terms are in current use in the literature to refer to interactive art installations and user responses (see the introduction). The first author compiled a list of terms (Figure 5(a)) found in the literature of the initial searches, continuing the search until no new terms were found. It is, however, possible that terms or combinations were missed. In combining the terms, an extensive query emerged [Figure 5(b)], which could not be managed by all selected databases. Therefore, a compact query was created and used alongside the full query (Figure 5(c)), which was applied in chunks if necessary. This may have led to results being missed.

\section{Conclusions}

The results indicate that interactive artworks can evoke a variety of verbal, physical, and cognitive/emotional responses within and between visitors, making these artworks powerful instruments. Interactive art has the potential to be used as an intentional immersive technology in domains where people have a hard time understanding, experiencing, and/or communicating with the world and people around them due to a permanent or temporary physical and/or cognitive condition. For example, when an interactive work of art is created that is tailored to residents of nursing homes, such as those diagnosed with Alzheimer's disease, they could experience the benefits of communicating with the people and the world around them through the artwork and/or of enjoying an aesthetic experience.

Most of the interactive art installations created today are not formally studied, because there are more people making interactive art than studying it. Some of these artworks intend to facilitate specific responses. Creating interactive artworks that can challenge new audiences and/or evoke specific responses requires more knowledge about the complex relationships and dynamics of people interacting with an interactive artwork and people interacting with each other through/within such an artwork. At present, studies of interactive artworks use different frameworks to assess the participants' responses. This makes it hard to objectively compare a large number of interactive artworks. Explorative studies should be carried out to assess which domains and target audiences can benefit from the immersive experience and the resulting effects of interactive art. 



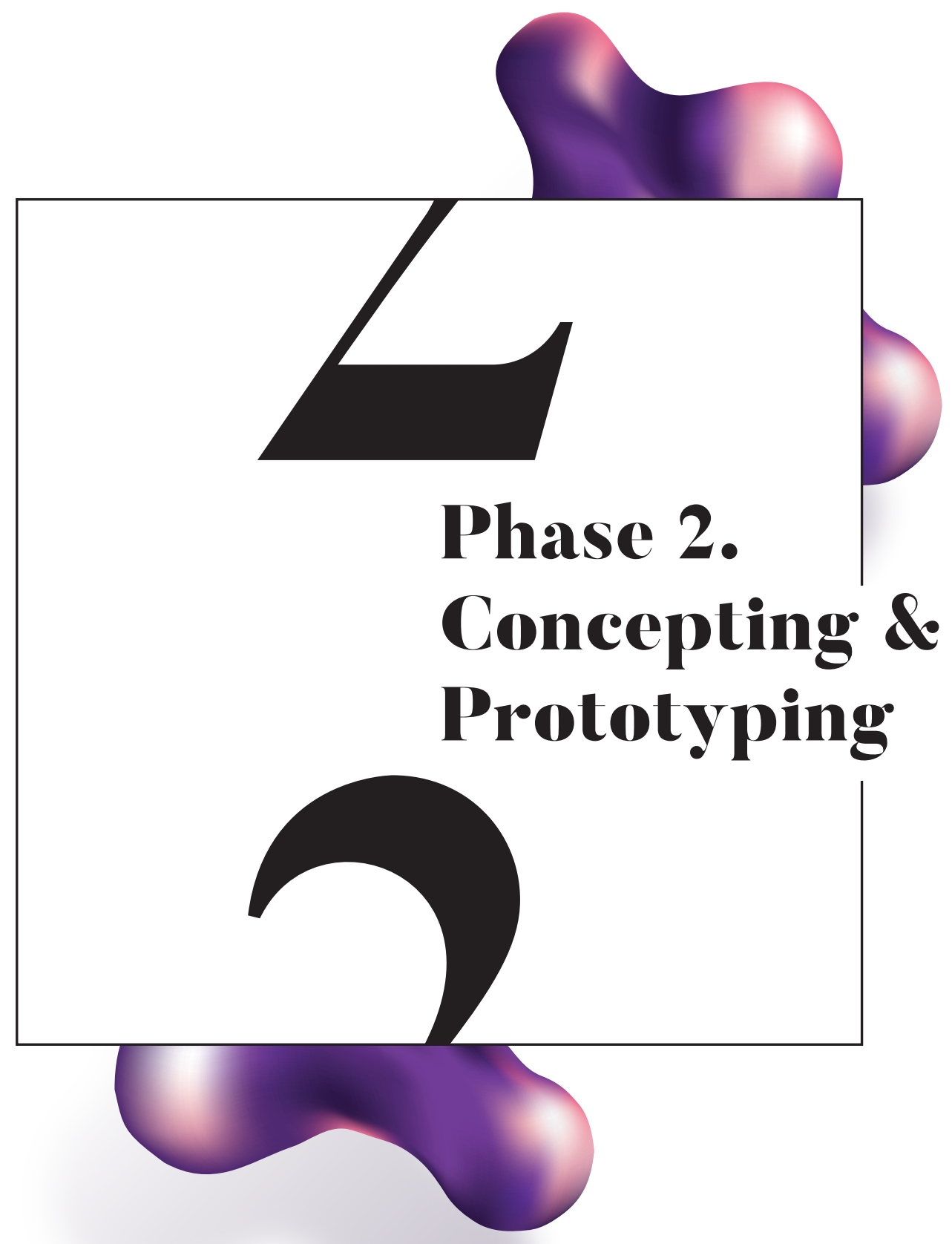




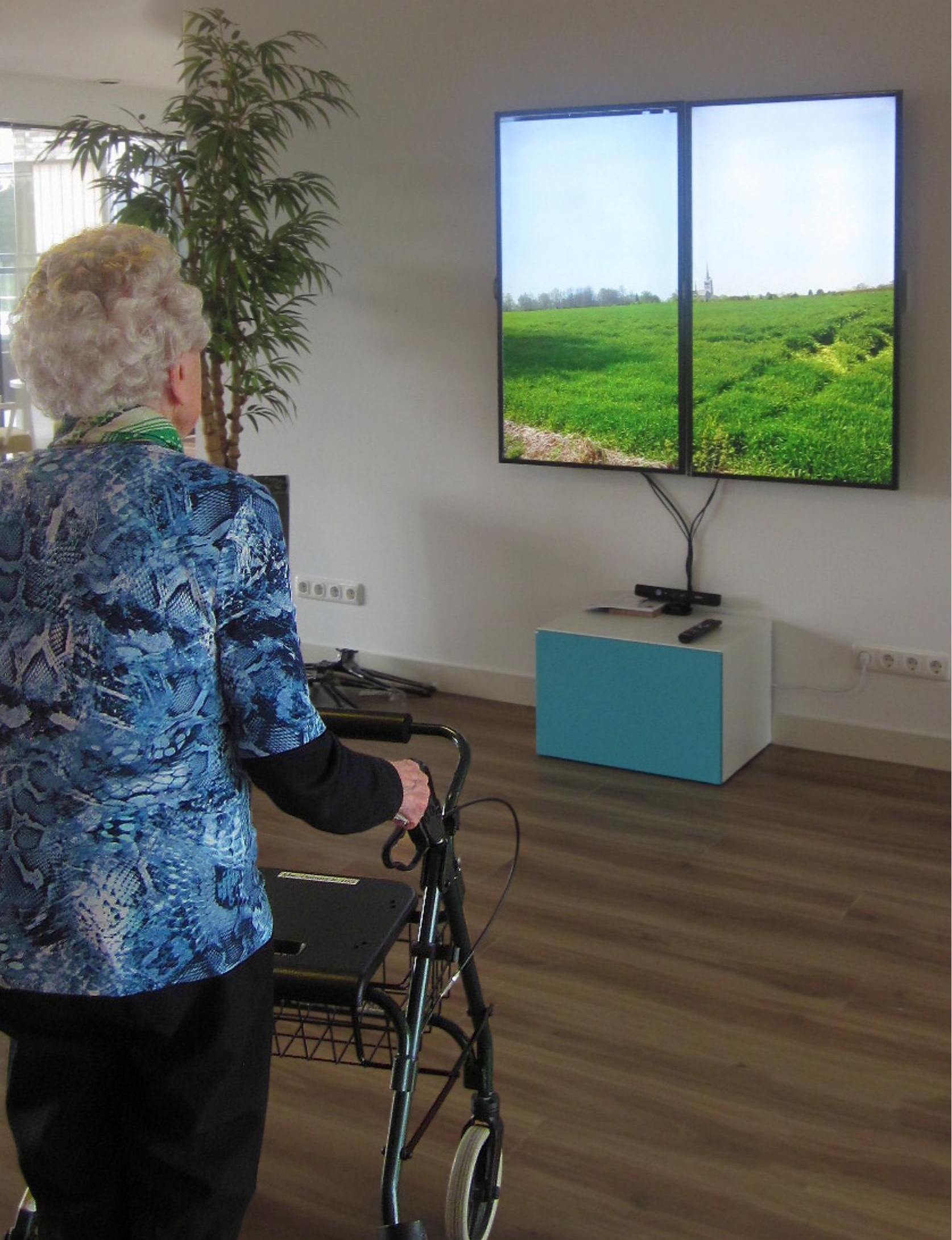


Chapter 3.

The process of

co-creating the interface

for VENSTER, an

interactive artwork for

nursing home residents

with dementia

Gaston Jamin

Tom Luyten

Rob Delsing

Susy Braun

Disability and Rehabilitation: Assistive Technology, 13(8), 809-818 DOI: 10.1080/17483107.2017.1385102 


\title{
Chapter 3
}

\begin{abstract}
Introduction: Interactive art installations might engage nursing home residents with dementia. The main aim of this article was to describe the challenging design process of an interactive artwork for nursing home residents, in co-creation with all stakeholders and to share the used methods and lessons learned.

This process is illustrated by the design of the interface of VENSTER as a case.

Methods: Nursing home residents from the psychogeriatric ward, informal caregivers, client representatives, health care professionals and members of the management team were involved in the design process, which consisted of three phases: (1) identify requirements, (2) develop a prototype and (3) conduct usability tests. Several methods were used (e.g. guided co-creation sessions, "Wizard of Oz"). Each phase generated "lessons learned", which were used as the departure point of the next phase.
\end{abstract}

Results: Participants hardly paid attention to the installation and interface. There, however, seemed to be an untapped potential for creating an immersive experience by focussing more on the content itself as an interface (e.g. creating specific scenes with cues for interaction, scenes based on existing knowledge or prior experiences). "Fifteen lessons learned" which can potentially assist the design of an interactive artwork for nursing home residents suffering from dementia were derived from the design process.

Conclusions: This description provides tools and best practices for stakeholders to make (better) informed choices during the creation of interactive artworks. It also illustrates how co-design can make the difference between designing a pleasurable experience and a meaningful one.

\section{Implications for rehabilitation}

Co-design with all stakeholders can make the difference between designing a pleasurable experience and a meaningful one. There seems to be an untapped potential for creating an immersive experience by focussing more on the content itself as an interface (e.g. creating specific scenes with cues for interaction, scenes based on existing knowledge or prior experiences). Content as an interface proved to be a crucial part of the overall user experience. The case-study provides tools and best practices (15 "lessons learned") for stakeholders to make (better) informed choices during the creation of interactive artworks. 


\section{Development of VENSTER}

\section{Introduction}

People with psychogeriatric complaints, such as dementia, form a large subgroup within the population of nursing home residents. Due to symptoms like apraxia (the inability to perform complex actions) and agnosia (the inability to process sensory information), they often have difficulties in processing and remembering instructions and consequently they represent an especially chal- lenging target population to engage in any activity (Anderiesen, Scherder, Goossens, \& Sonneveld, 2014; Kolanowski, Resnick, Beck, \& Grady, 2013). As the incidence and prevalence of dementia increases, there is a need to evaluate different ways to address or treat this target population (Douglas, James, \& Ballard, 2004; Hulme, Wright, Crocker, Oluboyede, \& House, 2010). It is important to maintain contact with the residents and stimulate social interaction and involvement where possible, especially in closed wards of nursing homes (den Ouden et al., 2015). Art may be a potential source to facilitate this contact, as it has the power to evoke thoughts and emotions (Johnson, 2007). A chairman of an elderly care organization states that "Arts and culture play a large role in people's lives [ ... ] this shouldn't stop when you come to live in a care home" (Steerneman, 2012).

Interactive art, as opposed to non-interactive art, makes the observer part of the artwork, thereby transforming him/her into an active participant. A recent systematic review indicates that interactive artworks can evoke a variety of verbal, physical and cognitive/emotional responses within and between visitors (Luyten, Braun, Jamin, van Hooren, \& de Witte, 2018). The meaning is formed during and through the interaction with the artwork, which has been described as "embodied interaction" (Dourish, 2004). This implies that there are several levels of understanding an interactive artwork and that a participant is able to form his/her own meaning during and through the interaction with the artwork. Although people who suffer from dementia generally lack initiative, they can explore and enjoy these types of artworks in their own way and on their own, individual cognitive level, given that the initial threshold to engage is overcome and kept to a minimum through informed design (Luyten, Braun, Jamin, van Hooren, \& de Witte, 2018).

Recognizing the potential of interactive art in relation to care is not novel. David Rokeby's Very Nervous System has been used as a therapy for as early as 1998 (Rokeby, 1998). Other examples include Andreas Refsgaard's Eye Conductor (Refsgaard, 2015), Daan Roosegaarde's Lunar (Roosegaarde, 2011) and the interactive instrument CRDL (Schuivens \& Chen, 2014). Positive effects of interactive installations on the behaviour of nursing home residents have been observed (Braun et al., 2015) and they seem able to provide a rich experience in which play, exploration, cooperation and social interaction are encouraged (Charitos, Bourdakis, \& Gavrilou, 2006; A. Morrison, Viller, \& Mitchell, 2011; A. J. Morrison, Mitchell, \& Brereton, 2007). Placing an existing interactive artwork in an elderly care home without taking into account the specific abilities and disabilities 


\section{Chapter 3}

of nursing home residents to operate such a work of art, would be ill-considered. In order to understand what a rich, meaningful experience is for people with dementia and to be able to build an interface that is comprehensible for and usable by them, they should be included in the design process (Sanders \& Stappers, 2008). Prior research shows that client participation has a positive influence on usability and usage when developing innovations in care (Boulos, Wheeler, Tavares, \& Jones, 2011; Patrick, Griswold, Raab, \& Intille, 2008). Tools and methods have been developed to involve patients, such as the EBCD toolkit (Donetto et al., 2014), the "participatiekompas" (Participatiekompas, 2014) and the Ambient Assisted Living Toolbox (AAL, 2015). In order to advance knowledge about co-creation in elderly care, the main aim of this article is:

1. to describe the challenging design process, in co-creation with the artist and all stakeholders, of the interface of VENSTER, an interactive artwork for nursing home residents, and

2. share the used methods during and lessons learned from this design process.

This description prevents reinventing the same methods, repeating past mistakes and will hopefully provide artists, designers as well as formal and informal caregivers tools and best practices to make (better) informed choices during the creation of interactive artworks for this specific target population.

\section{About VENSTER}

VENSTER is a concept for an intentional interactive artwork by Tom Luyten. It brings the outside world into the nursing home and the nursing home into the world through an interactive physical window. It is inspired by conversations held by the artist with health care professionals, management and people suffering from dementia. The general theme is (re)connecting with the outside world, thereby providing a counter action to the feeling of isolation that can occur when living in an elderly care facility. Isolation from one's self, his/her surroundings, family and friends, past or community. Its intention is to provide the opportunity for (a) meaningful experience(s) (Dewey, 2005) to the residents of a nursing home ward (see Figure 1).

Physically, VENSTER consists of two large (touch) screens, vertically mounted in a fake wall, plus a computer, a Kinect ${ }^{\mathrm{TM}}$ sensor and a roller blind with a string. The Kinect ${ }^{\mathrm{TM}}$ sensor tracks the user's position, and the computer adapts the perspective of the screens accordingly. The string attached to the roller blind serves as a switch to change the scene. When the installation detects the presence of a person, music starts playing. The installation can show pre-recorded "calming" or "activating content", and is also able to present "interactive content" which can be manipulated in real time. Each of the three content types comprises several different scenes. 


\section{Development of VENSTER}
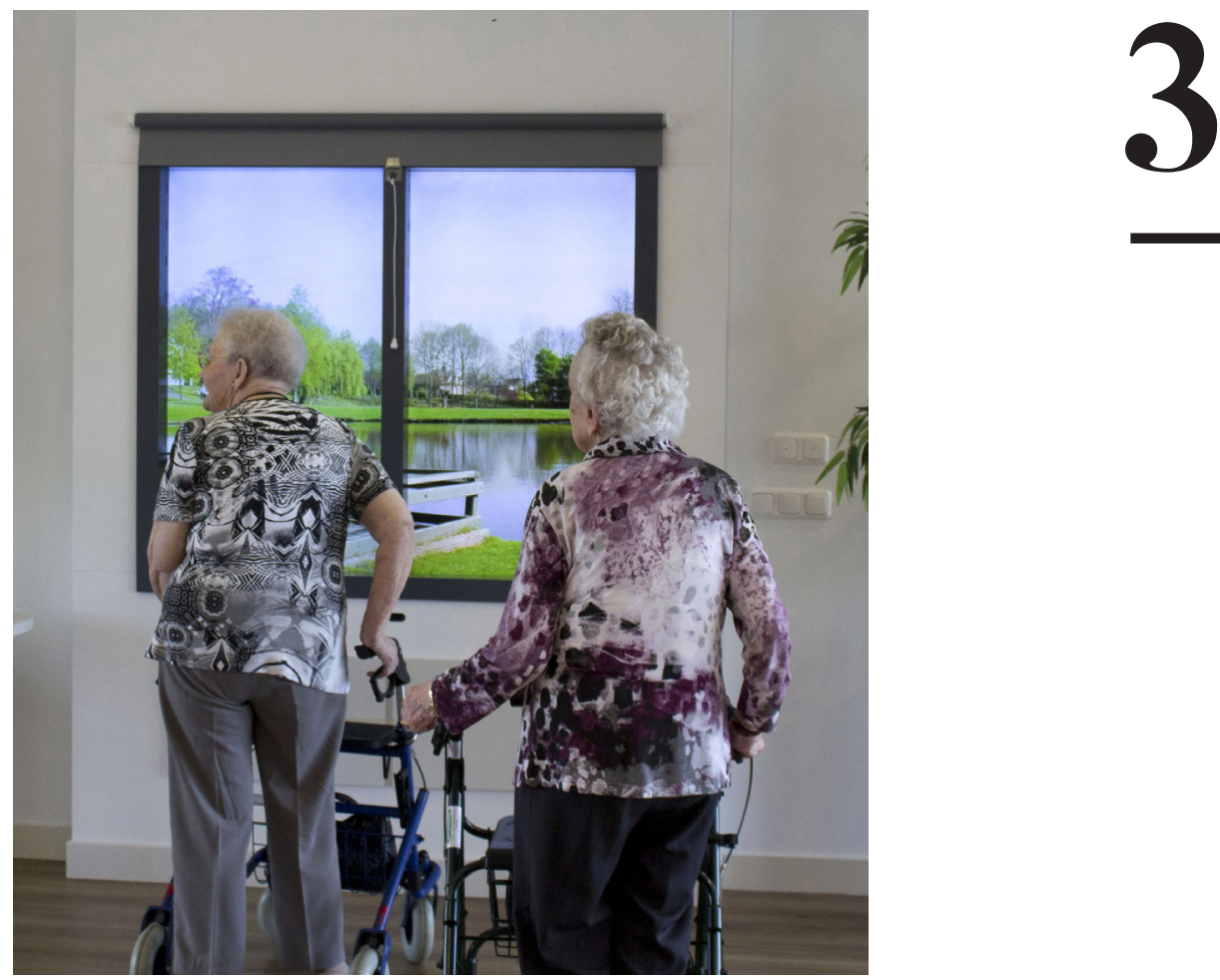

Figure 1: VENSTER during usability testing

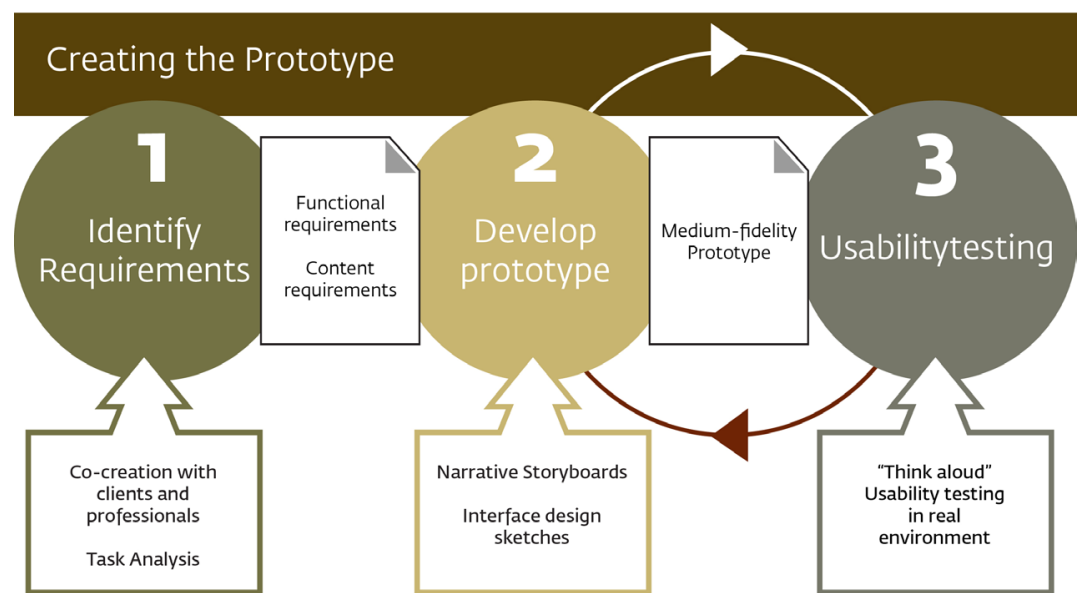

Figure 2: Design process showing three phases during which user requirements were identified and a working prototype was developed with the help of multiple iterations. 


\section{Chapter 3}

A study on the responses of nursing home residents with dementia to VENSTER [8] shows that VENSTER is able to evoke several different responses. Overall, frequently noted responses include naming or recognizing the depicted content, asking questions about the content and the functioning of the installation, physically gesturing or tapping on the screen and singing and tapping along to the music. Sessions with calming content seem suitable when the installation is not being used actively. It keeps the illusion of a real window alive and can draw attention because the scenery that is shown is different and enticing. Activating content can provide a meaningful experience during spare time in which nursing home residents were generally calm and focussed up to $1 \mathrm{~h}$ (in groups of around six people). This creates extra time for a care giver to initiate one-on-one conversations and provide some quality time. Interactive content can be used as an activating therapy, exercise or activity. The interactions are short and intense, and require the assistance of a trained professional. Results indicate that the type of content can influence the kind of responses.

\section{Methods}

An iterative design process (Figure 2) was used to ensure that the final prototype of VENSTER would meet the needs and preferences of the target audience. This process took place over a period of three to four months and consisted of three phases. Each phase generated "lessons learned" which were used as the departure point of the next phase.

\section{Identifying user requirements (Phase 1)}

The goal of this first phase was to gain a better understanding ofthe world of the nursing home residents from the psychogeriatric ward, and get a sense of what might work and what would not. A set of basic functionalities for the installation in this first phase was based on a systematic review, two guided co-creation sessions and "Activity Card Sort". Informed by a systematic review on Physical, Open-ended Interactive Digital Artworks (Sanders \& Stappers, 2008), some general requirements for the design of the interface could be derived: (1) users respond according to the affordance of real or virtual depicted objects, (2) Exploring the interface is primary. If the threshold is too high, immersion is not possible. Engagement starts at the moment of understanding, (3) personal connection and recognition can result in more enthusiastic/immersive experience.

Specific user requirements were gathered by means of two guided co-creation sessions, during which participants were asked to come up with as many ideas as possible regarding the content and functionalities of VENSTER. Ideas were not limited by technical feasibility. Notes were taken by the participants and an appointed note-taker.

Participants consisted of members of the management team of a nursing home, informal caregivers, client representatives (client board) and health care professionals (Table 1). Inclusion criteria for participation were that participants should be working with the target 


\section{Development of VENSTER}

Table 1: Number and function of participants involved in the two co-creation sessions

$\begin{array}{lllll} & \begin{array}{l}\text { activity } \\ \text { supervisor }\end{array} & \begin{array}{l}\text { Informal } \\ \text { caregivers }\end{array} & \begin{array}{l}\text { client } \\ \text { board }\end{array} & \text { Management } \\ \text { seam } \\ \text { session } 1 & 2 & 2 & 2 & 1 \\ \text { session } 2 & & & 3 & \end{array}$

Table 2: Number and gender of participants of usability tests 1 and 2

First session Second session Third session

$\begin{array}{ccccccc} & \text { Men } & \text { Women } & \text { Men } & \text { Women } & \text { Men } & \text { Women } \\ \text { usability test 1 } & 0 & 2 & 0 & 3 & 2 & 1 \\ \text { usability test 2 } & 0 & 2 & 1 & 1 & 0 & 2\end{array}$

Table 3: Identification of basic tasks and information needs, clustered and prioritized (11/4high, 51/4low) for potential users (clients and supervisors)

\begin{tabular}{lccc} 
Task & $\begin{array}{c}\text { Client with } \\
\text { disability }\end{array}$ & $\begin{array}{c}\text { Client with } \\
\text { minor disability }\end{array}$ & $\begin{array}{c}\text { Activity supervisor } \\
\text { (caregiver) }\end{array}$ \\
\hline $\begin{array}{l}\text { Looking at a scene } \\
\text { Interacting with a scene }\end{array}$ & 3 & 1 & 2 \\
\hline $\begin{array}{l}\text { Zooming in on/looking at } \\
\text { the details of a scene }\end{array}$ & 5 & 2 & 2 \\
\hline $\begin{array}{l}\text { Choosing a scene } \\
\text { Changing a scene }\end{array}$ & 4 & 2 & 3 \\
\hline $\begin{array}{l}\text { Controlling the sound } \\
\text { volume of a scene }\end{array}$ & 2 & 2 & 1 \\
What am I looking at? & 1 & 3 & 2 \\
Is there more to see of this & 3 & 1 & 2 \\
particular scene? & & 2 & 3
\end{tabular}




\section{Chapter 3}

population and at least half of them should be employed at the nursing home where the installation was to be placed.

Additional requirements, focusing on content for VENSTER, were collected by means of an activity card sort (Soranzo \& Cooksey, 2015). Three nursing home residents from a psychogeriatric ward were randomly selected and asked to participate in individual sessions. The goal of this method was to identify the types of content which would most likely evoke a response. Based on the input of the first cocreation session, images on the cards were chosen in several predetermined categories (religion, landscapes, local history, fruit harvest, crafts and music). The cards were shown in pairs to the participants, and they chose which image they preferred. The facilitator of the session engaged in casual conversation with the participants about their choices, and took notes.

\section{The prototyping process (Phase 2)}

Based on the insights collected in phase 1, the design of the interface started by sketching narrative storyboards. A storyboard puts each interaction in a specific context, and thereby tells an ever more complete story as interactions with the installation take place over time. It helps to determine possible weaknesses or critical issues that might have been missed (Greenberg, Carpendale, Marquardt, \& Buxton, 2011). A total of six storyboards were developed and discussed within the design team. Flaws in the design of the interface were modified and an actual physical prototype of VENSTER was constructed in order to test the interface and the content in the next phase.

\section{Usability testing (Phase 3)}

An important part of the iterative co-design process is to test ideas and functionalities as soon as possible with the actual users of the installation. Two rounds of usability testing were conducted within a period of five weeks, during which the prototype was further optimized. The methods used for these usability tests were "Think-Aloud" and "Wizard of Oz". The Think-Aloud method requires users to verbalize their actions and thoughts as they navigate an application (Krug, 2009), or in this case an installation. The Wizard of Oz technique has been described as follows: "In the field of humancomputer interaction, a Wizard of $\mathrm{Oz}$ experiment is a research experiment in which subjects interact with a computer system that subjects believe to be autonomous, but which is actually being operated or partially operated by an unseen human" (Hanington \& Martin, 2012). Using this latter method enabled us to test the prototype early on in the design process, without having to spend a great deal of time and resources programming each interaction. Ten nursing home residents from the psychogeriatric ward were invited to participate, always under the supervision of a health care professional and the researcher who facilitated the test (Table 2). The size and composition of each test group depended on the availability of residents at that particular moment. Four residents participated twice. Most of these residents suffered from a mild form of dementia, and as such were still capable (to a certain degree) of verbalizing their experience with the interactive installation. 


\section{Development of VENSTER}

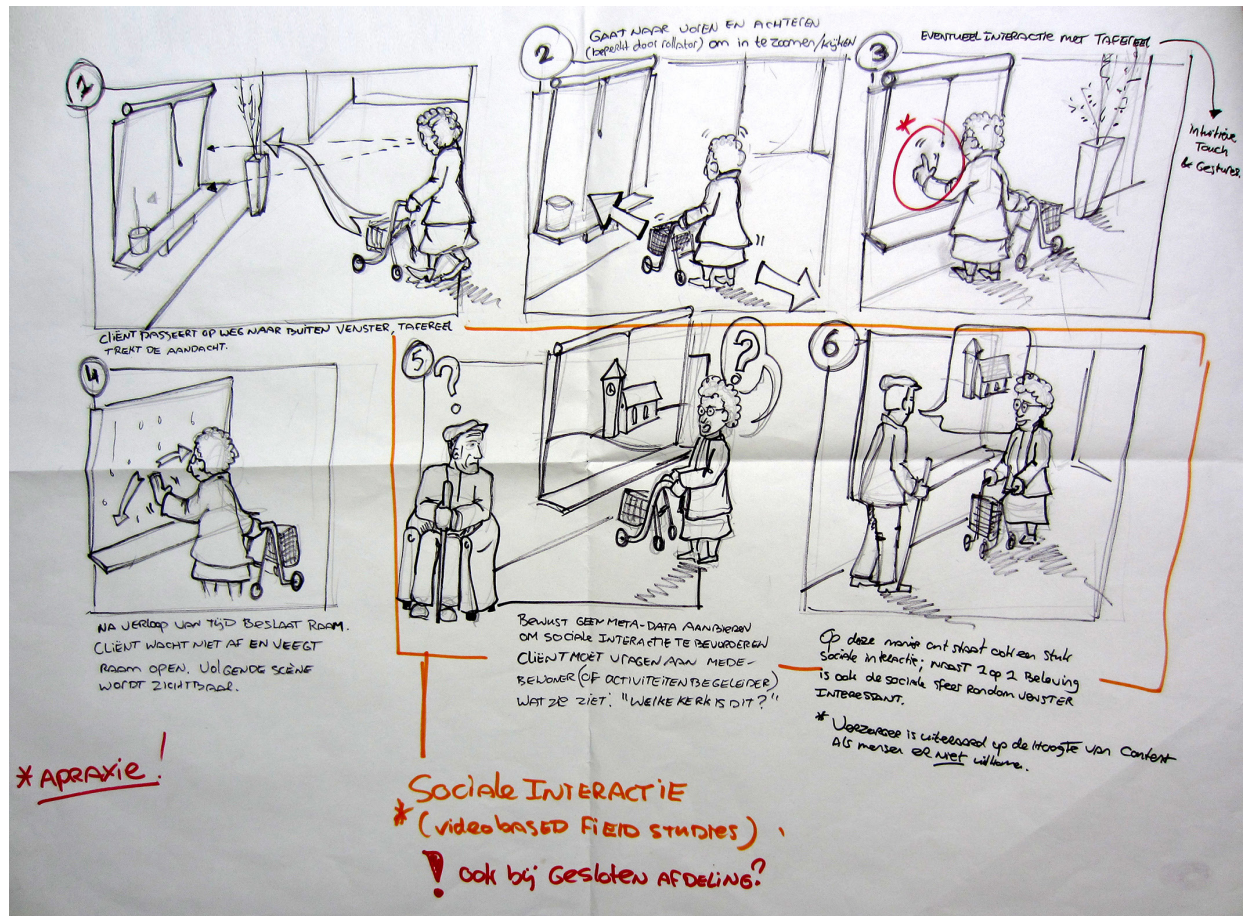

Figure 3: Example of a storyboard, depicting how a user might interact with the installation, and other residents.

Table 4: Potential topics for VENSTER, including some examples

Familiar places and spaces trigger the memory and provide something to talk about Children or grandchildren and animals in particular evoke strong responses

Show daily activities and occupations from the past and present

Add physical objects to augment the experience
A nearby village and church, a wide shot of a fishing pond

Children playing in a schoolyard, cows grazing in a field

Going to the market, driving a car, visiting a fair

A radio that plays music, a rag to "clean" the window 


\section{Chapter 3}

Guided by one of the researchers (GJ), the participants were led through a number of test scenarios that had been formulated beforehand. Data were collected by an observer and a note-taker by filming and taking notes and photographs. Each scenario presented a situation which prompted the participant to interact with VENSTER. An example: "You are trying to talk to someone next to you and the noise that is coming from VENSTER is bothering you. See if you can turn it down".

Normally a test like this would be conducted with one user at a time. But due to the nature of the installation, which was to be placed in an open, public space, multiple users could in fact simultaneously interact with VENSTER and each other. Each usability test therefore consisted of three rounds, and for each round 2-3 participants were invited to contribute. Each round lasted about 20-25 min.

To enable prototype testing, content needed to be developed. For the first usability test, it was decided to produce a number of passive scenes, of places within the vicinity of the care home. Examples are: wide shots of the surrounding countryside or shots from the edge of a nearby fishing pond. For the second usability test, activating and interactive scenes were added. These scenes contained content that was expected to invite verbal and/or physical action from the participants. After the first and second usability tests, the results were discussed within the design team. Based on shared observations, the usability and overall experience of the installation were evaluated and this led to adjustments in the design and the prototype.

\section{Results}

The results of the user-centred, iterative design process are described below for each phase. At the end of each phase description, the most important "lessons learned" that influenced the next phase are highlighted.

\section{Identifying user requirements (Phase 1)}

During co-creation sessions and the Activity Card Sort, the participants came up with numerous ideas for content on the screen, but also with ideas about physical objects on or around the VENSTER installation to augment the experience. They also confirmed that building upon existing knowledge and prior experiences might prove to be the most effective way for clients suffering from dementia to learn how to interact with VENSTER (Malcolm, Hodkinson, \& Colley, 2003).

All these findings led to the identification of a set of basic functionalities for the interface (Table 3). These functionalities consisted of eight basic tasks and information needs such as turning on the installation, choosing a scene or simply wanting to know what they were looking at.

Secondly, ideas emerged about utilizing the content itself as an interface by defining 


\section{Development of VENSTER}
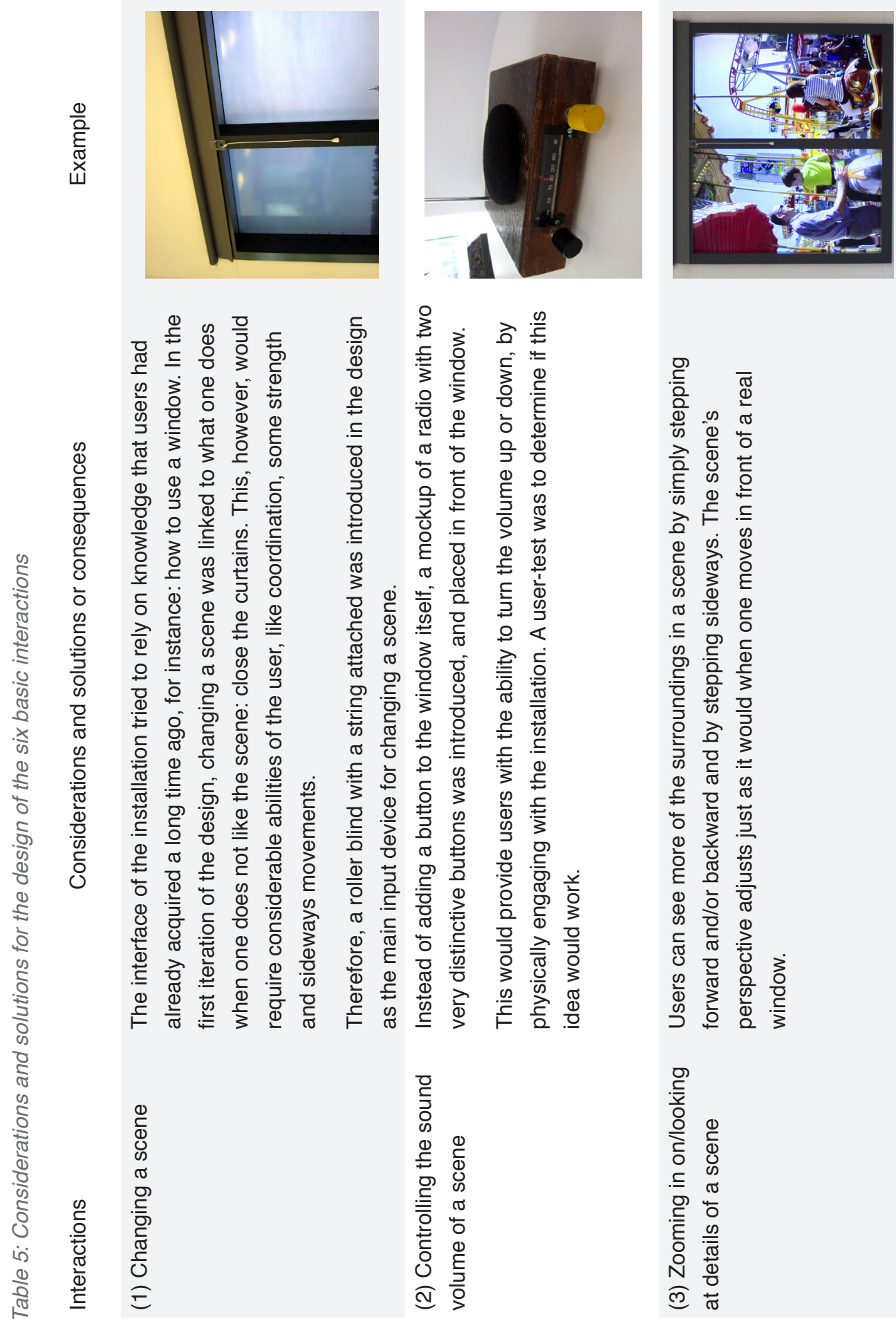


\section{Chapter 3}

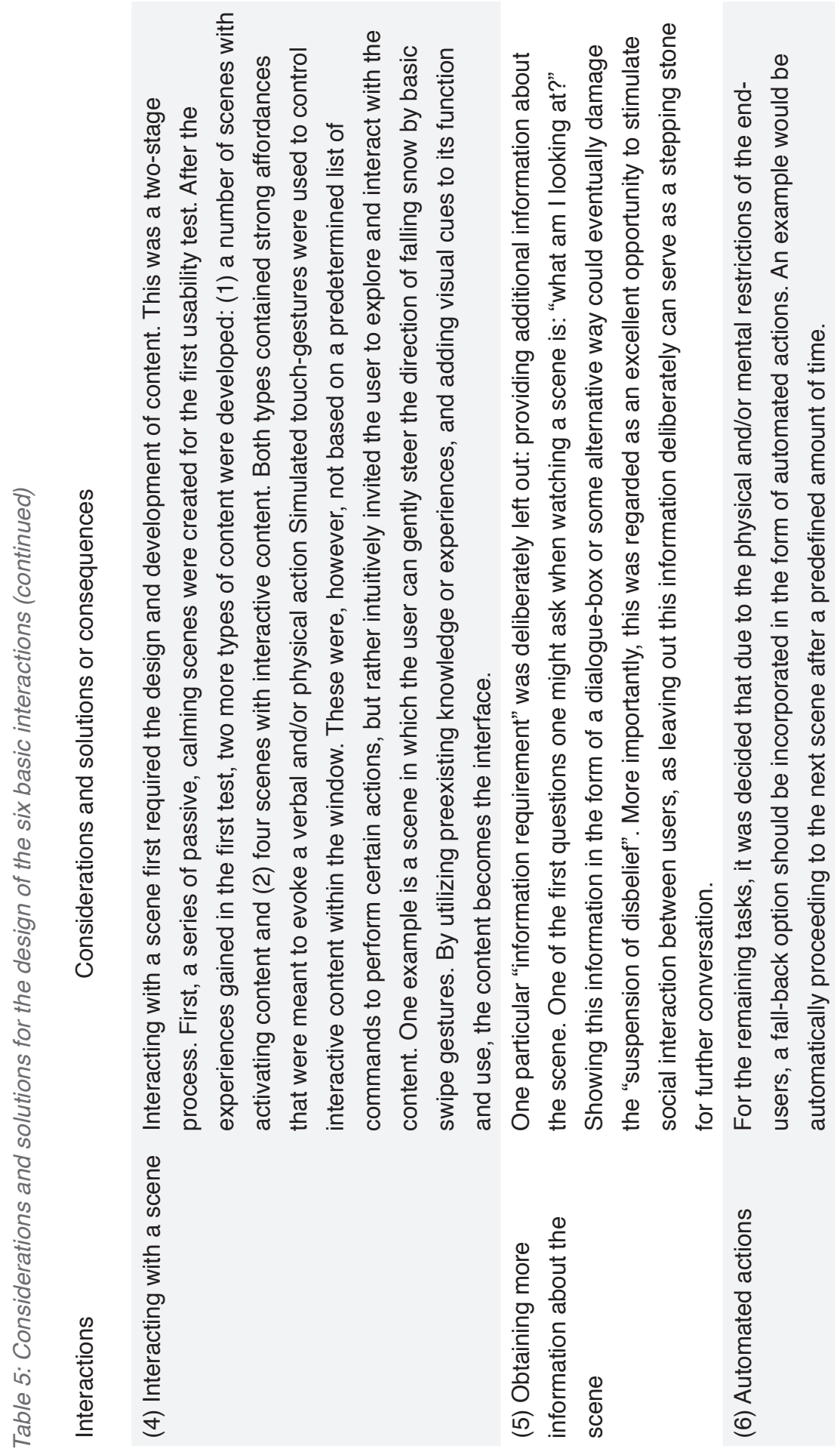

68 The art of feeling connected 


\section{Development of VENSTER}

potential topics for this specific target population the design of said content (Table 4). This first phase generated three "lessons learned":

\section{Lessons learned}

1. It is hard/impossible for the target group to store new information in memory, so building upon existing knowledge and prior experiences might prove to be the most effective way for nursing home residents suffering from dementia to learn how to interact with VENSTER.

2. VENSTER could create a more meaningful experience through engaged interaction with artefacts.

3. There were indications that the content itself could serve as an interface, by creating specific scenes and objects that invite users to engage and implicitly explain how the installation can be interacted with.

\section{The prototyping process (Phase 2)}

The different tasks and information requirements (Table 3) were translated into six basic interactions: (1) changing a scene, (2) controlling the sound volume of a scene, (3) zooming in on/looking at the details of a scene, (4) interacting with a scene, (5) obtaining more information about the scene and (6) automated actions. The next step was to explore how these basic tasks could be performed by the target audience, using narrative storyboards (Figure 3). Each of the six storyboards illustrates how interactions between the user and the installation might occur.

After the storyboards were completed, work on the actual physical prototype started. Table 5 describes and illustrates the considerations and solutions or consequences for the design of the six basic interactions. The prototype looks like a real window and is made up of three main technical components that work together. The window consists of two wide-screen LCD televisions placed vertically side by side, which are connected to a computer and work together as a single large screen that can show different videos and interactive content. The second component is a KinectTM sensor, which detects the movements of the users in front of the screen. When users step sideways or move forward or backward, the image in the window is adjusted according to their movements and perspective angle. The third component is a roller blind that functions as the main input-device for changing scenes. Based on the guidelines (Table 4), content for the prototype was developed to enable user testing. From the second phase five main "lessons learned" were derived, which were used as a departure point for the third phase of the design process: 


\section{Chapter 3}

\section{Lessons learned}

4. The interface should not require difficult physical actions, for which the residents lack the strength and/or motor skills, as these can become obstacles for users.

This also means that the use of gesture-based controls is limited and should be used cautiously.

5. Due to the cognitive impairments of the users on the one hand, and the "suspension of disbelief" on the other, some of the more complex tasks should be automated.

6. A walker or wheelchair can get in the way of approaching the installation, possibly hindering the controls. Input controls have to be placed low enough to be operated from a sitting position.

7. A walker or wheelchair makes moving sideways hard, so the change in perspective might go unnoticed. This means that understanding or simply viewing the content should not depend on using this feature.

8. Some of the design decisions have to take social interaction into account.

For instance: deliberately leaving out background information about the content might stimulate users to interact with each other, for example by asking where a particular scene is taking place.

\section{Usability testing (Phase 3)}

Five important observations were made during the first usability test. The first two observations seemed to be related to the installation, the remaining three to the target population's characteristics:

Content is King: during the design process a lot of effort went into making the interface as intuitive as possible. During testing, however, none of the participants showed any real interest in the installation itself. They were mostly engaged with the content and the music in the background, which seemed to suggest the interface was indeed "transparent". Participants were triggered by the content, not the interface or the installation in general.

The value of the element of perspective seems to be marginal: the element of perspective, one of the key features of VENSTER, was rarely noticed. It did not evoke a verbal or physical response from the participants, not even when a malfunction or glitches occurred. Participants simply seemed to disregard this feature as part of the narrative that was unfolding in front of them. Clients do not move in front of the screen: due to the participants' lack of mobility, there was hardly any movement in front of the screen. However, their physical impairments did not explain all the observations. Even participants who were physically able to become involved with the installation showed almost no inclination to play with or explore it. In most cases, they only interacted when prompted by a facilitator or care provider, and only after a while would they take the initiative to interact with the installation on their own. 


\section{Development of VENSTER}

Low learning curve for changing a scene: the learning curve for changing a scene proved to be low. Some explanation by a care provider was needed, but after seeing it a couple of times participants were confident enough to try it for themselves, without a nudge from a care provider. One instance was observed of participants explaining it to each other.

Social interaction is limited: although our participants were placed in front of VENSTER in groups of two or three, not a lot of interaction was observed among the participants. There were moments of interaction, but most of the time they took turns in interacting with VENSTER on their own, prompted by a care provider.

Based on the findings of the first usability test, a number of alterations were made to the design. More emphasis was put on content as an interface and a catalyst for interaction. To this end, a number of new test scenes were introduced: "activating scenes" and "interactive scenes". These were subsequently tested during a second usability test.

\section{Activating scenes}

These consisted of pre-recorded video that invited the participant to interact with VENSTER. One example is a scene in which a girl is first jumping rope and waving at the camera, and then walks up to it and places a hand on the window. The scene was explicitly designed to evoke verbal and/or physical interactions. Waving back at the girl was one goal, but the secondary goal was for the participant to respond to the girl by putting their own hand on the window.

\section{Interactive scenes}

These scenes consisted of small software programs that utilized the touch-screen functionalities of VENSTER. The participant was able to control basic elements in a scene by swiping or tapping with their hand. An example is a scene in which the participant controlled the speed and direction of falling white dots on a black background (often interpreted as snow).

The following lessons were learned from the two usability tests: 


\section{Chapter 3}

\section{Lessons learned}

9. Participants are more engaged with the content than with the installation as a whole. This would suggest that there is a potential to use this content as an interface by implementing strong affordances.

10. Abstract scenes are interesting to a certain degree. Although they did trigger curiosity, the participants were not always sure what they were looking at, and this made them uncertain about what they were expected to do. Besides strong cues for interaction, the content needs to provide enough context and should build upon existing knowledge and/or prior experiences in order to provide a meaningful and immersive experience.

11. The interface for changing a scene worked well. Although the participants needed guidance at first, once they knew how to operate the roller blind, they used it on their own throughout the rest of the test.

12. There needs to be a connection between the installation and any physical objects adjacent to it. In this case, the radio as a physical interface element for controlling the sound volume of the installation did not work well. Only once did a participant show any interest in the prototype. This suggests that cues and feedback need to be clearly discernible and integrated into the larger context of the experience in order to be a part of that experience.

13. The activating scenes proved to be very successful, and the responses at least suggested they provided a meaningful, pleasurable experience that appealed to the imagination. People, especially children, and animals worked exceptionally well as content for this target audience. In most cases, they even responded physically (i.e. waving) to people in a scene.

14. Social interaction between residents is limited. Most interactions occurred between the facilitator of the test and a single participant.

15. This specific target group seems reluctant to explore and play and/or interact with the installation. Some participants would only watch other participants interact, and were not persuaded to give it a try for themselves. In most cases a little nudge from a care provider was needed before they physically interacted with VENSTER directly. 


\section{Development of VENSTER}

\section{Discussion}

The main aim of this article was to (1) describe the challenging design process of the interface of VENSTER, an interactive artwork for nursing home residents, and (2) to share the used methods during and lessons learned from this design process.

The design process consisted of three phases (identifying user requirements, the prototyping process and usability testing), executed in co-creation with the artist, an interaction designer and adiverse group of 23 stakeholders at the nursing home (clients, informal caregivers, client representatives, health care professionals and members of the management team). Six different methods were used (Brainwriting, Activity Card Sort, storyboards, prototyping, Think Aloud and Wizard of $\mathrm{Oz}$ ) which generated 15 lessons learned.

Although co-creation adds complexity to the design process, involving stakeholders seemed to be a crucial element in the success of the creation of the interface for VENSTER. It helped us to keep the user at the centre of the decision-making process, while adapting to new insights as they emerged. The iterative nature also enabled us to identify flaws in the design early on, and even led to a change of perspective for the design team. It showed the importance of keeping an open mind during each phase, resulting in not only meeting the users' requirements but more importantly provide an understandable interface that significantly lowers the threshold to have a meaningful experience.

Although the goal of designing an interface of an interactive art installation that is to be learned and used by nursing home residents is relatively novel, some of the results confirm that general knowledge about nursing home residents is also relevant in this context: the challenge of storing and retrieving new information for people with dementia (LoGiudice, 2002) also limits their ability to learn a new interface (lesson 1). Positive reactions of the nursing home residents to people, especially children, and animals in the content shown (lesson 13) correlates with the effects of group and animal assisted therapy (Arean et al., 1993; Banks \& Banks, 2002). People with dementia seem to share the tendency to not engage in social interaction or explore new things (Camic, Tischler, \& Pearman, 2014), and this is also observed when interacting with (the interface of) VENSTER (lessons 14 and 15). Finally, physical limitations and/or the use of a stroller or wheelchair can have an effect on the usage of an interface (lessons 3 and 7 ).

The results also present some new challenges for interaction designers in elderly care: the installation or its interface were not interesting to the nursing home residents in this study (lesson 9). Instead, they were more engaged with the content. Therefore, focussing more on the content, and using it as an interface seems to be untapped potential for creating an immersive experience (lesson 3). Design exploration and research is needed to identify new possibilities for content to act as an interface in this context and to validate if and how external physical artefacts can be included in the experience. When physical 


\section{Chapter 3}

objects would be introduced as additional input, we suggest a connection between them and the installation should be established (lesson 12). This enables the interface elements to become an integral part of the story and the overall user experience, and hence are more likely to become discernible and meaningful parts of the experience.

Lack of curiosity accompanied with uncertainty presents a problem, especially when nursing home residents in this study interacted with abstract content (lesson 10). This presents a challenge for designing abstract installations or experiences. A little nudge from a caregiver (lesson 15) and an interface that is comprehensible (lesson 4) lowers this threshold, but the challenge remains and needs to be explored.

\section{Methodological quality}

When examining the process of co-creating the interface for VENSTER as a whole, it shows that true co-creation in practice differs from theory. Users can be unable to transcend their view of the world, or be so closely involved that it's impossible to have an overview. The designers or artists on the other hand can be too concerned with concept, aesthetics or technology. Additionally, each of the stakeholders use their own language and theories, resulting in the need to balance, bridge and harmonize and therefore compromise. Thus, the used methods and theories where not always applied in their purest form.

Another important limitation of the study was that VENSTER was evaluated in a closed ward, with residents who suffer from advanced to severe forms of dementia. During the development of VENSTER, however, residents from an open ward, suffering from mild to advanced forms of dementia, were asked to participate, because they are still capable (to a certain degree) of verbalizing their experience with the interactive installation. The responses of elderly people living in a closed ward could thus be different.

\section{Recommendations for further research}

The findings gained in this exploration can potentially inform artists/designers of interactive artworks working in co-creation with all stakeholders to create an intentional immersive experience for elderly people residing in a care home and suffering from dementia. More research is however needed to explore how physical elements can be designed and integrated in such a way that they become part of the story. Further exploration of the particular content that seems to appeal to the participants presents an exciting area for researchers and user experience practitioners. The combination of and the co-creation methods used need to be constantly re-evaluated.

Social interactions between participants were very limited, even though meta-data was intentionally left out of the scene to trigger social interaction, by letting participants search for extra information through conversations with other recipients. Further research should investigate how design can support successful social interaction amongst elderly people suffering from dementia. 


\section{Development of VENSTER}

During the second usability test we observed a reluctance in the participants to engage and interact with more abstract, interactive scenes in VENSTER. This could be related to a number of factors (e.g. the design of the content or uncertainty on how to interact). We believe abstract interactive scenes, catered to nursing home residents are worth exploring, but it is unclear what content and which level of abstraction is best suited. Further exploration and research is needed.

\section{Conclusion}

The iterative design process resulted in 15 lessons learned in each phase of the design process, which helped to adapt to new insights during the design process as they emerged. It enabled us to identify flaws in the design early on, and led to a change of perspective. The description will hopefully also provide artists, designers as well as formal and informal caregivers tools and best practices to make (better) informed choices during the creation of interactive artworks for this specific target population. From our experience, it seems that co-design might be the key component that will make the difference between designing a pleasurable experience and a meaningful one.

\section{Acknowledgements}

The authors would like to thank all participating residents and health care professionals of the "Op den Toren" nursing home in the town of Nuth, for participating in this study and sharing their time, thoughts and experience with us. We also want to thank NOOS design for their involvement in the development of the prototype, and additional thanks are due to Marc Delsing and Albine Moser for providing us with valuable feedback.

\section{Disclosure statement}

The authors report no conflicts of interest. The authors alone are responsible for the content and writing of this article.

\section{Funding}

This research was financially supported by Cicero Zorggroep and Zuyd University of Applied Sciences (Research Centre Technology in Care, the Maastricht academy of Media, Design and Technology and the board of executives). 



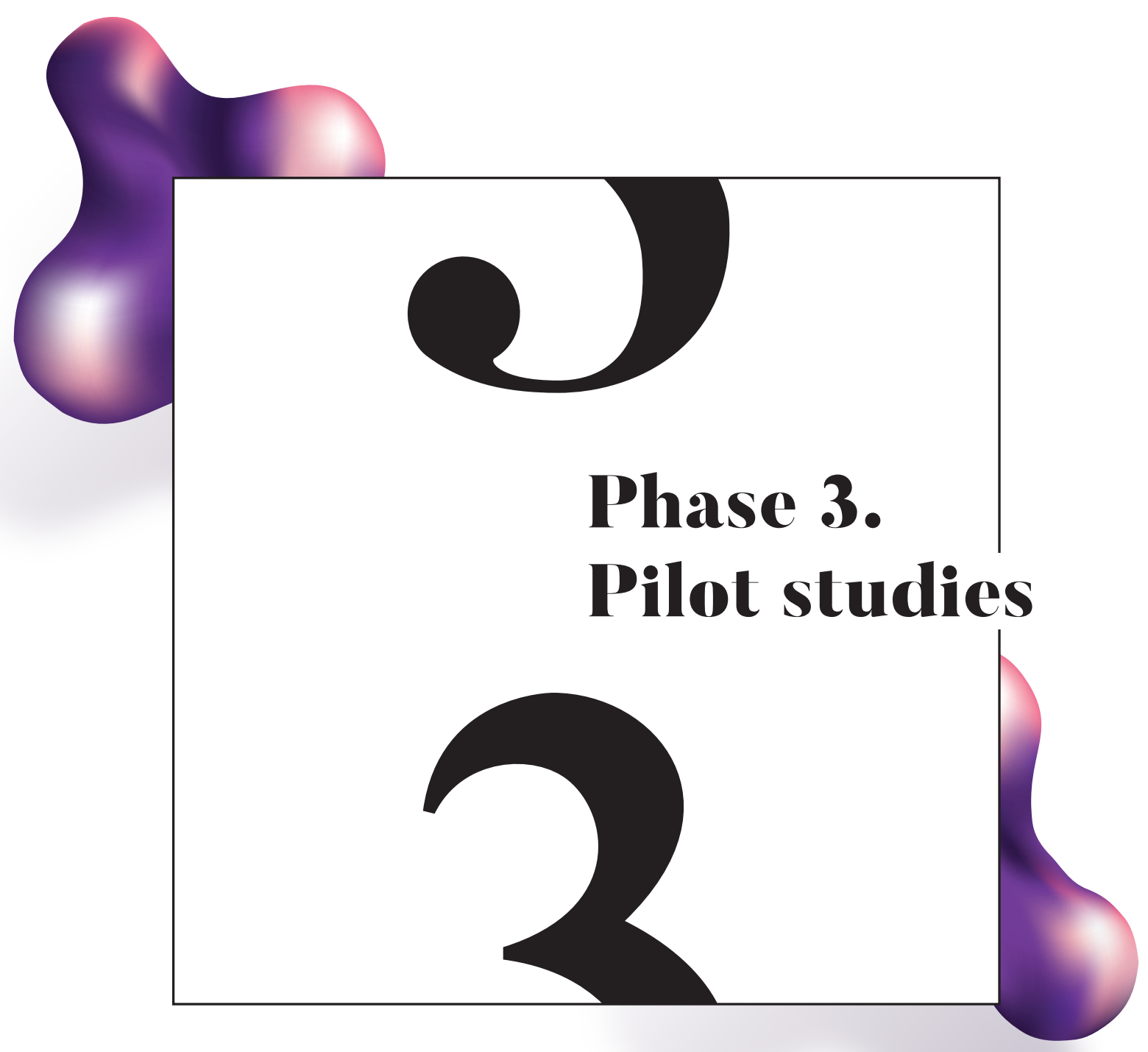



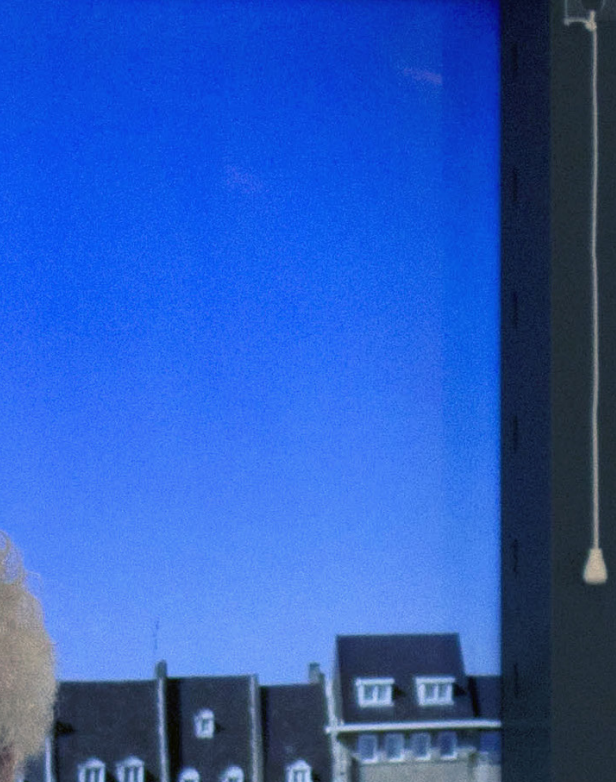

.

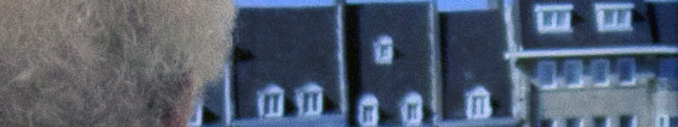

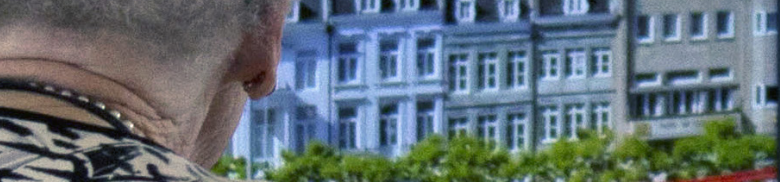
Las

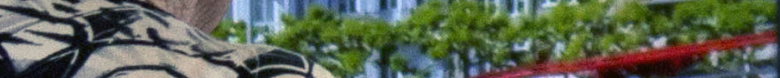
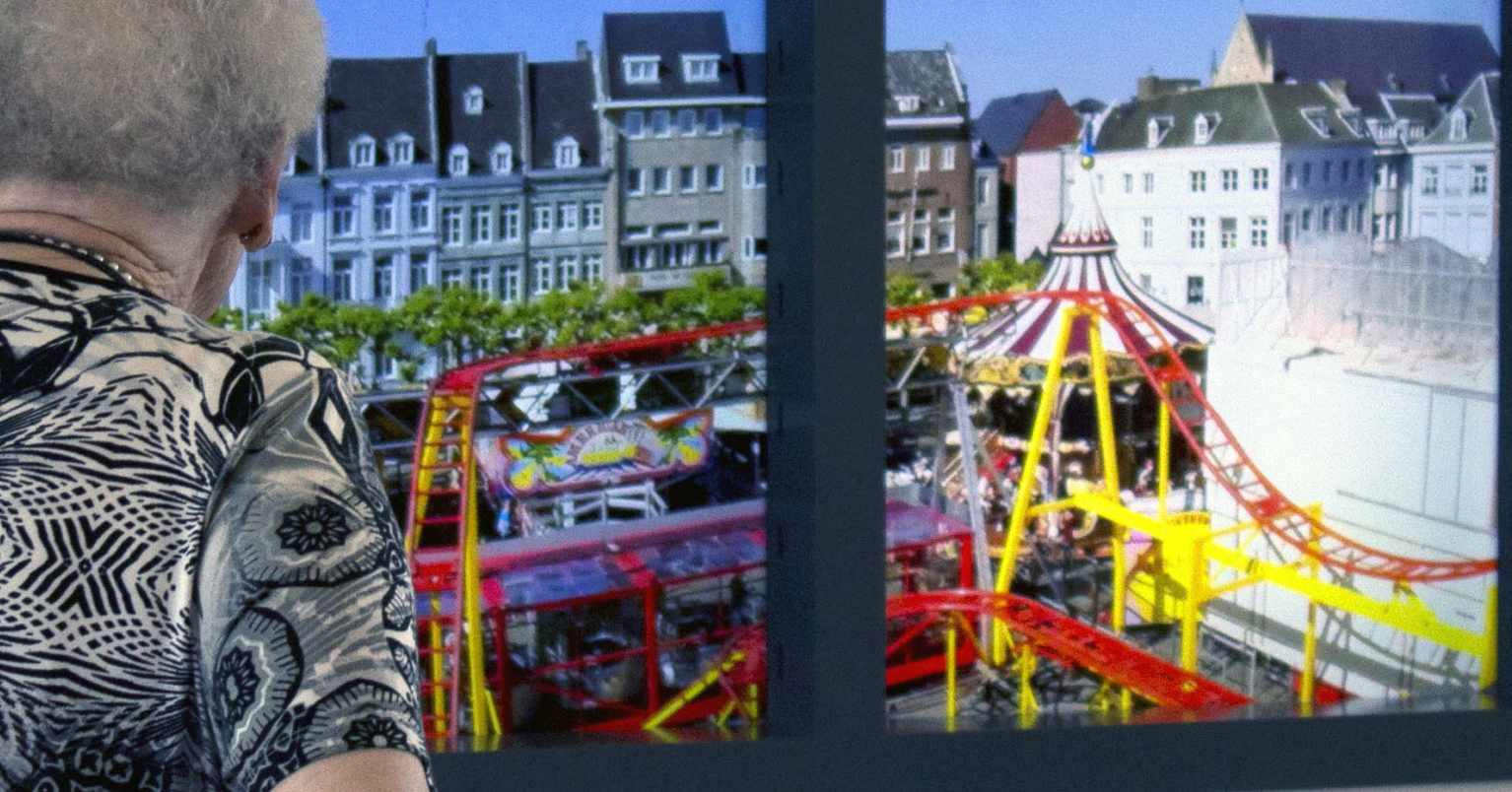
0 sos 4 50003 onco: 7 mo

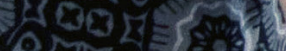
rut (I) ( 8703 


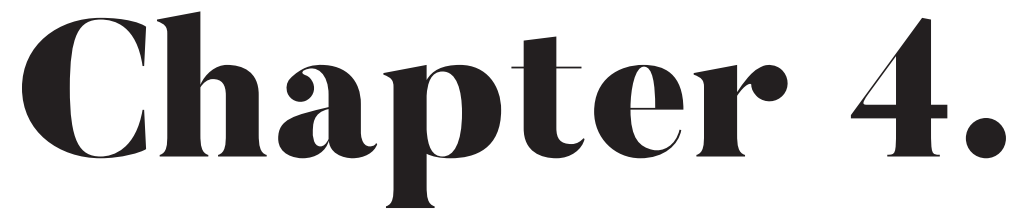

\section{How nursing home}

residents with dementia

respond to the interactive art installation 'VENSTER'; A pilot study

Tom Luyten

Susy Braun

Gaston Jamin

Susan van Hooren

Luc De Witte

Disability and Rehabilitation Assistive Technology 13(1):1-8 DOI: 10.1080/17483107.2017.1290701 


\title{
Chapter 4
}

\begin{abstract}
The goal of this study was (1) to determine whether and how nursing home residents with dementia respond to the interactive art installation in general and (2) to identify whether responses change when the content type and, therefore, the nature of the interaction with the artwork changes.

The interactive art installation 'VENSTER' evokes responses in nursing home residents with dementia, illustrating the potential of interactive artworks in the nursing home environment. Frequently observed responses were naming, recognizing or asking questions about depicted content and how the installation worked, physically gesturing towards or tapping on the screen and tapping or singing along to the music.

It seemed content matters a lot. When VENSTER is to be used in routine care, the choice of a type of content is critical to the intended experience/usage in practice. In this study, recognition seemed to trigger memory and (in most cases) a verbal reaction, while indistinctness led to asking for more information. When (initially) coached by a care provider, residents actively engaged physically with the screen. Responses differed between content types, which makes it important to further explore different types of content and content as an interface to provide meaningful experiences for nursing home residents.
\end{abstract}

\section{Implications for rehabilitation}

VENSTER can facilitate different types of responses ranging from verbal reactions to active physical engagement. The choice of a type of content is critical to the intended experience/ usage in practice. Activating content seems suitable for use as a meaningful experience during the spare time in between existing activities or therapy. Sessions with interactive content are short (avg. 30 mins) and intense and can therefore potentially be used as an activating therapy, activity or exercise. In order to actively engage residents with dementia, the role of the care provider seems very important. 


\section{Responses to VENSTER}

\section{Introduction}

The central philosophy in nursing homes today is emotion-oriented care, tailored to the residents' individual needs and possibil-ities (Finnema et al., 2005). This philosophy is put into practice in various forms, for instance in multi-sensory, musical or creative therapy. Although evidence for non-pharmacological approaches is accumulating (Hulme, Wright, Crocker, Oluboyede, \& House, 2010), they are restricted to a set timeframe and require a skilled professional to be present. This makes it worthwhile to explore if it is possible to provide nursing home residents with an experience they can enjoy on their own or with family and friends (informal caregivers), using interactive art as a medium.

Interactive art differs in its essence from non-interactive art. Recipients can only enjoy, watch and interpret a non-interactive artwork from a distance. Art historian Katja Kwastek states that "Interactive art places the action of the recipient at the heart of its aesthetics. It is the recipient's activity that gives form and presence to the interactive artwork, the recipient's activity is also the primary source of his aesthetic experience" (Kwastek, 2013). An example of an interactive art installation is Anthonin Fourneau's "Water Light Graffiti" (Fourneau, 2013). Without recipients' actions, it is just a black wall. But when they spray and splash water, the artwork comes to life. The experience and enjoyment lies in the interaction between the recipient and the interactive artwork. Research shows that interactive art has an effect on human behaviour. It can provide a rich experience in which play, exploration, cooperation and social interaction are encouraged (Charitos, Bourdakis, \& Gavrilou, 2006; A. Morrison, Viller, \& Mitchell, 2011; A. J. Morrison, Mitchell, \& Brereton, 2007). In view of the intuitive and playful characteristics of interactive artworks, they are more accessible for people who find it hard to communicate with other people and/or have problems understanding the world around them. This makes interactive art potentially interesting for people with dementia (Hill, Kolanowski, \& Kürüm, 2012; Kolanowski, Resnick, Beck, \& Grady, 2013).

The study reported in this paper assessed how nursing home residents with dementia responded to an interactive art installation called 'VENSTER', which was specifically designed for this study, and whether their responses differed when the nature of the interaction with the artwork changed.

VENSTER (Figure 1), which translates as "WINDOW" in English, is an interactive art installation which could facilitate nursing home residents in connecting or reconnecting with the outside world. Not by augmenting existing activities or therapy, but by providing a meaningful experience.

The concept of VENSTER was devised by designers and implemented in co-creation with residents and their informal and professional caregivers (care providers) in a Dutch nursing home. 


\section{Chapter 4}

The installation can show pre-recorded calming (Figure 2A) or activating (Figure 2B) content, and is also able to present inter-active content (Figure $2 \mathrm{C}$ ), which can be manipulated in real time using touch screen technology. Each of the content types comprises several different scenes. When the installation detects the presence of a person, music starts playing.

Physically, VENSTER consists of two large (touch) screens, verti-cally mounted in a fake wall, plus a computer, a Kinect ${ }^{\mathrm{TM}}$ sensor and a roller blind with a string. The Kinect ${ }^{\mathrm{TM}}$ sensor tracks the user's position, and the computer adapts the perspective of the screens accordingly. The string attached to the roller blind serves as a switch to change the scene.

The goal of the present study was (1) to determine whether and how nursing home residents with dementia respond to the interactive art installation in general and (2) to identify whether their responses change when the content type and, therefore, the nature of the interaction with the artwork changes. This study is a first step in assessing the potential of interactive art installations as an experience-oriented care technology in a nursing home setting.

\section{Methods}

The research protocol was set up as an observational explorative study. The study took place at a nursing home facility in the south of the Netherlands. Participants who took part lived at a closed facility for people suffering from psychogeriatric disorders.

\section{Study population}

During the observations, 35 residents were living in the participating ward. All of them suffered from dementia to such a degree that they were unable to live independently. The selection of actual participants from the closed ward was made by the professional caregivers, based on availability. They were invited to spend some time in an indoor public space. Residents from an open ward could freely walk in and out of this semi-public square during the observations and participate spontaneously if they wanted to do so.

\section{Ethical considerations}

The research protocol was approved by the local ethics board (METC Atrium, Orbis, Zuyd; 14-N-100). No actual consent form was completed and this was given an exempt status. The ethical board approved the way participants were selected and included to enable the exploration of spontaneous responses of the residents in a "real-life" setting. Two weeks prior to the observations all residents, their legal representatives and the professional caregivers were informed about the upcoming study by means of an information letter. They were invited to try out the installation (which had already been placed on site) for themselves and contact the researchers for additional information, and they could refuse study participation up to the start of the observations. 


\section{Responses to VENSTER}

\section{Design}

Six to eight residents of the ward and 1-2 care providers were invited to attend a session with VENSTER lasting a maximum of 2 hours, in a public space of the nursing home (Figure 3). The resi-dents were initially seated at a table, providing them with a clear view of the VENSTER installation. A public hallway, where other people could walk by, was located next to the seating area. The researchers were seated out of view and able to follow the session through a remote screen. Two video cameras (front and back) captured the participants' responses, which allowed repeated display of the observed responses.

During each session, one of three above-mentioned types of content (calming, activating and interactive, Figure 2) was presented. The calming content displayed for instance a nearby park and fishing pond (Figure 2(A)). Activating content showed videos that were designed to trigger (re)actions (e.g., a little girl placing her hand on the window and waving, Figure 2(B)). For the interactive content, the computer generated semi-abstract scenery (e.g., falling snow), which could be manipulated by touching the screen (Figure 2(C)).

When the majority of residents started to lose interest and focus, the care provider could signal the researchers to end the session sooner than the maximum duration of 2 hours.

\section{Data collection}

The gender of the participants and the ward in which they were staying (open/closed ward) were recorded. Two researchers (TL and GJ) were present during all the observations. The observers kept their involvement to a minimum, interfering only when there was a malfunction of the installation. Where needed, field notes were taken to complement the recordings. A short, open exit-interview about the care providers' impressions took place after each of the 8 sessions.

\section{Data analysis}

The data was analyzed by two researchers (TL and GJ). All visible and audible interactions recorded on video were transcribed and coded. In case of disagreement, the researchers consulted two other researchers (SB and $\mathrm{SvH}$ ) to reach consensus. The framework of codes was based on the results of a prior literature review on "Participant Responses to Physical, Open-ended Interactive Digital Artworks" (Luyten, Braun, Van Hooren, \& Witte, 2017). The framework distinguishes between human-human and human-artwork responses, each divided into verbal, physical and emotional/mental responses. This global division was further subdivided into 11 categories (see see categories Figure 4B). To provide a comprehensive structure, all coded responses were organized in mind maps, using MindJet MindManager $^{\text {TM }}$ (MindJet, Pleasanton, CA). 


\section{Chapter 4}

\section{Coding of responses}

Responses were coded as "human-artwork" when there was only one person involved and his/her response was directed towards the art installation. Responses were coded as "human-human" when 2 or more people were involved and their responses were directed towards each other. When multiple people directed a response towards VENSTER and each other, the response was coded as both human-human and human-artwork. When a response was individual, the coded name of the person was added; when two or more people were involved, all coded names were added, the initiator appearing first. If a resident simultaneously displayed two or more types of response, the response was recorded in all corresponding categories. The following categories were used:

All comprehensible verbal feedback with regard to the installation, either directed towards the installation or to another person, was coded as "verbal responses".

All distinguishable physical actions of any duration with regard to the installation, either directed towards the installa-tion or to another person were coded as "physical responses".

When participants looked away from the installation or other people, staring into the distance for more than 3s, the response was coded as "lost focus".

All actions unrelated to the installation were coded as "not important" and disregarded (e.g., conversation about pouring coffee).

Interactions that could not be interpreted by the research-ers because of poor articulation or sound quality were coded as "unclear interactions".

The data are presented in tables, showing both the absolute numbers of responses and percentages. All results are relative to the first column of the table. Because session lengths differed, results were averaged to a number of responses per hour. For example, all sessions with activating content added up to 3:36h of video, eliciting 790 coded interactions. This was averaged to 226 interactions an hour, by dividing all numbers by 3.5. Clustering of similar responses resulted in subcategories (Figure 4(B)). For instance, pulling the string and waving to person in scene emerged as subcategories of Respond according to affordance. 


\section{Responses to VENSTER}
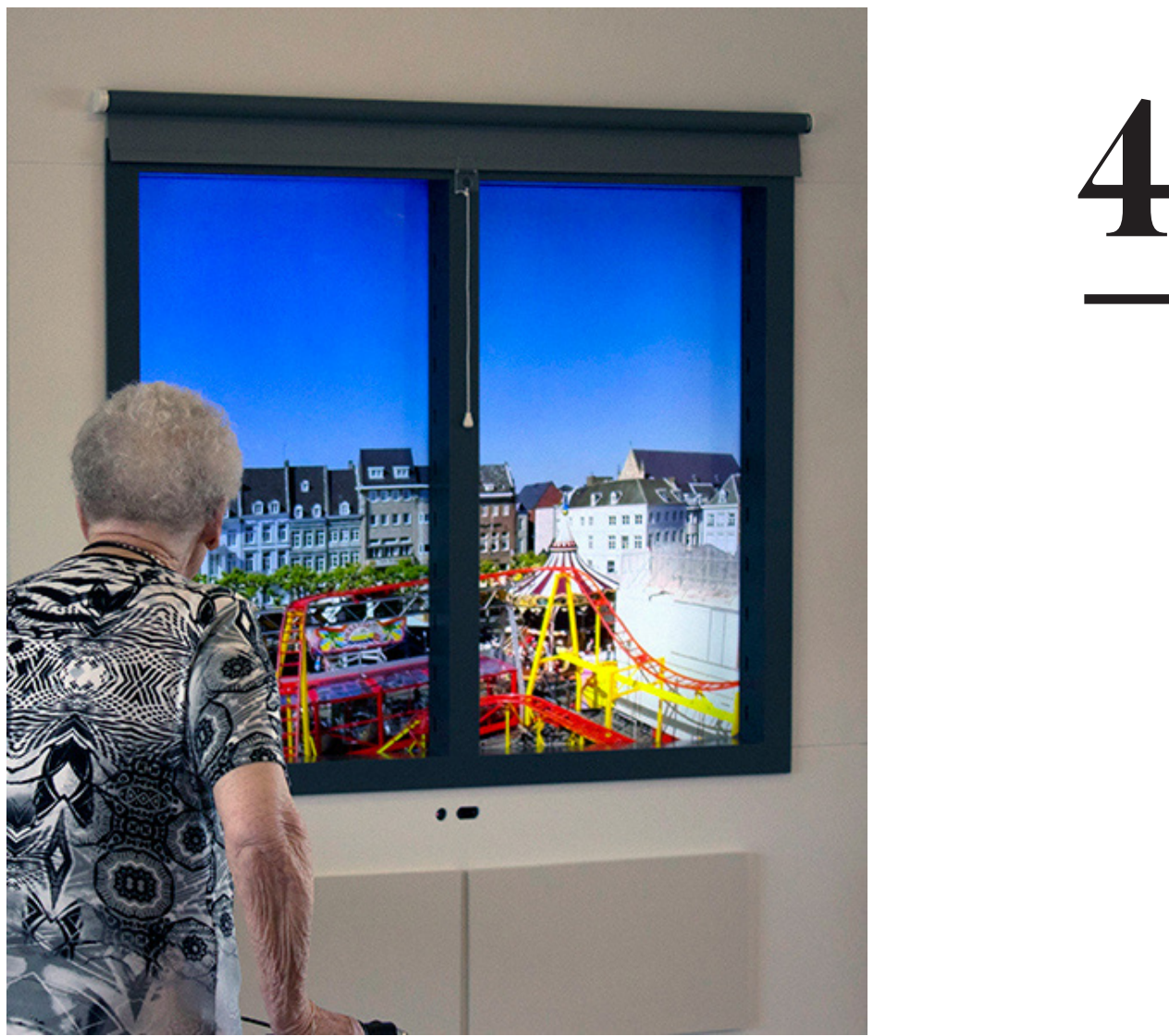

Figure 1: VENSTER: interactive art installation bringing the outside world into the nursing home.
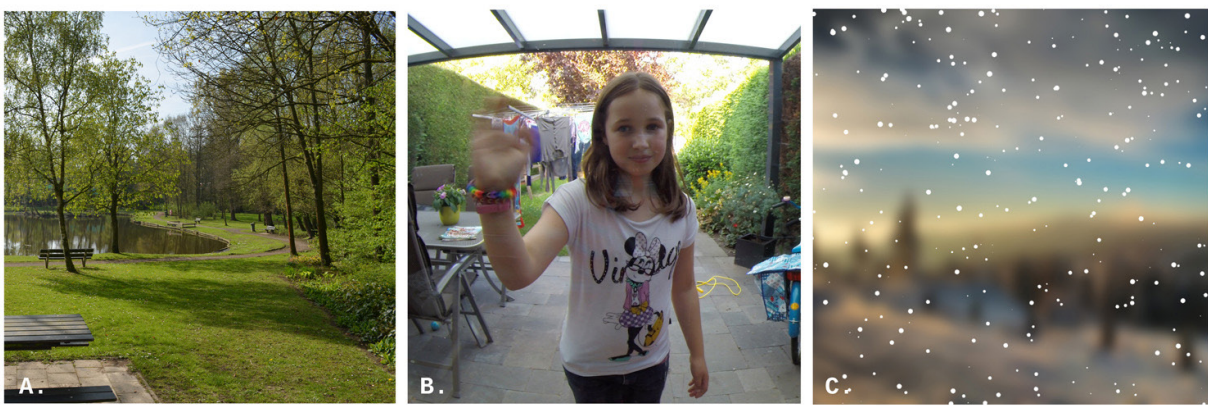

Figure 2: Examples of calming (A), activating (B), interactive and $(C)$ content. 


\section{Chapter 4}

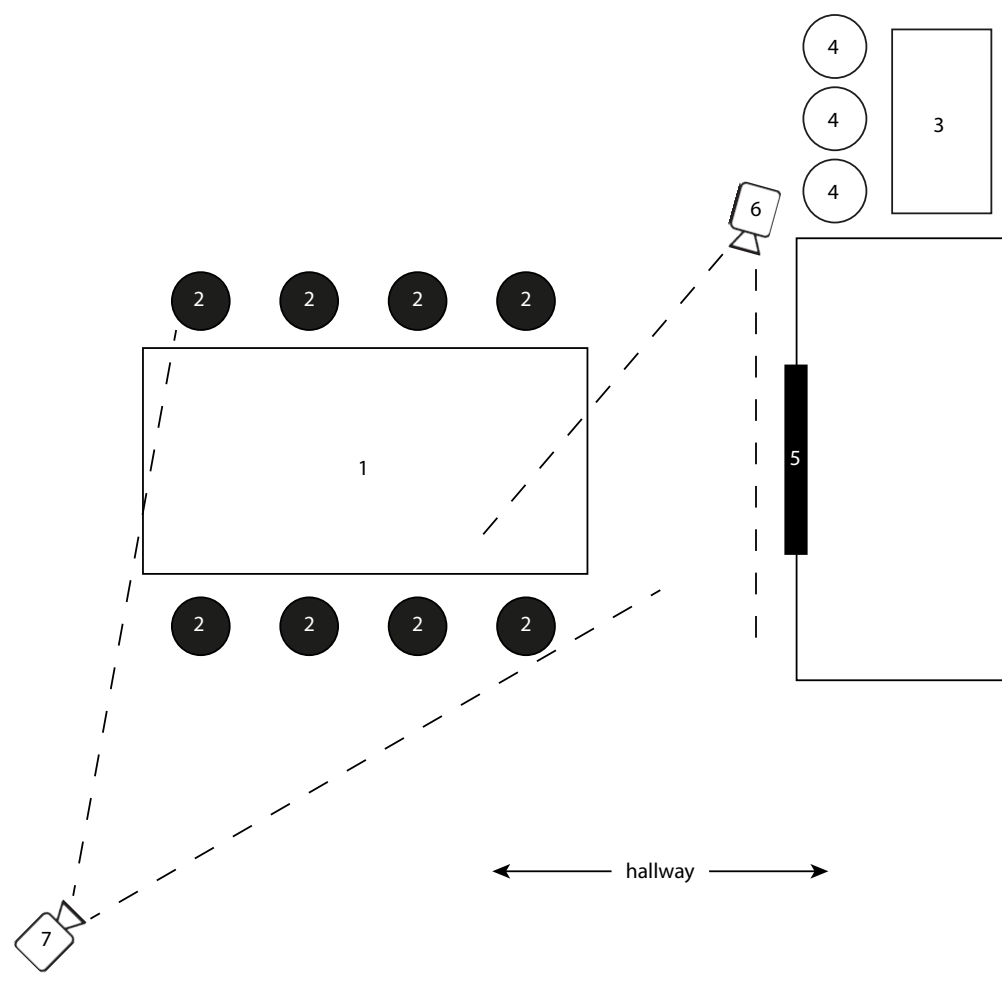

Figure 3. Overview of the position of VENSTER, the cameras and surroundings. Legend: 1: table, 2: chairs for participants, 3: table where researchers were seated, 4:plants, 5: VENSTER, 6: front camera, 7: back camera.

\section{Results}

None of the recipients of the information letter refused to participate in the study. Eight sessions took place, with a maximum duration of $1 \mathrm{~h} 32 \mathrm{~min}$. A total of $8 \mathrm{~h}$ and $43 \mathrm{~min}$ of video was recorded.

Ten clients (eight females) of the closed ward participated in the study. During the first session, one female resident of the open ward walked in and stayed, only for this session. Four pro-fessional caregivers, two activity supervisors and two volunteers, all of them female, guided the sessions (Table 1).

During eight sessions, a total of 1417 responses were identified (100\%). More than half of them (n $1 / 4737,52.8 \%$ ) were human-human responses. One-third (n $1 / 4481,36.6 \%$ ) were human-artwork responses. The remaining responses consisted of losing focus (n $1 / 4$ $138,7.7 \%$ ) and unclear interactions (n $1 / 461,2.9 \%)$. The average durations of calming and 


\section{Responses to VENSTER}

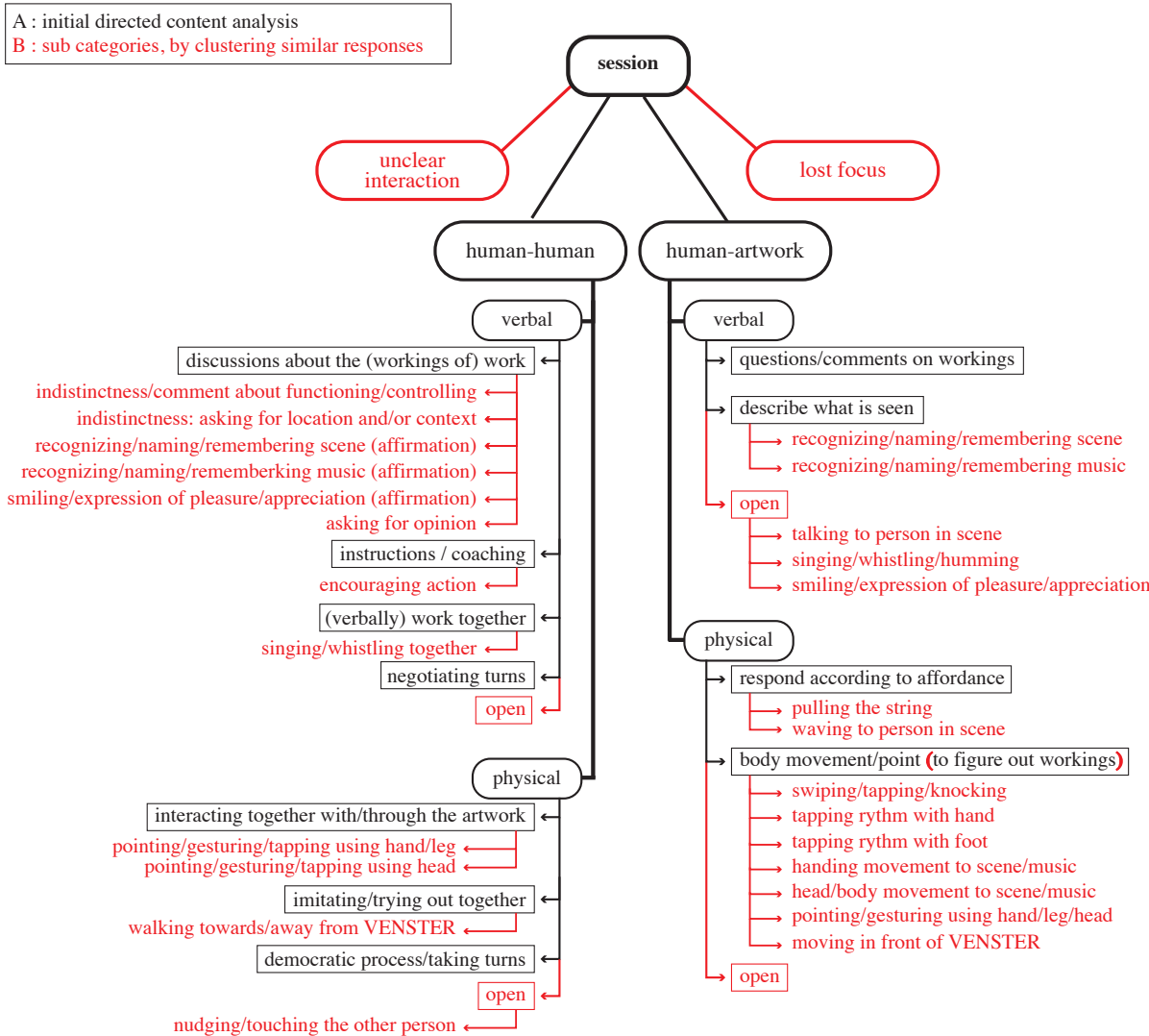

Figure 4: (A) Overview of the initial framework. (B) Subcategories created by clustering similar responses

activating sessions were comparable (91 and $83.5 \mathrm{~min}$, respectively). The sessions with interactive content were noticeably shorter (avg. 32.5 min). Figure 4A gives an overview of the initial framework.

Recognition seemed to play a major role in perceiving a personal connection and having an immersive experience for the nursing home residents: they commented on what they saw, asked for confirmation or reminisced about past memories when they saw something they could relate to. When the depicted content triggered memories or recognition, it initiated a conversation. If the memory or recognition was incomplete, it triggered the residents to ask others, mostly care providers, for more information or confirmation. Participants were also activated by content that was specifically designed to trigger a counter-reaction. Examples included a child waving and placing her hand on the window, and children skipping rope. Familiar music was recognized and the residents sang or tapped along by themselves or together with someone else. The attention shifted to music mostly when there was a less 


\section{Chapter 4}

interesting moment in the visual content. When semi-abstract content was shown, nursing home residents were hesitant to interact. They searched for instructions and confirm-ation from a care provider or someone else present (Tables 2-4).

\section{Human-human responses}

Human-human responses accounted for $52.8 \%$ of the total responses recorded. A detailed overview of the human-human responses is presented in table 2. The percentages reflect the relative occurrence of a response in relation to the total number of human-artwork responses (100\%). Nearly all human-human communication happened between clients and care providers, mostly initiated by the care provider (Table 2).

\section{Human-human: Verbal responses}

The category of Discussions about the installation and how it worked was the most frequently recorded human-human response overall (66.1\% of all human-human responses) It contained six subcategories, of which Recognizing/naming/remembering scene had the

Table 1. Overview of the eight sessions, with detailed information about the time of day, type of content, duration of the session, gender of the residents and profession of the caregivers.

\begin{tabular}{|c|c|c|c|c|c|c|}
\hline \multirow{2}{*}{\multicolumn{2}{|c|}{$\begin{array}{l}\text { Time of } \\
\text { day }\end{array}$}} & \multirow{2}{*}{$\begin{array}{l}\text { type of } \\
\text { content }\end{array}$} & \multirow[t]{2}{*}{ duration } & \multirow[t]{2}{*}{ gender residents } & \multicolumn{2}{|r|}{ care providers } \\
\hline & & & & & gender & role/profession \\
\hline 1 & Evening & Calming & $1 \mathrm{~h} 32 \mathrm{~min}$ & 2 male, 4 female ${ }^{a}$ & $\mathrm{~F}$ & Informal caregiver \\
\hline 2 & Midday & Activating & 1h $18 \min$ & 2 male, 3 female & $\mathrm{F}$ & $\begin{array}{l}\text { Professional } \\
\text { caregiver }\end{array}$ \\
\hline 3 & Midday & Activating & $1 \mathrm{~h} 29 \mathrm{~min}$ & 2 male, 2 female & $\mathrm{F}$ & $\begin{array}{l}\text { Professional } \\
\text { caregiver }\end{array}$ \\
\hline \multirow[t]{2}{*}{4} & \multirow[t]{2}{*}{ Morning } & \multirow[t]{2}{*}{ Calming } & \multirow[t]{2}{*}{ 1h $30 \mathrm{~min}$} & \multirow[t]{2}{*}{2 male, 3 female } & \multirow[t]{2}{*}{$\mathrm{F}$} & Informal caregiver \\
\hline & & & & & & $\begin{array}{l}\text { Activity supervisor } \\
\text { (in training) }\end{array}$ \\
\hline 5 & Midday & Interactive & $44 \mathrm{~min}$ & 1 male, 3 female & $\mathrm{F}$ & $\begin{array}{l}\text { Professional } \\
\text { caregiver }\end{array}$ \\
\hline 6 & Midday & Activating & $28 \mathrm{~min}$ & 1 male, 3 female & $\mathrm{F}$ & $\begin{array}{l}\text { Professional } \\
\text { caregiver }\end{array}$ \\
\hline 7 & Midday & Interactive & $21 \mathrm{~min}$ & 1 male, 3 female & $\mathrm{F}$ & Activity supervisor \\
\hline 8 & Midday & Activating & $28 \mathrm{~min}$ & 1 male, 3 female & $\mathrm{F}$ & Activity supervisor \\
\hline
\end{tabular}




\section{Responses to VENSTER}

largest number of responses (26.8\% of all human-human responses). When residents or care providers rec-ognized the content presented or when a memory was triggered, they shared this with a care provider, initiating conversation. Children playing, animals and familiar places particularly triggered verbal reactions.

The subcategory Indistinctness/commenting about functioning/ controlling had the second largest number of responses. When interactive content was shown, residents struggled to understand that the screen was touch-sensitive and the content reacted to their input. This then generated a lot of verbal responses by the clients asking for instructions. Care providers coached them ver-bally, provided instructions about the controls and figured out possible interactions or encouraged the residents to interact or keep interacting (subcategory encouraging action, 9.9\% of all human-human responses).

Although participants tapped their hands or feet and sang along to music, there were hardly any verbal comments in the subcategory recognizing/naming/remembering music. Finally, no responses were found for verbally negotiating turns to interact with the installation.

\section{Human-human: Physical responses}

Physical human-human responses accounted for less than a fourth of all human-human responses. By far, the largest number of responses occurred in the category of interacting together with/ through the artwork, in the form of pointing, gesturing or tapping, for example when recognizing a scene and pointing this out (physically) to someone. These responses were initiated by both care providers and residents.

When the response walking towards/away from VENSTER occurred, this was mostly initiated by the care provider, who phys-ically guided the resident to take a closer look.

\section{Human-artwork responses}

All human-artwork responses accounted for $36.6 \%$ of the total responses recorded. Table 3 shows the human-artwork responses in detail.

\section{Human-artwork: Physical responses}

Body movement and/or pointing (to figure out how it worked) accounted for half of all human-artwork responses overall. This mostly occurred in combination with encouragement by the care provider and was linked to recognition of the content (pointing something out) or using (or trying to use) the interface.

Music triggered the residents to tapping rhythm with hand/foot and head/body movement to scene/music.

As regard, responses that were linked to the interface or con-tent affordance, pulling the physical string attached to the roller blind was by far the most frequent response $(13 \%$ of 


\section{Chapter 4}

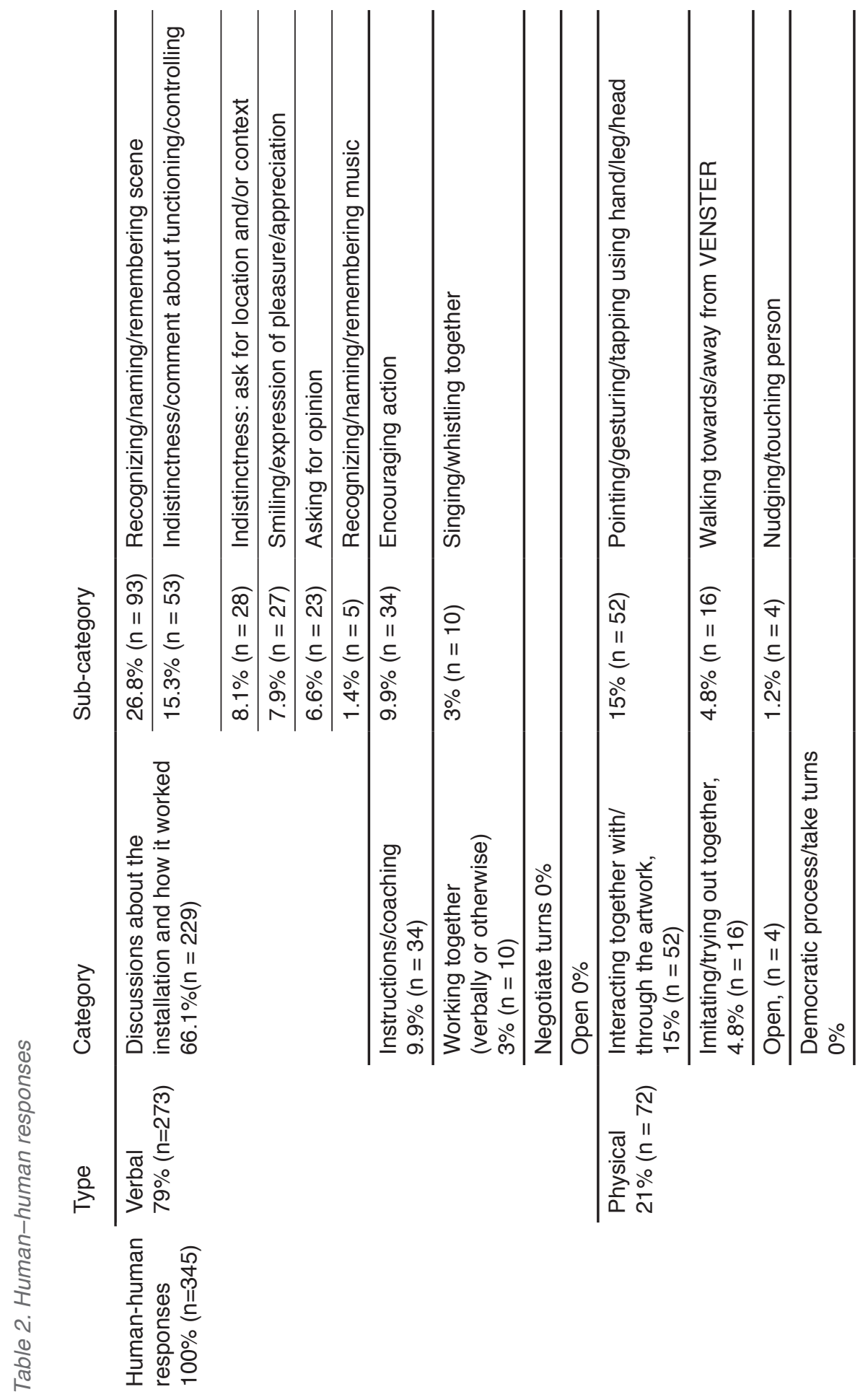

90 The art of feeling connected 


\section{Responses to VENSTER}

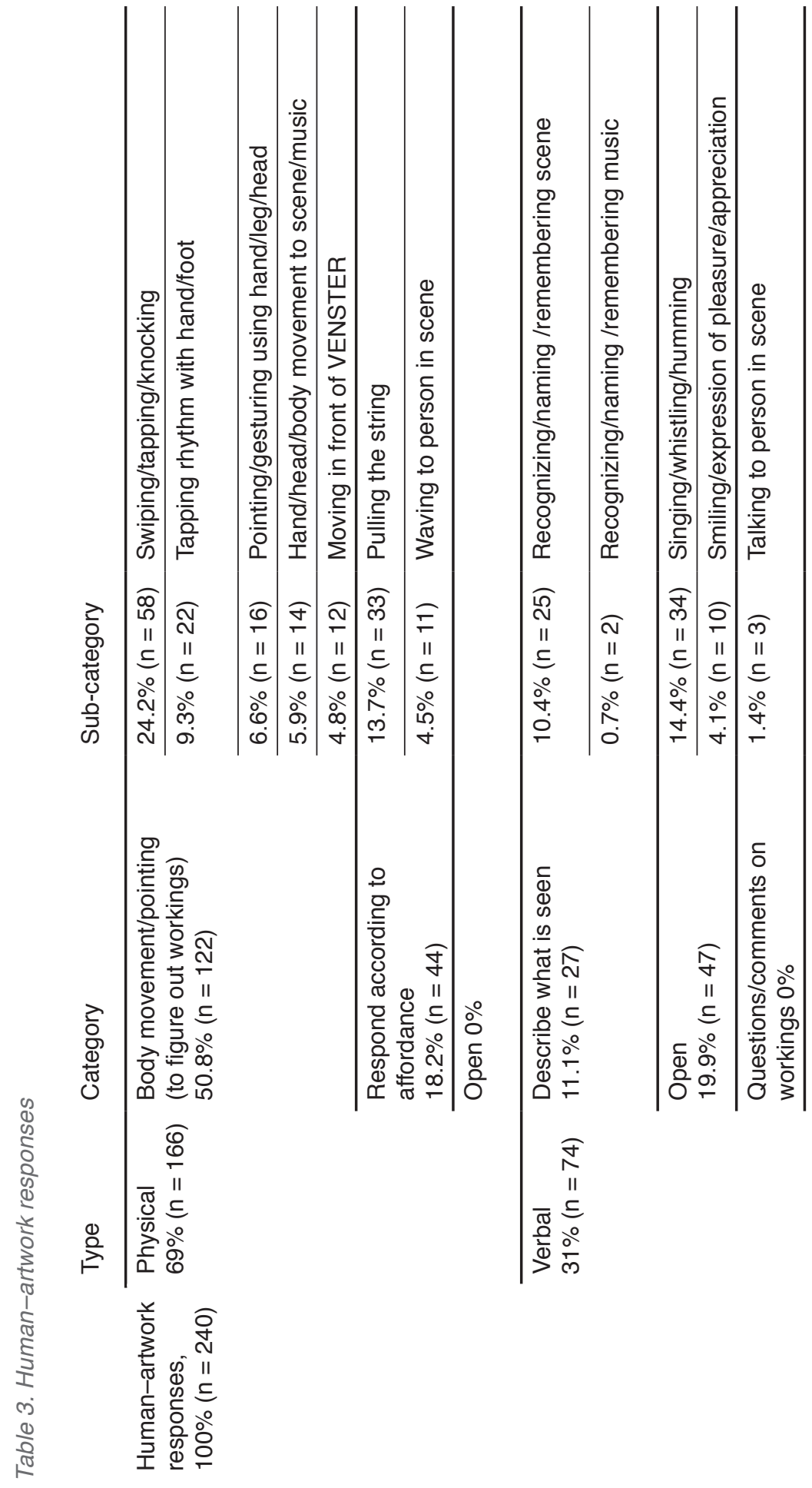




\section{Chapter 4}

all human- artwork responses). It was mostly the care providers and some residents who pulled the string to skip the current scene and advance to the next. Waving to person in scene occurred mostly during scenes specifically designed to trigger this behaviour, for instance showing a young girl interrupting her rope skipping, walking towards the camera, putting her hand on the window and then waving. Almost everyone, including care providers and passersby, waved back.

Full body movements were carried out mostly by care providers in front of VENSTER to adapt the perspective in order to see more of a particular scene or to figure out how the adjustable perspective worked.

\section{Human-artwork: Verbal responses}

When residents recognized the lyrics, rhythm or melody of a song, they sang, whistled or hummed along (14.4\% of all human- artwork responses). Responses in the category describing what is seen ( $11.1 \%$ of all human-artwork responses) were almost all related to the content. Residents responded verbally when a memory linked to the depicted content was triggered. In most cases, they recognized a place or context from their past. Responses in the subcategory smiling or expressing pleasure/appreciation included residents smiling, laughing or verbally stating that they were enjoying themselves.

Very few responses in the category Talking to person in scene were recorded. Residents would sometimes talk to a (real or imagined) person in the video, say hello or coach a child that was skipping rope for example. No questions or comments about the way the installation worked were expressed by the participants directly to the artwork.

\section{Responses per content type}

Table 4 shows an overview of responses for the three different types of content.

All sessions with calming content together account for 3:02 $\mathrm{h}$ of video. A total of 3:36 h of video was recorded during sessions with activating content, and one hour of video in total during sessions with interactive content. Overall, human-human responses were more common than human-artwork responses. Sessions with calming scenes generated the lowest number of responses, while those with activating scenes had more and those with interactive scenes the highest number. Human-human responses were mostly verbal, while human-artwork responses were largely physical.

The main aim of this pilot study was to assess whether the interactive art installation 'VENSTER' was able to evoke responses in nursing home residents with dementia. Both human-human and human-artwork responses were noted, each including verbal and physical responses, with individual differences between participants in the type and frequency of responses. 


\section{Responses to VENSTER}

Table 4: General overview of all participant responses.

\begin{tabular}{|c|c|c|c|c|c|}
\hline \multirow{7}{*}{$\begin{array}{l}\text { All Responses } \\
100 \% \\
(n=655)\end{array}$} & \multirow{3}{*}{$\begin{array}{l}\text { Human - human } \\
52.8 \% \\
(n=345)\end{array}$} & & Calming & Activating & Interactive \\
\hline & & $\begin{array}{l}\text { Verbal } \\
41.7 \% \\
(n=273)\end{array}$ & $6.1 \%$ & $14 \%$ & $21.6 \%$ \\
\hline & & $\begin{array}{l}\text { Physical } \\
11.1 \% \\
(n=72)\end{array}$ & $1.8 \%$ & $3.5 \%$ & $5.8 \%$ \\
\hline & \multirow[t]{2}{*}{$\begin{array}{l}\text { Human - artwork } \\
36.6 \% \\
(n=240)\end{array}$} & $\begin{array}{l}\text { Physical } \\
25.3 \% \\
(n=166)\end{array}$ & $1.9 \%$ & $8 \%$ & $15.4 \%$ \\
\hline & & $\begin{array}{l}\text { Verbal } \\
11.3 \% \\
(n=74)\end{array}$ & $1.7 \%$ & $3.9 \%$ & $5.7 \%$ \\
\hline & $\begin{array}{l}\text { Lost Focus } \\
7.7 \% \\
(n=51)\end{array}$ & & $2.1 \%$ & $3.6 \%$ & $2 \%$ \\
\hline & $\begin{array}{l}\text { Unclear interactions } \\
2.9 \% \\
(n=19)\end{array}$ & & $1.5 \%$ & $1.4 \%$ & $0 \%$ \\
\hline
\end{tabular}

\section{Discussion}

The main aim of this pilot study was to assess whether the interactive art installation 'VENSTER ' was able to evoke responses in nursing home residents with dementia. Both human-human and human-artwork responses were noted, each including verbal and physical responses, with individual differences between participants in the type and frequency of responses.

In general, frequently observed responses were naming or recognizing the depicted content, asking questions about the content and how the installation worked, physically gesturing towards or tapping on the screen and tapping or singing along to the music.

The nursing home residents we observed almost never communicated directly with each other. They rarely asked for instructions or additional information from each other, nor did they negotiate taking turns, either verbally or physically.

Our secondary aim was to identify possible differences in responses to each of the content types presented in "VENSTER" (calming, activating and interactive). Although sessions with calming content lasted up to $1.5 \mathrm{~h}$, the observed interactions were brief and limited. Some residents lost focus for minutes on end, even falling asleep for the bigger part of the session.

When presented with activating content, participants were generally calm and focused for up to $1 \mathrm{~h}$, in contrast to the normal situation (verbal information from nursing staff), where 


\section{Chapter 4}

a minimum of two care providers needed to be permanently present and the atmosphere was generally agitated. Responses were recorded steadily throughout the whole session, mostly linked to what was seen and/or recognized on the screen of the installation.

Sessions with interactive content were short (avg. $30 \mathrm{~min}$ ) but rich in responses. The reason for the short timespan could be that there were only four different interactive scenes available at the time of the study, or perhaps the participants grew tired more quickly because of the intensity of the interactions.

\section{Study limitations}

No cognitive/emotional responses were recorded, because of the observation method used (video observation), and the inability of the residents to reflect on their own behaviour.

The duration of interactions was not measured, which might have distorted some results. Loss of focus can serve as an example: although not directly reflected in the results, episodes of loss of focus lasted much longer in sessions with calming content, compared to sessions with activating and interactive content. This tendency was less distinct for other recorded responses, but some nuances were probably lost.

If a resident carried out two or more types of response simultaneously, these responses were coded in all corresponding categories. This influenced the total number of responses recorded, possibly overrecording some responses.

Group composition differed in most sessions, so results were influenced by the characteristics of the participants present. One example is that almost all responses in the subcategory of sing-ing/whistling/humming in a particular session with activating con-tent came from the same person.

Nursing home residents with dementia often lack initiative, because of existing medical conditions, so the role of care providers as facilitators for interaction is important. Although the type of content presented and the group composition differed across sessions, we are convinced that the involvement and dedication of the care providers present is of great importance.

\section{Implications for practice}

When VENSTER is to be used in routine care there are several aspects that need to be taken into account to make the experience as rich as possible for the residents. The choice of a type of content, for instance, is critical to the intended experience/usage in practice: the sessions with calming content seem suitable when the installation is not being used actively. It keeps the illusion of a real window alive and can draw attention because the scenery is different from the real windows. During the sessions with calming content, however, participants were not able to keep their focus on the installation, which needs to be considered when implementing it for other target populations. Activating content seems 


\section{Responses to VENSTER}

suitable for use as a meaningful experience during the spare time in between existing activities or therapy. Participants can be generally calm and focused for up to 1 hour. This creates time for a care provider to initiate one-on-one conversations and actively encourage the residents to interact with the installation. The installation can serve as a catalyst for conversation and action, providing something new to do or to talk about. Recognition triggers memory, indistinctness leads to asking for more information. After being initially coached by a care provider, residents actively engage with the screen through pointing, gesturing and/or tapping.

Sessions with interactive content seem less suitable as a pass-time in between activities, but could potentially be used as an activating therapy, activity or exercise. They are short (avg. $30 \mathrm{~min}$ ) and intense. The role of the care provider seems very important, however. The semi-abstract, interactive content is not always understood by the residents on their own, so care providers have to be the facilitators who invite them to interact, help them operate the installation where needed and coach them to keep the interaction going. Scenes with interactive content are specifically designed to induce residents to physically interact with the installation, mostly in combination with encouragement by the care provider. Some residents may search for context by asking, and when nudged by the care provider they may interact and explore.

\section{Implications for research}

Our findings suggest that recognition plays a major role for nursing home residents in terms of perceiving a personal connection and having an immersive experience with "VENSTER". This raises questions about the potential of abstract interactive art for nursing home residents. What is needed to help nursing home residents overcome their initial hesitance when there is no recognition or link to an existing mental model? Does a link to a mental model need to be present in order to succeed? And if so, to what extent?

Eventually, VENSTER will not only show pre-recorded content, but will be able to establish a live connection with the outside world and vice versa. Examples could include a direct live feed with a fun fair, primary school or musical performance. A short, promising pilot project was conducted using a Skype connection with low quality sound and image, connecting the elderly care home directly with a primary school. Without instructions, both parties overcame the technical obstacles and conversed with each other for over an hour. Further research is needed to explore this potential.

\section{Conclusion}

"VENSTER" evokes responses in nursing home residents with dementia, which illustrates the potential of interactive artwork in the nursing home environment.

It seemed that content matters a lot. In this study, recognition seemed to trigger the memory 


\section{Chapter 4}

and (in most cases) a verbal reaction, while indistinctness led to asking for more information. When (initially) coached by a care provider, residents actively engaged physically with the screen by pointing, gesturing and/or tapping. Responses differed between content types, which makes it important to further explore different types of content and content as an interface in order to provide meaningful experiences for nursing home residents.

In addition to the target population examined in this pilot study, "VENSTER" could also be interesting for other groups of people. More research into the potential of interactive art in health care is warranted, as all people who permanently or temporarily reside in a place that feels disconnected from the outside world might benefit from interactive art installations like "VENSTER".

\section{Acknowledgements}

The authors would like to thank all participating residents and health care professionals of the "Op den Toren" nursing home in the town of Nuth, for participating in this study and sharing their time, thoughts and experience with us. We also want to thank NOOS design for their involvement in the development of the prototype.

\section{Disclosure statement}

The authors report no conflicts of interest. The authors alone are responsible for the content and writing of this article.

\section{Funding}

This research was financially supported by Cicero Zorggroep and Zuyd University of Applied Sciences (Research Centre Technology in Care, the Maastricht academy of Media, Design and Technology and the board of executives). 



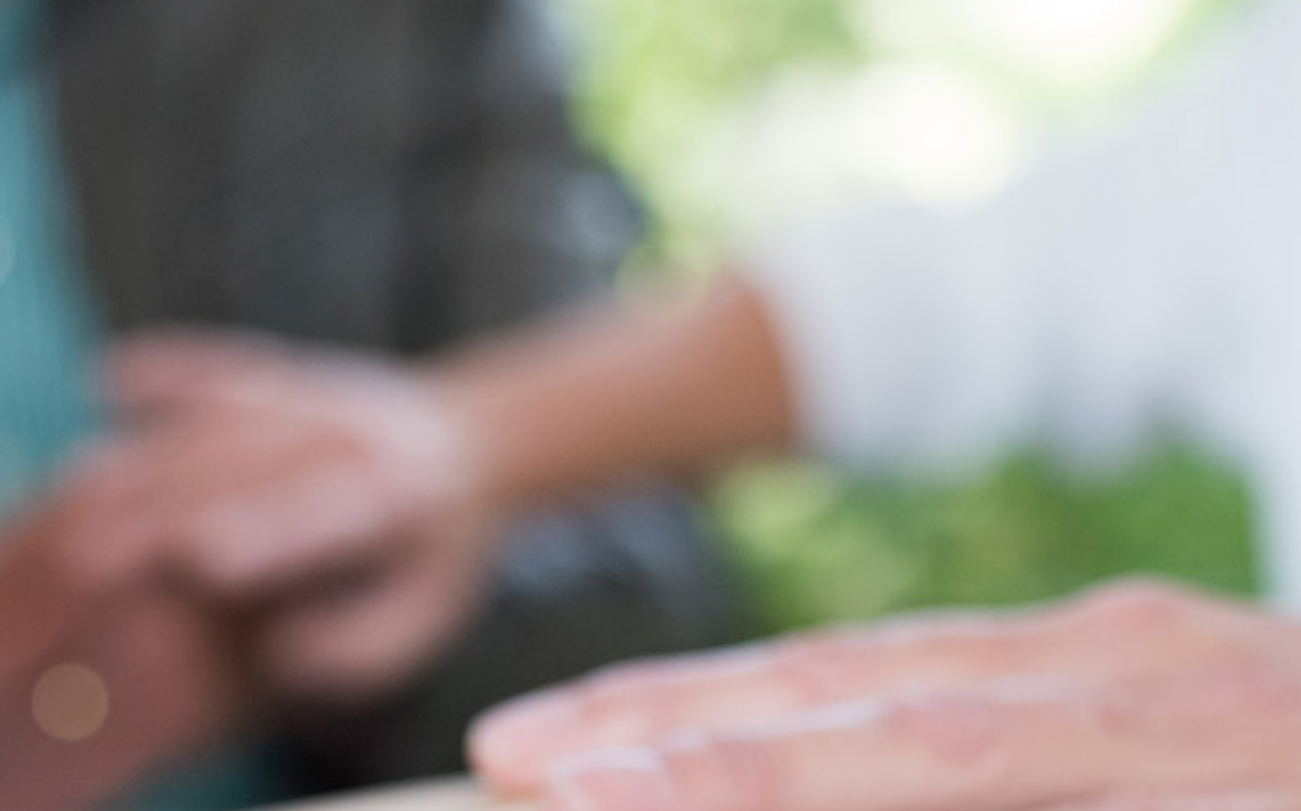

$(0)$

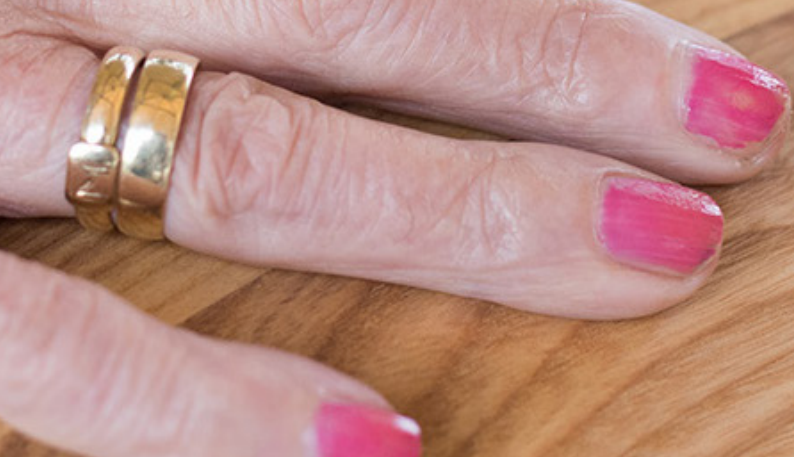


Chapter 5.

\section{How groups of nursing home residents respond to 'the CRDL'; A pilot study}

Tom Luyten

Susy Braun

Gaston Jamin

Susan van Hooren

Luc De Witte

Journal of Enabling Technologies, 12(4), 145-154

DOI: 10.1108/JET-05-2018-0025 


\title{
Chapter 5
}

\begin{abstract}
Purpose

The aim of this study was to describe whether and how groups of nursing home residents respond to the interactive object 'the CRDL'. The CRDL can translate touches between people into sounds. It recognises the type of touch and adjusts the produced sound accordingly.
\end{abstract}

\section{Design/Methodology/Approach}

This was as an observational explorative study. Responses were coded and analysed using an existing theoretical framework.

\section{Findings}

The CRDL creates an atmosphere of playfulness and curiosity. It lowers the threshold to touch, provides an incentive to touch and encourages to experiment with different types of touches on arms and hands. The sounds the CRDL produces sometimes trigger memories and provide themes to start and support conversation. Involving a (large) group of nursing home residents to interact with the $\mathrm{CRDL}$ is challenging.

\section{Research limitations/implications}

To fully understand the potential of the CRDL, the following is suggested: (1) studying different group compositions and individual sessions; (2) exploring the effects of tailored content adjusted to individual preferences and/or stages of cognition; and (3) examining the effects of using the CRDL on the general wellbeing of nursing home residents.

\section{Practical implications}

The CRDL can help caregivers to use touch to make contact with groups of their residents. A session should be guided by an experienced caregiver. Some familiarisation and practice with the CRDL are recommended and a quiet environment is advised.

\section{Originality/value}

This paper demonstrates the potential of interactive objects, such as the CRDL, in the nursing home. 


\section{Responses to the CRDL}

\section{Introduction}

A simple touch communicates a wealth of information. A mother caressing her newborn, the fingertips of a couple slightly touching or a pat on the back while shaking someone's hand. Touch is a language we use instinctively. It is our most developed sense when we are born, and it is critical during the development of an infant (Field, 2014). Humans are unknowingly skilled in deciphering the information that is contained within a single touch. Touch influences our behaviour and registers in our brain, whether or not the touch itself can be remembered (Gallace and Spence, 2010; Lindgren et al., 2012). People are even able to explicitly identify emotions from the experience of being touched, without seeing the touch itself (Hertenstein et al., 2006).

In nursing homes, touch is part of daily life and two types can be distinguished: physical and therapeutic touch. Therapeutic touch has the explicit intention to heal (Krieger, 1979). Physical touch is split into instrumental and expressive touch (Watson, 1975). An instrumental touch is deliberate and required for the task at hand. Helping a patient out of his/her wheelchair, for instance, is instrumental, whereas an expressive touch is often spontaneous and affective, such as an encouraging pat on the shoulder.

The effects of therapeutic touch on nursing home residents have been studied. Recent systematic reviews conclude there is insufficient evidence in favour of massage and touch interventions for long-term effects, but therapeutic touch interventions have proven to reduce restlessness and stress in nursing home residents during the intervention (Livingston et al., 2014; Hansen et al., 2006; Cai and Zhang, 2015; McFeeters et al., 2016; Wu et al., 2017). Touch is reciprocal: Nicholls et al. (2013) reported that seeing the person with dementia relaxed and content because of an everyday touch produced a similar impact on those close by.

When touch is put into practice, there are some considerations to take into account. The emotional bond between humans is key to where and how we want to be touched by someone (Suvilehto et al., 2015). Nonetheless, not everyone perceives a touch in the same way. The person being touched might experience it as a violation of personal boundaries. This depends on a multitude of factors including the relationship of both people and the context, such as the workplace culture. In a formal, more distant corporate culture, it might be considered inappropriate or be frowned upon for two people to touch while in some companies greeting each other with a hug is part of the daily ritual.

In the nursing home environment, some people might benefit from an increase in expressive touches and might even experience them as therapeutic. However, a safe context for both parties should be created for them to feel comfortable.

The CRDL (Figure 1), an interactive device that translates touch between two or multiple people into sound, could create a situation or context in which touch is considered part of the 


\section{Chapter 5}

experience and feels safe and playful for all parties to participate. The CRDL can be used by a minimum of two and no maximum number of people simultaneously. It recognises the type of touch (e.g. tickling, holding, kneading, tapping or grabbing) and adjusts the produced sound accordingly. For instance, a gentle touch could trigger a bird singing while a firm grasp results in the sound of a rainstorm. Through the CRDL, people can "play each other" like a musical instrument. It makes touching the other person more inviting and playful. The CRDL has no display. It produces only audible content.

The CRDL (pronounced: "the cradle") got its name due to its shape, size and weight, which refer to a baby or a crib. Physically, the CRDL has an abstract, rounded form. On opposite sides of the device, there is a grey felt inlay shaped like a larger-than-life fingerprint. Two participants have to place one hand on such a felt "pad" and simultaneously touch the other person's skin (e.g. hand, arm or shoulder). If more people are interacting, they all have to touch each other. This way they close an electric circuit and the speaker, located in the centre of the CRDL, produces a sound, influenced by the type of touch and the selected soundscape (e.g. nature, town, instrumental, animals and house-garden-kitchen sounds). To select a soundscape, the controls hidden in a side panel of the CRDL should be used.

Mergent, an architecture and product design firm located in the Netherlands, designed the CRDL to empower people who have trouble with communication and social interaction. People who live with dementia, autism or other cognitive limitations are invited to use the CRDL to communicate with their friends and family through touch, sound and play. The CRDL has been informally tested by Mergent. Sessions included people who live

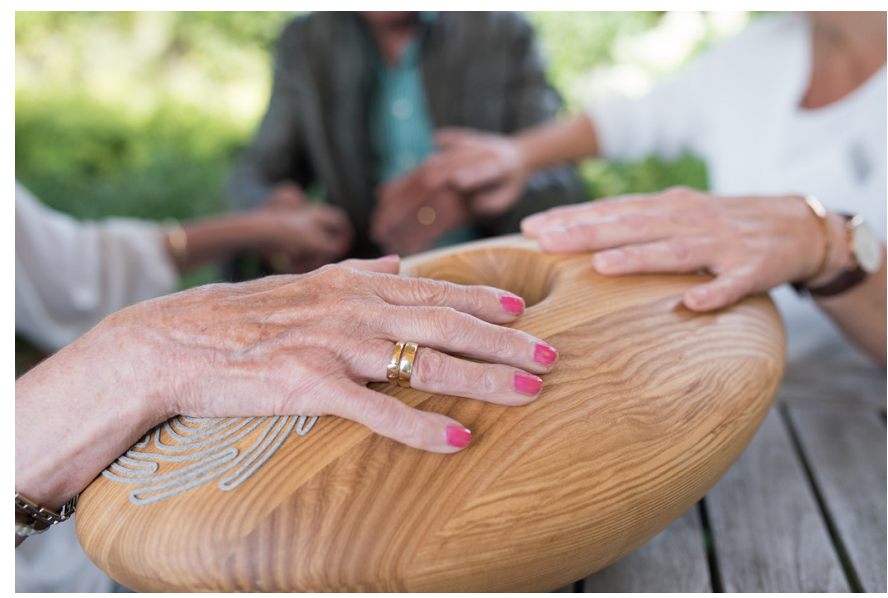

Figure 1: The interactive object "the CRDL". 


\section{Responses to the CRDL}

with (severe) dementia and a member of their family, caregivers or activity supervisors interacting one-on-one through the CRDL. Research on the CRDL in a group setting is lacking. Therefore, it is interesting to study how groups of nursing home residents with dementia respond to the CRDL.

\section{Methods}

This study was designed and carried out as an observational explorative study. It took place at a nursing home facility in the south of the Netherlands.

\section{Study population}

During the time of the study, 12 residents were living in a closed facility for people living with psychogeriatric disorders. All 12 experienced cognitive disabilities to such an extent that they were unable to live independently. The actual selection of participants was made by professional caregivers based on availability of the residents and their willingness to participate at that given moment. All residents were invited to try out the new device in the activity room. During the sessions, other residents and staff could freely walk in and out and participate.

\section{Ethical considerations}

The local ethics committee (METC Atrium, Orbis, Zuyd; 14-N-100) approved the research protocol. Because of the spontaneous selection and open character of the study design, no actual consent form was completed by the participants; thus, the study was given an exempt status. The ethical committee approved the way participants were selected and included. All residents, their legal representatives and the professional caregivers were informed about the study by means of an information letter two weeks prior to the study and could decline to participate by contacting the staff working on the reception desk or by telling a member of staff. If participants wanted to exit during the study, they could do so by signalling the caregiver in charge.

\section{Design}

In total, 9 of the 12 residents living in the closed ward participated in the study. Six participants attended more than one session. Two professional caregivers, one informal caregiver and two activity supervisors, all female, guided the sessions (Table 1).

In total, five sessions were held with a minimum duration of 16 mins and a maximum duration of 44 mins. This amounted to a total of two hours and $23 \mathrm{~min}$ of recorded video and 1,045 responses. The frequency of responses per session varied from 243 to 608 per hour. In total, 59 per cent of responses were initiated by a caregiver or activity supervisor (n $1 / 4619$ ) and 41 per cent by a resident (n $1 / 4426$ ). 


\section{Chapter 5}

Table 1: An overview of the sessions, including date, duration, participants and supervisors.

\begin{tabular}{|c|c|c|c|c|c|}
\hline \multirow[t]{2}{*}{ Date } & \multirow[t]{2}{*}{ Duration } & \multirow{2}{*}{$\begin{array}{l}\text { Responses } \\
\text { recorded }\end{array}$} & \multirow[t]{2}{*}{ Participants } & \multicolumn{2}{|r|}{ Supervisors } \\
\hline & & & & Gender & Role/profession \\
\hline 16 August 2017 & $44 \min$ & 178 & $\mathrm{M} 1, \mathrm{~V} 1, \mathrm{~V} 2, \mathrm{~V} 3$ & $\mathrm{~F}$ & Activity supervisor 1 \\
\hline 17 August 2017 & $19 \min$ & 184 & M2, M3, V4, V5 & $\mathrm{F}$ & Informal caregiver \\
\hline \multirow[t]{2}{*}{18 August 2017} & \multirow[t]{2}{*}{$16 \min$} & \multirow[t]{2}{*}{138} & \multirow[t]{2}{*}{$\mathrm{M} 1, \mathrm{M} 4, \mathrm{~V} 1$} & $\mathrm{~F}$ & Caregiver 1 \\
\hline & & & & $\mathrm{F}$ & Caregiver 2 \\
\hline $\begin{array}{l}9 \text { September } \\
2017\end{array}$ & $33 \mathrm{~min}$ & 231 & M3, M2, V3, V4 & $\mathrm{F}$ & Activity supervisor 2 \\
\hline $\begin{array}{l}13 \text { September } \\
2017\end{array}$ & $31 \mathrm{~min}$ & 314 & V1, V3, V4 & $\mathrm{F}$ & Activity supervisor 1 \\
\hline
\end{tabular}

\section{$143 \min \quad 1,045$}

In each session, 3 or 4 of the 12 residents accepted the invitation of a caregiver or activity supervisor to participate. The CRDL was placed at the centre of a table and residents were initially seated within arm's reach of it and each other. The researchers were seated out of view in another room and were able to follow the session through a remote screen. A single video camera captured the participants' responses, which allowed repeated display (Figure 2). All visible and audible interactions recorded on video were transcribed and coded independently by two researchers ( $T L, G J)$. The researchers consulted two other researchers $(\mathrm{SB}, \mathrm{SvH})$ in case of disagreement, to reach consensus.

The caregivers and activity supervisors received no instructions or protocol on how to guide the session. Some explanation about the functioning of the CRDL was provided by the researchers and a comprehensive manual, in the form of an A5 leaflet, was at the disposal of the caregiver or activity supervisor to refer to during the session. The CRDL was loaded with five soundscapes: sounds of nature, a town, animals, instruments and house-garden-kitchen sounds. One of five soundscapes could be selected at all times by the caregiver or activity supervisor. When the majority of residents started to lose interest and/or focus, the caregiver or activity supervisor could signal the researchers to end the session sooner than the maximum duration of 1 hour.

\section{Data collection}

A researcher was present in another room during each observation and followed the session through a remote screen. He/she interfered only when there was a malfunction of the CRDL or the recording equipment. In addition to the recording, field notes were taken. 


\section{Responses to the CRDL}

\section{Data analysis}

A framework was used to structure the coded responses, which emerged from the results of a literature review on "Participant responses to physical, open-ended interactive digital artworks" (Luyten et al., 2017) and has previously been used to structure the responses of nursing home residents in relation to the interactive artwork VENSTER (Luyten et al., 2018) (Figure 3). The framework presents a structure in which the most common responses of people who interact with an open-ended interactive artwork (such as the CRDL) can be placed.

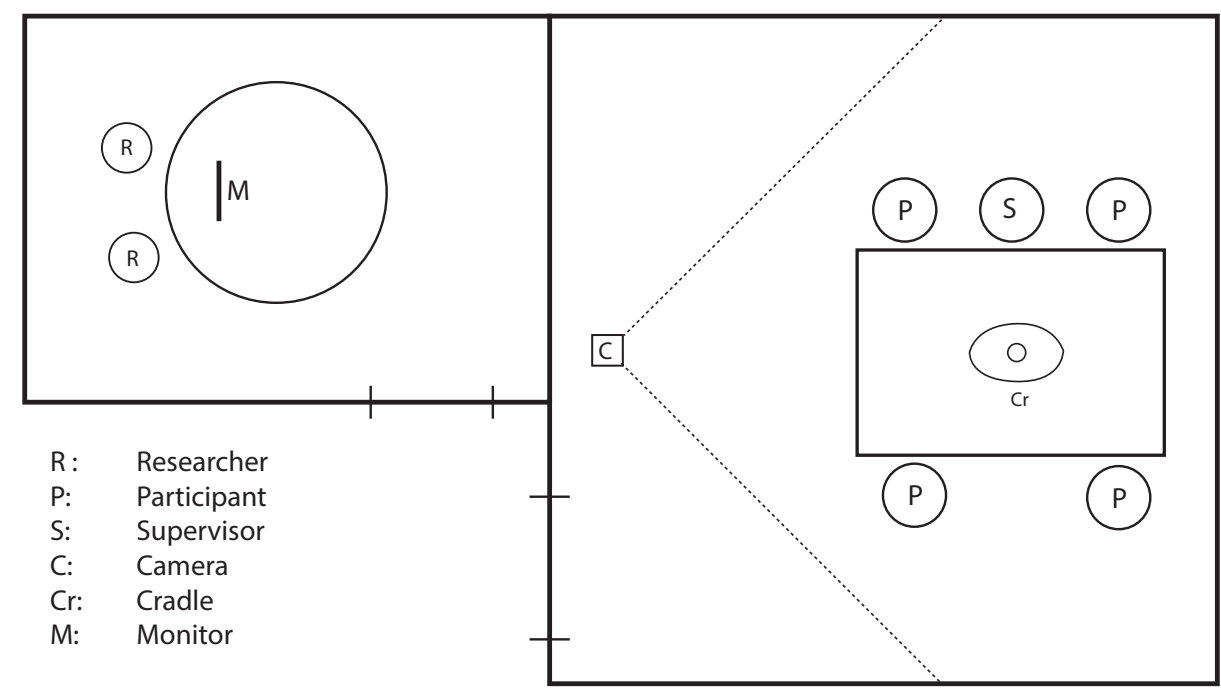

Figure 2: Overview of the position of CRDL, the camera and surroundings.

The framework distinguishes between human-human and human-artwork responses, divided into verbal, physical and cognitive/emotional responses. In this study, cognitive/ emotional responses were not noted. Interpretation of facial expressions or body language of the participants by the researcher and caregivers or activity supervisors has been attempted, but due to the complexity of some of the residents' cognitive condition, the disconnect between what is felt and communicated, combined with the absence of the voice of the residents themselves, it was decided to discard this category of responses.

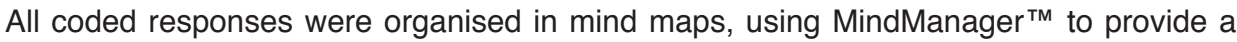
general overview. 


\section{Chapter 5}

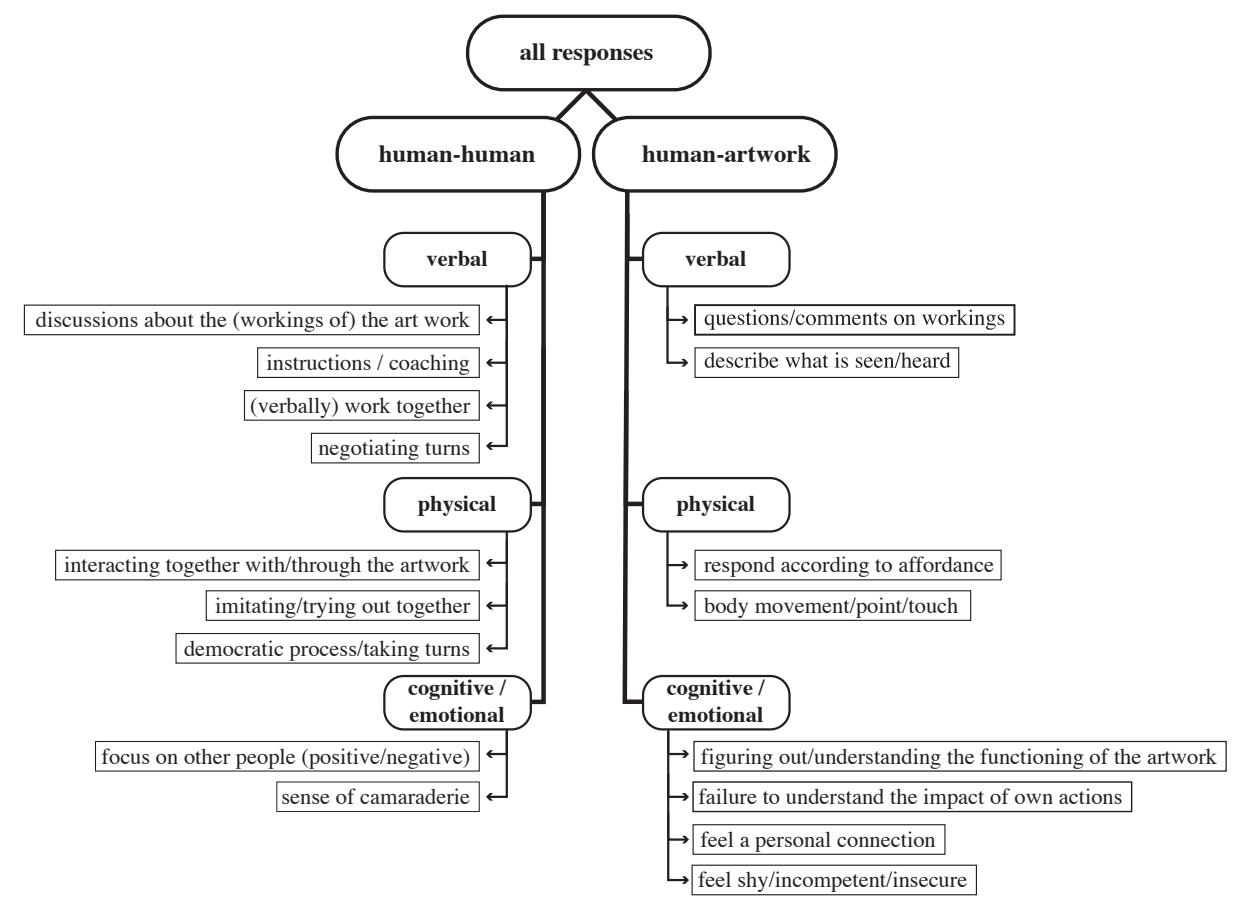

Figure 3: An overview of the coding framework

\section{Coding of responses}

Responses were coded as "human-artwork" when only one person was involved, and his/ her response was directed towards the CRDL. Responses were coded as "human-human" when two or more people were involved, and their responses were directed towards each other. When a response was individual, the coded name of the person was added; when two or more people were involved, all coded names were added, the initiator appearing first. If a person carried out two or more types of responses at the same time, the responses were recorded in all corresponding categories.

All understandable verbal feedback with reference to the CRDL, either directed towards the CRDL or to another person, was coded as "verbal responses" (e.g. a resident saying "that sounds like a train" to a caregiver). All distinguishable physical actions of any duration with reference to the CRDL, either directed towards the CRDL or to another person were coded as "physical responses" (e.g. a caregiver spinning the CRDL around its axis). All actions unrelated to the installation were coded as "not important to this study" and disregarded (e.g. conversation about pouring coffee).

Responses also were coded with the name of one or more corresponding categories of the aforementioned framework when they matched or alternatively got the label "open" if 


\section{Responses to the CRDL}

this was not the case. Lastly, responses were openly coded, which led to the emergence of sub-categories through clustering similar responses which are specific to the CRDL. For instance, the category "Discussions about the (working of ) the artwork holds the sub-categories comment on the CRDL functioning and comment on the CRDL build/ material".

The data are presented in tables, showing absolute numbers. Categories and sub-categories are arranged in the descending order from most occurrence to least. Between brackets, two numbers show the number of responses initiated by a caregiver or activity supervisor and the number of responses initiated by a resident respectively.

\section{Results}

Most of the recorded responses were of human-human nature (62 per cent, $n=650$ ), mostly initiated by caregivers or activity supervisors $(n=434)$ (Table 2$)$. Both verbal $(n=401)$ and physical $(n=252)$ responses were recorded. Human-artwork responses (38 per cent, $n=397)$ were nearly all physical in nature $(n=368)$ and initiated more by residents $(n=210)$.

\section{Human-human responses $(n=650)$}

Verbal responses $(n=399)$

Most discussions were about (the workings of ) the artwork $(n=222)$ (Table 3). Residents talked, asked questions $(n=25)$ and supervisors $(n=31)$ explained the functioning and controls $(n=56)$ of the CRDL. The sound and volume were often a topic of conversation ( $n=48$ ); while some could not hear the sounds, others thought they were too loud or annoying. The sounds the CRDL produces where recognised, named or remembered 42 times; residents identified the sound they recognised or remembered $(n=12)$ and supervisors named sounds they heard out loud to start a conversation or redirect the attention to the CRDL $(n=30)$. Some remarks were made and questions asked about the purpose or concept of the CRDL $(n=33)$, largely by clients $(n=25)$. The build and material of the CRDL got some attention as well $(n=23)$; it was found to be an odd and interesting device of high quality and pleasant to the touch. Finally, caregivers and activity supervisors asked for the opinions of others $(n=11)$ while residents were mostly the ones who expressed them $(n=6)$.

Table 2: An overview of all responses

\begin{tabular}{llll} 
All responses & Human-human & Verbal & $399(273,126)$ \\
\cline { 2 - 4 } $1,045(619,426)$ & $650(434,216)$ & Physical & $251(161,90)$ \\
\cline { 2 - 4 } & Human-artwork & Verbal & $27(8,19)$ \\
\cline { 3 - 4 } & $395(185,210)$ & Physical & $368(177,191)$ \\
\hline
\end{tabular}




\section{Chapter 5}

Responses in the category providing instructions/coaching $(n=131)$ were almost all carried out by caregivers or activity supervisors $(n=124)$. They encouraged interaction $(n=88)$ and provided instructions $(n=36)$ on how to interact with the CRDL.

The open category holds conversations that were triggered by the sounds or interactions with the CRDL $(n=32)$, mostly initiated by the caregivers or activity supervisors $(n=25)$. One resident explicitly wanted to learn the name of the CRDL. Negotiating turns contains responses of residents asking for clarity or refusal to interact with the CRDL $(n=13)$. They did not want to exit the activity but would rather watch from a distance or pass the "turn" to someone else.

No responses were noted in the category work together (verbally).

\section{Physical responses (n $1 / 4$ 251)}

Most of the physical human-human responses occurred in the category interact together with/through the artwork $(n=206)$. Most of these responses consisted of people touching each other on the hand or underarm $(n=150)$. There were instances of regularly touching or holding hands $(n=63)$, tapping $(n=46)$ and stroking $(n=37)$ as well as four instances of other means of touches (predominantly firmly grasping). Most of the touches were initiated by supervisors $(n=119)$. Residents and caregivers or activity supervisors also smiled or looked amazed at each other $(n=52)$, largely initiated by residents $(n=39)$. Four times, a caregiver or activity supervisor explicitly looked or pointed at CRDL $(n=4)$.

The category imitating/trying out together $(n=45)$ was dominated by supervisors who guided the hands of residents towards/corrected position on CRDL $(n=44)$. One resident physically mimicked the actions of someone else $(n=1)$.

The open category had one response of a resident carefully looking at the actions of other people interacting with CRDL.

No responses were recorded in the category democratic process/taking turns. This emphasises that a caregiver or activity supervisor actively curated most interactions. 
Responses to the CRDL

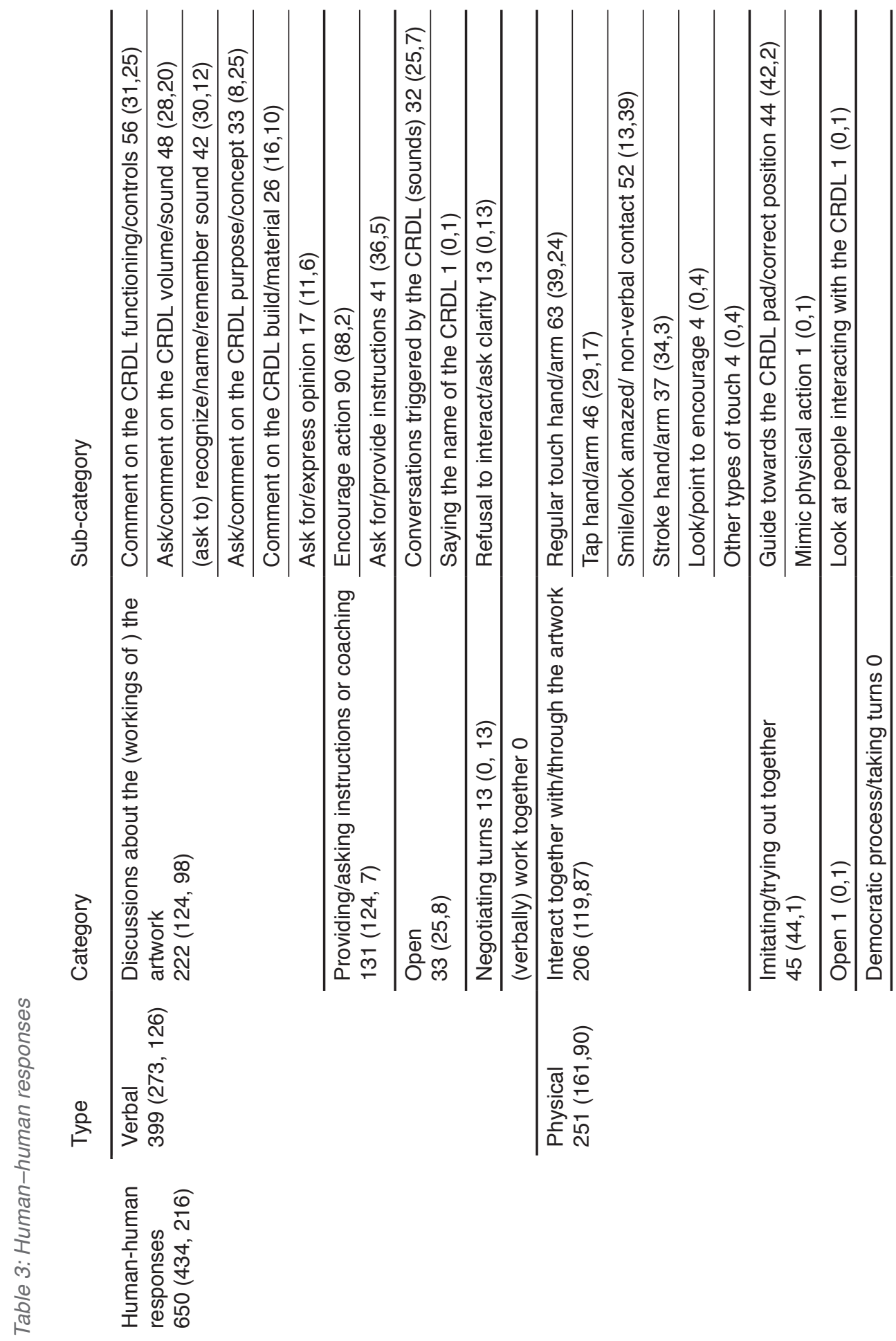




\section{Chapter 5}

\section{Human-artwork responses ( $\mathrm{n} 1 / 4$ 395)}

Physical responses $(n=368)$.

Most human-artwork interactions towards the CRDL were physical of nature $(n=368)$ (Table 4 ). This is of course closely linked to the nature of the device.

The category body movement/point/touch holds 247 responses. When all touch-like responses are added together, they amount to 204 of all 395 human-artwork responses. Most of them initiated by residents $(n=128)$ Most were regular touches of the CRDL pad $(n=139)$ followed by touching the CRDL somewhere else $(n=35)$. The CRDL pad was also tapped $(n=25)$ and stroked $(n=5)$. Sometimes the CRDL was released quickly to try out whether the sound would stop $(n=29)$. Finally, there were some gestures from a distance $(n=7)$, mostly to point out the correct spot (pad) to touch the CRDL $(n=4)$.

The category respond according to affordance $(n=60)$ described responses that were evoked because of the way the CRDL looks. The CRDL was moved to get it within reach or spun around its axis, something mostly initiated by a caregiver or activity supervisor $(n=53)$.

Half of the open category responses ( $n 1 / 461)$ consisted of a caregiver or activity supervisor controlling the settings of the CRDL $(n=30)$. They wanted to increase or decrease the volume or select another soundscape. Furthermore, there were residents looking at (their hand) on the CRDL with focus while they interacted $(n=22)$. Small numbers of residents closed their eyes a few times $(n=5)$ or were startled by a sudden sound pro $(n=4)$.

Verbal responses $(n=27)$.

There were very few verbal responses in the human-artwork category $(n=29)$. Most of them were in the sub-category describe what is seen/heard $(n=25)$. Mainly residents $(n=17)$ recognised, named or remembered a sound and made that remark out loud. The remaining four responses were instances where a resident verbally expressed their joy while interacting with CRDL.

\section{Discussion}

In nursing homes, touch is mainly used in a therapeutic and functional way by staff. An increase in expressive touches and the conscious use of them could be beneficial for residents. However, touching each other outside of the strictly functional and necessary is uncommon, especially in a hierarchical relationship such as a caregiver or activity supervisor and a nursing home resident. Therefore, it was the aim of this study to describe how groups of nursing home residents respond to the CRDL.

The results show that use of the CRDL in a group setting creates opportunities for expressive and therapeutic touch. It generates an atmosphere of curiosity, a playful context and is an intermediary between people. This lowers the threshold to touch, provides an incentive to 
Responses to the CRDL

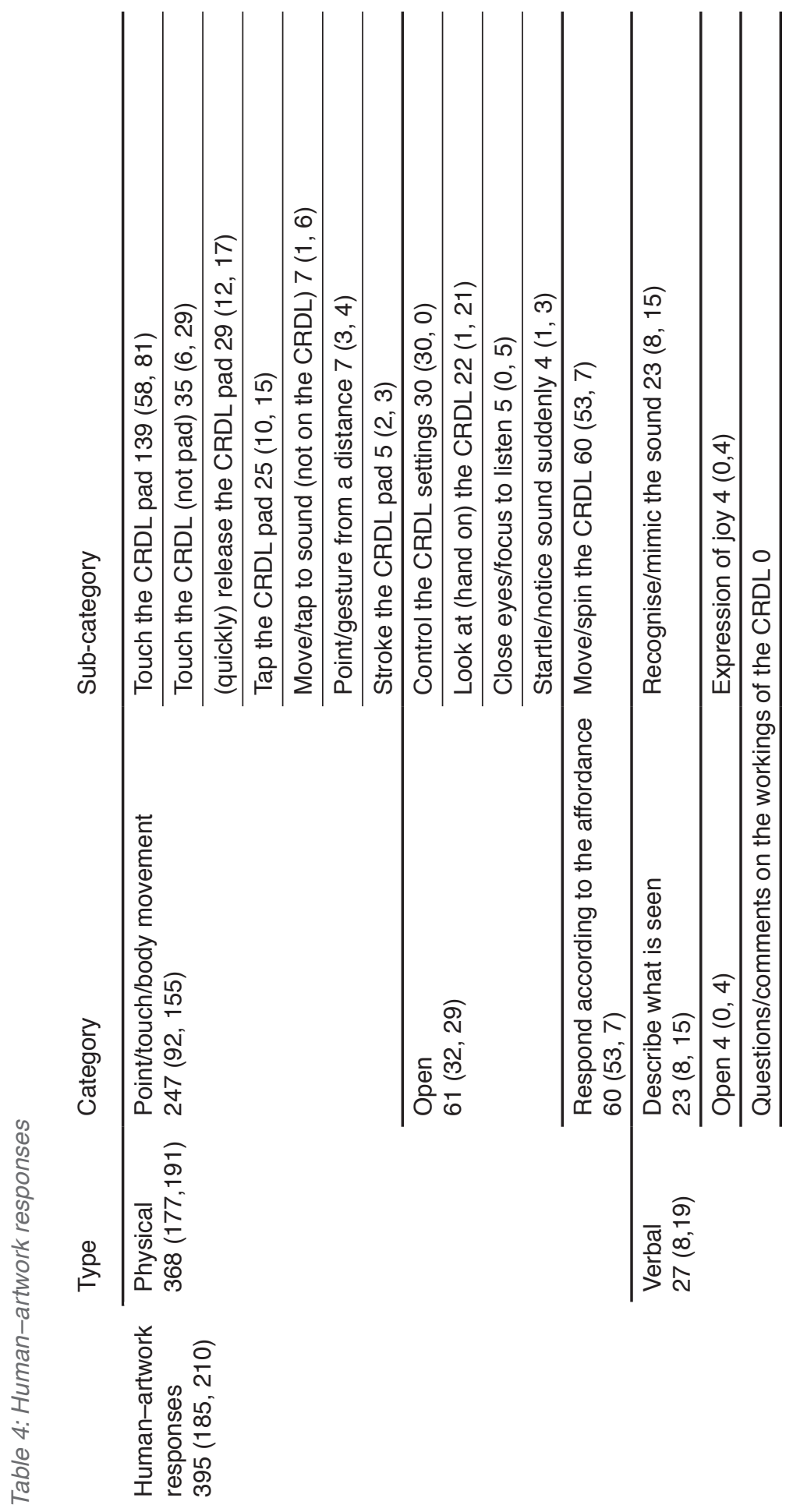




\section{Chapter 5}

touch and encourages experimentation with different types of touches on the arms and hands because the produced sound changes accordingly. Additionally, the sounds the CRDL produces sometimes trigger memories and provide themes to start and support conversation. The large amount of discussion about the controls, functioning and purpose of the CRDL can be attributed to the novelty of the CRDL and will probably diminish over time.

To involve a large group is challenging. Caregivers and activity supervisors often had a hard time making multiple residents close a circle of hands and make them understand the outer edges should touch the CRDL pads. All caregivers and activity supervisors eventually switched to several small groups (three people) or individual interactions with the residents (two people) while the other participants watched.

\section{Future development of the CRDL}

All caregivers, activity supervisors and residents agreed the CRDL looked well designed, rich textured and luxurious. The material used to cover the device was soft and smooth to the touch. However, the CRDL could benefit from a design iteration, as residents did not initially understand that the CRDL was designed to be touched. Additionally, the contrast between the touch pads and the wooden body of the CRDL was low; thus, it is unclear where a participant or user needed to place their hand. Because residents have to undertake two actions at once (place a hand on the felt pad and simultaneously use the other to touch someone else), they often forget that their hand needs to be on the felt pad. As a result of the rounded design of the CRDL, their hand slid off and the interaction was interrupted. The felt pad could be redesigned in such a way that a grip or hole is added so the hand is less likely to slide off when not actively kept in place.

The differences in interests, visual and auditory functioning and mental capabilities between individuals who live in a closed nursing home ward are large. A uniform volume, for instance, does not cater to the whole group; while some did not even register the sounds when at full volume, others became annoyed because of the loud "noise". Additionally, the interface to adjust volume and select another soundscape is too hard to reach for the caregivers and activity supervisors. The buttons also seem to be too deep to reach comfortably.

In order to make it easier for people who live with severe dementia to engage with the CRDL and for people who need a more complex challenge to remain engaged for a longer period, the design should incorporate opportunities for differentiation to address different needs and capabilities. The current soundscapes could be expanded with additional sounds and pieces of recognisable music to cater to different individual preferences (tailored content) and cognitive functioning. More research and development are required. 


\section{Responses to the CRDL}

\section{Study limitations}

The current study was explorative; it investigated how groups of nursing home residents respond to the CRDL. Effects on the emotional state and/or wellbeing of the residents during and after the sessions were not studied and no differentiation in cognitive functioning has been made when selecting the participants.

If a resident carried out two or more types of response at the same time, these were coded in all corresponding categories. This has influenced the total number of responses, possibly overstating some responses.

Moreover, the duration of interactions was not measured, which might have distorted some results. For example, when CRDL was touched, this was recorded only once. Because the duration is not taken into account, it has the same value as a quick glance or a touch that occurred while CRDL was continuously touched.

\section{Implications for research}

The results of this study illustrate the potential of interactive devices such as the CRDL in nursing home environments. In order to more fully understand the potential of the CRDL, its use should be studied in different group and individual sessions and the effects of tailored content, adjusted to individual preferences and/or stages of cognition should be explored. Finally, the effects of using the CRDL on the general wellbeing of nursing home residents should be studied.

\section{Implications for practice}

The CRDL has the potential to evoke interactions in the form of touches between residents and caregivers that otherwise would not occur as often or consciously. Furthermore, it is suited to start and support conversations in a group.

When the CRDL is used in a group setting during routine care, the session should be guided by an experienced caregiver, preferably an activity supervisor or music therapist. Some familiarisation and practice with the CRDL, such as knowing about and using the different settings and getting used to its possibilities to activate and engage residents, are advised. To make a group session work, a quiet environment with little sensory stimulation is advised.

\section{Conclusion}

The results of this study show that the CRDL can help caregivers and activity supervisors to use touch as an alternative way to make contact with groups of their residents. The potential for use of the CRDL in private sessions (two people) and as a tool to (re) establish contact with friends and family could also be further studied. The use of the CRDL requires some practice on the part of the therapist or staff member. Design improvements and differentiation of sounds and soundscapes may improve overall experience and better meet individual needs or preferences. 

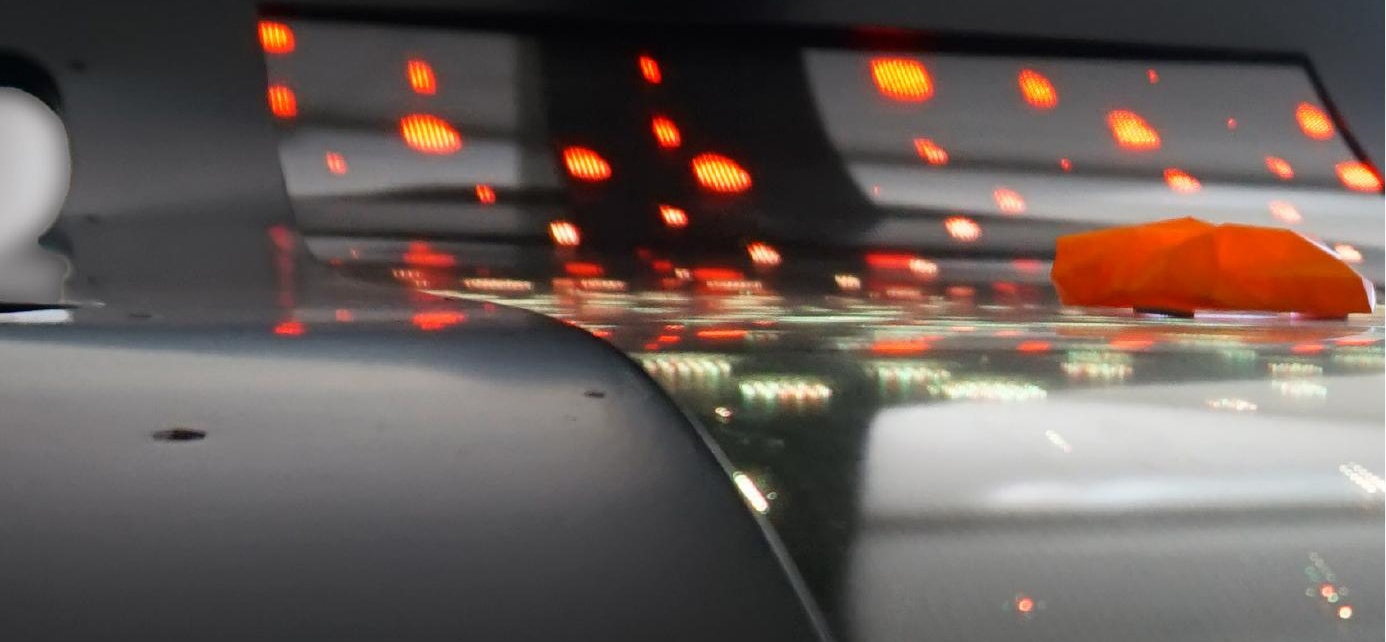

8
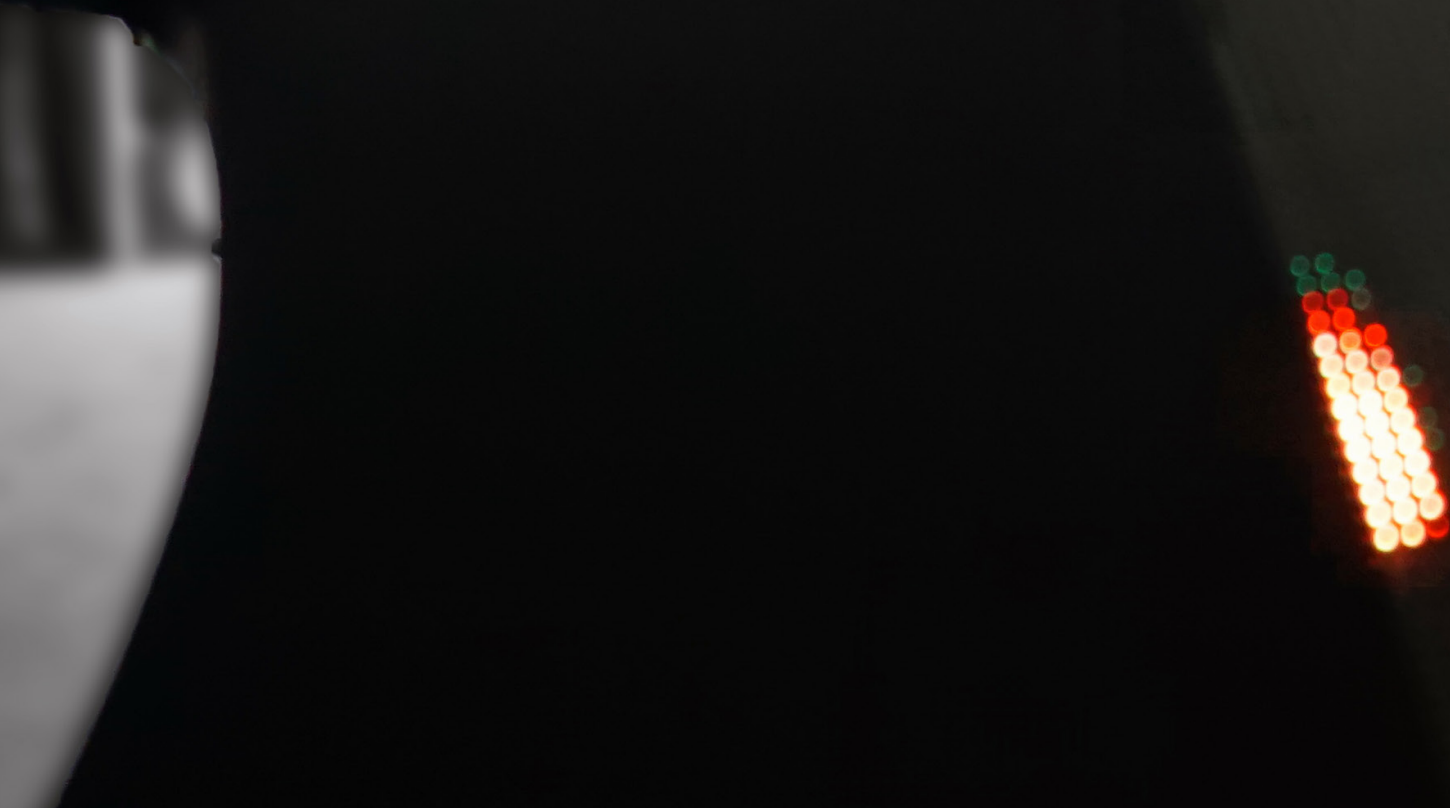
Chapter 6.

Ilow nursing home

residents respond to the

interactive art installation

'Morgendauw';

A pilot study

Tom Luyten

Susy Braun

Susan van Hooren

Luc De Witte 


\title{
Chapter 6
}

\begin{abstract}
In This study we investigated how nursing home residents responded to the abstract interactive art installation 'Morgendauw', which was specifically designed for this study. Overall, residents did not seem to notice Morgendauw. Only 15 interactions over the course of 14 hours were noted and almost all of them were initiated by someone of the nursing home staff, physiotherapy students or visitors $(n=12)$.

When prompted and/or directed, the initial threshold of noticing and approaching the installation was quickly overcome. Residents in general needed little explanation of the interface. Interactions lasted for about 3 minutes on average.

Although all stakeholders were involved in designing and implementing Morgendauw, very few responses were observed during the study. Morgendauw seems able to evoke responses in both the residents and their caregivers. However, the location in which Morgendauw was placed during the study or the characteristics of the installation seem to create a threshold. Further research should focus on the importance and the effects of context when designing and implementing an (abstract) interactive art installation in a nursing home environment.
\end{abstract}




\section{Responses to the Morgendauw}

\section{Introduction}

"Even when we lose our mind, we can still recognise beauty" (Sagmeister, 2016). This quote is based on research by Graham et al. which shows that people who live with Alzheimers' Disease still have aesthetic judgement, although their condition causes cognitive disruption in most other respects (Graham et al., 2013). When art is present in the living environment of people who live with cognitive problems, it can have beneficial effects. A review by Daykin et al. compared 600 papers and found art can reduce anxiety and depression in people who reside in mental health care (Daykin et al., 2008).

However, providing nursing home residents access to art requires some extra thought. Simply gazing upon an artwork and interpreting it from a distance on their own might become difficult due to the nature of their cognitive and/or physical state. If we want to extend their experience beyond just a short encounter of "something beautiful", we have to take the specific characteristics of nursing home residents into account when presenting and even while creating art. A recent program by MOMA New York, show that art in a museum context positively changes the mood of both the persons with dementia and their caregivers (Rosenberg, 2009). The key to the success seems to be 'interaction'. An innovative solution for the nursing home might lie in a type of art where the interactivity is part of the work itself.

\section{Interactive art}

One way to define interactive art is to oppose it to non-interactive art. An example of noninteractive art is a painting. When a painting is created, the artist is in complete control of the process. He or she lays every brush stroke and decides when the work is finished. Afterwards, a viewer can interpret it by looking at it from a distance.

In contrast, interactive art transforms a passive viewer into an active participant. Not only does the viewer become part of the artwork, but he/she has a role in the final outcome. Every interaction with an interactive artwork produces a different result. It makes the experience personal, and it is automatically catered to individual abilities. Because it can be explored by trying out, interactive art can be considered to have a low threshold to participate. No prior knowledge is needed. Examples of interactive art include "Water Light Graffiti" by Antonin Fourneau (Fourneau, 2013) (Figure 1. A), Audience by Random International (Random-International, 2008) (Figure. 1. B) or Scattered Light by Jim Campbell (Campbell, 2011) (Figure 1. C).

\section{Abstract interactive art in elderly care}

Just placing an existing interactive artwork in a nursing home residence, without taking the specific cognitive and physical conditions of the people living there into account, would be ill-considered. Previous studies have observed the responses of nursing home residents while interacting with interactive artworks that were explicitly designed with and for nursing 


\section{Chapter 6}

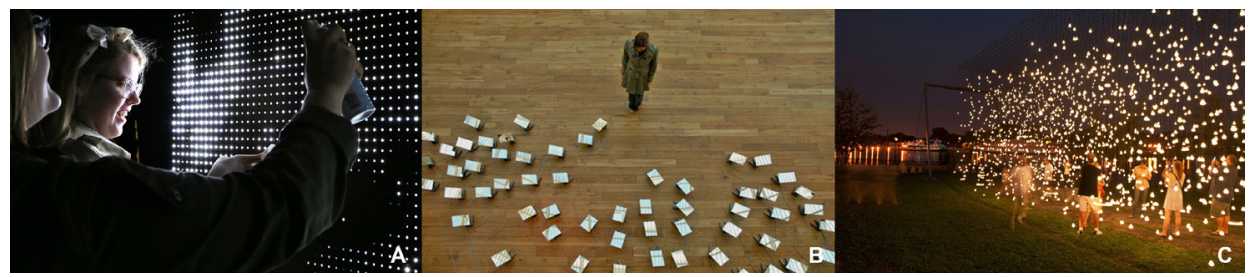

Figure 1: Examples of interactive art

home residents (Luyten et al., 2018b, Luyten et al., 2018a). These artworks (VENSTER, fig 2A, CRDL Figure 2B) translated reminiscence therapy and expressive and therapeutic touch therapy into an interactive environment and object respectively. The results show that these types of artworks evoke responses in nursing home residents and provide (informal) caregivers with new, exciting ways to engage their residents.

Abstract forms of interactive art have yet to be studied in the nursing home environment. Abstract multi-sensory experiences, such as provided by multi-sensory rooms and therapy have shown to increase social behaviour, counteract boredom, increase alertness and improve sleep quality in people with dementia (Baker et al., 2001, Sánchez et al., 2016a, Sánchez et al., 2016b, Sánchez et al., 2013, Todder et al., 2016). An abstract interactive art installation might provide a similar experience, without the need for a dedicated room, timeslot or caregiver to be present and displayed with a more "mature" aesthetic.

\section{Morgendauw}

Morgendauw ('Morning Dew' in English) (Fig 3) is an abstract, interactive artwork. It draws inspiration from multi-sensory rooms and experiences and presents a similar experience, without the limitation of a set time and place, with the aesthetics of an (interactive) artwork

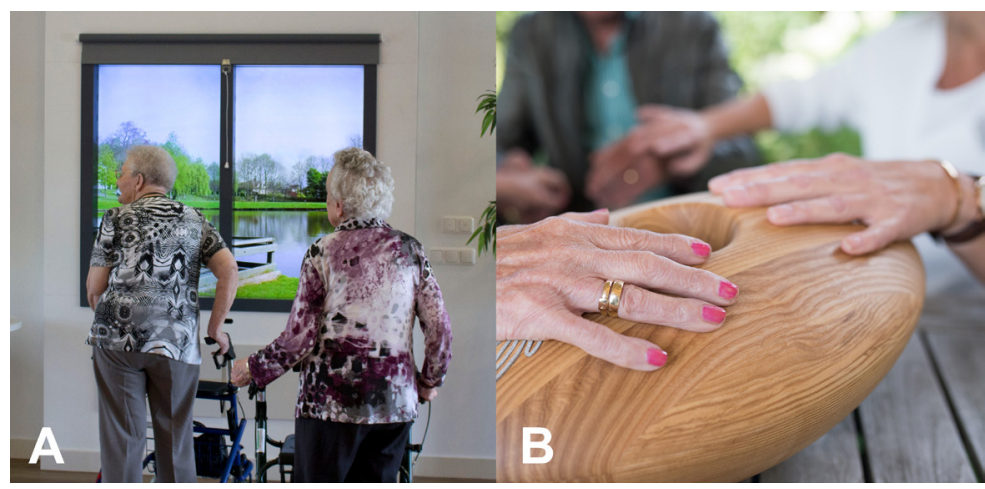

Figure 2: The interactive artworks VENSTER and CRDL 


\section{Responses to the Morgendauw}

and potentially without the need of a professional to guide the resident. Morgendauw was designed to provide short, meaningful interactions to escape the routine of daily life and promote introspection. Physically, Morgendauw is a black, table-like installation, shaped like the silhouette of a larger-than-life oak leaf. The surface of the leaf consists of touchreactive LED panels.

Morgendauw shows a constant stream of coloured particles, which resemble a stream of water flowing downhill. The colour, direction and velocity of the particles are influenced by the current weather conditions in one of five pre-programmed cities (Eindhoven, Quebec, Spitsbergen, Tokyo and Kaapstad). Every five minutes a different city is automatically selected.

When the surface of Morgendauw is touched, or an object (e.g. stone) is placed on it, the stream of particles will react and find a way around the hand or object. This results in a change of composition and a distortion in the particle system that will try to find a new balance. This choreography of light is augmented with an ambient soundtrack and subtle nature sounds.

The appearance and interactions of Morgendauw were developed in co-creation with people who work closely with the residents of the nursing home (managers, activity supervisors and caregivers) as early as the initial concept and iterated and tested in dialogue with these stakeholders and the residents themselves (Luyten et al., 2017b).

In This study we investigated how nursing home residents responded to the abstract interactive art installation 'Morgendauw', which was specifically designed for this study.

\section{Methods}

This study was set up and carried out as an explorative observational study. It took place at a nursing home facility in the south of the Netherlands. The installation was located at an indoor public square, where an open and a closed ward intersect. Both facilities house people who suffer from psychogeriatric disorders, often combined with physical limitations.

\section{Design}

The installation was observed for two days, from 10 AM to 5 PM in a semi-public square (Fig 4). The square was semi-public because it was freely accessible by caregivers, visitors and residents from other wards at any time. Residents of the closed ward, however, were unable to enter the square without guidance. Morgendauw (Figure 4A) was turned on, its soundscape audible when passing by and five 3D printed rocks were scattered on the surface. 


\section{Responses to the Morgendauw}

The researcher was seated outside direct view at a nearby table (Figure 4B). A single wide-view video camera (Figure 4C) captured the participants' responses, which allowed repeated display afterwards.

\section{Ethical considerations}

The research protocol was approved by the local ethics committee (METC Atrium, Orbis, Zuyd; 14-N-100). The ethical committee approved the spontaneous way participants were selected and included. No actual consent form was completed and this was given an exempt status. All residents, their legal representatives, the professional caregivers and physiotherapy students doing an internship were informed about the upcoming study through an information letter, two weeks before to the study. They could refuse participation up to and during the study.

\section{Study population}

During the time of the study, 22 residents were living in the open ward, another 22 in the closed ward, all of whom were unable to live independently due to a combination of cognitive and physical problems. No prior selection of participants was made. Participants were included in the study as soon as they expressed interest in Morgendauw by approaching or touching the installation during the days this study was carried out.

\section{Data collection}

A researcher (TL) was present during each observation. The observer kept his involvement to a minimum. He only interfered when addressed directly by someone to answer questions regarding the installation. Field notes were taken to complement the recordings. Every time a resident, visitor or caregiver expressed interest in Morgendauw by approaching it, touching it or discussing it from a distance, a recording was remotely started. The recording was ended when the person in question stopped interacting with Morgendauw and left. The moment from start to finish is referred to in this article as an "interaction". An interaction is a combination of many responses.

\section{Data analysis}

All recorded visible and audible responses were transcribed and coded. When the coding of a response was unclear, two other researchers could be consulted $(\mathrm{SB}, \mathrm{SvH})$ to reach consensus.

The framework, based on the results of a literature review on "Participant Responses to Physical, Open-ended Interactive Digital Artworks" (Luyten et al., 2017a)(Figure 5), distinguishes between human-human and human-artwork responses, divided further into verbal, physical and cognitive/emotional responses. Cognitive/emotional responses were not noted in this study. Interpretation of facial expressions or body language of the participants 


\section{Chapter 6}

concerning emotions or cognitive processes is unreliable due to the complexity of some of the residents' cognitive condition and the absence of the voice of the residents themselves. All coded responses were organised in mind maps, using MindJet MindManager@ to provide a general overview.

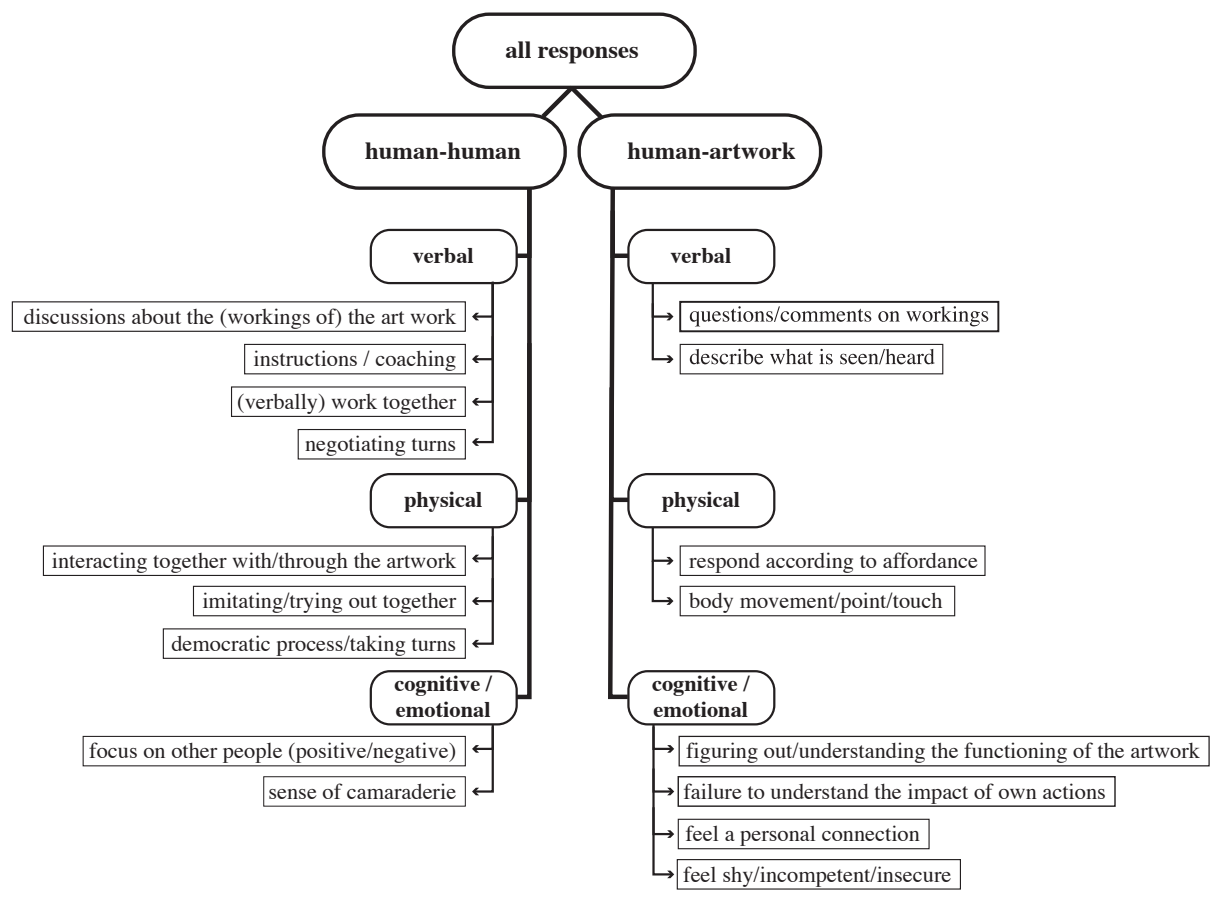

Figure. 5: An overview of the coding framework

\section{Coding of responses}

When only one person was involved, and his/her response was directed towards Morgendauw, the response was coded as "human-artwork". Responses in which two or more people were involved and their responses were directed towards each other were coded as "human-human". When people simultaneously directed a response towards Morgendauw and each other, it was coded as both human-human and human-artwork.

All understandable verbal feedback, either directed towards Morgendauw or to another person while interacting with Morgendauw, was categorized as "verbal responses". The same accounts for al distinguishable physical actions/responses. Responses were also placed into one or more corresponding categories of the framework, or got the label 'open' if they did not fit an existing category. By clustering similar responses, sub-categories emerged which are specific to Morgendauw. For example, the category respond according to affordance holds the subcategories move rock on Morgendauw and pick up/place rock on Morgendauw. 


\section{Responses to the Morgendauw}

All actions unrelated to the installation were coded as "not important to this study" and disregarded (e.g. conversation about the upcoming concert).

For each response, an identifier in the form of a letter was added to mark the persons role (e.g: student, caregiver, resident); when two or more people were involved, the identifier of the initiator was put first. If a person displayed two or more types of response at the same time, the response was recorded in all corresponding categories.

\section{Results}

After sending the information letters, no rejection to participate was received. 14 hours of observation, spread over two days, resulted in 42 minutes of recorded responses. 15 interactions took place, involving 23 people (10 residents, three physiotherapy students, four caregivers, one manager, four visitors and one researcher). The average duration of an interaction was 3:18 minutes. The shortest interaction lasted 21 seconds, the longest was 8:44 minutes long. In total, 333 responses were recorded (100\%).

The data is presented in tables 1 through 3, showing absolute numbers. Categories and subcategories are arranged in descending order from most to least occurrence. Two numbers between brackets respectively show the number of responses initiated by professional (a caregiver, manager, physiotherapy student or researcher) and the number of responses initiated by a resident.

A general overview of all responses (Table 1) shows that human-artwork responses make up for $60 \%(n=199)$ of all recorded responses. All but one response was physical of nature and most of the human-artwork responses were directed towards Morgendauw by a resident $(n=127)$. Human-human responses amount for $40 \%(n=134)$ of all responses and most of them are initiated by professionals (caregivers, physiotherapy students, managers or a researcher) $(n=96)$. They are predominantly verbal of nature $(n=111)$, while physical responses amount for $17 \%$ of all human-human responses $(n=23)$.

Table 1: An overview of all responses

\begin{tabular}{llll} 
All responses & Human-artwork & Physical & $198(72,126)$ \\
\cline { 2 - 3 } $333(168,165)$ & $199(72,127)$ & Verbal & $1(0,1)$ \\
\cline { 2 - 4 } & Human-human & Verbal & $111(82,29)$ \\
\cline { 2 - 3 } & $134(96,38)$ & Physical & $23(14,9)$ \\
\hline
\end{tabular}




\section{Chapter 6}

\section{Human-artwork responses}

\section{Physical responses}

All human-artwork responses are presented in table 2. Most of the physical human-artwork responses involved the 3D printed rocks that were present on the surface of Morgendauw $(n=108)$. People responded according to the affordances $(n=108)$ of a rock in a stream of water: they moved $(n=45)$, touched $(n=10)$, flicked $(n=16)$, picked up and placed $(n=29)$ the $3 \mathrm{D}$ printed rocks on the surface, thereby blocking and altering the particle flow or touched/ caressed the surface of Morgendauw itself $(n=8)$. Most of these responses were carried out by residents $(n=60)$, largely verbally initiated and/or encouraged by a physiotherapy student or caregiver $(n=48)$.

The open sub-category $(n=57)$ mostly comprised residents looking at the flow of particles on Morgendauw with focus $(n=50)$. The mesmerizing characteristic of the particles flowing down and arranging themselves around the rocks seemed to fascinate. Four residents directed a smile directly towards Morgendauw while interacting. Lastly the instruction sheet was read five times by visitors and physiotherapy students and Morgendauw was raised or lowered by physiotherapy students on three occasions to accommodate residents.

In the sub-category Body movement/point/touch residents got rolled towards Morgendauw by a physiotherapy student or caregiver $(n=8)$ or visitors and residents approached Morgendauw themselves $(n=6)$. Physiotherapy students or caregivers gestured from a distance $(n=6)$, explaining something or encouraging someone else. One resident tapped on Morgendauw as if it were a tablet.

\section{Verbal responses}

Only one verbal response towards Morgendauw was recorded. It involved a resident counting the cushioning feet on the bottom of one of the 3D printed rocks aloud.

\section{Human-human responses}

\section{Verbal responses}

All human-human responses are presented in table 3. The larger part of all humanhuman responses were recorded in the verbal category $(n=111)$. The most prominent sub-category consisted of asking for instructions or providing instructions $(n=59)$. Almost all encouragement was given by physiotherapy students and caregivers $(n=40)$, while residents were mostly the ones asking for instructions $(n=16)$.

The sub-category on discussions about the (workings of) the work accounts for 45 of all human-human responses. Residents and personnel equally comment on the function and concept of Morgendauw $(n=25)$ and ask or provide each other with opinions about it $(n=10)$. Other sub-categories show some people commenting on the music $(n=3)$, on the 
Responses to the Morgendauw
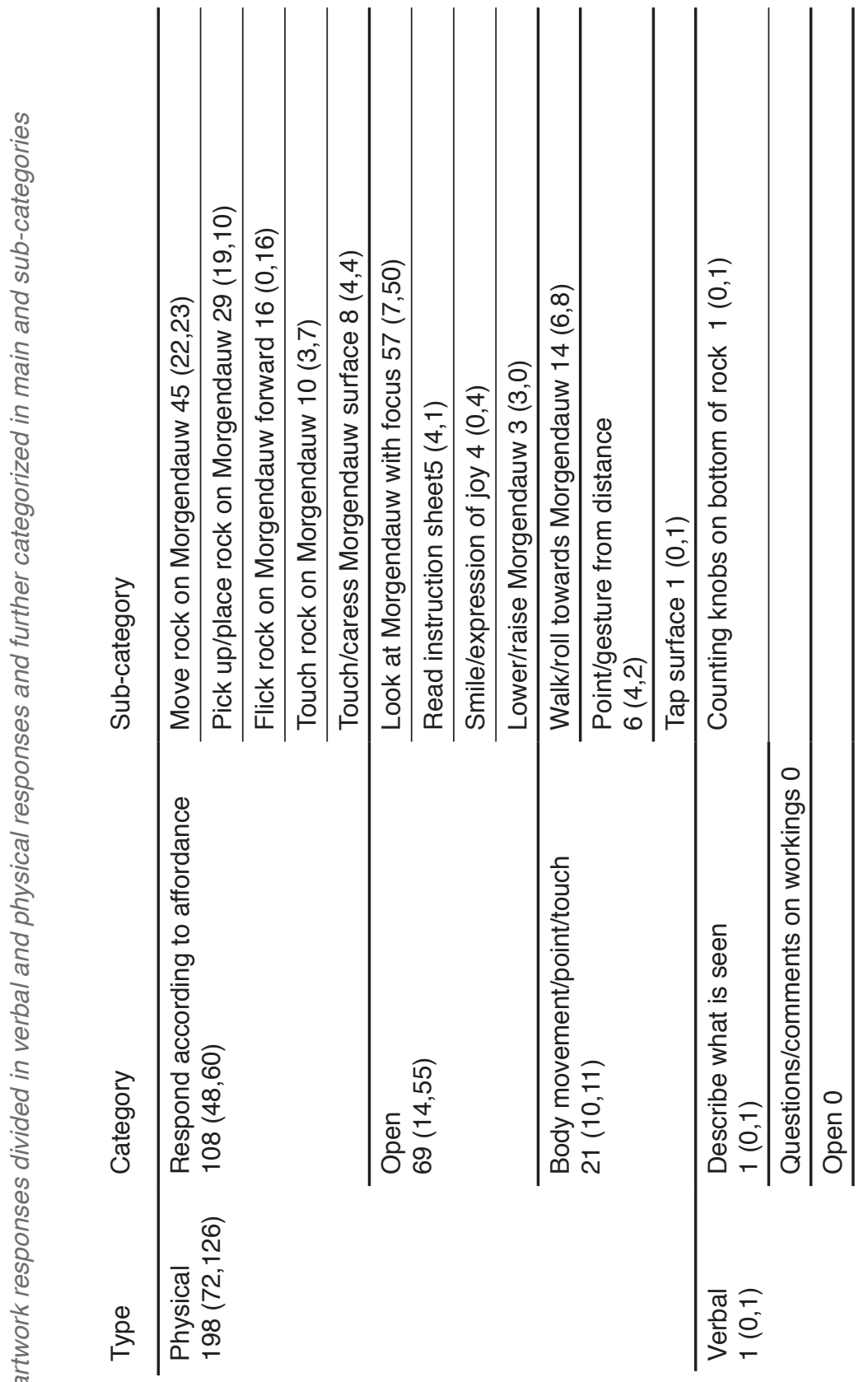


\section{Chapter 6}

visuals $(n=2)$ and one instance of someone commenting on the warmth of the Morgendauw surface $(n=1)$. Finally, physiotherapy students and caregivers asked residents to remember something connected to the Morgendauw experience (e.g. playing a game of shuffleboard with the rocks) and one resident mentioned the water reminds him to go to the toilet.

Other verbal human-human responses included residents asking for clarity and asking to stop $(n=3)$, or expressing their wonder $(n=3)$. Only one instance of residents and personnel verbally working together was noted $(n=1)$.

\section{Physical responses}

Most physical human-human responses consist of imitating someone else, or trying out Morgendauw together $(n=15)$ : physiotherapy students, caregivers, and one resident provide example movements and interactions $(n=10)$, others mimic those movements. Three caregivers and two residents look at another person while they are interacting, supposedly to learn $(n=5)$. Interacting with and through the artwork is made up of four people smiling at each other or making non-verbal contact $(n=4)$, equally initiated by personnel and residents.

In three instances a stone was handed to another person, all initiated by caregivers or physiotherapy students $(n=3)$ and lastly one resident looked amazed towards personnel $(n=1)$.

\section{Discussion}

The aim of the study was to investigate how nursing home residents respond to the abstract interactive art installation Morgendauw. The interactive artwork draws inspiration from multisensory rooms and therapy and presents a similar experience, without the limitation of a set time and place, with the aesthetics of an (interactive) artwork and potentially without the need of a professional to guide the resident. It was developed in co-creation with all stakeholders in the nursing home and thoroughly tested with nursing home residents.

Overall, residents did not seem to notice Morgendauw. Although the soundscape should have been audible for most people while walking past the installation and it was constantly displaying a movement of lights, residents as well as staff largely ignored the installation when passing it. Only 15 interactions over the course of 14 hours were noted and almost all of them were initiated by someone of the nursing home staff, physiotherapy students or visitors $(n=12)$. The one resident who did engage herself on three occasions appeared in a good cognitive state.

When prompted and/or directed, the initial threshold of noticing and approaching the installation was quickly overcome. Residents in general needed little explanation of the interface. Interactions lasted for about 3 minutes on average. The visuals seemed mesmerizing and resulted in a concentrated gaze upon the installation. The physical rocks placed in the abstract water were moved around and the effects it had on the particle system were observed. 


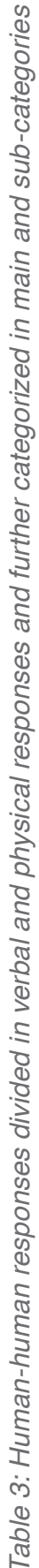

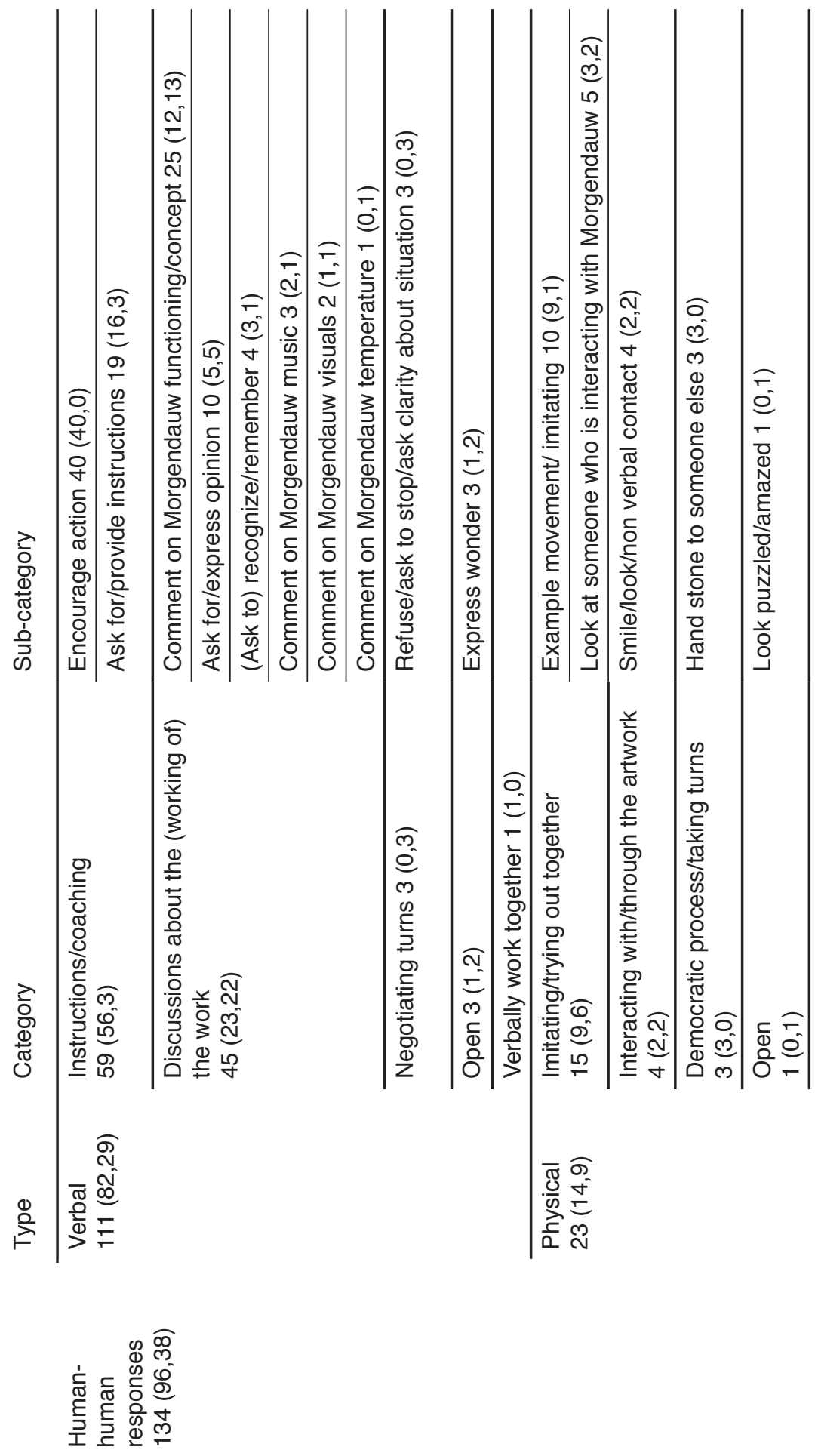




\section{Chapter 6}

Morgendauw seems able to evoke responses in both the residents and their caregivers. However, the location in which Morgendauw was placed during the study or the characteristics of the installation seem to create a threshold. The location was associated with quickly passing, providing daily care and meals. Caregivers and visitors were not inclined to "see" the installation and it seems that the installation itself does not entice people enough to approach it.

Although all stakeholders were involved in designing and implementing Morgendauw, very few responses were observed during the study. From earlier studies we know that an abstract interactive artwork could work in a nursing home environment (Luyten et al., 2018b). Further research should focus on the importance and the effects of context when designing and implementing an (abstract) interactive art installation in a nursing home environment.

\section{Study limitations}

The limited timeframe of the observations (2 days) and the variable availability of staff and residents may have influenced the amount of the recorded responses.

Because of the observation method used (video observation) and the inability of the residents to reflect on their own behaviour no cognitive/emotional responses were recorded.

The duration of individual responses was not measured and the duration of the interaction as a whole was not taken into account when presenting the total number of responses. This might have distorted some results. When someone looked at Morgendauw with focus for instance, this was counted once, regardless of the time that this stare held.

If a resident carried out two or more responses at the same time, these were coded in all corresponding categories. This influenced the total number of responses recorded, possibly over-recording some responses.

\section{Implications for practice}

Morgendauw is able to facilitate short interactions that can take the mind of nursing home residents out of the daily routine. The interface is easily understood when shortly explained and/or demonstrated. Based on the results of this study, the sounds and visuals of Morgendauw seem to be mesmerizing and promote a moment of interaction. The installation can be used and enjoyed without the need to understand what's going on exactly, much like a module in multi-sensory room.

When Morgendauw is to be used in daily care, all stakeholders should be informed about the concept, the use and the possibilities of the installation in relation to the residents of the nursing home. This study also suggests that the place where Morgendauw is located is important. 


\section{Responses to the Morgendauw}

\section{Conclusion}

When residents were invited and nudged towards Morgendauw, they expressed interest, understood the interface and interacted with the artwork. However, the installation itself failed to entice people to interact. Staff and volunteers should be informed about its concept, possibilities and functioning. The location and context of an interactive artwork in a nursing home environment and its effect on the perception need more research. 



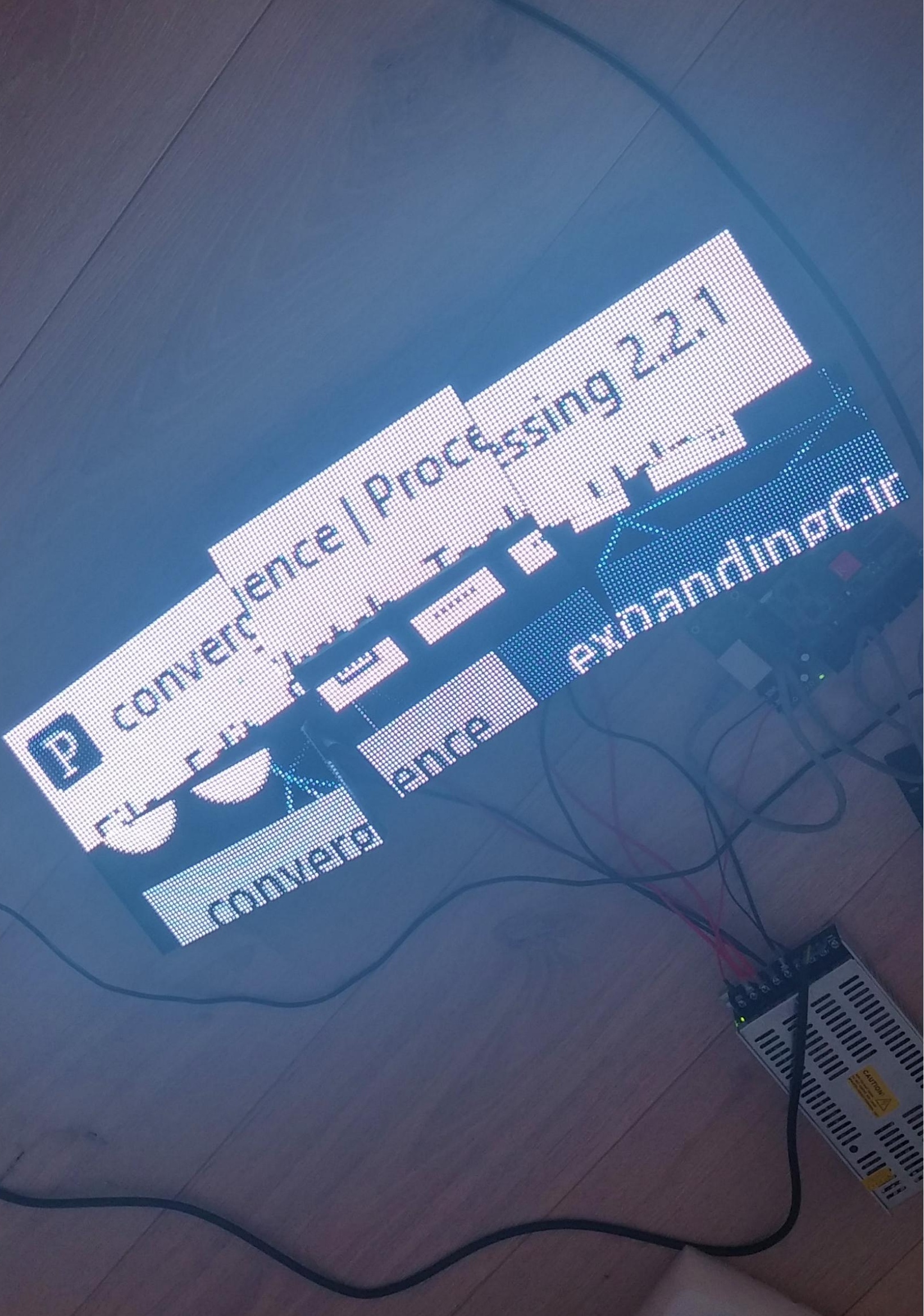


Chapter 7.

General Discussion 


\section{Chapter 7}

The main aim of this thesis was to explore the potential of interactive art as experienceoriented care technology in elderly care, specifically in the nursing home environment. Three sub-questions were formulated to achieve this aim:

1. How do you develop an interactive artwork for the nursing home environment?

2. (How) Do nursing home residents respond to interactive artworks?

3. Do the responses of nursing home residents differ, linked to the characteristics of an interactive artwork?

In order to answer these questions, the dissertation was performed in four phases (Figure 1, see introduction for more details):

\section{Interactive art as experience-oriented care technology in the nursing home?}
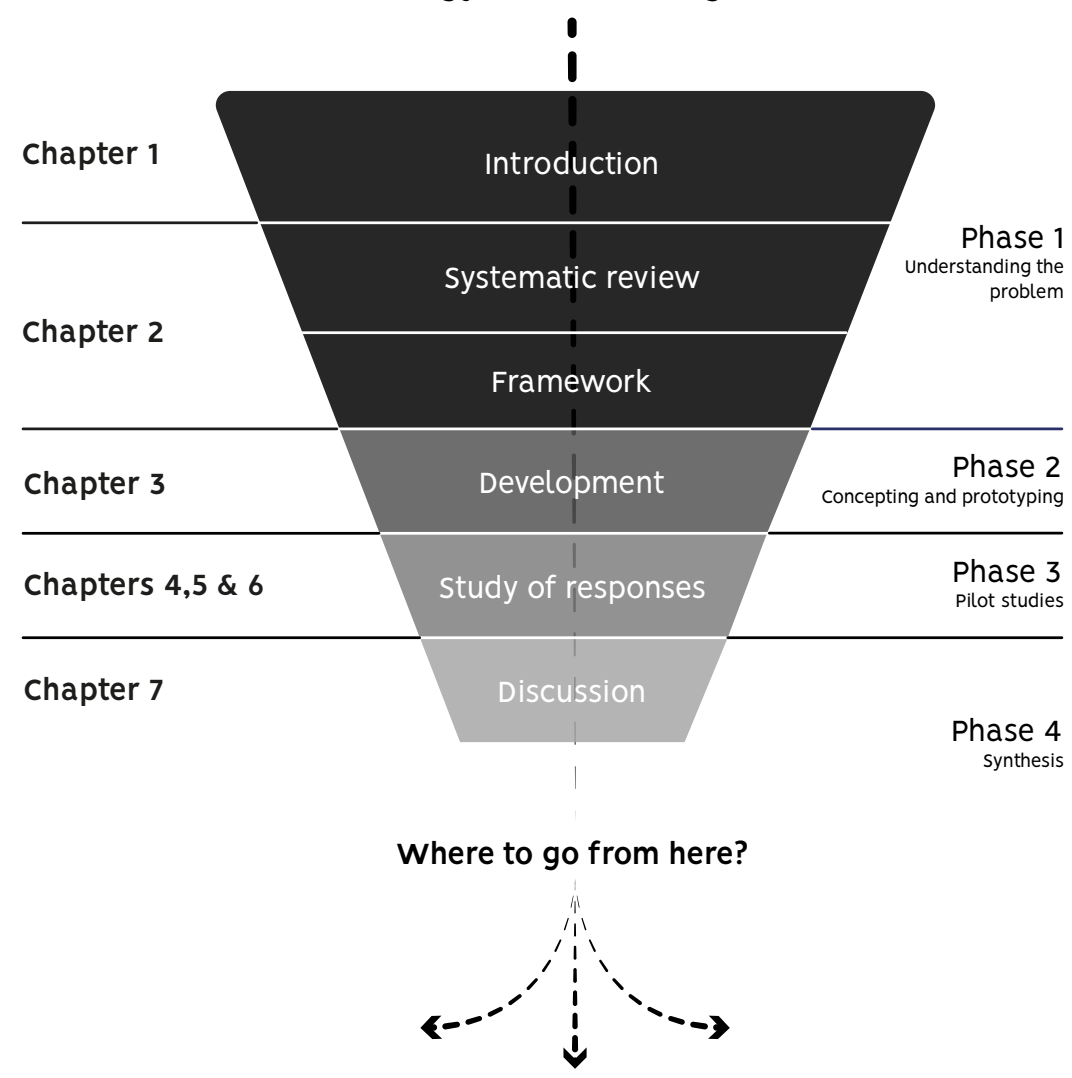

Figure 1: Overview of the chapter and phases of this dissertation 


\section{General discussion}

In this chapter, the main findings and methodological considerations for all phases are discussed and the above formulated sub-questions answered. Subsequently, the implications for (creative) practice and research are reported and future directions outlined (Where to go from here?).

\section{Main findings}

In the following, the main findings of this thesis are presented and discussed in the context of the themes of the four phases within this dissertation: 'Understanding the problem', 'Concepting and prototyping', 'Pilot studies' and 'Synthesis'.

\section{Phase 1: Understanding the problem}

In the introduction (Chapter 1) it was established that nursing homes lack the possibility for personal experiences. Specifically interactive artworks that are accessible at all times that can be enjoyed by residents on their own or together with somebody else, without the help of a professional caregiver are desired. It has been the goal of this thesis to establish whether interactive art can provoke responses in nursing home residents and to determine if responses could be linked to characteristics of the artworks, in order to potentially set a first step towards meaningful experiences for nursing home residents through interactive artworks.

It was decided in Chapter 2 to focus on physical open-ended interactive digital artworks, since these seemed to be a good match for open, personal experiences that can be enjoyed on different cognitive levels by one or multiple people simultaneously and thus suited to be 'always available' in the free time in between activities and therapies in the nursing home. Examples of physical, open-ended interactive digital artworks are 'Lunar' by Daan Roosegaarde (Chapter 2, Figure 5A), 'Starfield' by Lab212 (Chapter 2, Figure 5B), 'Water Light Graffiti' by Anthonin Fourneau (Chapter 2, Figure 5C), and 'Weather Worlds' by Design I/O (Chapter 2, Figure 5D).

The systematic review (Chapter 2) also reports the responses of people who interacted with physical, open-ended interactive digital artworks in a museum or media festival context

There is no consensus on the terminology used to describe different types of interactive artworks
(Luyten, Braun, Van Hooren, \& Witte, 2017). Interactive art manifests itself in many forms. There is no consensus on the terminology used to describe different types of interactive artworks. Artists and researchers that work with interactive art use a multitude of terms and combinations to describe different types of interactive artworks. Because of the need for a clear definition, scope and description of the type of artwork that would be developed and studied for the nursing home in this study, a combination of 23 different terms to carry out the literature search in a selection of databases was used. Despite the increasing 


\section{Chapter 7}

popularity of interactive art installations, only a few have been formally studied. Thirteen articles were identified that discussed the participant responses to 22 artworks (Bialoskorski, Westerink, \& Broek, 2010; Costello, Muller, Amitani, \& Edmonds, 2005; Deray \& Simoff, 2012; Gurion \& Jacoby, 2013; Her \& Hamlyn, 2010; Hespanhol \& Tomitsch, 2014; Hohl, 2009; Jacucci et al., 2009; Morgan \& Gunes, 2013; A. Morrison, Viller, \& Mitchell, 2011a, 2011 b; A. J. Morrison, Mitchell, \& Viller, 2008; E. Muller, 2008). The identified studies made use of different types of frameworks and methods to assess the responses, making it hard to compare the responses and find a possible connection between studied responses and artwork characteristics. Therefore, an alternative framework was developed (Figure 4, Chapter 4) that distinguishes between human-human and human-artwork responses, divided into verbal, physical and cognitive/emotional responses. Categories and sub-categories emerged through
A variety of verbal, physical and cognitive/emotional responses within and between visitors were noted the clustering of similar responses.

A variety of verbal, physical and cognitive/emotional responses within and between visitors were noted. Generally, participants displayed similar behaviour: The first thing people did when entering or approaching an interactive installation for the first time was deciphering how the artwork functioned. While doing this, they responded according to the affordance (Maier \& Fadel, 2009) of real or depicted objects. Recognition resulted in a more natural connection to the installation, while abstract content caused people to first take their time to figure out the general workings of the artwork. When the interface of an interactive artwork was not understood or figured out timely, the interaction was prematurely ended and the underlying meaning was not explored.

Presence of other people influenced the overall experience, although not in a clear or consistent way; strangers affected focus negatively for some, but did not affect others. People who knew each other interacted together longer with the artwork than strangers did and they felt their relationship was reinforced by the experience they shared.

The identified artworks varied from small table-top

No straightforward relationship between the characteristics of the artworks studied and the kind of responses reported could be identified installations to large, dark open spaces and had a broad range of interactive components and features. No straightforward relationship between the characteristics of the artworks studied and the kind of responses reported could be identified. However, some tendencies appeared to be present. Large installations (e.g. interactive walls) seemed to trigger people to use their whole body to interact; open and dark spaces promoted reflection, focus on the space for some people and made participants lose track of time. Small table top installations tended to evoke more considered, slow and sensual movements of the participants' hands. 


\section{General discussion}

\section{Phase 2: Concepting and prototyping}

Creating interactive art for a specific target population implies that the user is put at the centre of the design process. However, truly co-creating with someone is a challenge when you can't communicate directly or on a certain level of abstraction and complexity. Including nursing home residents with psychological difficulties (which

Co-creation methods are not an automatic guarantee for success in the nursing home was the case in the majority of included participants in this thesis/dissertatinon) as a full partner in the design process is therefore nearly impossible.

Co-creation methods are not an automatic guarantee for success in the nursing home. During the development of VENSTER all stakeholders could weigh in within the boundaries of the conceptual framework that was defined by the artist. It was well accepted by all stakeholders after implementation and used often. Morgendauw was developed by involving all stakeholders throughout the entire process. Morgendauw illustrates that more involvement of users does not necessarily translate into an artwork that is better comprehended or used more. Only consulting the end-users when the prototype is ready is dangerous as well: one could create something that is deemed unsuitable by and for the target audience. While there is room to have a more artist-centred or a more co-creation centred process to create interactive artworks for the nursing home, the "sweet spot" seems to be located in the middle of the spectrum (Figure 2).

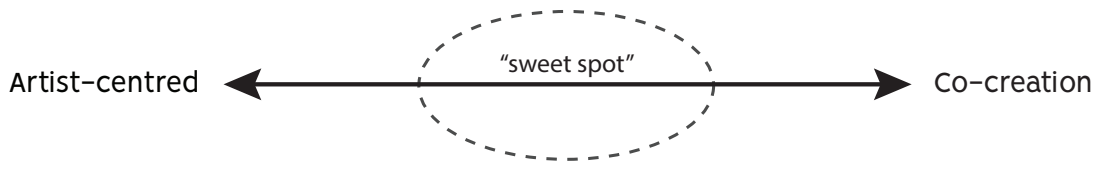

Figure 2: The sweet spot for creating an interactive artwork together with users seems to be located in the middle of the spectrum between artist-centred and co-creation

\section{Phase 3: Pilot studies}

In Chapters 4, 5 and 6 the responses of nursing home residents to the interactive artworks VENSTER, the CRDL and Morgendauw were studied (Luyten, Braun, Jamin, van Hooren, \& de Witte, 2018; Luyten, Braun, van Hooren, \& de Witte, 2018). All three artworks evoked responses from nursing home residents and their caregivers. Because of the many variables at play, it is not possible to link the influence of characteristics

\section{All three artworks evoked responses from nursing home residents and their caregivers}

of the artworks to the amount or type of responses directly.

The video-recorded material was coded by placing responses in the developed framework (Chapter 4, Figure 4).

The division between responses directed towards the artwork (human-artwork) and responses directed to someone else (human-human), as well as the 


\section{Chapter 7}

division between verbal and physical responses and general categories were preserved. Additionally, it was recorded whether the residents or the caregiver initiated the response and sub-categories emerged through clustering similar responses. These could be different for each artwork, underlining the differences in interaction between the artworks.

\section{VENSTER (Chapter 4)}

VENSTER (Figure 3) is a virtual window that connects the inside of the nursing home to a (real and fictional) outside world. It is designed so that nursing home residents can actively engage with its content, but can also lean back and just watch.

Observations of residents indicated that VENSTER prompted them to name or recognise what they saw. When (initially)

VENSTER prompted nursing home residents to name or recognise what they saw coached by a care provider, they actively engaged physically with the screen by pointing, gesturing and/or tapping. They asked questions about the content, on how the installation worked and sang or tapped along to the music. It seemed that content mattered a lot. The responses differed according to the type of content that was displayed on VENSTER's screens: during sessions with calming content (pre-recorded

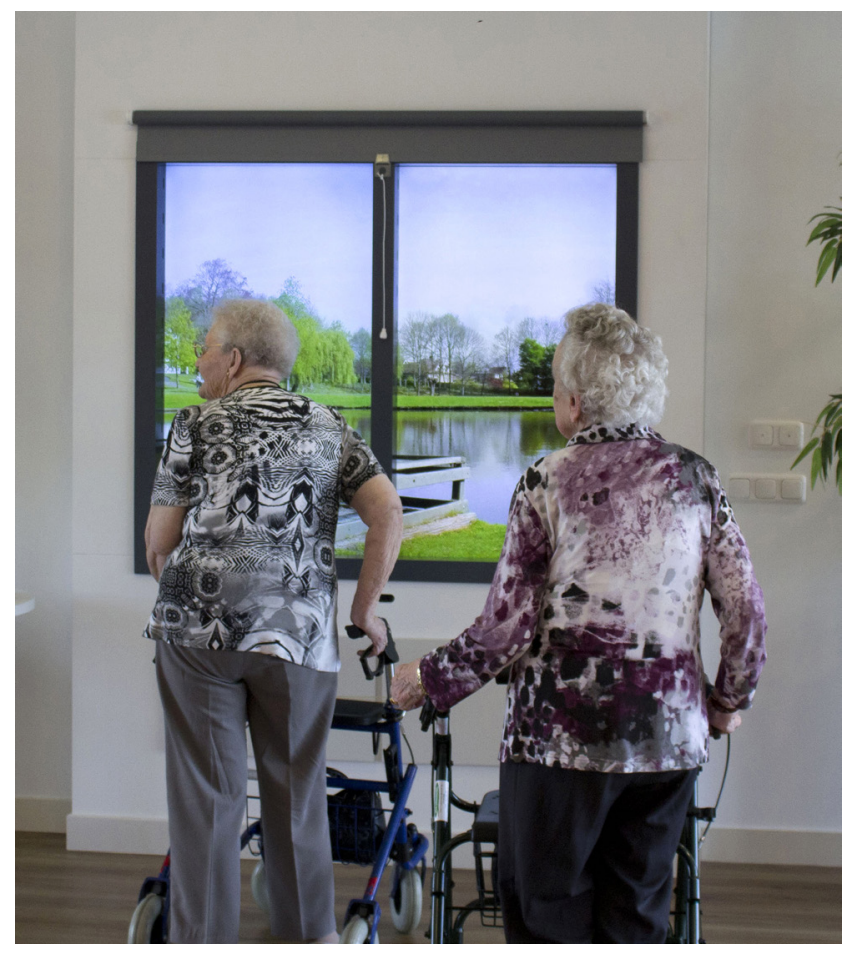

Figure 3: The interactive artwork 'VENSTER', nursing home 'Op den Toren', Nuth, The Netherlands 


\section{General discussion}

video content of relatively passive scenery) interactions were brief and limited. Some residents lost focus for minutes on end or fell asleep for the bigger part of the session. During sessions in which activating content was shown (pre-recorded video content with calls to action in it, e.g. a girl waving to the viewer), residents interacted throughout the whole session, mostly related to what was seen and/or recognized on the screen. Participants were generally calm and focussed for up to one hour and only one (non-professional) caregiver was needed to supervise and guide a group of up to six residents throughout the session. In contrast, a group size like this typically requires supervision of a minimum of two care providers and the atmosphere is generally (more) agitated. Sessions with interactive content (visuals that could be manipulated in real time by touching the VENSTER display) were short(er) (on average 30 minutes), rich in responses and needed constant guidance of a (non-professional) caregiver.

\section{The CRDL (Chapter 5)}

The CRDL (pronounced: 'the cradle') (Figure 4) is an interactive object that translates different types of touches into sound when people touch each other and the CRDL at the same time. The CRDL was created to stimulate touch

CRDL created opportunities for expressive touch in a group setting between nursing home residents and their caregivers or loved ones.

Observations of groups of residents indicated that the CRDL created opportunities for expressive touch in a group setting.

During the observed sessions, the CRDL generated an atmosphere of curiosity and playfulness by acting as an intermediary between people. It encouraged experimentation

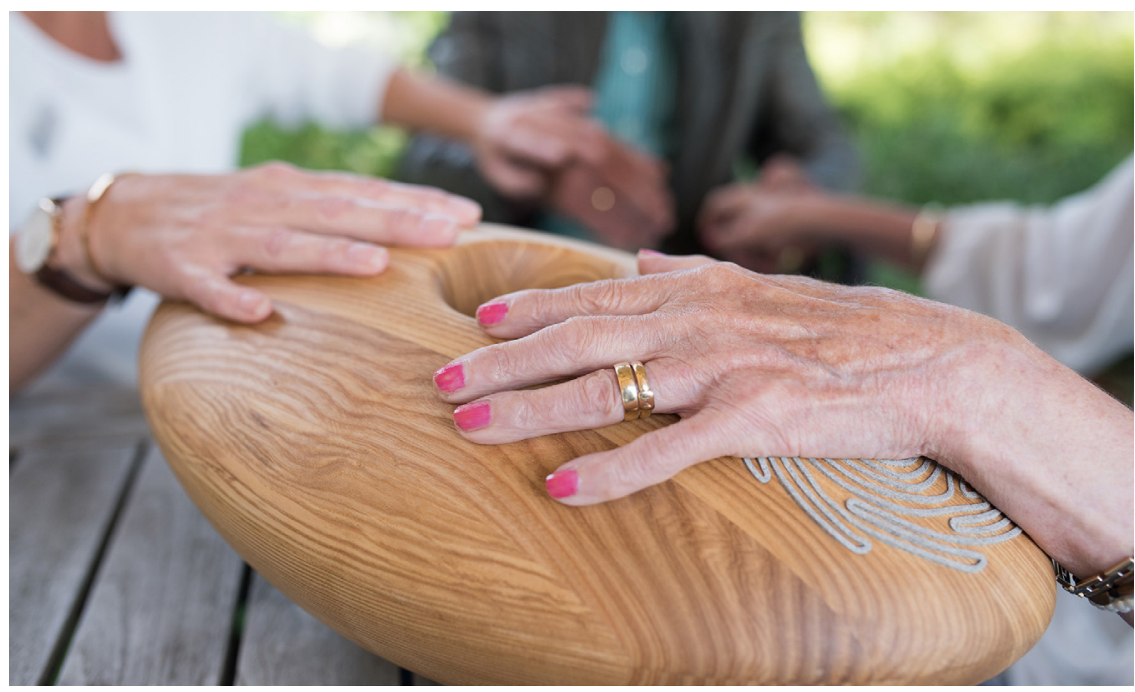

Figure 4: The interactive artwork 'the CRDL" 


\section{Chapter 7}

with different types of touches on the arms and hands. Additionally, the sounds of the CRDL triggered memories and provided themes to start and support conversation. Sessions lasted around half an hour on average.

However, to involve a large group with the CRDL proved challenging. It was hard to get multiple residents to close a circle of hands and make them understand the outer edges should touch the CRDL pads. Supervisors therefore eventually switched to several small groups (three people) or one-on-one interactions.

The visuals of Morgendauw seemed mesmerizing and resulted in a concentrated gaze

\section{Morgendauw (Chapter 6)}

Morgendauw (Figure 5) is a large table shaped like an oak leaf. By placing plastic rocks or moving your hands across the interactive surface, a system of flowing water particles can be distorted. Morgendauw draws inspiration from multi-sensory rooms and -therapy. It was created to be a contemplative installation that promotes an aesthetic, relaxing experience, meant for one or two people to enjoy.

During the observations residents as well as staff largely ignored the installation when

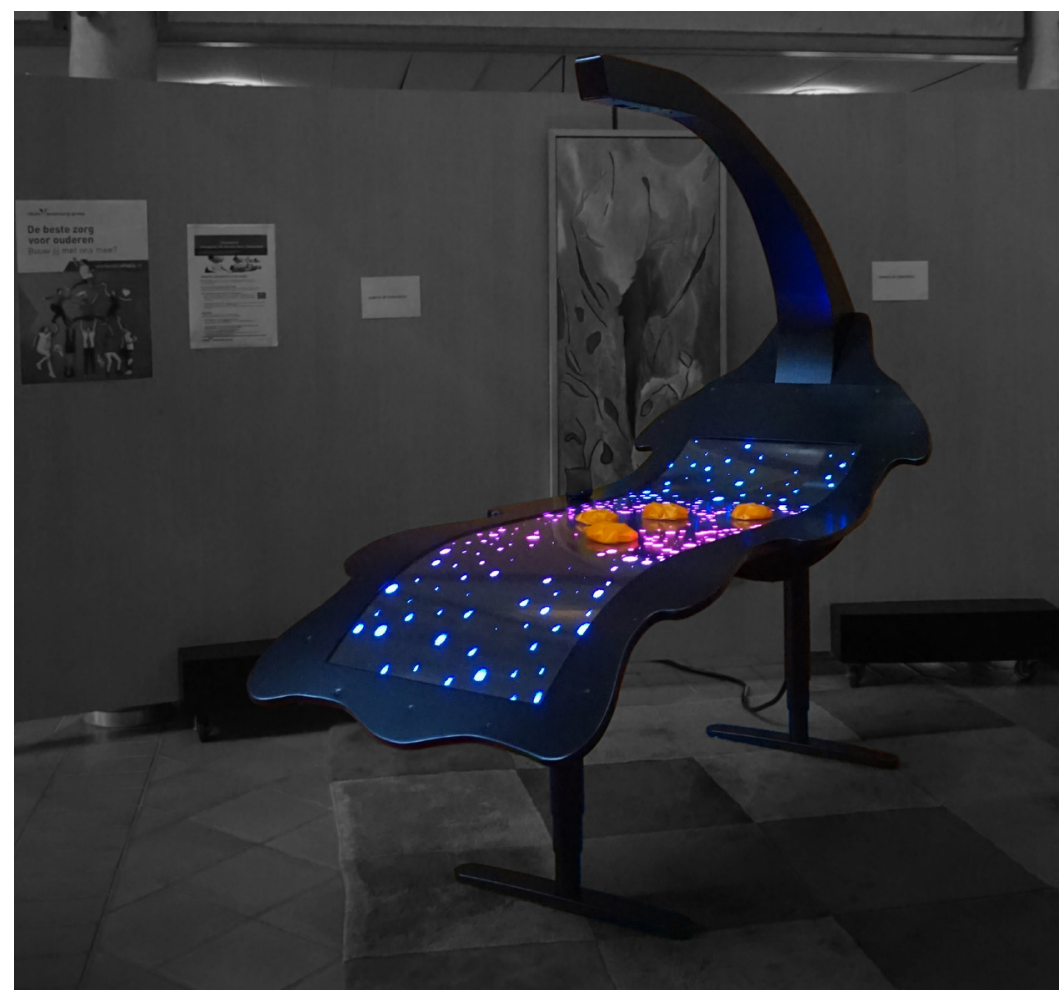

Figure 5: The interactive artwork 'Morgendauw', nursing home 'Brunswijck', Eindhoven, The Netherlands 


\section{General discussion}

passing it during their daily routines. If residents were invited and nudged towards the installation by a caregiver or visitor, they expressed interest, understood the interface and interacted with the artwork. Interactions were (very) short (about three minutes) and responses were initiated almost equally by a resident or someone else (caregiver or visitor). The visuals seemed mesmerizing and resulted in a concentrated gaze upon the installation. Physical rocks, placed in the abstract water on the surface of Morgendauw, were moved around and the effects this had on the particle system were studied by the residents.

\section{Phase 4: Synthesis}

In general, nursing home residents were hesitant to interact. Without nudges, encouragement and/or guidance from a (non-professional) caregiver, only a few residents were curious enough to try things on their own. Contrary to the results found in the literature on the responses of museum and media festival visitors to interactive artworks (Chapter 2), figuring out the interface was of no interest to the nursing home residents (Luyten, Braun, Jamin, et al., 2018; Luyten, Braun, van Hooren, et al., 2018). They seemed not to perceive it at all, or only as a hurdle. Nursing home residents responded

They seemed not to perceive the interface at all, or only as a hurdle according to the affordance of real or depicted objects (e.g. real, plastic stones were understood to block water, virtual snow was expected to behave like real snow when manipulated). Recognizable content in the form of (interactive video or sound of) people, children or places triggered (real or made up) memories and conversations. Abstract content (or interface elements) needed more explanation and guidance by a caregiver.

There was almost no direct social interaction between residents. They rarely interacted together, asked for instructions or additional information from each other, nor did they negotiate taking turns, either verbally or physically. Nursing home residents nearly exclusively communicated with the (non-professional) caregiver.

The average session time varied (Table 1). Sessions with VENSTER lasted around an hour,

Table 1: Amount of responses initiated by caregivers and residents, the average duration and amount of responses per hour of the sessions for VENSTER, the CRDL and Morgendauw

\begin{tabular}{lllll} 
& $\begin{array}{l}\text { Responses } \\
\text { initiated by } \\
\text { caregiver }\end{array}$ & $\begin{array}{l}\text { Responses } \\
\text { initiated by } \\
\text { resident }\end{array}$ & $\begin{array}{l}\text { Average } \\
\text { duration of } \\
\text { session }\end{array}$ & $\begin{array}{l}\text { Average \# of } \\
\text { responses/hour }\end{array}$ \\
\cline { 2 - 5 } VENSTER & 492 & 966 & 59 minutes & 163 \\
\hline the CRDL & 619 & 426 & $28: 36$ minutes & 438 \\
\hline Morgendauw & 168 & 165 & $3: 18$ minutes & 233 \\
\hline
\end{tabular}

The art of feeling connected 


\section{Chapter 7}

while the CRDL was used for half an hour on average and interactions with Morgendauw were as short as 3 minutes. This might be related to the type of interaction(s) needed to enable the experience (e.g. just sitting and watching VENSTER, compared to constantly touching the CRDL) and the richness of the possibilities offered by the artwork (e.g. the limited amount of possibilities offered by Morgendauw compared to the rich content database of VENSTER). The number of responses that occurred on average within an hour differed as well: VENSTER and Morgendauw don't need to be actively used to generate output, but when the CRDL and a person are not touched simultaneously, no sound is produced. This might explain the high number of average responses per hour observed during sessions with the CRDL when compared to VENSTER and Morgendauw.

Lastly it looks like the intended use, as defined by the creators of the artworks seemed to resonate with the most noted responses in the sub-categories. VENSTER is mainly based In general, all artworks needed coaching and nudging from a caregiver on recognizable video and interactive content and it made people mostly name or recognize what they saw. The CRDL is designed to be touched and to entice people to touch each other. The most noted response in the sub-categories during observations with the CRDL was it being touched. Morgendauw, lastly, was meant to slow people down, contemplate and interact shortly. Results show that people indeed largely looked at Morgendauw with a focus.

Although we strived to develop and study artworks that could be used and enjoyed by nursing home residents themselves and/or together with visitors or non-professional caregivers, the former does not seem possible with the three artworks studied in this thesis. In general, all artworks needed coaching and nudging from a caregiver. Nursing home residents rarely approached an artwork or initiated an interaction themselves. Despite this, a volunteer or visitor is able to accompany one or a group of nursing home residents when interacting with the artworks. There is no need for multiple (professional) caregivers to be present. The distraction the artworks created opened up more opportunity to initiate (meaningful) conversation.

\section{Methodological considerations}

In this section the overall methodological considerations of the thesis are discussed per phase. For a more detailed reflection about the methods of the underlying studies, I refer to the discussions of the separate chapters.

\section{Phase 1: Understanding the problem}

Due to the multitude of terms used to describe different types of interactive artworks, and a fragemented distribution in different databases, it is possible that some terms or combinations were missed when carrying out the literature review and that the selection of databases was not exhausting. 


\section{General discussion}

No evaluation of potential existing interactive artworks outside of the nursing home environment, possibly suitable to be adapted, was carried out initially. Instead, two artworks were developed by the author. This did not only generate hands-on experience with the target group, but has given a transparent and complete insight in the process of concepting and prototyping and the relation between this phase and the studying of responses afterwards (Phase 2 and 3). However, unconscious confirmation bias might have occurred, because of the authors' hypothesis that interactive art can be a part of (emotion-oriented) elderly care. To counteract this, a third artwork (the CRDL) was identified that was not developed by the author and all evaluations have been carried out by more than one researcher.

\section{Phase 2: Concepting and prototyping}

To develop and build the interactive artworks and fitting interfaces that were comprehensible and useable for the residents themselves, their visitors and caregivers, all stakeholders were included in the design process. Although some accents were placed differently, the same co-design process was used for the development of the artworks in this dissertation. Figure 6 (p.134) illustrates this process.

Co-designing an (interactive) artwork and involving all stakeholders is in itself novel. Although the process is derived from "design thinking" (Brown, 2008) and the actual methods used are borrowed from the field of Human-Computer Interaction and User-Centred Design, the process used for co-creation in this dissertation could be

\section{All stakeholders were included} in the design process

optimized, by increasing involvement of the nursing home residents themselves (Hendriks, Truyen, \& Duval, 2013). The field of co-designing with nursing home residents, people living with dementia and people who have cognitive impairments in general is growing (Phillipson \& Hammond, 2018; Slegers, Duysburgh, \& Hendriks, 2015). Current research can inform and improve the used method.

The physical context is an important part of an (aesthetic) experience. It did not receive enough attention when implementing the artworks in the nursing home. Physical context can create the setting for an emotional and cognitive state that opens up the individual for aesthetic experiences or do the opposite (Brieber, Nadal, Leder, \& Rosenberg, 2014). The physical context did not seem to provide any issues for sessions with VENSTER and the CRDL. Perhaps because VENSTER intuitively got the context right by integrating with the existing physical environment and the CRDL was properly introduced as an interactive art object at the beginning of each group session by the caregiver. Morgendauw, however, either seemed to be 'out of place' in the public hallway of a nursing home or was seen as expensive and 'not to be touched'. This illustrates the dialectic problem of the physical context of an interactive artwork in the nursing home. It should be perceived as art, with a mature and interesting aesthetic, while it should also invite people to interact, touch and explore. 


\section{Chapter 7}

\section{understanding the problem}

creative practice

literature search

conversation

concepting

creative practice guided brainstorm activity card sort

\section{prototyping}

task analysis

narrative storyboards

interface design sketching

live and video observation

think aloud

wizard of oz

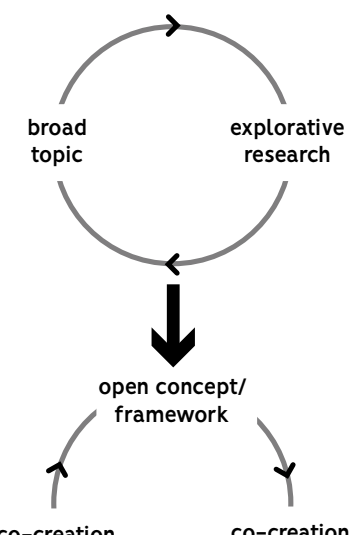

co-creation co-creation with clients with experts

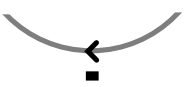

identify requirements

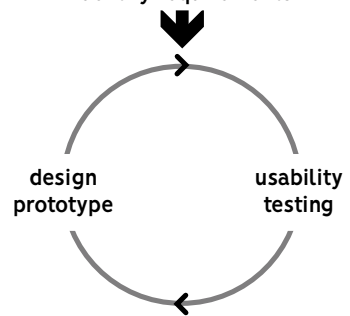

Figure 6: Generalised co-design process used for the development

of the artworks in this dissertation. The phases and used methods are noted on the left, the outcomes and how they relate and advance each other are shown on the right.

\section{Phase 3: Pilot studies}

There are some remarks to be made about the way the responses of the nursing home residents were captured and coded. The process of observing and coding has always been carried out by a minimum of two researchers and in case of disagreement, the researchers consulted two other researchers to reach consensus. All researchers involved checked their coding with each other regularly, but some interpretation bias or errors might have occurred. Unfortunately, the observation method used (video observation) and the inability of the residents to reflect on their own behaviour through video-cued recall inhibited cognitive/emotional responses to be recorded. Attempts at video-cued recall were made by having the caregiver who was present to guide the sessions

The methods used inhibited cognitive/emotional responses to be recorded look at the recorded footage and comment on the presumed emotional and cognitive processes of the residents on video, but the caregivers themselves stated it was merely their interpretation of certain behaviour and expressed their doubts 


\section{General discussion}

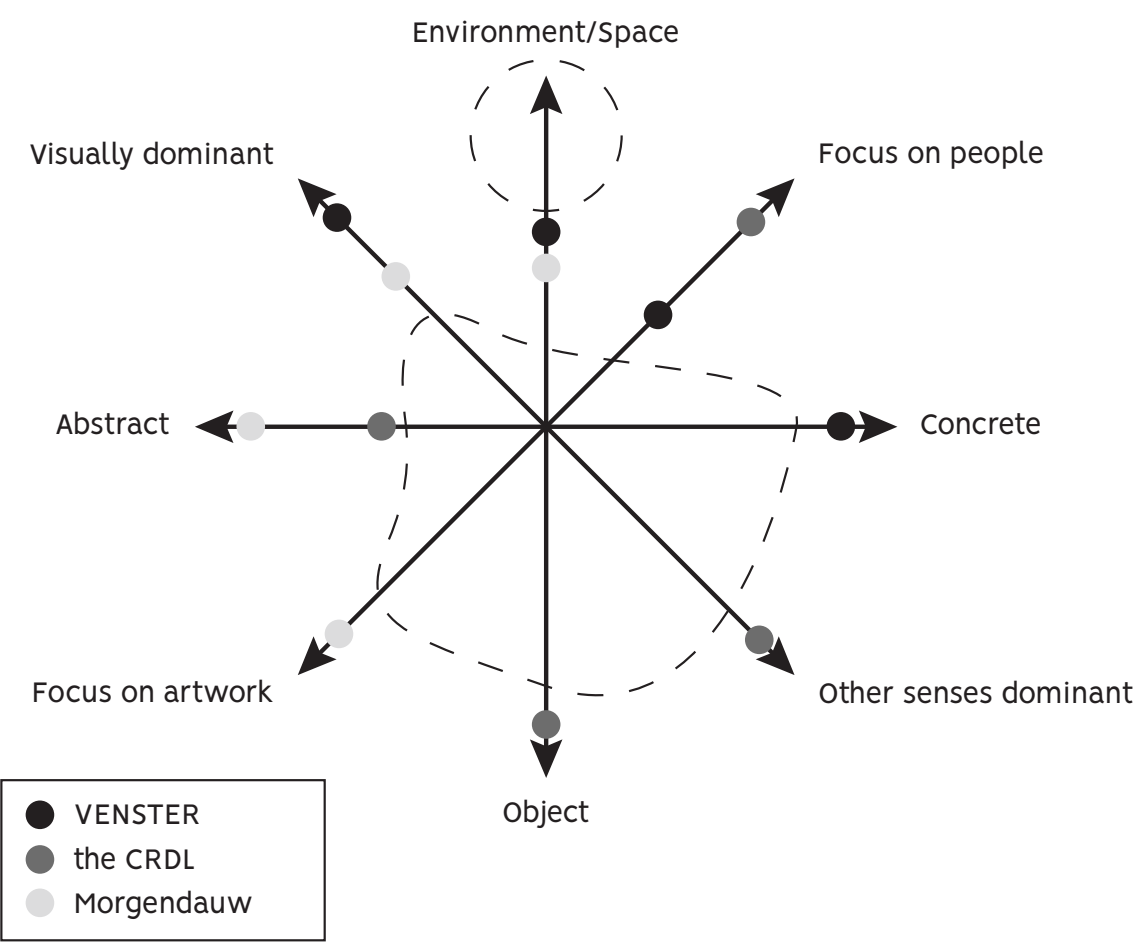

Figure 7: Overview of differences in some of the characteristics of the 3 studied artworks and areas of characteristics that were left unexplored in this dissertation.

about the accuracy on numerous occasions. Therefore, the data on potential emotional and cognitive responses were discarded.

\section{Phase 4: Synthesis}

Because of the many variables at play, it is not possible to link the influence of characteristics of the artworks to the amount or type of responses directly. The three studied artworks in

Because of the many variables at play, it is not possible to link the influence of characteristics of the artworks to the amount or type of responses directly this dissertation merely scratch the surface of the possible range of interactive artworks that could potentially provide a meaningful experience in the nursing home (Figure 7). For example: VENSTER and Morgendauw are room-filling installations, while the CRDL is a relatively small, table-top object. There is a large variety of possible interactive artworks in between, but also outside of this spectrum. Figure 7 identifies some characteristics of possible additional interactive artworks (empty spots, marked with a dotted line). This emerging field would benefit from studying more, and different types of interactive artworks in the nursing home.

The framework has made the comparison of responses to the different artworks possible, 


\section{Chapter 7}

but does not take the different circumstances into account in which the artworks were studied. Both the CRDL and VENSTER were studied in a group situation, guided by a (professional) caregiver. Interactions with Morgendauw were based on chance encounters. Group composition and locations differed across sessions, so results were influenced by the characteristics of the participants present. The duration of a responses as well as the time in between responses was not measured. For responses such as keeping or losing focus or tapping gestures that lasted multiple seconds, this might have resulted in understating the impact of some recorded responses. When a response was interrupted and restarted a lot, this might have led to overstating certain responses. If a resident or caregiver carried out two or more types of response simultaneously, these responses were coded in all corresponding categories. This influenced the total number of responses recorded, possibly over-recording some responses.

The framework has made the comparison of responses to the different artworks possible

The experience of the nursing home residents, or other people while interacting with the artworks, as well as the effects on wellbeing or happiness were not studied in this dissertation. Because of the explorative nature of this study, we first needed to establish whether and how nursing home residents respond to these interactive artworks. Evaluating experience is only valid when there are actual responses by nursing home residents and it is established that "something" happens.

\section{Implications for (creative) practice and research}

Based on the studies in this dissertation, implications for (creative) pratice and research emerge regarding 'developing interactive art with special attention to the interface', 'the involvement of all stakeholders as requirement for successful implementation of interactive art in nursing homes, and on 'continuous improvement of the interactive artwork'.

\section{Developing interactive art with special attention to the interface}

To perceive something as art and have an (aesthetic) experience, a multitude of factors are at play: It is, for example, highly dependent on the current Zeitgeist, the physical place where an artwork is shown, the previous experiences and the current emotional (and cognitive) state of the person looking at it (Leder \& Nadal, 2014). VENSTER can serve as an example: While VENSTER and its (interactive) video content might not be perceived as an artwork today by the present-day museum visitor, works like 'Hole in space' (Galloway \& Rabinowitz, 1980) and 'Bicycle TV' (Paterson, 1992) were created by renowned artists and put on display by MOMA and the World Fair respectively at the time. While the frequent museum visitor of today might not see VENSTER as an artwork by today's standards or expectations in the museum, it seems that the context and audience in the nursing home need to be evaluated differently. 


\section{General discussion}

Most artists do not have the tendency to study their audience's reactions in a scientific way alongside of their artistic merits, although exceptions exist (Khut \& Muller, 2005). This is deeply rooted in the artistic practice. It's the artists' prerogative to create and implement their work, regardless of reception by an audience. When developing an interactive artwork for the nursing home, however, there are some things that need to be considered. An interface stands between the person and the experience of an interactive artwork. Figuring out the interface is part of the experience for most people, but when it is not understood timely, frustration arises and people do not reach the actual experience. This phenomenon is magnified when working with nursing home residents. If they are not included in the design process and the interface is not a part of their experience, with the lowest learning curve possible, they will not engage.

It is hard for nursing home residents to store new information. Recognisable content seems to make it easy for nursing home residents to

An interface stands between the person and the experience of an interactive artwork connect to the experience of the artwork. Designing (video or other) content in such a way that the interface is actually comprised within (e.g.: a small child asking to help her find something) seems to generate promising results. Research and experimentation into this phenomenon, its boundaries

and possibilities is encouraged. Where are the sweet spots located between recognition and novelty or abstraction? Recognition can provide an "entrance" that lowers the initial threshold to engage with an artefact or installation. Physical manipulation of artefacts and/ or deeply engrained mental models such as gravity seem to be a good starting point to create an interface. Small learning curves (seconds) are important, for most actions need to re-learned by nursing home residents every time an interaction with the installation takes place. Complex tasks should be automated if not carried out timely.

Some nursing home residents lack strength, mobility, motor skills or a combination. An interface should not require difficult physical actions and take care of wheelchairs and walkers when positioning and designing controls.

Due to the characteristics of their mental challenges (e.g. dementia), nursing home residents become increasingly harder to make contact with over time. When an interactive artwork can (re)trigger this social response, it is a powerful element of the overall experience. Astrategy that seems promising is to trigger memory and/or leave out information deliberately to spark a conversation. Once the interaction has started, the suspension of disbelief can be stretched. A little girl waving to the screen can trigger curiosity and the action of waving back, and can then steer the attention towards more abstract content and spark further interest and curiosity. Abstract content can trigger some curiosity, but elevates the threshold to engage for nursing home residents.

Content, interface and context should be integrated and indistinguishable. Further 


\section{Chapter 7}

explorations are needed to study the implications of the physical context on the perception of interactive artworks in the nursing home. All designed artefacts need to clearly be part of the presented experience. If it does not explicitly play a part in the experience, it is not noticed. Content itself (abstract or not) can be used as an integrated interface (e.g: someone in a depicted movie asks to carry out an action).

\section{Involvement of all stakeholders required for successful implementation of interactive art in nursing homes}

When an interactive artwork is to be used in daily care, all stakeholders should be informed about the concept, the use and the possibilities of the installation in relation to the residents of the nursing home. Involving all stakeholders early in the process of development can generate broad support, acceptance and involvement early on. These people can help advocate the use of interactive artworks as well as help to educate others in the use and possible benefits. Some practical knowledge and hands-on practice are advised as well. Caregivers that supervised more than one session reported a learning curve and experienced a second session as smoother, with less focus on the interface of the artwork and more on the people involved.

It has been established in this dissertation that autonomous use by most nursing home residents is impossible, therefore the quality of the experience for most nursing home resident is directly linked to the involvement and level of familiarity of the (professional) caregiver or visitors.

Contemporary (interactive) art clearly is not for everyone, as are soccers, cycling, pigeon keeping, playing cards and all

Autonomous use is impossible for most nursing home residents other popular pass time activities. Personal preference and a multitude of other factors play a role. This is not different for nursing home residents. Their preferences should be respected as much as possible.

\section{Continuous improvement of the framework and interactive art installations}

For future research, it would be beneficial to upgrade the framework developed and used in this dissertation. The duration of responses as well as the time in between responses and the amount of responses per person should be added to present a more complete image of the observed and recorded responses.

All the studies mentioned in this dissertation looked at the immediate responses of people interacting with the artworks. It would of course be favourable to also learn about the long-term usage patterns. Do people in the nursing home grow bored of the installations or start using them differently over time and what does that mean for the designer? It is possible to keep it interesting over the long term?

If we want to learn whether interactive art can create meaningful experiences for nursing 


\section{General discussion}

home residents, subjective experience and perception of general wellbeing should be measured. An evaluation of the suited methods to gain insight in short- and long-term effects on happiness, perceived wellbeing and quality of life should take place. The field of "positive computing" can possibly inform the selection of proper methods and frameworks (Calvo \& Peters, 2014).

Aside from measuring experience and wellbeing, data aggregation could be automated through integrating sensors in the artworks that monitor use and record responses automatically and individually. It can provide insight in whether and how people interact with the artworks over longer periods of time and register the number and amount of time an artwork is used.

\section{Where to go from here?}

Everyone is entitled to experience art and culture. In the case of the nursing home, it seems that interactive art can be a valuable addition to the

It seems that interactive art can be a valuable addition to the existing palette of experience-oriented care technologies existing palette of experience-oriented care technologies, especially during the inactive time in between existing activities and therapies. It can possibly even change the perception of the nursing home environment, provide meaningful experiences for nursing home residents, despite their mental and physical challenges, and might affect wellbeing of all who reside, work in or visit in the nursing home.

\section{Increasing chance of change towards an art-included life in care facilities}

Unfortunately, due to a general climate of budget cuts in the elderly care sector, an unfamiliarity with the possibilities of (interactive) art and a general tendency of (media) artists to ignore less "attractive" target audiences, there are currently no interactive artworks present in the nursing home environment and only a handful in other fields of care. Defining success of interactive artworks in the nursing home is an impossible task. All stakeholders involved might have a different perspective on this. The nursing home residents themselves might measure success by changes in their own overall mood or perceived wellbeing. Nursing staff might look to effects on their workload. Management might consider financial reasoning, while the artist is perhaps most concerned with artistic quality. An objective parameter for success therefore seems impossible. Therefore, the experience of nursing home residents, staff and visitors should be leading. However, the immediate and/or aesthetic experience of someone is very multi-faceted and hard to measure. As defined in Chapter 1, an experience is a strictly personal event. It can probably not be quantified. This is most certainly the case for psychological impaired nursing home residents with whom all form of communication is difficult and happens outside the realm of language. Even through questioning a proxy, the personal or aesthetic experience of a person at a given moment is impossible to pinpoint. 


\section{Chapter 7}

However, observing and studying their responses helps to communicate the potential of these artworks and helps the future development and improvement of interactive artworks in these types of settings. In short, we should keep on studying and learning how to set up all conditions to enable a meaningful and/or aesthetic experience to happen in the nursing home, without trying to quantify the experience itself. Instead, measuring the responses and kind of responses with respect to different characteristics to detect whether and how these installations are used to inform the development of a range of different types of interactive artworks suited for the nursing home.

The presence and use of interactive artworks should also be explored in other fields of care, mental health care first and foremost. Intuitively, some parallels can be drawn, but further exploration into whether other domains and target audiences could also benefit from the experiences that interactive art can offer are needed. By building upon the experiences and knowledge gathered so far, it would be interesting to see whether there are similarities and to learn about the differences with respect to other domains.

\section{More initiatives with changing interactive art collections in health care}

To embed interactive artworks into the nursing home and to tear down the wall that separates museums, media festivals and exhibitions and the society in general from the nursing home, an experiment with a museum-like environment inside the nursing home should be explored. This could take form as a living lab where the art is on display during development and viewers are aware their data is being collected to advance the development of the works, such as Beta_space (L. Muller, Edmonds, \& Connell, 2006). The collection needs to have artworks that are equally interesting for the people who live inside and outside of the nursing home, but created in such a way that everyone, including the nursing home residents,

An experiment with a museum-like environment inside the nursing home should be explored can understand and enjoy them in their own way, within their possibilities. Awareness of the possibilities and budget made available by the government or health insurance could advance the implementation. Some initiatives that are already common within the art world could increase the general awareness for interactive art in elderly care. Having artist residencies inside the nursing home for instance, or organising interactive art exhibitions in the nursing home that are open to all, exchanging artworks with museums or having care organisations or the government commission works. Such exhibitions could work as a living lab, continuously monitoring the (kind of) use of the installations. When made mobile, these exhibitions can travel to different nursing homes and explore other care setting, such as mental health care.

\section{Conclusion}

The results discussed in this dissertation establish that interactive art deserves a place in 


\section{General discussion}

(Dutch) nursing homes as an emotion-oriented care technology. The insights and knowledge generated in this study can be channelled into a (travelling) exhibition inside the nursing home, but open to all. It should present interactive art in such a way that it is interesting and intuitive for all to visit and enjoy, and creates connections between the nursing homes and the rest of society, residents and staff or visitors, the (interactive) art world and the field of (elderly) care. These living labs/exhibitions can advance our knowledge on how to build and set the stage together with nursing home residents for personal, meaningful experiences to take place. 

References 


\section{References}

AAL. (2015). Getting older adults really involved. Retrieved from: http://www.aal-europe. eu/wp-content/uploads/2015/02/AALA_ToolboxA5_online.pdf

Abraha, I., Rimland, J. M., Trotta, F. M., Dell'Aquila, G., Cruz-Jentoft, A., Petrovic, M., \& Cherubini, A. (2017). Systematic review of systematic reviews of non-pharmacological interventions to treat behavioural disturbances in older patients with dementia. The SENATOR-OnTop series. BMJ open, 7(3), e012759. doi:10.1136/bmjopen-2016-012759

Alper, S., \& Raharinirina, S. (2006). Assistive technology for individuals with disabilities: A review and synthesis of the literature. Journal of Special Education Technology, 21(2), 47-64.

Alzheimer-Nederland. (2017). Cijfers en feiten over dementie 2015. Retrieved from: http://www. alzheimer-nederland. nl/media/840711/factsheet_dementie_algemeen_-_ publieksversie_03-02-2015. pdf

Alzheimer-Nederland. (2018). Manifest voor en door mensen met dementie. Retrieved from: https://www.alzheimer-nederland.nl/sites/default/files/directupload/Manifest-vooren-door-mensen-met-dementie.pdf

Anderiesen, H., Scherder, E. J., Goossens, R. H., \& Sonneveld, M. H. (2014). A systematic review-physical activity in dementia: the influence of the nursing home environment. Applied ergonomics, 45(6), 1678-1686.

Arean, P. A., Perri, M. G., Nezu, A. M., Schein, R. L., Christopher, F., \& Joseph, T. X. (1993). Comparative effectiveness of social problem-solving therapy and reminiscence therapy as treatments for depression in older adults. Journal of consulting and clinical psychology, 61(6), 1003.

Australian-Centre-on-Quality-of-Life. (2019). Australian Centre on Quality of Life Instruments. Retrieved from: http://www.acqol.com.au/instruments

Baker, R., Bell, S., Baker, E., Gibson, S., Holloway, J., Pearce, \& R., Wareing, L. A. (2001). A randomized controlled trial of the effects of multi-sensory stimulation (MSS) for people with dementia. Br J Clin Psychol, 40(Pt 1), 81-96.

Banks, M. R., \& Banks, W. A. (2002). The effects of animal-assisted therapy on loneliness in an elderly population in long-term care facilities. J Gerontol A Biol Sci Med Sci, 57(7), M428-432.

Bemelmans, R., Gelderblom, G. J., Jonker, P., \& de Witte, L. (2012). Socially assistive robots in elderly care: a systematic review into effects and effectiveness. J Am Med Dir Assoc, 13(2), 114-120 e111. doi:10.1016/j.jamda.2010.10.002 


\section{References}

Bialoskorski, L. S. S., Westerink, J. H. D. M., \& Broek, E. L. V. d. (2010). Experiencing affective interactive art. International Journal of Arts and Technology, 3(4), 341. doi:10.1504/ijart.2010.035826

Bianchini, S., \& Verhagen, E. (2016). Practicable: From participation to interaction in contemporary art: MIT Press.

Bilda, Z., Edmonds, E., \& Candy, L. (2008). Designing for creative engagement. Design Studies, 29(6), 525-540.

Boulos, M. N. K., Wheeler, S., Tavares, C., \& Jones, R. (2011). How smartphones are changing the face of mobile and participatory healthcare: an overview, with example from eCAALYX. Biomedical engineering online, 10(1), 24.

Bourdieu, P., Darbel, A., \& Schnapper, D. (1997). The love of art: European art museums and their public: Polity Press Cambridge.

Braun, S. M., Kleynen, M., Bleijlevens, M. H., Moser, A., Beurskens, A. J., \& Lexis, M.

A. (2015). "Interactive surfaces" technology as a potential tool to stimulate physical activity in psychogeriatric nursing home residents. Disability and Rehabilitation: Assistive Technology, 10(6), 486-492.

Brieber, D., Nadal, M., Leder, H., \& Rosenberg, R. (2014). Art in time and space: Context modulates the relation between art experience and viewing time. PloS one, 9(6), e99019.

Brown, T. (2008). Design thinking. Harvard business review, 86(6), 84.

Burke, L., Kleinman, S., \& Cheung, T. (2012). Branching out. New York: New York University.

Cai, F.-F., \& Zhang, H. (2015). Effect of therapeutic touch on agitated behavior in elderly patients with dementia: A review. Int J Nurs Sci, 2(3), 324-328.

Calvo, R. A., \& Peters, D. (2014). Positive computing: technology for wellbeing and human potential: MIT Press.

Camic, P. M., Tischler, V., \& Pearman, C. H. (2014). Viewing and making art together: a multi-session art-gallery-based intervention for people with dementia and their carers.

Aging \& Mental Health, 18(2), 161-168.

Campbell, J. (2010). Scattered Light. New York.

Capybara Games, S. (2011). Swords and Sworcery. Toronto.

Charitos, D., Bourdakis, V., \& Gavrilou, E. (2006). Embedding an audiovisual interactive installation environment in urban space for enhancing social interaction. Paper presented at the 2nd IET International Conference on Intelligent Environments. Athens, Greece: IE. 


\section{References}

Coleman, D. J., \& Asiri, N. A. S. (2017). A person-centred communication approach to working with older people who have dementia. British Journal of Healthcare Assistants, 11(11), 548-552.

Costello, B., Muller, L., Amitani, S., \& Edmonds, E. (2005). Understanding the experience of interactive art: lamascope in Beta_space. Paper presented at the Proceedings of the second Australasian conference on Interactive entertainment.

Cupchik, G. C., \& Winston, A. S. (1996). Confluence and divergence in empirical aesthetics, philosophy, and mainstream psychology. Handbook of perception and cognition: Cognitive ecology, 61-85.

Daykin, N., Byrne, E., Soteriou, T., \& O'Connor, S. (2008). The impact of art, design and environment in mental healthcare: a systematic review of the literature. J R Soc Promot Health, 128(2), 85-94.

den Ouden, M., Bleijlevens, M. H., Meijers, J. M., Zwakhalen, S. M., Braun, S. M., Tan, F. E., \& Hamers, J. P. (2015). Daily (in) activities of nursing home residents in their wards: an observation study. Journal of the American Medical Directors Association, 16(11), 963-968.

Deray, K., \& Simoff, S. (2012, July). Framing interaction through engagement in interactive open ended environments. In 2012 16th International Conference on Information Visualisation (pp. 534-539). IEEE.

Dewey, J. (1934). Art as experience. New York: Minton, Balch, and Company.

Donetto, S., Tsianakas, V., \& Robert, G. (2014). Using Experience-based Co-design (EBCD) to improve the quality of healthcare: mapping where we are now and establishing future directions. London: King's College London.

Douglas, S., James, I., \& Ballard, C. (2004). Non-pharmacological interventions in dementia. Advances in psychiatric treatment, 10(3), 171-177.

Dourish, P. (2004). Where the action is: the foundations of embodied interaction: MIT press.

Edmonds, E., \& Candy, L. (2011). Interacting: art, research and the creative practitioner. Faringdon: Libri Publishing.

FAT. (2003). Eye Writer Project. New York.

Field, T. (2014). Touch, 2nd ed. Cambridge, MA, USA: MIT Press.

Finnema, E., Droes, R. M., Ettema, T., Ooms, M., Ader, H., Ribbe, M., \& van Tilburg, W. (2005). The effect of integrated emotion-oriented care versus usual care on elderly persons with dementia in the nursing home and on nursing assistants: a randomized clinical trial. Int J Geriatr Psychiatry, 20(4), 330-343. doi:10.1002/gps.1286 


\section{References}

Fourneau, A. (2013). Water Light Graffiti. Paris.

Gallace, A., \& Spence, C. (2010). The science of interpersonal touch: an overview. Neurosci Biobehav Rev, 34(2), 246-259. doi:10.1016/j.neubiorev.2008.10.004

Galloway, K., \& Rabinowitz, S. (1980). A Hole in Space. In. New York.

Graham, D., Stockinger, S., \& Leder, H. (2013). An island of stability: art images and natural scenes-but not natural faces-show consistent esthetic response in Alzheimer'srelated dementia. Frontiers in psychology, 4, 107.

Greenberg, S., Carpendale, S., Marquardt, N., \& Buxton, B. (2011). Sketching user experiences: The workbook: Elsevier.

Griffiths, J. L. (2009). Drawing Machine NO.1. Melbourne.

Gurion, T., \& Jacoby, N. (2013). Audio-Only Augmented Reality System for Social Interaction. In C. Stephanidis (Ed.), HCl International 2013 - Posters' Extended Abstracts (Vol. 373, pp. 322-326). Berlin/Heidelberg: Springer

Hanington, B., \& Martin, B. (2012). Universal methods of design: 100 ways to research complex problems, develop innovative ideas, and design effective solutions: Rockport Publishers.

Hansen, N. V., Jorgensen, T., \& Ortenblad, L. (2006). Massage and touch for dementia. Cochrane Database Syst Rev, 4.

Heesbeen, A., Hout, L. v. d., Droes, R. M., Hendriks, I., Koelewijn, J., Meiland, F., \& Bruijne, D. d. (2017). Onvergetelijk : Kunst en cultuur toegankelijk maken voor mensen met dementie en hun dierbaren. Amsterdam: Stedelijk Museum : Van Abbemusem : VUmc.

Hendriks, N., Truyen, F., \& Duval, E. (2013). Designing with dementia: Guidelines for participatory design together with persons with dementia. Paper presented at the IFIP Conference on Human-Computer Interaction.

Her, J.-J., \& Hamlyn, J. (2010). Meaningful Engagement: Computer-Based Interactive Media Art in Public Space. In Arts and Technology (pp. 17-24). Berlin/Heidelberg: Springer.

Hertenstein, M. J., Keltner, D., App, B., Bulleit, B. A., \& Jaskolka, A. R. (2006). Touch communicates distinct emotions. Emotion, 6(3), 528-533. doi:10.1037/1528-3542.6.3.528

Hespanhol, L., \& Tomitsch, M. (2014). Understanding the effects of contextual constraints on performative behaviour in interactive media installations. Personal and Ubiquitous Computing, 18(7), 1651-1665. doi:10.1007/s00779-014-0765-4 


\section{References}

Hill, N. L., Kolanowski, A., \& Kürüm, E. (2012). Agreeableness and activity engagement in nursing home residents with dementia: a pilot study. Journal of gerontological nursing, 36(9), 45-52.

Hohl, M. (2009). Designing the art experience: using Grounded Theory to develop a model of participants' perception of an immersive telematic artwork. Digital Creativity, 20(3), 187-196.

Huang, H.-C., Chen, Y.-T., Chen, P.-Y., Hu, S. H.-L., Liu, F., Kuo, Y.-L., \& Chiu, H.-Y. (2015). Reminiscence therapy improves cognitive functions and reduces depressive symptoms in elderly people with dementia: a meta-analysis of randomized controlled trials. Journal of the American Medical Directors Association, 16(12), 1087-1094.

Hulme, C., Wright, J., Crocker, T., Oluboyede, Y., \& House, A. (2010). Nonpharmacological approaches for dementia that informal carers might try or access: a systematic review. International journal of geriatric psychiatry, 25(7), 756-763.

I/O, D. (2013). Weather Worlds. Norfolk.

Itten, J. (1973). The Art of Color the Subjective Experience and Objective Rationale of Color. New York: John Wiley \& Sons Inc.

Jacucci, G., Spagnolli, A., Chalambalakis, A., Morrison, A., Liikkanen, L., Roveda, S., \& Bertoncini, M. (2009). Bodily explorations in space: Social experience of a multimodal art installation. In Human-Computer Interaction-INTERACT 2009 (pp. 62-75). Berlin/ Heidelberg: Springer.

Johnson, J. (2007). Deeper than Reason: Emotion and its Role in Literature, Music, and Art. By Jenefer Robinson. In: Oxford University Press.

Khut, G. P., \& Muller, L. (2005). Evolving Creative Practice: A reflection on working with audience experience in Cardiomorphologies. Vital Signs: Creative Practice \& New Media Now, 21.

Klink, S., \& Alliance, U. (2009). Moodwall. Amsterdam.

Kolanowski, A. M., Resnick, B., Beck, C., \& Grady, P. A. (2013). Advances in nonpharmacological interventions, 2011-2012. Res Gerontol Nurs, 6(1), 5-8. doi:10.3928/19404921-20121204-03

Krieger, D. (1979). The therapeutic touch: How to use your hands to help or to heal (Vol. 15). Englewood Cliffs, NJ, USA: Prentice-Hall.

Krug, S. (2009). Rocket surgery made easy: The do-it-yourself guide to finding and fixing usability problems: New Riders.

Kwastek, K. (2013). Aesthetics of Interaction in Digital Art: MIT Press. 


\section{References}

Lab212. (2012). Starfield. Montreuil.

Lawson, B., Phiri, M., \& Wells-Thorpe, J. (2003). The architectural healthcare environment and its effects on patient health outcomes: a report on an nhs estates funded research project. In: Stationery Office London, England.

Leder, H., \& Nadal, M. (2014). Ten years of a model of aesthetic appreciation and aesthetic judgments: The aesthetic episode-Developments and challenges in empirical aesthetics. British Journal of Psychology, 105(4), 443-464.

Lee, J.-H., Park, J.-Y., \& Nam, T.-J. (2007). Emotional Interaction Through Physical Movement. In J. Jacko (Ed.), Human-Computer Interaction. $\mathrm{HCl}$ Intelligent Multimodal Interaction Environments (Vol. 4552, pp. 401-410). Berlin/Heidelberg: Springer Berlin Heidelberg.

Lindgren, L., Westling, G., Brulin, C., Lehtipalo, S., Andersson, M., \& Nyberg, L. (2012). Pleasant human touch is represented in pregenual anterior cingulate cortex. Neuroimage, 59(4), 3427-3432.

Livingston, G., Kelly, L., Lewis-Holmes, E., Baio, G., Morris, S.,Patel, N., \& Cooper, C. (2014). Non-pharmacological interventions for agitation in dementia: systematic review of randomised controlled trials. Br J Psychiatry, 205(6), 436-442. doi:10.1192/bjp. bp. 113.141119

LoGiudice, D. (2002). Dementia: an update to refresh your memory. Intern Med J, 32(11), 535-540.

Luyten, T., Braun, S., Hooren, S. V., \& Witte, L. D. (2017). Participant responses to physical, open-ended interactive digital artworks: a systematic review. International Journal of Arts and Technology, 10(2), 94-134.

Luyten, T., Braun, S., Jamin, G., van Hooren, S., \& de Witte, L. (2018). How nursing home residents with dementia respond to the interactive art installation 'VENSTER': a pilot study. Disability and Rehabilitation: Assistive Technology, 13(1), 87-94.

Luyten, T., Braun, S., van Hooren, S., \& de Witte, L. (2017). co-design method for creating meaningful art installations for residents of nursing homes. In T. v. d. Laan (Ed.), Shared insights on co-creation in healthcare. Utrecht: U-create.

Luyten, T., Braun, S., van Hooren, S., \& de Witte, L. (2018). How groups of nursing home residents respond to "the CRDL": a pilot study. Journal of Enabling Technologies, 12(4), 145-154.

Luyten, T., Braun, S., Van Hooren, S., \& Witte, L. D. (2017). Participant responses to physical, open-ended interactive digital artworks: a systematic review. International Journal of Arts and Technology, 10(2), 94-134. 


\section{References}

Maier, J. R., \& Fadel, G. M. (2009). Affordance based design: a relational theory for design. Research in Engineering Design, 20(1), 13-27.

Malcolm, J., Hodkinson, P., \& Colley, H. (2003). The interrelationships between informal and formal learning. Journal of workplace learning, 15(7/8), 313-318.

McFeeters, S., Pront, L., Cuthbertson, L., \& King, L. (2016). Massage, a complementary therapy effectively promoting the health and well-being of older people in residential care settings: a review of the literature. Int J Older People Nurs, 11(4), 266-283. doi:10.1111/ opn. 12115

MindJet. (2018). MindManager.

Moher, D., Liberati, A., Tetzlaff, J., \& Altman, D. G. (2009). Preferred reporting items for systematic reviews and meta-analyses: the PRISMA statement. Annals of internal medicine, 151(4), 264-269.

Morgan, E., \& Gunes, H. (2013). Human nonverbal behaviour understanding in the wild for new media art. In Human Behavior Understanding (pp. 27-39). Barcelona: Springer.

Morrison, A., Viller, S., \& Mitchell, P. (2011a). Building sensitising terms to understand free-play in open-ended interactive art environments. Paper presented the Proceedings of the 2011 annual conference on Human factors in computing systems $\mathrm{CHI}$ '11, Vancouver, BC, Canada.

Morrison, A., Viller, S., \& Mitchell, P. (2011b). Open-ended art environments motivate participation. Paper presented at the Proceedings of the 8th International Conference on Advances in Computer Entertainment Technology - ACE '11, Lisbon, Portugal.

Morrison, A. J., Mitchell, P., \& Brereton, M. (2007). The lens of ludic engagement: evaluating participation in interactive art installations. Paper presented at the Proceedings of the 15th ACM international conference on Multimedia.

Morrison, A. J., Mitchell, P., \& Viller, S. (2008, 2008). Evoking gesture in interactive art. Muller, E. (2008). The experience of interactive art: A curatorial study. (PhD), University of Technology, Sydney.

Muller, L., Edmonds, E., \& Connell, M. (2006). Living laboratories for interactive art. CoDesign, 2(4), 195-207.

Nardelli, E. (2012). A classification framework for interactive digital artworks. In User Centric Media (pp. 91-100). Berlin/Heidelberg: Springer.

Nederlandse-Zorgautoriteit. (2017). Impactanalyse verpleeghuiszorg 2017. Retrieved from: https://www.rijksoverheid.nl/documenten/rapporten/2017/03/31/ impactanalyse-verpleeghuiszorg-2017 


\section{References}

Nicholls, D., Chang, E., Johnson, A., \& Edenborough, M. (2013). Touch, the essence of caring for people with end-stage dementia: a mental health perspective in Namaste Care. Aging Ment Health, 17(5), 571-578. doi:10.1080/13607863.2012.751581

Nielsen, S. L., Fich, L. B., Roessler, K. K., \& Mullins, M. F. (2017). How do patients actually experience and use art in hospitals? The significance of interaction: a useroriented experimental case study. International journal of qualitative studies on health and well-being, 12(1), 1267343.

Norman, D. A. (2002). The Design of Everyday Things: Basic Books.

Participatiekompas. (2014). Participatiekompas. Retrieved from: http://www. participatiekompas.nl

Paterson, N. (1992). Bicycle TV: Expo'92 Installation. Leonardo, 25(2), 163-165.

Patrick, K., Griswold, W. G., Raab, F., \& Intille, S. S. (2008). Health and the mobile phone. Am J Prev Med, 35(2), 177-181. doi:10.1016/j.amepre.2008.05.001

Phillipson, L., \& Hammond, A. (2018). More than talking: a scoping review of innovative approaches to qualitative research involving people with dementia. International Journal of Qualitative Methods, 17(1), 1609406918782784.

Prince, M., Comas-Herrera, A., Knapp, M., Guerchet, M., \& Karagiannidou, M. (2016). World Alzheimer report 2016: improving healthcare for people living with dementia: coverage, quality and costs now and in the future.

Random-International. (2008). Audience. In. London.

Rautio, N., Filatova, S., Lehtiniemi, H., \& Miettunen, J. (2018). Living environment and its relationship to depressive mood: A systematic review. Int J Soc Psychiatry, 64(1), 92-103. doi:10.1177/0020764017744582

Refsgaard, A. (2015). Eye conductor. Copenhagen.

Rego, P., Moreira, P. M., \& Reis, L. P. (2010). Serious games for rehabilitation: A survey and a classification towards a taxonomy. Paper presented at the 5th Iberian Conference on Information Systems and Technologies (CISTI), 2010

Robinson, J. (2007). Deeper than reason: Emotion and its role in literature, music, and art. Oxford: Clarendon Press.

Rokeby, D. (1998). The construction of experience: Interface as content. Digital Illusion: Entertaining the future with high technology, 27-48.

Roosegaarde, D. (2011). Lunar. Breda. 


\section{References}

Rosenberg, F. (2009). The MoMA Alzheimer's Project: Programming and resources for making art accessible to people with Alzheimer's disease and their caregivers. Arts \& Health, 1(1), 93-97.

Ryff, C. D. (1989). Happiness is everything, or is it? Explorations on the meaning of psychological well-being. Journal of personality and social psychology, 57(6), 1069.

Ryff, C. D., \& Keyes, C. L. (1995). The structure of psychological well-being revisited. J Pers Soc Psychol, 69(4), 719-727.

Sagmeister, S. (2016). Why Beauty Matters. Namur: Kikk festival.

Sánchez, A., Marante-Moar, M. P., Sarabia, C., de Labra, C., Lorenzo, T., Maseda, A., \& Millán-Calenti, J. C. (2016). Multisensory stimulation as an intervention strategy for elderly patients with severe dementia: a pilot randomized controlled trial. American Journal of Alzheimer's Disease \& Other Dementias ${ }^{\circ}, 31$ (4), 341-350.

Sanchez, A., Millan-Calenti, J. C., Lorenzo-Lopez, L., \& Maseda, A. (2013). Multisensory stimulation for people with dementia: a review of the literature. Am J Alzheimers Dis Other Demen, 28(1), 7-14. doi:10.1177/1533317512466693

Sanders, E. B.-N., \& Stappers, P. J. (2008). Co-creation and the new landscapes of design. Co-design, 4(1), 5-18.

Schols, J. (2008). Verpleeghuisgeneeskunde al langer officieel erkend; maar ook herkend en gekend? : Maastricht University.

Schols, J., \& Swelsen, P. (2019). Buitenland is jaloers op goede Nederlandse verpleegzorg. Gezond in Limburg.

Schraffenberger, H., \& van der Heide, E. (2012). Interaction Models for Audience-Artwork Interaction: Current State and Future Directions. In A. Brooks (Ed.), Arts and Technology (Vol. 101, pp. 127-135). Berlin/Heidelberg: Springer.

Schuivens, D., \& Chen, J. (2014). the CRDL. Haarlem

SensoriumHealth. (2014). BrightHearts. Sydney.

Slegers, K., Duysburgh, P., \& Hendriks, N. (2015). CoDesign with people living with cognitive and sensory impairments. CoDesign, 11(1), 1-3. doi:10.1080/15710882.2015.1 020102

Slettebø, Å., Sæteren, B., Caspari, S., Lohne, V., Rehnsfeldt, A. W., Heggestad, A. K. T., ... \& Aasgaard, T. (2017). The significance of meaningful and enjoyable activities for nursing home resident's experiences of dignity. Scandinavian journal of caring sciences, 31(4), 718-726.

Sociaal-en-Cultureel-Planbureau. (2017). Kerncijfers Ouderen in verpleeghuizen 


\section{References}

en verzorgingshuizen. Retrieved from https://www.scp.nI/Nieuws/

Kerncijfers_leefsituatie_ouderen_in_verpleeghuizen_en_verzorgingshuizen

Soranzo, A., \& Cooksey, D. (2015). Testing taxonomies: beyond card sorting. Bulletin of the Association for information Science and Technology, 41(5), 34-39.

Steerneman, P. (2012). Uit de Kunst. Zuid Magazine. Retrieved from: https://www. pimsteerneman.nl/images/documenten/Zuid-nov-12-column-pim-steerneman.pdf

Suvilehto, J. T., Glerean, E., Dunbar, R. I., Hari, R., \& Nummenmaa, L. (2015). Topography of social touching depends on emotional bonds between humans. Proceedings of the National Academy of Sciences, 112(45), 13811-13816.

Todder, D., Levartovsky, M., \& Dwolatzky, T. (2016). Measuring the effect of multisensory stimulation in the snoezelen room on sleep quality of alzheimer patients using Actigraph. Harefuah, 155(12), 727-730.

van Campen, C., \& Verbeek-Oudijk, D. (2017). Gelukkig in een verpleeghuis?

Retrieved from: https://www.scp.nl/Publicaties/Alle_publicaties/Publicaties_2017/ Gelukkig_in_een_verpleeghuis

Van Steenwinkel, I., Verstraeten, E., \& Heylighen, A. (2016). Adjusting an older residential care facility to contemporary dementia care visions. In Designing around people (pp. 219-228): Springer.

van Stenis, A. R., van Wingerden, J., \& Kolkhuis Tanke, I. (2017). The Changing Role of Health Care Professionals in Nursing Homes: A Systematic Literature Review of a Decade of Change. Front Psychol, 8, 2008. doi:10.3389/fpsyg.2017.02008

Völker, N. (2010). One Hundred And Eight. In. Berlin.

Vuong, N. K., Chan, S., \& Lau, C. T. (2015). mHealth sensors, techniques, and applications for managing wandering behavior of people with dementia: A review. In Mobile Health (pp. 11-42): Springer.

Watson, W. H. (1975). The meanings of touch: geriatric nursing. J Commun, 25(3), 104-112.

Wu, J., Wang, Y., \& Wang, Z. (2017). The effectiveness of massage and touch on behavioural and psychological symptoms of dementia: A quantitative systematic review and meta-analysis. J Adv Nurs, 73(10), 2283-2295. doi:10.1111/jan.13311 

Summary 


\section{Summary}

In the Netherlands, when you are no longer able to live by yourself due to psychogeriatric problems, chronic physical conditions caused by old age or a combination of both, you are likely to move to a nursing home. For over 10 years now, emotion-oriented care is the guiding philosophy in most Dutch nursing homes. Although challenges remain, elderly care in the Netherlands is very good when compared to the rest of the world (J. Schols \& Swelsen, 2019; J. M. Schols, 2008). In spite of all the benefits of emotion-oriented care, there's still inactivity and boredom among nursing home residents during time in between activities (den Ouden et al., 2015) and a general lack of cultural activities within nursing homes. Most leisure technology in the nursing home is therapy: goal or activity-oriented and game-like. Although these games and activities are beneficial and fun for residents, they need intensive guidance from professionals and are planned on a fixed moment of the day.

Open-ended interactive digital artworks might provide an addition to the spectrum of emotion-oriented care technology that creates the needed conditions for a personal experience to take place. Specifically, interactive artworks that are accessible at all times that can be enjoyed by residents on their own or together with somebody else, without the help of a professional caregiver are desired. It was therefore the main aim of this thesis to explore the potential of interactive art as experience-oriented care technology in elderly care, specifically in the nursing home environment.

This aim was researched in several studies and distinguishes four phases. The first phase, Phase 1 (chapters 1 and 2), of this dissertation provides insight in the larger scope of interactive art and how people respond to interactive artworks in general. The second phase, Phase 2 (chapter 3), describes the co-creation process that has taken place to develop the interactive artworks created and studied in this PhD-project. Phase 3 (chapters 4 to 6 ), consists of three pilot studies that describe the responses of nursing home residents in relation to three different interactive artworks. In the fourth phase, Phase 4 (chapter 7 ), the results are synthesized and discussed.

In chapter 1 the main problem is introduced. Interactive artworks are suggested as potential solutions to increase personal experiences for nursing home residents without professional supervision. The chapter ends with the main aim, three formulated sub-questions and an overview of the studies and four phases of the dissertation.

Although most of the interactive art installations created today are not formally studied, the systematic review in chapter 2 identified 22 open-ended interactive digital artworks of which the participants' responses were studied. Both human-to-artwork and human-to-human responses were noted for all identified artworks. The results indicate that interactive artworks can evoke a variety of verbal, physical, and cognitive/emotional responses within and between visitors, making these artworks powerful instruments.

Results imply there is no straightforward relationship between the features of the artwork 


\section{Summary}

and the kind of response. However, two factors seemed to influence the participants' responses: 'the content' (concrete or abstract) of the artwork, and 'the presence of others'.

Chapter 3 illustrates the co-creation process of interactive artworks by the design of the interface of VENSTER as a case. Results imply that although co-creation adds complexity to the design process, involving stakeholders seemed to be a crucial element in the success of the creation of the interface for VENSTER. Participants hardly paid attention to the installation and interface. There, however, seemed to be an untapped potential for creating an immersive experience by focusing more on the content itself as an interface (e.g. creating specific scenes with cues for interaction, scenes based on existing knowledge or prior experiences). "Fifteen lessons learned" which can potentially assist the design of an interactive artwork for nursing home residents suffering from dementia were derived from the design process. This description provides tools and best practices for stakeholders to make (better) informed choices during the development of interactive artworks. It also illustrates how co-design can make the difference between designing a pleasurable experience and a meaningful one.

VENSTER (chapter 4) is an interactive artwork that brings the outside world into the nursing home and vice versa through an interactive physical window. Physically, VENSTER consists of two large (touch) screens, vertically mounted in a fake wall. A string attached to the roller blind in front of the screens serves as a switch to change what is seen. When the installation detects the presence of a person, music starts playing. The installation can show pre-recorded "calming" (e.g. a lake) or "activating content" (e.g. children playing), and is also able to present "interactive content" which can be manipulated in real time (e.g. manipulate the direction of falling snow).

The goal of this study was (1) to determine whether and how nursing home residents with dementia respond to the interactive art installation in general and (2) to identify whether responses change when the content type and, therefore, the nature of the interaction with the artwork changes.

The research protocol was set up as an observational explorative study. Six to eight residents of the closed ward and 1-2 care providers were invited to attend a session with VENSTER in a semi-public square of the nursing home. All responses carried out by nursing home residents and the caregivers present were recorded on video, coded and placed in a framework.

Results show that the interactive art installation 'VENSTER' evokes responses in nursing home residents with dementia, illustrating the potential of interactive artworks in the nursing home environment. Frequently observed responses were naming, recognizing or asking questions about depicted content and how the installation worked, physically gesturing towards or tapping on the screen and tapping or singing along to the music. It seemed 


\section{Summary}

content matters a lot. When VENSTER is to be used in routine care, the choice of a type of content is critical to the intended experience/usage in practice. Recognition seemed to trigger memory and (in most cases) a verbal reaction, while indistinctness led to asking for more information. When (initially) coached by a care provider, residents actively engaged physically with the screen. Responses however differed between content types, which makes it important to further explore different types of content and content as an interface to provide meaningful experiences for nursing home residents.

The results in chapter 5 show that use of the CRDL (pronounced: 'the cradle') in a group setting creates opportunities for expressive and therapeutic touch. The CRDL got its name due to its shape, size and weight, which refer to a baby or a crib. Physically the CRDL has an abstract, rounded form. On opposite sides of the device, there is a grey felt inlay shaped like a larger-than-life fingerprint. Two participants have to place one hand on such a felt "pad" and simultaneously touch the other person's skin (e.g. hand, arm or shoulder). If more people are interacting, they all have to touch each other. This way they close an electric circuit and the speaker, located in the centre of the CRDL, produces a sound, influenced by the type of touch (e.g. tap, stroke,...) and the selected soundscape (e.g. nature, town, instrumental, animals and house-garden-kitchen sounds).

This study was designed and carried out as an observational explorative study. Three to four residents and one to two caregivers tried out the new device in an activity room. All responses carried out by nursing home residents and the caregivers present were recorded on video, coded and placed in the aforementioned framework.

In a group setting the CRDL creates an atmosphere of curiosity, a playful context and can function as an intermediary between people. This lowers the threshold to touch, provides an incentive to touch and encourages experimentation with different types of touches on the arms and hands because the produced sound changes accordingly. Additionally, the sounds that the CRDL produces sometimes trigger memories and provide themes to start and support conversation. The large amount of discussion about the controls, functioning and purpose of the CRDL can be attributed to the novelty of the device and will probably diminish over time. To involve a large group is challenging.

Caregivers and activity supervisors often had a hard time making multiple residents close a circle of hands and make them understand the outer edges should touch the CRDL pads. All caregivers and activity supervisors eventually switched to several small groups (three people) or individual interactions with the residents (two people) while the other participants watched.

Chapter 6 describes that Morgendauw seems able to evoke responses in both the residents and their caregivers. Morgendauw is a black, table-like installation, shaped like the silhouette of a larger-than-life oak leaf. The surface of the leaf consists of touch-reactive LED panels. 


\section{Summary}

Morgendauw shows a constant stream of coloured particles, which resemble a stream of water flowing downhill. The colour, direction and velocity of the particles are influenced by the current weather conditions in one of five pre-programmed cities (Eindhoven, Quebec, Spitsbergen, Tokyo and Kaapstad). Every five minutes a different city is automatically selected. When the surface of Morgendauw is touched or an object (e.g. stone) is placed on it, the stream of particles will react and find a way around the hand or object. This results in a change of composition and a distortion in the particle system that will try to find a new balance. This choreography of light is augmented with an ambient soundtrack and subtle nature sounds.

This study was set up and carried out as an explorative observational study. The installation was observed for two days, from $10 \mathrm{AM}$ to $5 \mathrm{PM}$ in a semi-public square at an indoor public square, where an open and a closed ward intersect. All responses carried out by nursing home residents, caregivers or anyone else who interacted with the installation were recorded on video, coded and placed in the aforementioned framework.

Overall, residents did not seem to notice Morgendauw. The location in which Morgendauw was placed during the study and/or the characteristics of the installation seemed to create a threshold. When prompted and/or directed, the initial threshold of noticing and approaching the installation was quickly overcome and residents in general needed little explanation of the interface to interact with it. The visuals seemed mesmerizing and resulted in a concentrated gaze upon the installation. The physical rocks placed in the abstract water were moved around and the effects it had on the particle system were observed.

In chapter 7, the main aim and formulated sub-questions are answered. The main findings and methodological considerations for all four phases are synthesized and discussed. Subsequently, the implications for (creative) practice and research are reported and can be clustered in three main themes: 'developing interactive art with special attention to the interface', 'the involvement of all stakeholders as requirement for successful implementation of interactive art in nursing homes, and on 'continuous improvement of the interactive artwork'. Finally, future directions are outlined (Where to go from here?). The first topic discusses how to increase the chance of change towards an art-included life in care facilities. More initiatives with changing interactive art collections in health care is the second subject discussed. The chapter concludes with the wish of the other to organize a (travelling) exhibition inside the nursing home, but open to all. The exhibition should present interactive art in such a way that it is interesting and intuitive for all to visit and enjoy, and creates connections between the nursing homes and the rest of society, residents and staff or visitors, the (interactive) art world and the field of (elderly) care. These exhibitions can advance our knowledge on how build and set the stage together with nursing home residents for personal, meaningful and cultural experiences to take place. 

Samenvatting 


\section{Samenvatting}

Als zelfstandig wonen niet meer mogelijk is door psychogeriatrische problemen of een chronische fysieke aandoening ten gevolge van ouder worden, ga je in Nederland meestal in een verpleeghuis wonen. De Nederlandse verpleeghuiszorg is, zeker in vergelijking met de rest van de wereld, van hoge kwaliteit (J. Schols \& Swelsen, 2019; J. Schols, 2008). Belevingsgerichte zorg is momenteel binnen de verpleeghuissetting de richtinggevende filosofie. Ondanks de hoge zorgstandaard blijven er echter uitdagingen: Er is nog steeds inactiviteit en verveling onder verpleeghuisbewoners (den Ouden et al., 2015) en er worden onvoldoende culturele activiteiten aangeboden. Er zijn innovaties en technologie voorhanden, maar deze zijn vaak gericht op het behalen van een doel of het volbrengen van een activiteit. Alhoewel deze therapie, spellen en activiteiten hun nut hebben bewezen en als plezierig worden ervaren, is intensieve begeleiding van een professional noodzakelijk en worden ze veelal aangeboden op een vast moment in de dag.

Open-ended interactieve digitale kunstwerken zouden mogelijk een aanvulling kunnen zijn op het huidige aanbod van belevingsgerichte zorgtechnologie. De kunstwerken kunnen immers een setting creëren waarin persoonlijke ervaringen spontaan kunnen plaatsvinden. Bovendien zijn de kunstwerken altijd beschikbaar. De bewoners kunnen zelf, of samen met iemand anders van deze ervaring(en) genieten, zonder dat de aanwezigheid van een professioneel zorgverlener noodzakelijk is.

Het doel van dit promotieonderzoek is, om het potentieel van interactieve kunst als belevingsgerichte zorgtechnologie in de verpleeghuissetting te exploreren.

Het promotieonderzoek kent vier fasen. De resultaten van het onderzoek zijn beschreven in zeven hoofdstukken. In de eerste fase, 'Fase 1' (hoofdstukken 1 en 2) wordt inzicht verkregen in het fenomeen 'interactieve kunst' en wordt beschreven hoe mensen op interactieve kunstwerken reageren. De tweede fase, 'Fase 2', (hoofdstuk 3) geeft het co-creatie proces weer dat is doorlopen om twee van de drie interactieve kunstwerken uit dit promotieonderzoek te ontwikkelen. Fase 3, (hoofdstukken 4, 5 en 6) bestaat uit drie piloot studies die de reacties van verpleeghuisbewoners op drie verschillende interactieve kunstwerken beschrijven. In de vierde fase, 'Fase 4' (hoofdstuk 7) vindt een synthese en discussie van de resultaten plaats.

In Hoofdstuk 1 wordt de centrale probleemstelling geïntroduceerd. Interactieve kunstwerken worden naar voren geschoven als potentiële oplossing om persoonlijke ervaringen voor verpleeghuisbewoners te laten plaatsvinden zonder dat hiervoor professionele begeleiding noodzakelijk is. Het hoofdstuk sluit af met de centrale doelstelling, drie onderzoeksvragen en een overzicht van alle studies binnen de vier fasen van het promotieonderzoek.

Hoofdstuk 2 beschrijft een literatuurreview naar de reacties van mensen ten aanzien van open-ended interactieve digitale kunstwerken. De resultaten uit deze review laten zien, dat de meeste actuele interactieve kunstwerken niet formeel bestudeerd worden. 


\section{Samenvatting}

Over het algemeen werden bij de onderzochte en beschreven werken zowel menskunstwerk als mens-mens interacties gerapporteerd. Het blijkt dat interactieve kunstwerken een scala aan verbale, fysieke en cognitief/emotionele reacties teweeg kunnen brengen bij individuele bezoekers, alsook tussen mensen onderling. Dit maakt van interactieve kunstwerken krachtige instrumenten.

Er kon geen direct verband worden gelegd tussen enerzijds de kenmerken van verschillende interactieve kunstwerken en anderzijds de manier waarop mensen erop reageerden. Twee factoren lijken de reacties over het algemeen wel te beïnvloeden: De 'inhoud van de installatie (abstract of concreet)' en de 'aanwezigheid van andere mensen'.

Hoofdstuk 3 beschrijft het co-creatie proces dat doorlopen werd bij het ontwikkelen van de interface voor het interactief kunstwerk VENSTER. Het hoofdstuk toont aan hoe co-design het verschil kan maken tussen het ontwerpen van een aangename of een betekenisvolle ervaring en biedt daarnaast tools en 'best practices' voor ontwerpers of andere stakeholders om betere keuzes te maken gedurende het ontwikkeltraject van een interactief kunstwerk voor de ouderenzorg.

De resultaten tonen aan dat co-creatie een extra laag van complexiteit toevoegt aan het ontwerpproces, maar dat het betrekken van alle stakeholders een cruciaal element vormt in het ontwerpen van een succesvol interactief kunstwerk voor de verpleeghuissetting. Verpleeghuisbewoners schonken amper aandacht aan de fysieke verschijning van het interactieve kunstwerk en de interface, maar richtten hun aandacht op de content die op de schermen van VENSTER werd getoond. Er lijkt dus potentieel te zitten in het creëren van een immersieve ervaring voor verpleeghuisbewoners door focus op de content van een interactief kunstwerk te leggen en deze content als een interface te ontwerpen en in te zetten. Dat kan door bijvoorbeeld specifieke scènes te ontwerpen waarin verwijzingen en triggers zitten om interactie uit te lokken of scènes te laten zien die zich baseren op bestaande kennis of eerdere ervaringen van verpleeghuisbewoners. Ten slotte zijn in totaal vijftien 'lessons learned' geformuleerd die kunnen helpen bij het ontwerpen van een interactief kunstwerk voor verpleeghuisbewoners leven met dementie.

VENSTER (hoofdstuk 4) is een interactief kunstwerk dat de buitenwereld met het verpleeghuis verbindt en vice versa. VENSTER bestaat fysiek uit twee grote (aanraakgevoelige) schermen, die verticaal gemonteerd zijn op een valse muur. Een rolluik met touwtje dient als schakelaar waarmee je kiest wat er op de schermen getoond wordt. Als de installatie een persoon detecteert, start er muziek. De installatie kan vooraf opgenomen 'kalmerende' (bv. een meer) of 'activerende' (bv. spelende kinderen) inhoud tonen en heeft ook de mogelijkheid om 'interactieve' inhoud te laten zien die in 'real time' kan worden gemanipuleerd (bv. het sturen van de richting van virtuele vallende sneeuw).

De reacties van verpleeghuisbewoners ten aanzien van VENSTER zijn bestudeerd in een 


\section{Samenvatting}

observationele exploratieve studie. Verpleeghuisbewoners van een gesloten afdeling en verplegend personeel namen deel aan sessies met VENSTER op een semipubliek plein van hun verpleeghuis. Tijdens deze sessies werd rustgevende, activerende of interactieve content getoond. Alle reacties door verpleeghuisbewoners en verplegend personeel zijn op video vastgelegd, gecodeerd en in een raamwerk geplaatst.

Het doel van deze studie was (1) erachter komen of en hoe verpleeghuisbewoners die leven met dementie reageren op VENSTER en (2) het kunnen vaststellen of de reacties veranderen naar gelang de aangeboden inhoud.

De resultaten tonen aan dat VENSTER reacties teweeg brengt bij verpleeghuisbewoners die leven met dementie. Het lijkt erop dat vooral de getoonde content hier een rol bij speelt. In het algemeen leek herkenning het geheugen van de bewoners te triggeren en leidde (meestal) tot een verbale reactie, terwijl onduidelijkheid bij de bewoners aanleiding gaf tot het stellen van vragen. Als het verplegend personeel een eerste aanzet gaf, gingen bewoners in interactie met het kunstwerk door fysiek op het op het scherm te tikken. Veel voorkomende reacties waren het benoemen, herkennen of vragen naar meer informatie omtrent de getoonde inhoud of de werking van de installatie. Ook werd er fysiek naar de installatie gewezen, getikt op het scherm, meegezongen of -getikt met de muziek. Deze resultaten illustreren dat interactieve kunstwerken potentieel hebben als zorgtechnologie in het verpleeghuis.

Als VENSTER in de dagelijkse praktijk wordt ingezet, is de keuze van het type inhoud belangrijk om de juiste ervaring teweeg te brengen. De reacties verschilden met betrekking tot de verschillende typen content. Kalmerende taferelen waren het minst interessant, deze kunnen vooral als screensaver dienen als VENSTER niet wordt gebruikt. Activerende taferelen verleidde de bewoners tot interactie en hield een groep van zes bewoners tot een uur rustig en gefocust. De interactieve content lokt veel interactie uit, maar hier is intensieve begeleiding van een verzorgende nodig. Om een rijk aanbod aan betekenisvolle ervaringen binnen het verpleeghuis te laten plaatsvinden is het belangrijk om verder te experimenteren met verscheidene typen content en door content als een interface in te zetten.

De CRDL (hoofdstuk 5) is een interactief object met een abstracte, ronde vorm. Het kreeg deze naam omdat de vorm, de grootte en het gewicht refereren aan een kribbe en een baby. Aan weerszijden van het apparaat is een grijze, vilten inleg te zien in de vorm van een grote vingerafdruk. Twee deelnemers dienen hun handen op de grijze 'pads' te plaatsen en elkaar vervolgens op de huid aan te raken (bv. hand op schouder). Als meerdere mensen participeren moeten ze een kring vormen terwijl ze elkaar allemaal aanraken. Op deze manier wordt een elektrisch circuit gesloten en maakt de speaker, die in het midden van de CRDL zit verwerkt, een geluid. Dit geluid wordt gevormd door een combinatie van de manier waarop de personen elkaar aanraken (bv. strelen, tikken,...) en het geselecteerde thema (bv. natuur, instrumentaal, dieren,...). 


\section{Samenvatting}

Tijdens een exploratieve, observationele studie, beschreven in hoofdstuk 5, probeerden bewoners en leden van het verplegend personeel de CRDL uit in een activiteitenkamer. Alle reacties van bewoners of personeel zijn opgenomen op video, gecodeerd en in een raamwerk geplaatst.

Zowel verpleging als activiteitenbegeleiders hadden het tijdens deze studie moeilijk om een grote groep bij de CRDL te betrekken. Het sluiten van een cirkel, elkaar continu de hand geven of aanraken en tegelijk de CRDL aanraken blijkt moeilijk. Alle begeleiders gingen daarom ook over naar interacties in kleinere groepen (drie mensen) of gingen individueel met CRDL en een bewoner aan de slag, terwijl de andere deelnemers keken.

Er werd door verpleging en bewoners geëxperimenteerd met verschillende soorten aanrakingen op armen en handen om de geluiden die de CRDL produceerde te laten variëren. De verschillende geluiden triggerden soms herinneringen bij bewoners en boden thema's aan bewoners en personeel om een gesprek aan op te hangen. Er werd regelmatig over de bediening, werking en het doel van de CRDL gesproken, maar dit kan (deels) worden toegeschreven aan de 'nieuwigheid' van de CRDL en deze onduidelijkheden nemen mogelijk af als de CRDL meer wordt gebruikt.

Als de CRDL in de dagelijke praktijk wordt ingezet, is deze het meest geschikt voor één-op-één gebruik of kleine groepen.

De CRDL creëert in een groep-setting de juiste omstandigheden om expressieve en therapeutische aanrakingen te laten plaatsvinden. Als de CRDL wordt gebruikt heerst er een atmosfeer van speelsheid, nieuwsgierigheid en functioneert het als intermediair tussen mensen. De CRDL verlaagt de drempel om elkaar aan te raken en biedt een reden om een aanraking uit te voeren.

Morgendauw (hoofdstuk 6) is een zwarte, tafel-achtige installatie, die gevormd is naar het silhouet van een glooiend eikenblad dat bestaat uit aanraakgevoelige LED panelen. Morgendauw laat een constante stroom van gekleurde deeltjes zien, die lijken op een waterstroom. De kleur, richting en snelheid van elk deeltje wordt beïnvloed door het huidige weer. Als het oppervlak van Morgendauw wordt aangeraak of er wordt een object (bv. een plastic steen) op geplaatst, dan zal de stroom van deeltjes worden verstoord en zich een weg om de hand of het object heen zoeken. Deze choreografie van licht wordt bijgestaan door een rustgevende soundtrack van achtergrondmuziek en natuurgeluiden.

In Hoofdstuk 6 worden de reacties beschreven die het interactief kunstwerk Morgendauw teweeg heeft gebracht bij verpleeghuisbewoners en verplegend personeel. De studie is opgezet als een exploratieve en observationele studie. Morgendauw werd twee dagen geobserveerd op een semipubliek plein in het verpleeghuis. Alle reacties uitgevoerd door bewoners of personeel zijn opgenomen op video, gecodeerd en in een raamwerk geplaatst.

De bewoners leken Morgendauw eerst niet op te merken. De locatie en/of de kenmerken 


\section{Samenvatting}

van de installatie vormden een drempel waardoor de installatie niet werd gezien. Wanneer het personeel of iemand anders de bewoners er attent op maakten of hen naar het werk toe leidde, werd de initiële drempel en 'onzichtbaarheid' overwonnen. Vanaf dat moment hadden bewoners weinig instructie nodig om met het kunstwerk te kunnen interacteren. De visuals leken betoverend te werken en dat resulteerde bij bewoners vaak in een blik richting het kunstwerk vol concentratie en fascinatie. Daarnaast werd het effect van stenen te verplaatsen in het abstracte water bekeken en bestudeerd.

Morgendauw kan kort interactie teweeg brengen bij bewoners en helpen om even te breken met de dagelijkse routine in het verpleeghuis. De interface wordt vlot begrepen als deze even wordt uitgelegd/getoond door verpleging of bezoek. Zonder helemaal te begrijpen wat er precies gebeurt, leken de bewoners van de installatie te genieten. Wanneer Morgendauw wordt ingezet in de dagelijkse praktijk, dienen alle stakeholders op de hoogte worden gebracht van het concept en de mogelijkheden die de installatie biedt voor bewoners, bezoek en personeel. Ook is de plaats waar Morgendauw terecht komt van groot belang.

In hoofdstuk 7 worden de belangrijkste bevindingen en methodische overwegingen samengevat en bediscussieerd. Vervolgens worden implicaties voor de (creatieve) sector en onderzoek beschreven, geclusterd in drie thema's: (1) het ontwikkelen van interactieve kunst, met extra aandacht voor de interface, (2) het betrekken van alle stakeholders als voorwaarde om een interactief kunstwerk succesvol te implementeren in een verpleeghuis en (3) de voortdurende cyclische verbetering van een interactief kunstwerk. Ten slotte worden lijnen voor de toekomst uitgezet: Allereerst wordt besproken hoe (interactieve) kunst meer geïntegreerd kan worden met het leven in een verpleeghuis en hoe wisselende interactieve kunstcollecties in de gezondheidszorg een plaats zouden moeten krijgen. Het hoofdstuk sluit af met de wens om een (reizende) expositie op te zetten die plaats vindt in het verpleeghuis, maar open en interessant is voor iedereen. Op deze manier kunnen er connecties ontstaan tussen het verpleeghuis en de rest van de maatschappij, tussen bewoners en personeel of bezoekers, tussen kunstwereld en (ouderen) gezondheidszorg. Deze exposities kunnen ook als proeftuin fungeren en kennis verbreden voor het creëren van randvoorwaarden om een persoonlijke, betekenisvolle en culturele ervaring in het verpleeghuis te laten plaatsvinden. 


Valorization 


\section{Valorization}

In 2005, the Dutch Ministry of Science defined 'knowledge transfer and utilization' as third primary task for universities, in addition to research and education (Science, 2005). In this context, valorization is defined as the value that novel research knowledge creates on a societal, technical and/or economic level.

Because of the practical nature of this PhD-project, some of the generated knowledge is readily available for end-users in forms that can be directly used or implemented in daily practice. Examples include two interactive artworks that were developed and implemented in nursing homes, reports on the effects of three interactive artworks on people who live in nursing homes, information on how to use the interactive artworks in daily practice and guidelines for artists and/or designers to develop interactive artworks in an elderly care setting. Other outcomes which influence society, the economy, end-users, educators or researchers might be less apparent. Therefore, this chapter provides insight into how the results of this PhD-project are relevant for different stakeholders and outlines the steps that have been taken/or are planned to implement the generated knowledge.

\section{Relevance of the clinical problem}

Estimations show that about 117.000 people were living in Dutch nursing homes in 2016 (Planbureau, 2017). Although there is no generic profile for the nursing home resident, $98 \%$ lived with physical limitations and $73 \%$ coped with cognitive complaints or problems. Despite the implementation and benefits of emotion-oriented care in most Dutch nursing homes, there's still inactivity of residents and boredom during time in between activities (den Ouden et al., 2015). The absence of cultural activities that are adapted in ways that they can be carried out by the nursing home residents themselves in their free time is a missed opportunity. However, to add these activities to the workload of nursing staff is currently not an option, since budget cuts and existing workload already impact the quality of professional health care (Boer \& Vreede, 2016).

This situation presents a challenge: In order to keep providing a worthy and full life to elderly who live in nursing homes, innovations are needed. In the light of these developments, interactive artworks can be a valuable addition to emotion-oriented care technology in nursing homes. This dissertation shows that they can evoke responses from nursing home residents during inactive moments during the day, without putting unnecessary pressure on staff.

\section{Target group and other stakeholders}

The findings of this PhD-project might be relevant for several stakeholders as described below.

\section{Nursing home residents}

All three interactive artworks studied in this PhD-project put the experiences of nursing 


\section{Valorization}

home residents first. Active participation and individualized activities might provide them with dignity, meaning and joy (Slettebø et. al, 2016). Inspired by the lack of cultural activities (van Campen \& Verbeek-Oudijk, 2017) and inactivity (den Ouden et al., 2015) during the day in a nursing home residence, the potential of interactive artworks as a qualitative pass-time was explored. The reported responses in this dissertation show that the interactive artworks studied in this dissertation can trigger memories, spark conversation, stimulate nursing home residents to be physically engaged, focused and calm. In the form of (temporary) exhibitions, interactive art could make state of the art cultural experiences accessible (again) for nursing home residents.

\section{Nursing home visitors}

It can be a difficult task to make contact with a nursing home resident whilst visiting them. The experience of new things without the need to rely so heavily on verbal communication could be empowering for both visitors and nursing home residents. Unfortunately, these types of activities, which can be shared with the residents without having a professional caregiver present, are uncommon. Interactive artworks can fulfill three roles here: (1) They can be an interesting destination, something to walk towards and pay a visit. (2) While present, the content and experience that these artworks present can start or keep a conversation going. It provides visitors and residents with "something else to talk about", and lastly (3) the shared experience can lead to (an increase in) interaction between visitors and residents and might improve their bond.

\section{Nursing home staff and institutions}

Although the interactive artworks designed and studied in this dissertation are meant for nursing home residents to enjoy by themselves or together with a non-professional, It has been established in this dissertation that autonomous use by most nursing home residents is impossible, therefore the quality of the experience for most nursing home resident is directly linked to the involvement and level of familiarity of the (professional) caregiver or visitors. Professional nursing home staff can be of great value in guiding an experience with interactive artworks, the interactive artworks studied in this PhD-project can also be used by nursing home residents under the guidance of a non-professional or in some instances even independently. The presence of the artworks therefore does not create extra pressure on the nursing home staff.

The results of this dissertation show that when groups of nursing home residents interacted with interactive artworks like VENSTER (Chapter 4) or the CRDL (Chapter 5), they were generally calm and focused. This made scarce time available to start a conversation with an individual or a group, or to provide someone with some extra attention.

The presence of interactive artworks can change the perception of a nursing home. By embracing interactive artworks, nursing home institutions can show that a nursing home 


\section{Valorization}

can also be a place of culture and that people who live with cognitive and/or physical challenges are not left out. Although economic value is hard to calculate in this case, there is value in being on the forefront of developments and innovations like these that are in the best interest of the nursing home residents themselves. It has an effect on the image of the institution and can play a role in the branding strategy. The artworks discussed and developed during this $\mathrm{PhD}$-project have already generated positive (media) attention for all involved.

\section{Design/art education}

Design and art schools are changing. They adapt to the ever more rapidly changing world and elderly care is one of the societal issues that needs designers who are trained and capable of ascribing meaning to this altering field in collaboration with others. This PhDproject has proven to find its way into education. The knowledge that was generated with regard to interface design for people who have cognitive and physical limitations and how they react to interactive (art) installations is used to educate bachelor students in minor programs and bachelor projects to design their own installations for these target groups.

These students benefit not only from the generated knowledge that is put into place in the curriculum, but also from the network that has been formed. This network consists of local businesses, different alpha and beta faculties, research groups and care organizations that provide students with professional guidance, a place to perform research and experiments and even options to bring their ideas to market.

\section{future health care professionals}

To ensure the successful implementation of interactive artworks it is important that future health care professionals know that they can be part of the continuous development of these types of artworks. Once implemented, they should know what the possibilities of interactive artworks are. Although these artworks should not be treated as obligated activities or therapy, future professionals can be the linking pin between the artwork and introduce colleagues, visitors or volunteers by showing them how they work. Future professionals can spread knowledge and enthusiasm about interactive artworks and incorporate them in their own daily practice.

\section{Media artists}

Most artists do not have the tendency to study their audience's reactions in a scientific way alongside of their artistic merits, although exceptions exist (Khut \& Muller, 2005). Nursing home residents, and people living with cognitive challenges by extension, are not an obvious target audience for most media artists. It is common knowledge for artists in this profession that an interface stands between the person who visits or participates in the artwork and the experience. The way nursing home residents interact with interfaces of interactive artworks, 


\section{Valorization}

however, are not familiar grounds for most media artists. The guidelines and pointers that are described in this dissertation can start paving the way for more inclusive artworks that are accessible for a multitude of people. Studying the reactions of people towards interactive artworks in general, and in this case nursing home residents specifically, will lead to knowledge about how interface and installation characteristics enable and influence the experience of participants.

Documenting the process of creating interactive artworks also has its merits. Creating documentation of the design process and writing down experiences regarding the involvement of all stakeholders during the rapidly iterating process informs media artists on how to involve people in their process and will possibly lead to a practice of continuous examining and improvement.

\section{Researchers}

The results of this PhD-project show that there is a lot of interesting research still to be done. Most of the interactive artworks created today are not formally studied in any setting. The established framework could provide some insight into how people react to different interactive artworks. The framework itself could use some scrutiny as well. To easily compare participant responses to different artworks, consensus on a framework and word choice is needed.

While the explorations in the nursing home indicate that nursing home residents react to interactive artworks and that there is potential for broader implementation, further research is needed to explore the possibilities in other care fields and to gather more data in order to differentiate and broaden the market for these artworks.

All the studies mentioned in this dissertation looked at the immediate responses of people interacting with the artworks. It would off course be favorable to also learn about the long-term usage patterns. Do people in the nursing home grow bored of the installations or start using them differently over time and what does that mean for the designer? Is it possible to keep it interesting over the long term?

If we want to learn whether interactive art can create meaningful experiences for nursing home residents, subjective experience and perception of general wellbeing should be measured. An evaluation of the suited methods to gain insight in short- and long-term effects on happiness, perceived wellbeing and quality of life should take place.

Aside from measuring experience and wellbeing, data aggregation could be automated through integrating sensors in the artworks that monitor use and record responses automatically and individually. It can provide insight in whether and how people interact with the artworks over longer periods of time and register the number and amount of time an artwork is used. 


\section{Valorization}

\section{Dissemination of findings}

Since this PhD-project has been carried out by a teacher, researcher and practitioner, there has been a constant knowledge flow from the beginning of this project. In addition to the knowledge, different products and services are presented into which the research has been or will be translated.

\section{Knowledge transfer to society and elderly care}

Public presentations

Public online videos

Online articles

\section{TEDx talk}

https://www.youtube.com/watch?v=Dkku71m_w_g

High tech meets health

https://www.slideshare.net/posiXtom/

tom-luyten-hightechinhealthcare2014

\section{Barsten in het Brein IV}

26 januari 2016, Zuyd Hogeschool, Heerlen

\section{VENSTER}

https://vimeo.com/142050697

https://www.tis.tv/user/posixtom/

\section{Morgendauw}

https://vimeo.com/232712051

\section{Interfaces voor interactieve kunstbeleving}

https://vimeo.com/255724735

https://vimeo.com/242055091

\section{VICE}

https://www.vice.com/nl/article/gv89v4/hoe-gaan-

nederlandse-kunstacademies-om-met-digitale-kunst

\section{Fondation Mederic Alzheimer}

https://www.fondation-mederic-alzheimer.org/

technologies-16

\section{Mieke van Os}

https://miekevanos.com/2016/07/27/social-design/ 
Knowledge transfer to society and elderly care

Television appearance

Articles in plain language

Interactive art

installation
SBS6 - samen sterk

https://www.youtube.com/watch?v=VwmoU7DGK2s

Digitaal VENSTER als zorghulpmiddel

Cicerone - Jaargang 9 nummer 3 september

http://www.innovatiesindezorg.eu/

files/8214/1450/3943/artikel_Cicero.pdf

Morgendauw, een interactieve

kunstinstallatie

Vitalis Next - 12/2016

http://www.fiftylab.be/wp-content/uploads/15936942_1

274675229242144_7158101164912058092_o.jpg

\section{VENSTER}

https://vimeo.com/14205069

Morgendauw

https://vimeo.com/232712051

Knowledge transfer to education

Hackatons

Hackaton snoezelrobot Daelzicht Heel 2015

Hackaton Licht en Liefde 2013

Minor courses

\author{
Interfacing Tomorrow \\ https://vimeo.com/255562433 \\ https://vimeo.com/203003182 \\ https://vimeo.com/163461972 \\ Installation Design
}




\section{Valorization}

Knowledge transfer to education

Bachelor Theses

Interfaces voor interactieve kunstbeleving in het verpleeghuis

Sabien Douven

Doorbreken van dwaalgedrag bij mensen met dementie

Kelly Grootheest

Ouderen met dementia activeren met de Qwiek.up

Armand Meessen

Bij kinderen noemen we het fantasie

Fré Hermans

Co-creatie met ouderen

Tessa Biermans

Draadloze persoonsidentificatie met als doel personalisatie, case VENSTER

Hans Hoogenboom

Knowledge transfer to (creative) industry

Collaborations

The development of VENSTER occurred in close collaboration with software company Noos Design

The development of Morgendauw occurred in close collaboration with software company PciD and hardware company Audioworx

A network of artists, engineers, health care professionals and research has been formed 


\section{Knowledge transfer to research community}

Articles in

journals
Participant responses to physical, open-ended interactive digital artworks: a systematic review. Luyten, T., Braun, S., van Hooren, S., \& de Witte, L. (2017). International Journal of Arts and Technology, 10(2), 94-134.

process of co-creating the interface for VENSTER, an interactive artwork for nursing home residents with dementia.

Jamin, G., Luyten, T., Delsing, R., \& Braun, S. (2018). The Disability and Rehabilitation: Assistive Technology, 13(8), 809-818.

co-design method for creating meaningful art installations for residents of nursing homes. Luyten, T., Braun, S., van Hooren, S. de Witte, L. 2017. LAAN, T. V. D. (ed.) Shared insights on co-creation in healthcare. Utrecht: U-create.

How nursing home residents with dementia respond to the interactive art installation 'VENSTER': a pilot study.

Luyten, T., Braun, S., Jamin, G., van Hooren, S., \& de Witte, L. (2018). Disability and Rehabilitation: Assistive Technology, 13(1), 87-94.

Reconnecting People with Dementia by Using the Interactive Instrument CRDL. Teunissen, L., Luyten, T., \& de Witte, L. (2017). AAATE Conf. (pp. 9-15).

How groups of nursing home residents respond to "the CRDL": a pilot study.

Luyten, T., Braun, S., van Hooren, S., \& de Witte, L. (2018). Journal of enabling technologies, 12(4), 145-154.

How nursing home residents respond to the interactive art installation 'Morgendauw'; a pilot study Luyten, T., Braun S., van Hooren, S., \& de Witte, L. (2019) Design for Health (submitted) 


\section{Valorization}

\section{Future dissemination and implementation activities}

Everyone is entitled to experience art and culture. In the case of the nursing home, it seems that interactive art can be a valuable addition to the existing palette of experience-oriented care technologies, especially during the inactive time in between existing activities and therapies. It can possibly even change the perception of the nursing home environment, provide meaningful experiences for nursing home residents, despite their mental and physical challenges, and might affect wellbeing of all who reside, work or visit in the nursing home. The following paragraph describes several future dissemination activities to further upscale the implementation and use of knowledge that was gathered in this PhD-project.

\section{Knowledge transfer to society and elderly care}

The results of this PhD-project will further be disseminated to the public by press releases of Maastricht University and Zuyd University and the PhD-project will be accessible worldwide via the research portal repository of Maastricht University (https://cris.maastrichtuniversity. $\mathrm{nl} /$ portal/).

The interactive art installation VENSTER and Morgendauw will remain active in the respective wards of the nursing homes. To embed interactive artworks into the nursing home and to tear down the walls that separate museums, media festivals, exhibitions and the society in general from the nursing home, an experiment with a museum-like environment inside the nursing home should be explored. This could take form as a living lab where the art is on display during and after development and viewers are aware their data is being collected to advance the development of the works, such as Beta_space (L. Muller, Edmonds, \& Connell, 2006) Artworks in the lab need to be equally interesting for the people who live inside and outside of the nursing home, but created in such a way that everyone, including the nursing home residents, can understand and enjoy them in their own way, within their possibilities.

\section{Knowledge transfer to education}

The author remains active as a teacher in higher design education, transferring knowledge in minor programs such as "interfacing tomorrow", where students learn to create meaningful experiences for people living with disabilities and "installation design" where installations are created for museum experiences. Bachelor students can graduate on the topic of interactive art, design for people with limitations and participate in the living lab. Several presentations and weblectures on the different topics that have been addressed in this PhD-project will be generated and shared openly.

\section{Knowledge transfer to (creative) industry}

During the PhD-project a network of artists, engineers, health care professionals and research has been formed which is needed to assemble interdisciplinary teams which can 


\section{Valorization}

create the often complex and challenging projects that interactive artworks in a health care setting are. This network will be formalized and made visible.

\section{Knowledge transfer to research}

It is the intention of the interactive art expo to become a living lab that provides continuous results on how nursing home residents and other people react to different interactive artworks. This will result in publications by students, artists and researchers on the topic and provides fertile ground for experimentation and exploration.

Furthermore, a factsheet providing an overview PhD-project and its results will be published open access to inform researchers worldwide about the knowledge gathered.

\section{Innovative aspects}

To our knowledge, the interactive artworks developed and studied in this PhD-project are the first that were specifically designed for a nursing home environment. The project lived in the center of a triangle that consists of art, technology and care, combining these three disciplines in a single research and development trajectory.

The novel interactive artworks presented in this dissertation were developed in thorough co-creation with different stakeholders including patient representatives, who were involved in all phases of the project. This close collaboration with different stakeholders ensured commitment to the project and continuous feedback on the design of the artworks. Furthermore, it actively involved students, professionals and researchers in interdisciplinary and diverse teams, which meant challenges but also a lot of knowledge sharing and valuable partnerships that break down walls.

Seeing (interactive) art as an important part of life within the nursing home walls connects to the theme of "the human and his/her environment as a whole", defined by the NWA (NWA, 2018). They state that the physical, social and cultural space are of great importance for health and prevention and that more knowledge is needed and needs to become available. This project contributes to that task.

Lastly, the role of media artist or designer in this PhD-project as researcher, entrepreneur and interdisciplinary project manager has been novel. Due to the complex nature of the problem space, and the mix of different disciplines it was not always easy to navigate. It required open minded institutions and people to share, work together and share a common goal. Designers and artists are trained to come up with creative solutions, and would be well suited to tackle the societal challenges ahead by (conceptually) leading interdisciplinary teams. 

Dankwoored 


\section{Dankwoord}

Met het schrijven van dit dankwoord wordt een periode van 7 jaar afgesloten waarin levensveranderende gebeurtenissen elkaar in een hoog tempo hebben opgevolgd. Tussen het schrijven, doceren, programmeren en ontwerpen door trouwde ik met Elke, kochten we en verbouwden we een huis en werden we ouders van Floris en Lisette. Zowel in persoonlijke als professionele sfeer heeft de afgelopen periode uitdagingen en succes gekend die ik met velen heb mogen delen. Ik ben trots dat ik samen met eenieder die hier genoemd wordt pionierswerk heb mogen verrichten op het snijvlak van kunst, technologie en (ouderen) zorg en hoop dat we dit samen verder zullen zetten.

Allereerst wil ik mijn promotieteam bedanken. Luc, Susan en Susy, jullie expertise, geduld en doortastendheid waren een constante tijdens dit project. We delen een liefde voor esthetiek en schoonheid en zijn in de eerste plaats gemotiveerd om iets betekenisvol te creëren met en voor mensen. Tegelijkertijd komen we van verschillende achtergronden. Dat leverde interessante discussies en verrijkende inzichten op. Ik heb genoten van de dynamiek en ik ben dankbaar dat ik van jullie heb mogen leren.

Luc, ik besloot je 7 jaar geleden, als volslagen onbekende, op te bellen in verband met een vaag idee omtrent kunst en ouderenzorg en de intentie om daar werk van te maken. Jij hebt toen zonder aarzelen de tijd genomen om naar mijn verhaal te luisteren. Dat zal ik altijd blijven waarderen. Ik heb veel van je geleerd. Tijdens onze gesprekken wist je helderheid te brengen in complexe materie en mogelijke twijfels weg te nemen. Je netwerk en aanbevelingen hebben deuren geopend en je hebt meer dan eens borg gestaan als er twijfels waren door het innovatieve karakter van dit project.

Susan, als lector creatieve therapie was jij mijn link tussen kunst en zorg. Je hebt ervoor gezorgd dat mijn schrijven en de resulterende artikelen naar een hoger niveau zijn getild. Telkens als ik dacht klaar te zijn, waren daar die paar gouden tips en aanmerkingen die terug tot nadenken aanzetten. Je rust en perspectief op momenten dat mijn ongeduld of frustratie de kop opstaken waren een houvast.

Susy, ik ben bang dat ik met een paar woorden niet kan vatten wat je voor het project en voor mij persoonlijk hebt betekend. In je rol als co-promoter hebben we elkaar bijna wekelijks gezien en heb jij alle ups en downs meegekregen. De kleine brandjes, grote successen, moeilijke persoonlijke momenten en kleine overwinningen. Je hebt me de kneepjes van het academische vak bijgebracht en ik ben blij dat design jou ook een beetje heeft mogen besmetten. De uren die je hebt gespendeerd aan mailen, appen, bellen, verbeteren en samen discussiëren zijn onmogelijk te tellen. Je was altijd bereikbaar en hebt me weten te motiveren om te bewaken wat ik belangrijk vind en schuwde niet om me met een paar lastige vragen een aantal dagen aan het denken te zetten. Bedankt voor de koffie, je geduld, begrip, kennis en introductie bij talloze collega's, vrienden en familie die nu deel van mijn leven uitmaken.

Mijn paranimfen, Gaston en Joris, hebben beiden een speciale rol vervuld in deze periode. 


\section{Dankwoord}

Gaston, de talloze uren die we transcriberend op het ZAP hebben doorgebracht zullen me altijd bijblijven. Gelukkig kunnen we er nu om lachen, maar Limburgse liederen hoeven wij de eerste paar jaar niet meer te horen. Ik heb samen met jou zoveel geleerd. Je bent er gedurende het hele traject als collega docent en startend onderzoeker bij geweest. We schreven samen aan je eerste artikel, deelde auteurschap en ook VENSTER en Morgendauw zijn mede jouw verdienste. Je structuur, talent als UX sketcher en designer zijn bepalend geweest voor de realisatie van deze twee werken en ook onze minor "interfacing tomorrow" is iets om trots op te zijn. Als vrienden en vaders onder elkaar hoop ik dat we nog veel legendarische gesprekken mogen voeren.

Joris, het is heel bijzonder om ook op professioneel gebied met je broer te mogen en te kunnen samenwerken. Morgendauw was voor mij een proefstuk, een eerste grote installatie waarvan de (fysieke) vorm een uitdaging was. Je hebt daarin met geduld en expertise houvast geboden. De uren in het atelier en de ritten naar Bladel koester ik. Het slapen onder een bureau misschien iets minder. Ik hoop dat we snel weer een project kunnen realiseren.

Verder zou ik graag de beoordelingscommissie, Prof. dr. F.R.J. Verhey (voorzitter), prof. dr. P.F. Peters, prof. dr. J.M.G.A. Schols, dr. K. Slegers en prof. dr. E.J.M. Wouters, willen bedanken om deze thesis te evalueren en Erik van Rossum en Ruth Benschop om deel uit te maken van de corona van mijn verdediging.

Graag bedank ik ook de lectoren en collega's van het Expertise Centrum voor Innovatieve zorg en Technologie (EIZT), Limburg Meet (LIME), de lectoraten (ondersteunende) technologie in de zorg en Voeding, Leefstijl en Bewegen. Jullie hebben mij, ondanks dat ik op een snijvlak van disciplines opereer, een plek gegeven om aan mijn onderzoek te werken en stonden klaar met eigen voorbeelden, ervaringen en tips.

Mijn collega's bij de Maastricht Academy of Media, Design and Technology (MAMDT): Annelies, Berry, Dave, Diana, Erik, François, Gaston, Guido, Guus, Eddy, Jetty, Jos G., Jos S., Judith, Koen, Lars, Manon, Marcel L., Marcel H., Marco, Marie, Maurice, Maxime, Pascalle, Paul, Raoul, Rob D., Rob V., Roger, Romy, Roy H., Roy W., Stefano, Sylvia, Theo, Verena, Vincent, Will en Willemien. De combinatie onderzoek en onderwijs was niet altijd even gebalanceerd en jullie hebben taken overgenomen en mij 'uit de wind gezet' om ervoor te zorgen dat ik tijd had voor mijn onderzoek. Bedankt ook aan de teamleiders en leden van het managementteam die tijd en middelen hebben gefaciliteerd en lobby werk hebben verricht: Jos de Seriere, Bert Melief, Trui ten Kampe, Jos Schreurs, Roy Hoet en Dave Krapels.

Mede-promovendi (of gepromoveerden) Melanie, Renée, Iris, Li-Juan, Steffy, Stephie, Jerôme, Anita, Emmylou, Stephanie, Jolanda, Linda en Barbara dank voor jullie ideeën, meedenken en delen van voorbeelden, kennis en ervaringen uit jullie eigen promotietraject. Lisanne Teunissen, Rob Delsing, Albine Moser, Gaston Jamin, Melanie Kleynen, Andreas Rothgangel en Peter Missotten, bedankt voor het meelezen, meedenken en 


\section{Dankwoord}

schrijven aan diverse stukken.

De dames die hele organisaties draaiende houden: Bea, Chantal, Kristien, Manon, Marja, Prisca, Romy, Stephanie, Verena en Yolande. Jullie maakten me wegwijs in de eerste dagen, en zorgden er zo vaak voor 'dat het goed komt'.

Het College van Bestuur van Zuyd Hogeschool voor het toekennen van een promotievoucher.

Marleen van der Laan en Diana Moolevliet voor het ondersteunen van het schrijven en managen van subsidies. Een nieuwe wereld, met eigen dynamieken en regels waarin jullie super gidsen zijn.

De Qeske community, een plek en gemeenschap die aan de start van dit project niet bestond en ondertussen niet meer weg te denken is. In het bijzonder, Paul Crutzen. Paul, bedankt voor je advies, je enthousiasme en het creëren van kansen door het verbinden van mensen.

Svenn, Marcel, Stefan en Kevin van PCiD, Piet, Frans en Joris van Audioworx, bedankt voor de technische ondersteuning bij Morgendauw.

Het co-creatie team van LIME, Anita, John, Marije, Andreas en Gaston, de bus-club in het bijzonder.

Tanja van der Laan, Remco Breuker en Ucreate voor het samenwerken aan een mooie publicatie over co-creatie.

Richard, Franz en Marion van RepRapUniverse, Rick en Peter van H20 Sonic en Predrag voor het bieden van een stabiel en gedreven groep waarin we mooie dingen gaan verwezenlijken voor de zorg in de nabije toekomst.

De cliëntenraad en werknemers van Cicero zorggroep, locatie op den Toren in Nuth, Mohammed Elyamani, Henk Kevers, Maureen van Veldhuizen en Hilde Heussen in het bijzonder. Dankzij jullie vertrouwen en investering in VENSTER heb ik mijn eerste interactieve installatie in de zorg kunnen verwezenlijken. Dank voor het vertrouwen, de medewerking tijdens de co-creatie sessies en observaties van VENSTER.

Léon Savelkoul en Liesbeth Bijlmakers van Vitalis woonzorggroep. Jullie liefde voor kunst en de mensen die bij jullie wonen heeft er in onze samenwerking voor gezorgd dat we Morgendauw hebben kunnen verwezenlijken. Bedankt voor de kansen, gesprekken en het vertrouwen. Er zijn mooie, ambitieuze plannen op til.

Vrienden van Vitalis, bedankt voor het ondersteunen van het Morgendauw project. Verder ook de cliëntenraad en medewerkers van Vitalis, in het bijzonder Cindy Tenbult, Roos van Boerdonk en Michel Bleijlevens, jullie inzet en kritisch meedenken tijdens het co-creëren en de efficiëntie van het opzetten van de observaties met de CRDL en 


\section{Dankwoord}

Morgendauw waren verfrissend.

Audrey Lemmens, Tonnie Braeken en Corine Smits van Daelzicht. Bas de Langen en Sandra Massier van Envida om ons tijdens onze minoren zo warm te ontvangen en als proeftuin en partner van de studenten te fungeren in innovaties voor jullie cliënten.

Ruud Bongers, Jeanne Heijkers en Ramon Jongen, ooit lukt het ons om écht interfacultair samen te werken.

Tom, Chris en Paul van Noos design. Bedankt voor het initiële development van VENSTER. Goed om te zien dat onderzoeksresultaten worden geïmplementeerd in commerciële producten en studenten CMD een plek vinden bij jullie.

Jack, Dennis en Ger, het team rond de CRDL. Hartelijk dank om jullie mooie object uit te lenen voor een studie. Ik wens de CRDL alle succes toe, het is een mooi instrument dat mensen contact met elkaar laat maken.

De bachelorstudenten die hebben meegewerkt aan (een deel van) dit onderzoek. Kelly, Sabien, Fré, Armand en Lara, bedankt voor jullie inzet, het gaat jullie goed.

Studio Roosegaarde, LAB212, Nils Völker, ThatGameCompany, Studio Moniker, Golan Levin, Camille Scherrer, ART+COM, Superbrothers, Mari Velonaki, Antonin Fourneau, Design I/O, Joseph Griffiths, Studio Klink, Jack Finnigan, Urban Alliance thank you for lending photography of your respective artwork to publish in my research.

Oma, opa, moeke en vake, ik ben dankbaar dat er bij jullie al 30 jaar altijd tijd is voor een gesprek. Merci om te helpen relativeren, te begrijpen en impliciet duidelijk te maken wat écht belangrijk is.

Jeanine en Joël, bedankt dat Floris en Lisette altijd op jullie konden rekenen, het heeft kostbare tijd vrij gemaakt.

Jos en Reinhilde, jullie bezoekjes en baby-sit momenten gaven ons tijd om weer even op te laden.

Mama en papa, ik ben dankbaar dat ik jullie als ouders heb. Bedankt om mij gedurende al die jaren mijn eigenzinnige weg te laten gaan en om altijd klaar te staan met grote en kleine hulp. Jullie vormden de basis voor wie ik ben.

Lieve Elke, om in een paar zinnen weer te geven wat jouw aandeel is geweest in dit traject is onmogelijk. Bedankt om het gewicht, dat soms te zwaar leek om alleen te torsen, te helpen dragen. We hebben een intense tijd achter de rug, met pieken en dalen waar ik het bestaan niet vanaf wist. Het resultaat is ons prachtig gezin, hechter dan ooit. Bedankt voor je onvoorwaardelijke liefde en inzet.

Floris en Lisette, al beseffen jullie het nog niet, jullie plaatsen alles in perspectief. 

About the

author 
"Technology and aesthetics can make the world a more beautiful, poetic place, even for those who struggle to comprehend it" 


\section{About the author}

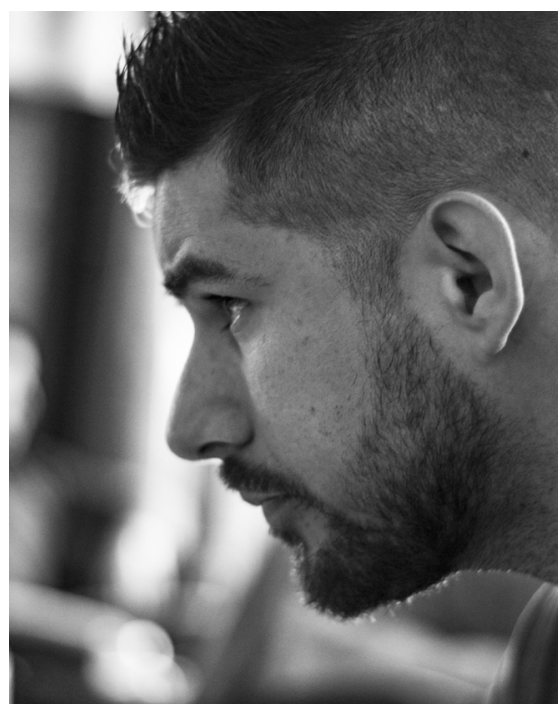

Tom Luyten was born on May 17th 1987, grew up in Vorst Laakdal, Belgium and attended secondary school in Tessenderlo and Diest. While growing up, he was always interested in the idealism and aesthetics of counterculture and technology. These interests resulted in applying for a Master's education in 'Communication- and Multimedia Design' at LUCA school of arts in Genk. His master thesis, titled "the interactive multi-sensory room" connected the disciplines of art and design with technology and health care, a trifecta that would define the rest of his career. After graduating cum laude in 2010, Tom started his own studio and became a lecturer at the Maastricht Academy of Media, Design \& Technology in 2011, which is part of Zuyd University of Applied Science. Convinced by the fact that technology and aesthetics can make the world a more beautiful, poetic place, even for those who struggle to comprehend it, he secured a position as $\mathrm{PhD}$ candidate in 2012 on the topic of "interactive art in elderly care" at the Research Centre for Assistive Technology in Health Care, under the guidance of Prof. dr. Luc de Witte, Prof. dr. Susan van Hooren and dr. Susy Braun.

Currently, Tom is working as a senior lecturer at the Maastricht Academy of Media, Design \& Technology and researcher at the Research Center for Nutrition, Lifestyle and Exercise at Zuyd University of Applied Science, does art direction for a multitude of projects and remains active as a media artist.

\section{www.tomluyten.com}



List of

publications 


\section{List of publications}

\section{Publications within this thesis}

Participant responses to physical, open-ended interactive digital artworks: a systematic review.

Luyten, T., Braun, S., van Hooren, S., \& de Witte, L. (2017). International Journal of Arts and Technology, 10(2), 94-134.

process of co-creating the interface for VENSTER, an interactive artwork for nursing home residents with dementia.

Jamin, G., Luyten, T., Delsing, R., \& Braun, S. (2018). Disability and Rehabilitation: Assistive Technology, 13(8), 809-818.

How nursing home residents with dementia respond to the interactive art installation 'VENSTER': a pilot study.

Luyten, T., Braun, S., Jamin, G., van Hooren, S., \& de Witte, L. (2018). Disability and Rehabilitation: Assistive Technology, 13(1), 87-94.

How groups of nursing home residents respond to "the CRDL": a pilot study.

Luyten, T., Braun, S., van Hooren, S., \& de Witte, L. (2018). Journal of enabling technologies, 12(4), 145-154.

How nursing home residents respond to the interactive art installation 'Morgendauw'; a pilot study

Luyten, T., Braun S., van Hooren, S., \& de Witte, L. (2019). Design for Health (submitted)

\section{Other publications}

co-design method for creating meaningful art installations for residents of nursing homes.

Luyten, T., Braun, S., van Hooren, S. de Witte, L. 2017. LAAN, T. V. D. (ed.) Shared insights on co-creation in healthcare. Utrecht: U-create.

Reconnecting People with Dementia by Using the Interactive Instrument CRDL.

Teunissen, L., Luyten, T., \& de Witte, L. (2017). AAATE Conf. (pp. 9-15). 


\section{List of publications}

\section{Artworks}

Luyten, T. (2015). VENSTER. Nuth, the Netherlands.

https://vimeo.com/142050697

Luyten, T. (2016). Morgendauw. Eindhoven, the Netherlands.

https://vimeo.com/232712051 